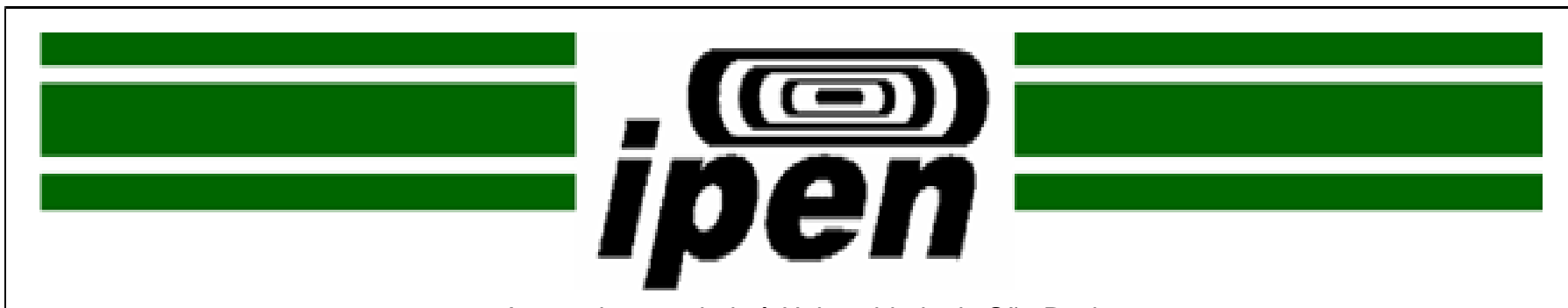

Autarquia associada à Universidade de São Paulo

AVALIAÇÃO DO GRADIENTE DE CONTAMINAÇÃO POR ELEMENTOS METÁLICOS E HIDROCARBONETOS NOS SEDIMENTOS DESDE A ZONA COSTEIRA DO SISTEMA ESTUARINO DE SANTOS E SÃO VICENTE ATÉ O PARQUE ESTADUAL MARINHO DA LAJE DE SANTOS

GUSTAVO MALUF GOBBATO

Dissertação apresentada como parte dos requisitos para obtenção do Grau de Mestre em Ciências na Área de Tecnologia Nuclear - Materiais

Orientador (a):

Prof. Dr. Jorge Eduardo de Souza Sarkis

SÃO PAULO 
Instituto de Pesquisas Energéticas e Nucleares

Autarquia associada à Universidade de São Paulo

\section{AVALIAÇÃO DO GRADIENTE DE CONTAMINAÇÃO POR ELEMENTOS METÁLICOS E HIDROCARBONETOS NOS SEDIMENTOS DESDE A ZONA COSTEIRA DO SISTEMA ESTUARINO DE SANTOS E SÃO VICENTE ATÉ O PARQUE ESTADUAL MARINHO DA LAJE DE SANTOS}

Gustavo Maluf Gobbato

Dissertação apresentada como parte dos requisitos para a obtenção do Grau Mestre em Ciências na Área de Tecnologia Nuclear - Materiais

Orientador:

Prof. Dr. Jorge Eduardo de Souza Sarkis 


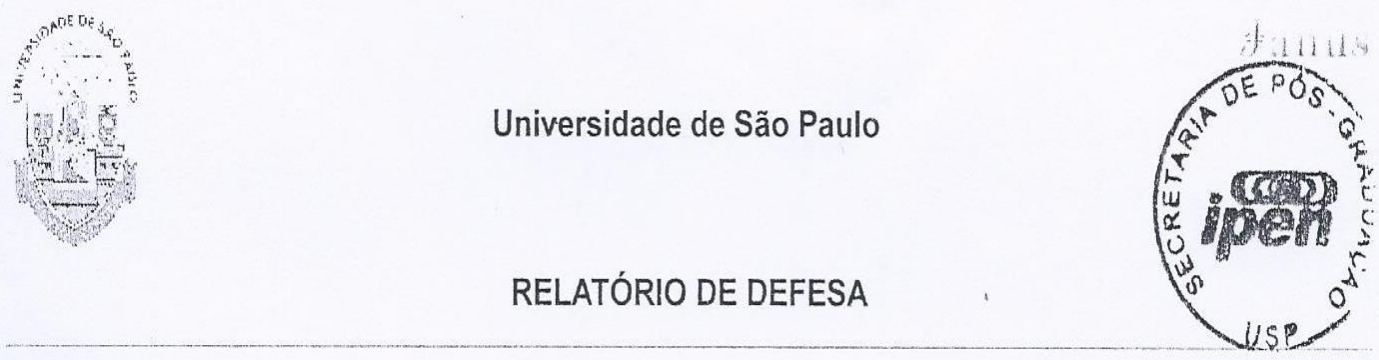

Aluno: 85134 - 6021220 - 2 / Página 1 de 1

Relatório de defesa pública de Dissertação do(a) Senhor(a) Gustavo Maluf Gobbato no Programa: Tecnologia Nuclear, do(a) Instituto de Pesquisas Energéticas e Nucleares da Universidade de São Paulo.

Aos 14 dias do mês de dezembro de 2012, no(a) Auditório Rui Ribeiro Franco realizou-se a Defesa da Dissertação do(a) Senhor(a) Gustavo Maluf Gobbato, apresentada para a obtenção do título de Mestre intitulada:

"Avaliação do gradiente de contaminação por elementos metálicos e hidrocarbonetos nos sedimentos desde a zona costeira do sistema estuarino de Santos e São Vicente até o parque estadual marinho da laje de Santos"

Após declarada aberta a sessão, $O($ a) Sr(a) Presidente passa a palavra ao candidato para exposição e a seguir aos examinadores para as devidas arguições que se desenvolvem nos termos regimentais. Em seguida, a Comissão Julgadora proclama o resultado:

$\begin{array}{llll}\text { Nome dos Participantes da Banca } & \text { Função } & \text { Sigla da CPG } & \text { Resultado } \\ \text { Jorge Eduardo de Souza Sarkis } & \text { Presidente } & \text { IPEN } & \text { Aprovado } \\ \text { Déborah Inês Teixeira Fávaro } & \text { Titular } & \text { IPEN } & \text { Aprovado } \\ \text { Elisabete de Santis Braga da Graca Saraiva } & \text { Titular } & \text { IO - USP } & \text { Aprovado }\end{array}$

Resultado Final: Aprovado

Parecer da Comissão Julgadora *

Eu, Ana Claudia Martinelli Feher
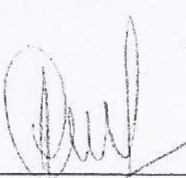
lavrei o presente relatório, que assino juntamente com os(as) Senhores(as) examinadores. Sãó Paulo, aos 14 dias do mês de dezembro de 2012.

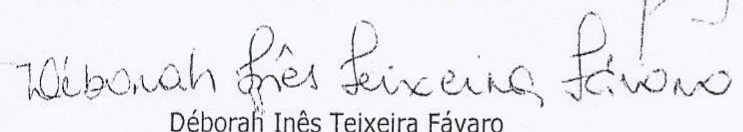
Déborafi Inês Teixeira Fávaro

Elisabete de Santis-Braga da Gráca Saraiva

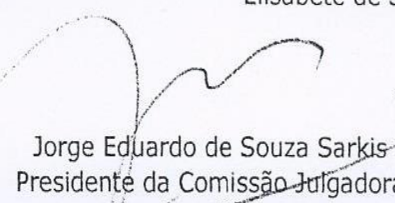


"Quanto mais nos elevamos, menores parecemos aos olhos daqueles que não sabem voar"

(Friedrich Nietzsche) 


\section{Agradecimentos}

À Deus, acima de tudo, pela presença e pela força constante em todos os momentos da vida!

Ao Prof. Dr. Jorge Eduardo de Souza Sarkis, pela orientação e pela oportunidade de aprendizado.

Aos meus pais, Alvaro e Cristiane e ao meu irmão, Renato, pelo amor incondicional e pelo apoio em todos os momentos. Não tenho palavras para descrever minha gratidão a vocês e por ter vocês em minha vida! Nossa família é linda!!! Amo vocês!

À Doutoranda Isabella Cristina da Costa Leal Bordon pela ajuda durante todas as etapas do presente trabalho e acima de tudo, por ser uma grande amiga, pelas conversas, pela evolução constante e pelos bons momentos. Ao futuro!

Ao Prof. Dr. Denis Moledo de Souza Abessa, pelas oportunidades, pelas coletas de sedimentos, pelas conversas, contribuições no texto de grande valia e pela amizade.

Ao pessoal do Laboratório de Caracterização Química e Isotópica/IPEN: Msc. Marcos Hortellani pelos treinamentos, pelas nas análises de metais no e pelas risadas. Ao Dr. João Cristiano Ulrich pelo auxílio em toda a parte laboratorial e de qualidade, pelas conversas e pelos ensinamentos durante todo o meu período no laboratório. A Bianca, Mariana, Patrícia, Luciana, Rafael Marin, Rafael Pestana, Talita, Cris, Ernesto, Glaucia, Newton, João Carlos, Daniele. Muito obrigado.

Ao pessoal do Laboratório de Química Orgânica Marinha do IOUSP: Profa. Dra. Márcia Caruso Bícego, Prof. Dra. Satie Tanigushi, Dr. Silvio e Lourival, pelas análises químicas, auxílio na interpretação dos dados, pelas conversas e participação nas bancas examinadoras.

À Profa. Dra. Deborah Inês Teixeira Fávaro por me abrir as portas do laboratório, me disponibilizar equipamentos além das conversas e de compor minhas bancas de avaliação.

Ao Prof. Dr. Jose Oscar William Veiga Bustillos pelas análises de carbono orgânico total, pelas aulas e ensinamentos. 
Aos meus amigos e companheiros de Ipen, Joaquim, Dymes, Caio, Fabio, Francine, Rafael Pestana, Gustavo, Vanessa, Giovana, Gisela, Carol, Renan, Thiago, Ligia, Marina, muito obrigado, pois sem vocês meus dias de trabalho não seriam os mesmos.

Aos meus amigos de vida (os muitos verdadeiros) pelas risadas, papos cabeça, alegrias, felicidades e viagens por lugares incríveis que me fortaleceram e me deram força para evoluir e concluir mais essa fase da vida.

Aos integrantes da Comissão de Pós Graduação do IPEN pelas inúmeras ajudas e pelo excelente trabalho desenvolvido por vocês.

À Netuno e Yemanjá, pela energia do mar e pelas ondas que me alimentam e me dão força para viver!!! A Natureza pela magia fascinante e por sempre me proporcionar momentos inesquecíveis!

A todos que contribuíram direta e indiretamente para esse trabalho os meus sinceros agradecimentos.

MUITO OBRIGADO!!! 
SUMÁRIO

RESUMO

ABSTRACT

LISTA DE TABELAS

LISTA DE FIGURAS

LISTA DE SIGLAS E ABREVIATURAS

1. INTRODUÇÃO

2. OBJETIVOS 8

3 RELEVÂNCIA DO TRABALHO 9

4 ÁREAS DE ESTUDO E REVISÃO DA LITERATURA 11

4.1 Parque Estadual Marinho da Laje de Santos $\quad 11$

$\begin{array}{ll}\text { 4.2 Zona marinha adjacente } & 14\end{array}$

$\begin{array}{ll}\text { 4.3 Baia de Santos } & 15\end{array}$

4.4 Sistema Estuarino de Santos e São Vicente 17

5 MATERIAL E MÉTODOS 21

$\begin{array}{ll}5.1 \text { Amostragem } & 21\end{array}$

5.1.1 Sistema Estuarino de Santos e São Vicente 21

5.1.2 PEMLS, zona marinha adjacente e Baía de Santos 22

5.2Análise Granulométrica $\quad 25$

5.3Análise de Carbono Orgânico Total 25

5.4 Análise da Matéria Orgânica 26

5.5Determinação do teor de Carbonato de Cálcio $\left(\mathrm{CaCO}_{3}\right)$ 
5.6Preparação do Material Sedimentológico 26

5.7 Análises de Elementos Metálicos 27

5.7.1 Método de solubilização de amostras de sedimento 28

5.7.2 Quantificação dos Elementos Metálicos 29

5.7.3 Validação dos procedimentos analíticos para análise de
metais

5.8Análises de Hidrocarbonetos 30

5.8.1 Método de Extração e fracionamento 30

5.8.2 Determinação dos Hidrocarbonetos 31 5.8.3 Validação dos procedimentos analíticos para análise de
hidrocarbonetos

5.8.4 Determinação da Origem dos Hidrocarbonetos no meio ambiente

5.8.4.1 Determinação da Origem dos Hidrocabonetos Alifáticos

5.8.4.2 Determinação da Origem dos Hidrocarbonetos Policíclicos Aromáticos

5.9Valores da qualidade dos sedimentos

5.10 Análises Estatísticas e multivariadas

5.10.1 Correlação de Pearson

5.10.2 Análise de Componentes Principais e Agrupamento 40

6. RESULTADOS E DISCUSSÃO 42

6.1 Validação do método $\quad 42$

$\begin{array}{ll}\text { 6.1.1 Metais } & 42\end{array}$

$\begin{array}{ll}\text { 6.1.2 Hidrocarbonetos } & 43\end{array}$ 
6.2.3.1.1 Identificação de Fontes dos HAs para o Sistema Estuarino de Santos e São Vicente 
6.3.4.2 Análise de componentes principais

6.3.4.3 Análise de Agrupamento

7 Gradiente de Contaminação

7.1 Metais

7.2 Hidrocarbonetos Policíclicos Aromáticos

8 CONCLUSÃO

9 REFERÊNCIAS BIBLIOGRÁFICAS 


\section{RESUMO}

O Parque Estadual Marinho da Laje de Santos (PEMLS) é considerado um dos melhores pontos de mergulho do Brasil além de apresentar grande importância ecológica para a região. Está localizado a $40 \mathrm{~km}$ de uma das áreas costeiras mais contaminada do Brasil, o Sistema Estuarino de Santos e São Vicente (SESSV) que apresenta como principais fontes de contaminação as atividades industriais e o maior porto da América Latina. O presente estudo teve como objetivo avaliar o gradiente de contaminação por metais e hidrocarbonetos alifáticos $(\mathrm{AH})$ e policíclicos aromáticos (HPA) nos sedimentos desde o SESSV até o PEMLS para identificar o grau de contaminação e as possíveis fontes dos contaminantes. Amostras de sedimento superficial foram coletadas em pontos distribuídos por todo SESSV, na baia de Santos, na zona marinha adjacente e no PEMLS. Os resultados foram comparados aos valores da qualidade dos sedimentos (VGQS) propostos na literatura para avaliar o grau de contaminação nos sedimentos. De acordo com os resultados, a contaminação por metais e hidrocarbonetos nos sedimentos do SESSV é elevada, acima dos limites estabelecidos nos VGQS, principalmente na porção interna do estuário próximo as atividades industriais. As principais fontes de emissão de contaminantes para o SESSV são os efluentes industriais e a queima de combustíveis fósseis. A zona marinha adjacente, onde está localizada a área de descarte do material dragado, apresentou, depois do estuário, as maiores concentrações de metais e hidrocarbonetos. Essas concentrações foram mais elevadas que as encontradas na baia de Santos. No PEMLS foram registrados indícios de contaminação por $\mathrm{Cr}, \mathrm{Hg}, \mathrm{Ni}, \mathrm{Pb}$ e $\mathrm{Zn}$, os quais tem origem de fontes localizadas na costa, que exportam os contaminantes até a região do PEMLS através das correntes marinhas e ainda fontes locais como barcos de operadoras de mergulho e o tráfego de navios. O Ni apresentou concentrações que estiveram acima dos limites do VGQS. Os hidrocarbonetos não apresentaram concentrações elevadas nos sedimentos do PEMLS. Sendo assim, é importante que seja realizado um controle de poluição no SESSV a fim de remediar as áreas mais contaminadas e um monitoramento continuo do gradiente de contaminação desde a zona de costa até o PEMLS para garantir a preservação desse ecossistema que já apresenta indícios de contaminação. A 
criação de um plano de manejo específico para o PEMLS auxiliaria na proteção dessa Unidade de Conservação.

Palavras - Chave: Unidade de Conservação; Parque Estadual Marinho da Laje de Santos; Hidrocarbonetos; Metais; Sedimentos. 


\section{ABSTRACT}

The Marine State Park of Laje de Santos (MSPLS) is considered one of the best diving spots in Brazil and presents great ecological importance to the region. It is located $40 \mathrm{~km}$ from one of the most polluted coastal areas of Brazil, Santos and São VIcente Estuarine System (SSVES) which has as main sources of contamination industrial activities and the largest port in Latin America. The present study aimed to evaluate the gradient of metal and aliphatic hydrocarbons (AH) and polycyclic aromatic hydrocarbons (PAH) contamination in sediments from the SSVES until MSPLS to identify the degree of contamination and the possible sources of contaminants. Sediment samples were collected at sites distributed around SSVES, in the bay of Santos, in the nearby seashore and PEMLS. The results were compared to the values of sediment quality (VGQS) proposed in the literature to assess the degree of contamination in sediments. According to the results, the contamination by metals and hydrocarbons in the sediments of SSVES is very high, above the limits established in the VGQS, mainly in the inner portion of the estuary near the industrial activities. The main sources of contaminants to the SSVES are industrial effluents and the burning of fossil fuels. In the zone nearby seashore between SSVES and MSPLS, where is located the area of disposal of dredged material presented after the estuary, the highest concentrations of metals and hydrocarbons higher than those recorded in the bay of Santos were found. In MSPLS were found evidence of contamination by $\mathrm{Cr}, \mathrm{Hg}, \mathrm{Ni}, \mathrm{Pb}$ and $\mathrm{Zn}$ were found, which originated from sources located on the coast, the contaminants that export to the region MLSPS through ocean currents and even local sources as boats operators diving and vessel traffic. Therefore, it is important to establish a pollution control program in SSVES in order to remediate the contaminated areas and a continuous monitoring of the pollution gradient from the coast to the MSPLS to ensure the preservation of this ecosystem that is already showing signals of contamination. The creation of a management plan specific to the MSPLS will help the protection of this important Conservation Unit.

Key-words: Conservation Unit; Marine State Park of Laje de Santos; Hydrocarbons; Metals; Sediments. 


\section{Lista de Tabelas}

Páginas

TABELA 1 Principais fontes de contaminação industrial para os corpos hídricos da Baixada Santista (Adaptado de Lamparelli et al., 2001)

TABELA 2. Coordenadas dos pontos amostrais dos sedimentos do PEMLS, zona marinha adjacente e Baia de Santos.

TABELA 3 Valores da qualidade dos sedimentos estipulados pelo

CCME (2002) e por Choueri et al., 2009 para metais $\left(\mu \mathrm{g} \mathrm{g}^{-1}\right)$.

TABELA 4 Valores da qualidade dos sedimentos estipulados pelo

CCME (2002) e por Choueri et al., 2009 para HPAs ( $\left.\mathrm{ng} \mathrm{g}^{-1}\right)$.

TABELA 5. Valores mensurados, valores certificados e valores de recuperação para amostras do material de referencia Buffalo River

Sediments para as análises das amostras de sedimentos do SESSV.

TABELA 6 Valores mensurados, valores certificados e valores de recuperação para amostras do material de referencia Buffalo River Sediments para as análises das amostras de sedimentos do PEMLS e Zona Marinha Adjacente

Tabela 7 Resultados das análises do branco fortificado, matriz forticada e material de referência SRM 1944 para validação do método analítico.

TABELA 8 Porcentagem de \% silte e argila $(<63 \mu \mathrm{m})$ e de carbono orgânico total (TOC) nas amostras de sedimentos do SESSV. 
provenientes do SESSV

TABELA 10 Concentrações de hidrocarbonetos alifáticos $\left(\mu \mathrm{g} \mathrm{g}{ }^{-1}\right)$ em amostras e sedimento do SESSV e as razões entre os compostos

TABELA 11 Concentrações de HPAs em amostras de sedimento do SESSV ( $\mathrm{ng} \mathrm{g}^{-1}$ ) e razões entre pares de isômeros.

TABELA 12 Correlação de Pearson entre os metais hidrocarbonetos e parâmetros sedimentológicos, analisados nos sedimentos do SESSV

TABELA 13 Autovalor, \% de variância, Autovalor acumulativo e \% acumulativa referente a cada componente gerada.

TABELA 14 Correlação das variáveis (metais hidrocarbonetos e analises sedimentológicas) com cada componente principal.

TABELA 15 Correlação dos casos (pontos amostrais) com cada componente principal

TABELA 16 Classificação da porcentagem de \% de areia (>63 $\mu \mathrm{m})$, silte e argila $(<63 \mu \mathrm{m}), \mathrm{TOC}, \mathrm{M} . \mathrm{O}$ e $\mathrm{CaCO}_{3}$ nos sedimentos dos pontos de coleta.

TABELA 17 Concentrações de metais nas amostras de sedimentos provenientes do SESSV.

TABELA 18 Concentrações de n-Alcanos, isoprenóides, MCNR, HAs resolvidos e HAs totais $\left(\mu \mathrm{g} \cdot \mathrm{g}^{-1}\right)$ e razões entre os compostos

TABELA 19 Concentrações de HPAs (ng g ${ }^{-1}$ ) em amostras de sedimento do PEMLS, zona marinha adjacente e baia de Santos e razoes entre os compostos.

TABELA 20 Correlação de Pearson entre os metais hidrocarbonetos 
e parâmetros sedimentológicos, analisados nos sedimentos do

PEMLS, zona marinha adjacente e baia de Santos

TABELA 21 Autovalor, \% de variância, Autovalor acumulativo e \% acumulativa referente a cada componente gerada

TABELA 22 Correlação das variáveis (metais hidrocarbonetos e

parâmetros sedimentológicos) com cada componente principal.

TABELA 23 Correlação pontos amostrais com cada componente principal. 


\section{Lista de Figuras}

FIGURA 1 Mapa representando a APA Litoral Centro e a localização do PEMLS.

FIGURA 2 Localização do Sistema Estuarino de Santos 5

FIGURA 3 Mapa representando a localização do PEMLS 11

FIGURA 4 Mapa geográfico da zona costeira da Baixada Santista e a localização do PEMLS

FIGURA 5 Mapa demonstrando a localização da Zona Marinha

Adjacente

FIGURA 6 Mapa demonstrando a localização da Baia de Santos.

FIGURA 7 Localização das principais fontes poluidoras no SESSV

FIGURA 8 Localização do Sistema Estuarino de Santos e a

distribuição dos pontos amostrais

FIGURA 9 Localização dos pontos amostrais desde o PEMLS até a

Baia de Santos

FIGURA 10 Localização dos pontos amostrais no interior do PEMLS e as respectivas profundidades

FIGURA 11 Concentração de $\mathrm{Al}(\%)$ nos pontos de coleta.

FIGURA 12 Concentração de $\mathrm{Fe}(\%)$ nos pontos de coleta.

FIGURA 13 Concentração de Co $\left(\mu \mathrm{g} \mathrm{g}^{-1}\right)$ nos pontos de coleta.

FIGURA 14 Concentração de $\mathrm{Cr}\left(\mu \mathrm{g} \mathrm{g}^{-1}\right)$ nos pontos de coleta.

FIGURA 15 Concentração de $\mathrm{Cu}\left(\mu \mathrm{g} \mathrm{g}^{-1}\right)$ nos pontos de coleta.

FIGURA 16 Concentração de $\mathrm{Hg}\left(\mu \mathrm{g} \mathrm{g}{ }^{-1}\right)$ nos pontos de coleta.

FIGURA 17 Concentração de $\mathrm{Mn}\left(\mu \mathrm{g} \mathrm{g}{ }^{-1}\right)$ nos pontos de coleta.

FIGURA 18 Concentração de Ni $\left(\mu \mathrm{g} \mathrm{g}^{-1}\right)$ nos pontos de coleta. 62

FIGURA 19 Concentração de $\mathrm{Pb}\left(\mu \mathrm{g} \mathrm{g}^{-1}\right)$ nos pontos de coleta. 64

FIGURA 20 Concentração de $\mathrm{Zn}\left(\mu_{\mathrm{g} \mathrm{g}}{ }^{-1}\right)$ nos pontos de coleta 66

FIGURA 21 Gráfico da razão de Ant/178 vs. FIFI+Py 76

FIGURA 22 Gráfico da razão BaA/228 vs. Fl/Fl+Py 77

FIGURA 23 Gráfico da razão IP/IP+BghiP vs. Fl/FI+Py 78

FIGURA 24 Gráfico de dispersão dos casos referente as CP1 x CP2 84 
FIGURA 25 Gráfico de dispersão das variáveis referentes a CP1 x CP2

FIGURA 26 Dendrograma das análises de agrupamento referente aos pontos coletados no SESSV.

FIGURA 27 Concentração de $\mathrm{Al}(\%)$ nos pontos de coleta.

FIGURA 28 Concentração de $\mathrm{Fe}(\%)$ nos pontos de coleta.

FIGURA 29 Concentração de Co $\left(\mu \mathrm{g} \mathrm{g}^{-1}\right)$ nos pontos de coleta

FIGURA 30 Concentração de $\mathrm{Cr}\left(\mu \mathrm{g} \mathrm{g}{ }^{-1}\right)$ nos pontos de coleta.

FIGURA 31 Concentração de $\mathrm{Cu}\left(\mu_{\mathrm{g} \mathrm{g}} \mathrm{g}^{-1}\right)$ nos pontos de coleta.

FIGURA 32 Concentração de $\mathrm{Hg}\left(\mu \mathrm{g} \mathrm{g}^{-1}\right)$ nos pontos de coleta.

FIGURA 33 Concentração de $\mathrm{Mn}\left(\mu \mathrm{g} \mathrm{g}^{-1}\right)$ nos pontos de coleta.

FIGURA 34 Concentração de $\mathrm{Ni}\left(\mu \mathrm{g} \mathrm{g} \mathrm{g}^{-1}\right)$ nos pontos de coleta.

FIGURA 35 Concentração de $\mathrm{Pb}\left(\mu \mathrm{g} \mathrm{g}^{-1}\right)$ nos pontos de coleta.

FIGURA 36 Concentração de $\mathrm{Zn}\left(\mu \mathrm{g} \mathrm{g} \mathrm{g}^{-1}\right)$ nos pontos de coleta.

FIGURA37 Gráfico de dispersão dos casos referentes a CP1 x CP2

FIGURA 38 Gráfico de dispersão das variáveis referentes a CP1 $\mathrm{x}$ CP2

FIGURA 39 Gráfico de dispersão das variáveis referentes a CP1 x CP3

FIGURA 40 Dendrograma das análises de agrupamento referente aos pontos coletados no SESSV.

FIGURA 41 Gráfico de dispersão tridimensional abordando todos os pontos de estudo., referente ao $\mathrm{Zn}, \mathrm{Cr}$ e Fe. Legenda: Fundo do Estuário (pontos mais contaminados - 5, 11, 12, 13 e 15 ), BS - Baia de Santos (número 17), AD - Área de descarte do material dragado (número 18), ZM - Zona marinha adjacente (número 19), Pontos em rosa - PEMLS (números 20 a 24).

FIGURA 42. Gráfico de dispersão tridimensional desde a baia de Santos até o PEMLS referente ao Zn, Cr e Fe. Legenda: BS - Baia de Santos (ponto 17), AD - Área de descarte do material dragado (ponto 18), ZM - Zona marinha adjacente (ponto 19). PEMLS (pontos de 20 a 24) 
FIGURA 43. Gráfico de dispersão tridimensional abordando todos os pontos de estudo, referente ao $\mathrm{Al}, \mathrm{Ni}$ e $\mathrm{Zn}$. Legenda: Fundo do Estuário (pontos mais contaminados - 5, 11, 12, 13 e 15 ), BS - Baia de Santos (número 17), AD - Área de descarte do material dragado (número 18), ZM - Zona marinha adjacente (número 19), Pontos em rosa - PEMLS (números 20 a 24).

FIGURA 44. Gráfico de dispersão tridimensional desde a baia de Santos até o PEMLS referente ao Al, Ni e Zn. Legenda: BS - Baia de Santos (ponto 17), AD - Área de descarte do material dragado (ponto 128 18), ZM - Zona marinha adjacente (ponto 19). PEMLS (pontos de 20 a 24)

FIGURA 45 Gráfico de dispersão tridimensional abordando todos os pontos de estudo, referente ao $\mathrm{Cu}, \mathrm{Pb}$ e $\mathrm{Co}$. Legenda: Fundo do Estuário (pontos mais contaminados - 5, 11, 12, 13 e 15 ), BS - Baia de Santos (número 17), AD - Área de descarte do material dragado (número 18), ZM - Zona marinha adjacente (número 19), Pontos em rosa - PEMLS (números 20 a 24).

FIGURA 46. Gráfico de dispersão tridimensional desde a baia de Santos até o PEMLS referente ao $\mathrm{Cu}, \mathrm{Pb}$ e Co. Legenda: BS - Baia de Santos (ponto 17), AD - Área de descarte do material dragado 131 (ponto 18), ZM - Zona marinha adjacente (ponto 19). PEMLS (pontos de 20 a 24)

FIGURA 47 Gráfico de dispersão tridimensional abordando todos os pontos de estudo referente aos metais $\mathrm{Ni}, \mathrm{Mn}$ e $\mathrm{Hg}$. Legenda: Fundo do Estuário (pontos mais contaminados - 5, 11, 12, 13 e 15),BS Baia de Santos (número 17), AD - Área de descarte do material dragado (número 18), ZM - Zona marinha adjacente (número 19), Pontos em rosa - PEMLS (números 20 a 24).

FIGURA 48. Gráfico de dispersão tridimensional desde a baia de 134 Santos até o PEMLS referente ao Ni, $\mathrm{Hg}$ e Mn. Legenda: BS - Baia de 
Santos (ponto 17), AD - Área de descarte do material dragado (ponto 18), ZM - Zona marinha adjacente (ponto 19). PEMLS (pontos de 20 a 24)

FIG 49 Gráfico de dispersão tridimensional abordando os pontos do SESSV referente aos HPA de 2 e 3 aneis aromáticos (naftaleno, acenaftileno e acenafteno).

FIG 50 Gráfico de dispersão tridimensional abordando os pontos do SESSV referente aos HPA de 3 anéis aromáticos (fenantreno, acenaftileno e antraceno).

FIG 51 Gráfico de dispersão tridimensional abordando os pontos do SESSV e da área de descarte do material dragado (em vermelho) referente aos HPA de 4 anéis aromáticos (fluoranteno, criseno e pireno).

FIG 52 Gráfico de dispersão tridimensional abordando os pontos do SESSV e da área de descarte do material dragado (em vermelho) referente aos HPA de 4 e 5 anéis aromáticos (benzo(e)pireno, benzo(a)pireno e benzo(a)antraceno).

FIG 53 Gráfico de dispersão tridimensional abordando os pontos do SESSV e da área de descarte do material dragado (em vermelho) referente aos HPA de 5 anéis aromáticos (benzo(b)fluoranteno, benzo(j)fluoranteno e benzo(k)fluoranteno).

FIGURA 54 Gráfico de dispersão tridimensional abordando os pontos do SESSV e da área de descarte do material dragado (em vermelho) referente aos HPA de 5 e 6 anéis aromáticos (indeno[1, 2, 3143 cd]pireno, dibenzo(ah)antraceno e benzo(ghi)perileno). 


\section{Lista de Siglas e Abreviaturas}

ACP - Análise de Componentes Principais

AD - Área de Descarte do Material Dragado do Canal Porto de Santos

Al - Alumínio

BS - Baia de Santos

Co - Cobalto

$\mathrm{Cr}-$ Cromo

$\mathrm{Cu}$ - Cobre

Fe - Ferro

FIG - Figura

HA - Hidrocarbonetos Alifáticos

HPA - Hidrocarbonetos Policíclicos Aromáticos

GC-MS - Cromatógrafo a Gás Acoplado ao Espectrômetro de Massas

GC-FID - Cromatógrafo a Gás Acoplado ao Detector por lonização por Chama

SNUC - Sistema Nacional de Unidades de Conservação

Hg - Mercúrio

LD - Limite de Detecção

Mn - Manganês

MCNR - Mistura Complexa Não Resolvida

NC - Não Calculado

$\mathrm{Ni}$ - Níquel

NIST - National Institute of Standards and Technology

$\mathrm{Pb}-$ Chumbo

PEMLS - Parque Estadual Marinho da Laje de Santos 
SESSV - Sistema Estuarino de Santos e São Vicente

SRM - Standard Reference Material

TAB - Tabela

UC - Unidade de Conservação

VGQS - Valores Guia da Qualidade dos Sedimentos

ZM - Zona Marinha Adjacente

Zn - Zinco 


\section{INTRODUÇÃO}

O litoral brasileiro, com cerca de 8.000 quilômetros de extensão, apresenta uma ampla variedade de ambientes, incluindo restingas, estuários, praias, costões rochosos, recifes, baías, manguezais, marismas, ilhas costeiras e oceânicas, parcéis e lajes, entre outros. Esses ambientes concentram parte significativa da biodiversidade brasileira, além de espécies raras, endêmicas e ameaçadas. Além disso, abrigam importantes recursos econômicos e exercem funções ecológicas que repercutem em benefícios para o homem.

Por outro lado, as regiões costeiras são propícias ao desenvolvimento de atividades humanas, tais como indústrias, portos, terminais petrolíferos, aquicultura e pesca, implantação de cidades e turismo. Hoje em dia, cerca de metade da população brasileira vive na zona costeira ou em áreas que distam até $100 \mathrm{~km}$ da costa, além disso, parte significativa da produção industrial também se realiza nessa área (DIEGUES, 1985, LAMPARELLI et al., 2001; Lia, 2008). Soma-se a isso o fato das áreas litorâneas receberem grandes contingentes populacionais como consequência dos processos de turismo e urbanização e da concentração de habitantes nas áreas urbanizadas.

As atividades humanas, sobretudo as econômicas, acabam degradando o ambiente, pelo uso ou extração excessiva de alguns recursos naturais (como pesca, caça, extrativismo, mineração, uso da água, entre outros), pela sua contaminação ou ainda pela eliminação do recurso (como por exemplo, a substituição de florestas por cidades e zonas industriais). Como consequência de muitas dessas atividades, ocorre o lançamento de uma grande variedade de contaminantes orgânicos e inorgânicos nos corpos d'água, provenientes de esgotos domésticos e industriais, da agricultura, das atividades de navegação recreativa e comercial, entre outras fontes (KENNISH, 1992; MACHADO et al., 2002; McLUSKY \& ELLIOTT, 2004).

A presença de substâncias tóxicas no ambiente pode causar diversos efeitos nos organismos, desde efeitos comportamentais e bioquímicos até a 
morte, passando pela alteração na reprodução, crescimento e a indução de tumores e teratogenias. Potenciais impactos aos organismos incluem também a bioacumulação do contaminante e a possibilidade da sua transferência ao longo da cadeia alimentar, podendo atingir o homem (ADAMS et al., 1992; USEPA, 2000).

Um dos instrumentos utilizados em diversos países com o intuito de preservar áreas ecologicamente importantes é a criação de áreas protegidas. Nesse sentido, a legislação brasileira prevê a criação de diferentes categorias de Unidades de Conservação (UC), de acordo com a Lei 9.985, de 18 de julho de 2000, que estabeleceu o Sistema Nacional de Unidades de Conservação da Natureza (SNUC). De acordo com essa lei, as UC são definidas como: "Espaço territorial e seus recursos ambientais, incluindo as águas jurisdicionais, com características naturais relevantes, legalmente instituídos pelo Poder Público, com objetivos de conservação e limites definidos, sob regime especial de administração, ao qual se aplicam garantias adequadas de proteção" (BRASIL, 2000).

As UC são criadas com o objetivo de proteger a biodiversidade, proteger as espécies ameaçadas de extinção, preservação e restauração da diversidade de ecossistemas naturais, contribuir na manutenção da viabilidade da pesca, proporcionar meios e incentivos para atividades de pesquisas científicas, estudos e monitoramento ambiental, entre outros, assim garantindo a proteção de áreas de grande importância ecológica (SÃO PAULO, 2003).

Enquanto os ambientes terrestres possuem aproximadamente $9 \%$ de suas áreas protegidas, o mesmo não acontece com as áreas marinhas. Do total de áreas protegidas do mundo, apenas $18 \%$ incluem componentes marinhos e costeiros (PRATES \& PEREIRA, 2000), significando que menos de $1 \%$ do ambiente marinho mundial se encontra abrangido por instrumentos de proteção ambiental. TOMMASI (1987) demonstrou que muitas áreas costeiras do Brasil apresentavam problemas, principalmente devido ao uso inadequado do solo e do lançamento de contaminantes nas águas costeiras. Além disso, mesmo áreas de proteção ambiental sofrem diversos problemas, dos quais um dos mais agravantes é a poluição (ROJAS \& ABESSA, 2008). 
Dentre as UC insulares paulistas está o Parque Estadual Marinho da Laje de Santos (PEMLS), localizado a aproximadamente $40 \mathrm{~km}$ de distância da costa. O PEMLS é o primeiro e único parque integralmente marinho do Estado de São Paulo. Em termos geográficos, o PEMLS pertence ao município de Santos e está inserido na Área de Proteção Ambiental - Litoral Centro, setor Itaguaçu (FIG 1) e o acesso somente é possível por meio de embarcação particular ou transporte credenciado.

O PEMLS é um local de grande interesse para a conservação da diversidade biológica, uma vez que não há outras formações rochosas ou ilhas em áreas próximas, acarretando grande concentração de peixes de passagem e recifais na área. Tem como objetivo a proteção da biodiversidade e importância na reposição dos estoques de recursos marinhos e manutenção do potencial pesqueiro da região onde numerosas espécies de importância comercial encontram abrigo, alimento abundante, local para reprodução e sobrevivência. Constitui também um dos mais importantes pontos do litoral paulista de abrigo e reprodução de aves marinhas, demonstrando a importância desta UC para a região.

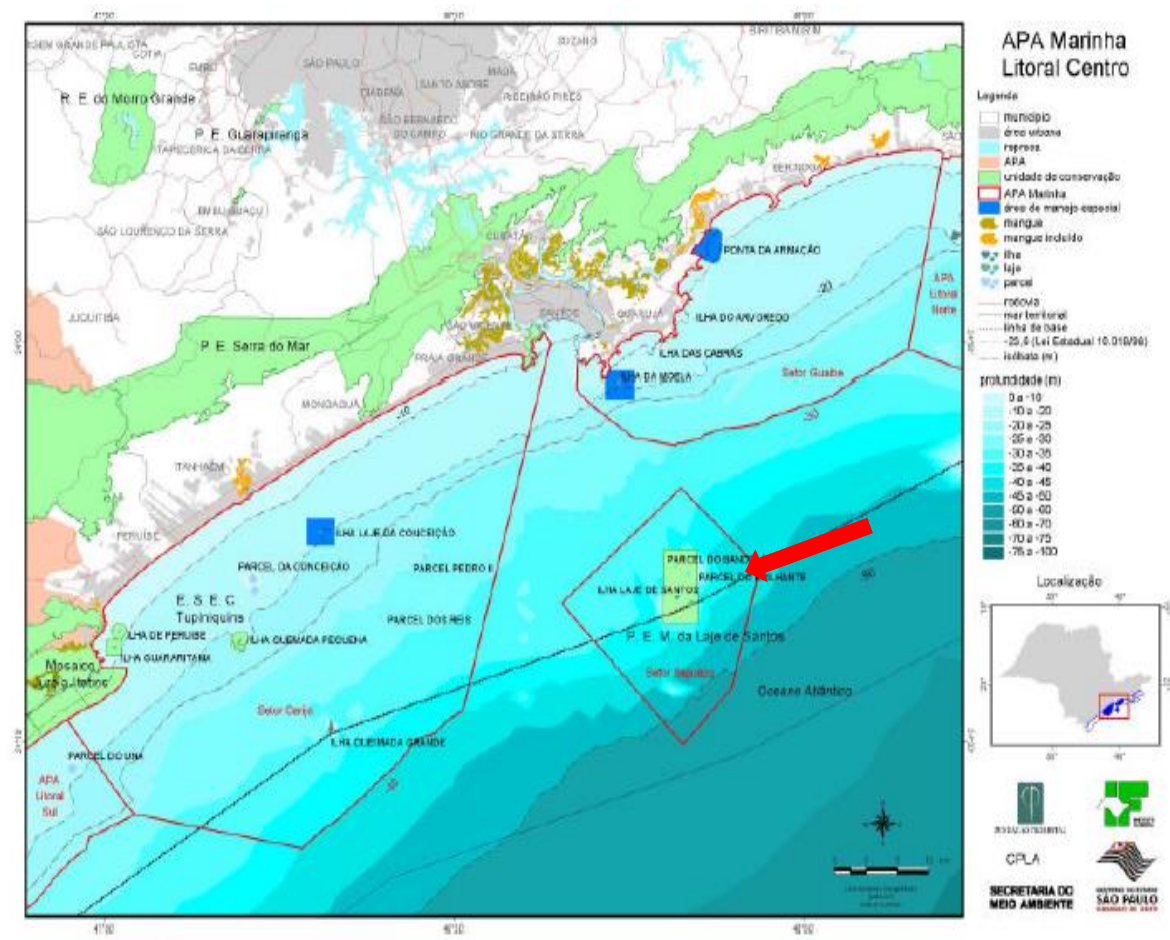

FIGURA 1 Mapa representando a APA Litoral Centro e a localização do PEMLS (Modificado de Decreto 53526 - APA Marinha Litoral Centro) 
No entanto, considerando que o PEMLS prevê por lei, o uso público como uma de suas funções e que a visitação pode constituir efetivo fator indutor de estresse ambiental, particularmente a poluição, essa UC vem enfrentando alguns problemas ambientais que estão relacionados com 0 fundeio de navios, pesca esportiva e profissional, acúmulo de lixo e vazamentos de óleo proveniente de embarcações (ROJAS E ABESSA, 2008). Pelo fato do parque ser reconhecidamente um dos melhores pontos de mergulho do Brasil, recebe influência das embarcações que visitam o local (MACHADO et al., 2002) cujos impactos ainda não foram completamente estudados.

Análises preliminares demonstraram indícios de alterações na qualidade ambiental do PEMLS indicando a presença de metais nas águas e bioacumulação nos tecidos de organismos marinhos (LAMPARELLI et al, 2001) além de toxicidade em algumas amostras de água (ABESSA et al., 2004).

Todavia, além das fontes locais que podem estar causando impactos ambientais negativos ao parque, suspeita-se que fontes emissoras localizadas na zona de costa possam estar contribuindo para a contaminação dessas UC.

A região costeira próxima ao PEMLS constitui-se na área mais impactada do litoral paulista. O Sistema Estuarino de Santos e São Vicente SESSV (FIG 2) está localizado na porção central do litoral do Estado de São

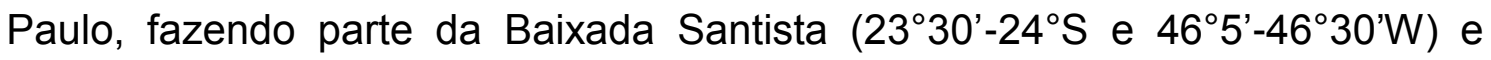
englobando as Baías de Santos e São Vicente, até a região do Rio Casqueiro. $\mathrm{Na}$ Baixada estão situados os municípios de Santos, São Vicente, Cubatão, Praia Grande, Mongaguá, Guarujá e Bertioga. Essa região possui grande importância econômica, devido à presença de um dos mais importantes polos industriais do país, o Complexo Industrial de Cubatão, do Porto de Santos, maior porto da América Latina, do imenso potencial turístico e também dos recursos pesqueiros e naturais proporcionados pelos manguezais que ocorrem junto ao estuário (ABESSA, 2002), além de quatro emissários submarinos de esgoto doméstico os quais constituem as principais fontes de contaminação para o sistema local (CETESB, 2007). 
As atividades portuárias são consideradas fontes importantes de contaminantes para o SESSV, devido ao lançamento de petróleo e seus derivados, poluição por substâncias decorrentes de tintas antiincrustantes, perda durante operações de carga e descarga e também pelo lixo. Além disso, o tráfego constante de navios obriga a uma dragagem contínua dos sedimentos, visando manter a profundidade do canal do porto adequada para as atividades portuárias. As atividades de dragagem e disposição do material dragado, embora estritamente necessárias, são altamente impactantes e têm sido alvo de intensas discussões visando minimizar os seus efeitos sobre 0 ambiente e zonas adjacentes (ABESSA, 2002).

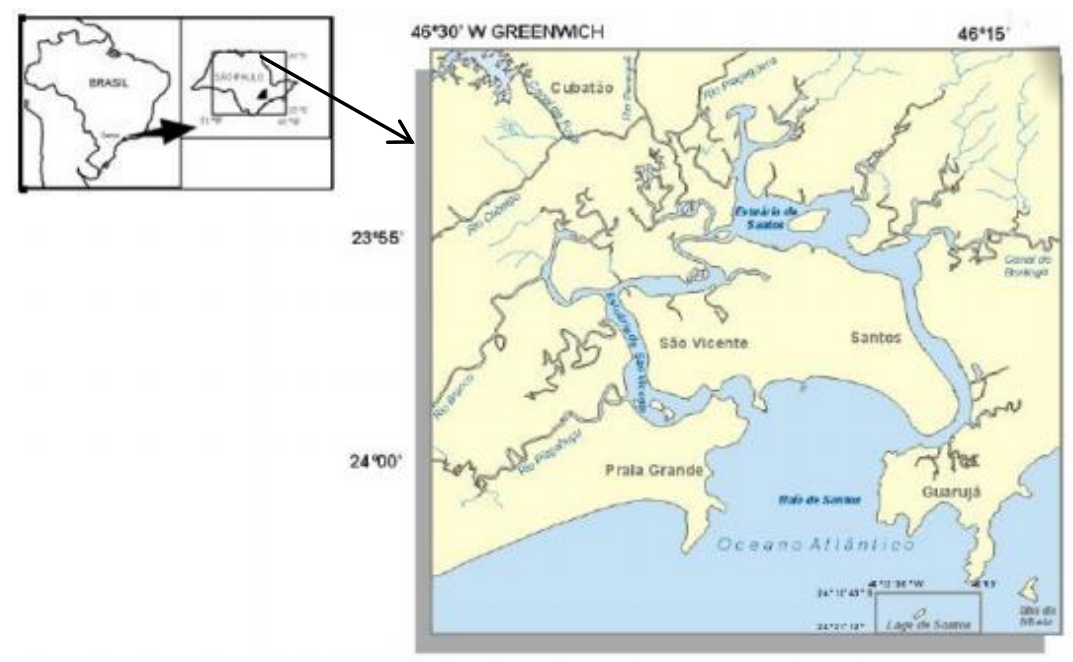

FIGURA 2 Localização do Sistema Estuarino de Santos (Adaptado de Lamparelli et al., 2001).

Como consequência da baixa hidrodinâmica dos estuários, alta porcentagem de finos, os contaminantes tais como metais e hidrocarbonetos proveniente das atividades antrópicas, tendem a se acumular próximo as fontes de origem (LAMPARELLI et al., 2001; HORTELLANI et al., 2008; MARTINS et al., 2007; PEREIRA, 2008; SMELLER, 2007).

Nesse contexto, na avaliação da qualidade ambiental deve-se considerar aspectos relativos aos sedimentos, pois eles têm a propriedade de acumular compostos químicos em concentrações mais elevadas do que aquelas 
observadas na coluna de água adjacente (NIPPER et al., 1989), sendo o principal destino para as substâncias introduzidas nos corpos d'água (ADAMS et al., 1992; SWARTZ et al., 1985). Quando introduzidos no sistema aquático, os contaminantes tendem a permanecer por curto período na coluna d'água e a maior parte é adsorvida pelos materiais em suspensão ou se associa aos sais, carbono orgânico e argilas, precipitando-se no fundo e acumulando-se no sedimento, onde entram em contato com os organismos bentônicos ou podem retornar à coluna d'água (COSTA et al., 2005; HORTELLANI et al., 2005; DELVALLS et al., 2002).

Um grande número de trabalhos vem abordando a contaminação por metais, hidrocarbonetos alifáticos (HA) e policíclicos aromáticos (HPA) nos sedimentos do SESSV, da baía de Santos e zona marinha adjacente (ABESSA 2002; ABESSA et al., 2005; 2008; CESAR et al., 2006; 2007; HORTELLANI et al. 2005; 2008; LAMPARELLI et al., 2001; MEDEIROS E BICEGO, 2004; BICEGO et al., 2006; MARTINS et al., 2007; 2011).

Metais tendem a estar fortemente associados ao material particulado. As principais rotas de entrada dos metais no meio ambiente incluem o transporte atmosférico, efluentes industriais e lixiviação continental (BRYAN, 1971). As taxas de solubilização dos metais dependem de fatores ambientais como concentração de oxigênio dissolvido, $\mathrm{pH}$, salinidade e temperatura (WALDICHUK, 1985). Uma vez dissolvidos na coluna d'água, alguns metais metais são tóxicos e podem bioacumular nos tecidos de invertebrados marinhos e peixes através da assimilação passiva pelas superfícies permeáveis como as brânquias e o trato digestivo.

Os HA constituem uma importante fração orgânica presente nos sedimentos estuarinos. As principais fontes de introdução desses compostos no ambiente aquático são provenientes de fontes naturais como da fotossíntese de algas e plantas superiores e/ou fontes antropogênicas da lixiviação continental, efluentes industriais e do petróleo (ABOUL-KASSIM \& SIMONEIT, 1996). Em sedimentos contaminados por petróleo, a fração dos HA é composta por um amplo espectro de n-alcanos, compostos ramificados e também por uma mistura complexa não resolvida (MCNR) que consiste 
primariamente de uma magnitude de compostos cíclicos e ramificados com propriedades físicas muito similares e muitas estruturas não conhecidas (mais de 250 mil substâncias) que não podem ser resolvidas pelas colunas capilares (VOLKMAN et al., 1992; SUTON et al., 2005). Essa característica é normalmente associada com petróleo recém introduzido ou degradado (READMAN et al., 2002).

Os HPA são compostos que prevalecem em sedimentos de estuários que apresentam intensas atividades antrópicas. HPA são geralmente derivados de fontes antropogênicas incluindo combustão de combustíveis fósseis, transporte de material particulado associado aos HPA, lixiviação de ruas e asfaltos com a abrasão de pneus dos automóveis, emissões veiculares e vazamento de petróleo (BOULOUBASSI \& SALIOT, 1993; YUNKER et al., 2004). Geralmente há duas fontes de introdução dos HPA nos ambientes marinhos costeiros: pirogênica e petrogênica. As principais fontes para os HPA são de origem pirogênica como usinas de energia, gases de escape dos motores diesel e óleo de cárter usado. Os HPA de origem petrogênica podem vir de óleo derramado diretamente na água do mar, bem como o escoamento doméstico e industrial de efluentes (VOLKMAN et al., 1992). Estes compostos são importantes de serem determinados em ambientes marinhos e estuarinos, pois apresentam potencial carcinogênico, mutagênico e teratogênico tanto para organismos aquáticos como para o homem.

Deve-se levar em consideração que esses contaminantes podem ser bioacumulados nos tecidos dos organismos e que as atividades de pesca comerciais e de subsistência (mexilhões, ostras, caranguejos, peixes, etc) são frequentemente realizadas na região e o estuário é largamente utilizado para recreação, expondo a população aos diferentes contaminantes presentes no meio ambiente.

Portanto, a caracterização da contaminação ambiental através de análises químicas dos sedimentos é muito utilizada não somente para identificar impactos (e seu grau), mas para subsidiar futuros estudos que abordem a influência das fontes emissoras situadas na zona costeira e a dispersão dos contaminantes para áreas próximas. 


\section{OBJETIVOS}

O objetivo principal do presente estudo foi verificar se existe um gradiente de contaminação desde a zona costeira até o Parque Estadual Marinho da Laje de Santos, por meio de análises químicas de amostras de sedimentos superficiais.

Os objetivos específicos deste trabalho foram:

Avaliar a contaminação por metais e hidrocarbonetos alifáticos e policíclicos aromáticos dos sedimentos do Sistema Estuarino de Santos e São Vicente por meio de análises químicas;

Avaliar a contaminação por elementos metálicos e hidrocarbonetos alifáticos e policíclicos aromáticos nos sedimentos desde a baia de Santos até o Parque Estadual Marinho da Laje de Santos.

Identificar as eventuais contaminações às fontes emissoras por meio de assinaturas químicas nos sedimentos. 


\section{RELEVÂNCIA DO TRABALHO}

No Brasil, a preocupação com a proteção dos ambientes insulares começou há mais de 40 anos. Hoje, as UCs estão distribuídas por todo o litoral brasileiro e abrangem algumas ilhas oceânicas do país, com diferentes categorias de manejo. Apesar disso, os instrumentos para preservação destes ambientes, em SP e no Brasil, não têm sido eficientes, por uma série de motivos, tais como as dificuldades de acesso a algumas áreas marinhas, as idéias equivocadas de que o ambiente marinho está disponível para a exploração de todos e de que seus recursos são infinitos (PRATES \& PEREIRA, 2000), baixa percepção pública da importância dos ambientes costeiros e marinhos. Soma-se a isso a ausência ou precariedade de políticas públicas no sentido da efetiva implantação das diretrizes de proteção e manejo propostas nos instrumentos legais, independentemente de quais sejam. Grande parte dos problemas das áreas protegidas reside no desconhecimento de suas funções e das necessidades para o seu funcionamento, e no desconhecimento dos múltiplos benefícios que essas áreas proporcionam a todos os setores da sociedade, direta ou indiretamente (MENDONÇA et al, 2000).

No caso das áreas protegidas e unidades de conservação marinhas, a quantidade de dados publicados sobre qualidade ambiental é ainda muito incipiente. Como agravante, o conjunto de áreas protegidas marinhas de São Paulo é pouco conhecido e necessita urgentemente de estudos que permitam identificar problemas comuns e específicos, de modo a orientar 0 estabelecimento de políticas públicas coerentes (ROJAS E ABESSA, 2008).

O PEMLS é o único parque integralmente marinho do estado de São Paulo e possui uma função ecológica muito importante pelo fato de apresentar formações rochosas únicas que proporcionam habitats, locais de reprodução e alimentação para várias espécies marinhas incluindo as de interesse comercial e as aves exclusivamente marinhas. Todavia, há somente alguns trabalhos preliminares (LAMPARELLI et al., 2001; ABESSA et al., 2004) os quais detectaram indícios de contaminação no parque por compostos orgânicos, não existindo um estudo sistemático que avaliou a contaminação nos sedimentos 
por elementos metálicos e hidrocarbonetos e faça a atribuição das possíveis contaminações às fontes emissoras, sendo o presente projeto inédito.

Esse estudo irá gerar dados que poderão, em um futuro próximo, subsidiar estudos da modelagem de dispersão desses contaminantes auxiliando na preservação dessa UC. Além disso, a detecção de impactos (e do seu grau) poderá auxiliar os órgãos gestores (diretores, órgãos ambientais e conselho gestor) na orientação dos planos de manejo e no estabelecimento de políticas públicas das UCs. 


\section{4 ÁREAS DE ESTUDO E REVISÃO DA LITERATURA}

\subsection{Parque Estadual Marinho da Laje de Santos}

Criado pelo decreto no 37.537/93, o PEMLS é o único Parque Estadual integralmente marinho dentre as UC do Estado de São Paulo. Está inserido na Área de Proteção Ambiental Litoral Centro, setor Itaguaçu a aproximadamente $40 \mathrm{~km}$ da costa e pertence ao município de Santos (FIG 3).

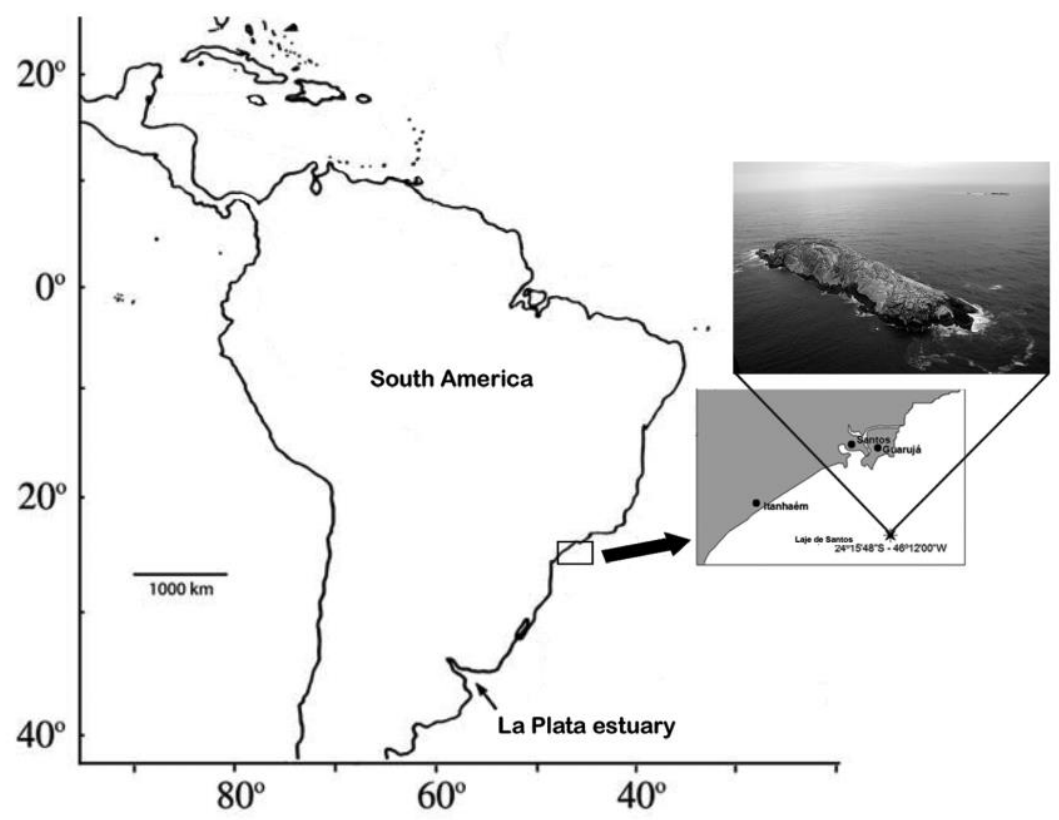

FIGURA 3 Mapa representando a localização do PEMLS

Em termos oceanográficos, o PEMLS está situado na plataforma continental interna do estado de São Paulo, que apresenta a largura de 10 a 80 $\mathrm{km}$, até as isóbatas de 20 a $70 \mathrm{~m}$ e salinidade que varia de 34,4 a 38,8 e a temperatura de 22 a $28^{\circ} \mathrm{C}$, sendo o verão a estação com as águas são mais quentes e salinas (FIG 4).

Essa região apresenta uma alta homogeneidade de suas características tridimensionais hidrográficas durante todo o ano (MAZZINI, 2009). Segundo estudo realizado por Harari et al., (2001), as correntes geradas pelas marés 
basicamente predominam em direção a nordeste. As correntes geradas pelo vento fluem para oeste e as correntes geradas pela densidade tem um padrão de direção para sudeste ocorrendo pulsos de fundo e transporte de sedimentos.

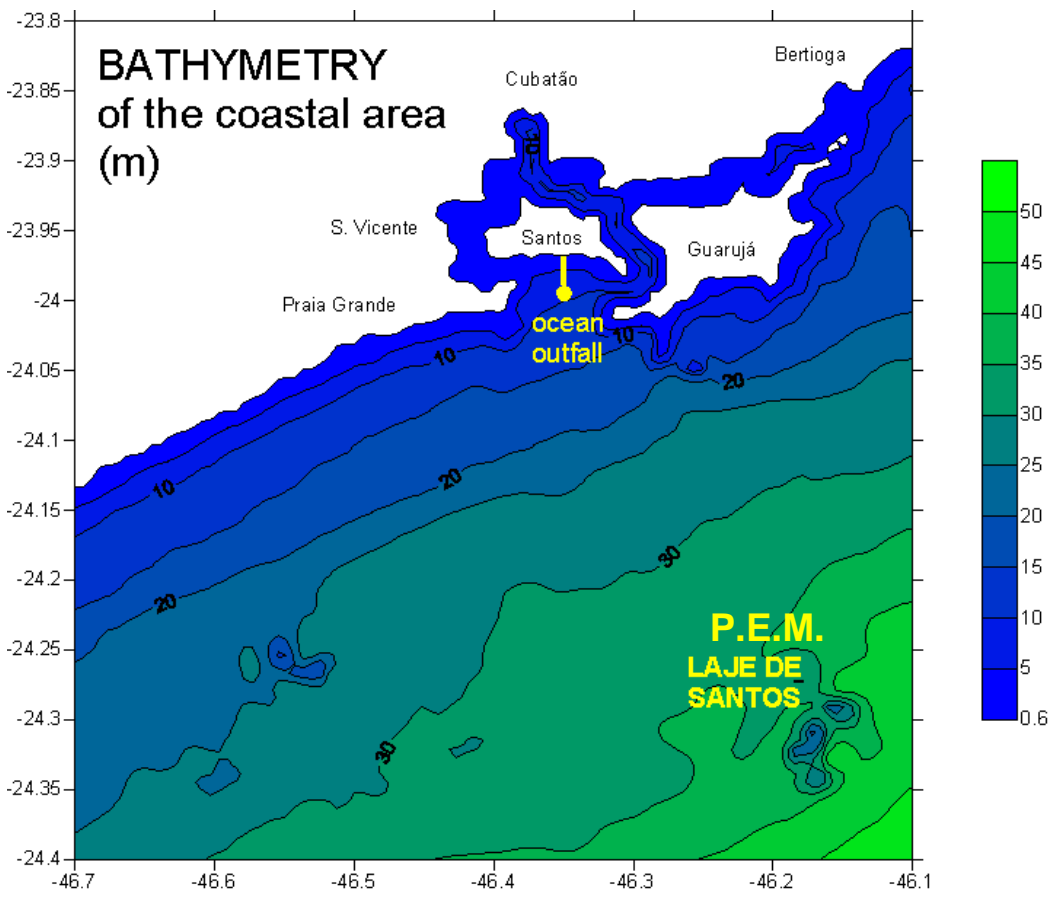

FIGURA 4 Mapa geográfico da zona costeira da Baixada Santista e a localização do PEMLS (Retirado de Harari et al., 2007).

O PEMLS delimita uma área de 5.000,00 ha,que se inicia no vértice 01 nas coordenadas geográficas $24^{\circ} 15^{\prime} 48^{\prime \prime} \mathrm{S}, 46^{\circ} 12^{\prime} 00^{\prime \prime} \mathrm{W}$. Segue com azimute de $90^{\circ} 00^{\prime} 00^{\prime \prime}$ e seca numa distância de $5.000,00 \mathrm{~m}$ até o vértice 02 nas coordenadas geográficas $24^{\circ} 15^{\prime} 48^{\prime \prime} S, 46^{\circ} 09^{\prime} 00^{\prime \prime} W$. Deflete à direita e segue com azimute de $180^{\circ} 00^{\prime} 00^{\prime \prime}$ e seca numa distância de $10.000,00 \mathrm{~m}$ até o vértice 03 nas coordenadas geográficas $2^{\circ} 21^{\prime} 12^{\prime \prime} \mathrm{S}, 46^{\circ} 09^{\prime} 00^{\prime \prime W}$. Deflete à direita e segue com azimute de $270^{\circ} 00^{\prime \prime} 00^{\prime \prime}$ e seca numa distância de $5.000,00 \mathrm{~m}$ até o vértice 04 nas coordenadas geográficas 2421'12"S 46²'00”W. Deflete novamente à direita e segue com azimute de $360^{\circ} 00^{\prime} 00^{\prime \prime}$ e seca numa distância de $10.000,00 \mathrm{~m}$ até o vértice 01 onde teve início esta descrição (SÃO PAULO, 2003). 
$\mathrm{Na}$ área do PEMLS estão localizadas algumas formações rochosas peculiares à região. Dentre elas inclui a Laje de Santos que apresenta $33,00 \mathrm{~m}$ de altitude, 550,00m de comprimento e 185,00m de largura máxima e se encontra aproximadamente na área central do parque; tendo ao norte o Parcel do Brilhante e a Laje do Bandolim, ao sul o Parcel do Sul e o Parcel Novo, e a sudeste os Rochedos, conhecidos como Calhaus (IF, 2009).

De acordo com o decreto no 37.537/93 (São Paulo, 1993), o PEMLS tem como objetivo assegurar integralmente a proteção à flora, à fauna, às belezas cênicas e aos ecossistemas naturais, marinhos e terrestres. A ausência de outras formações rochosas ou ilhas próximas ao PEMLS acarreta em uma grande concentração de espécies marinhas que encontram na área do parque habitats, locais de reprodução e alimentação, desempenhando uma função ecológica muito importante na manutenção da biodiversidade e do potencial pesqueiro da região.

O PEMLS abriga em seu entorno numerosas espécies de peixes e constitui-se um dos mais importantes pontos do litoral paulista de abrigo e reprodução de aves marinha. Nos costões rochosos que circundam a Laje pode-se presenciar a visita de numerosas espécies de peixes de passagem, tartarugas marinhas e mamíferos aquáticos. Cardumes de espécies de importância comercial são frequentemente observados na área do parque (IF, 2009).

Considerado um dos principais pontos turísticos de mergulho subaquáticos do país, pelas belezas cênicas das paisagens submarinas, o PEMLS recebe frequentemente a visita de operadoras de mergulho sendo essa atividade potencialmente impactante. A pesca de arrasto e a caça submarina predatórias, além da captura de peixes ornamentais e invertebrados marinhos para o mercado aquariófilo e de decoração de interiores são fatores que ameaçam a qualidade ambiental do PEMLS (SÃO PAULO, 2003).

No caso das áreas protegidas e unidades de conservação marinha, a quantidade de dados publicados sobre a qualidade ambiental é ainda muito incipiente. Todavia, em um trabalho preliminar foram detectados indícios de 
contaminação no parque por metais nas águas e bioacumulados nos organismos (LAMPARELLI et al., 2001). Como agravante, estudos sobre a contaminação no conjunto de áreas protegidas marinhas do estado de São Paulo é incipiente e necessita de pesquisas que permitam identificar problemas comuns e específicos, de modo a orientar o estabelecimento de políticas públicas coerentes (ROJAS E ABESSA, 2008).

\subsection{Zona marinha adjacente}

A Zona Marinha Adjacente ao PEMLS é a região situada em mar aberto, com profundidades superiores a 15 metros (FIG 5).

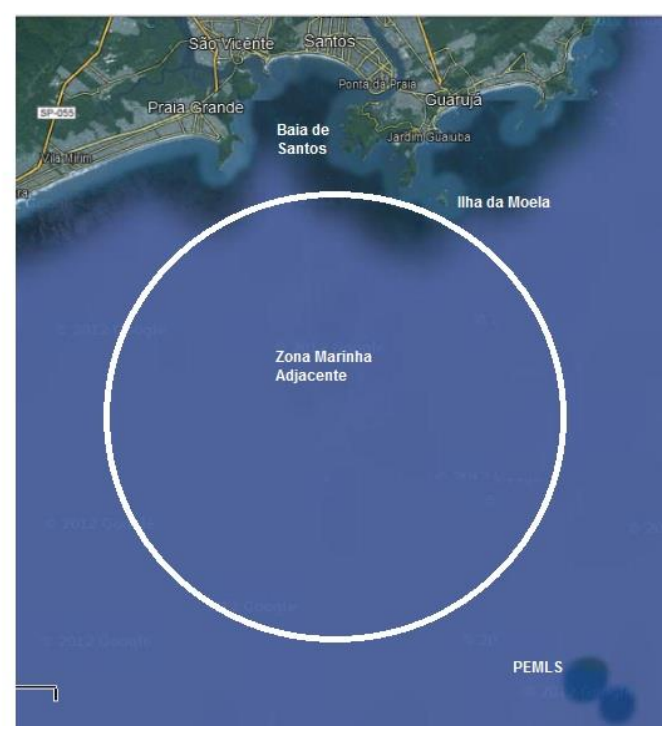

FIGURA 5 Mapa demonstrando a localização da Zona Marinha Adjacente (Fonte: Google Earth).

Como fontes de poluição direta nessa zona destacam-se, o lançamento de esgotos pelos emissários de Santos, Guarujá e Praia Grande, o transporte de sedimentos contaminados através das correntes e a área de disposição de sedimentos contaminados dragados do canal do porto de Santos. 
A zona de descarte do material dragado do porto de Santos é um quadrilátero delimitado pela Marinha Brasileira e a CETESB, localizado em uma área considerada oceano aberto, com coluna d'água de $22 \mathrm{~m}$ e área de $3,24 \mathrm{~km}^{2}$ aproximadamente, situado entre as latitudes $24^{\circ} 04^{\prime} \mathrm{S}$ e $24^{\circ} 05^{\prime} \mathrm{S}$ e longitudes $46^{\circ} 18^{\prime}$ ' W e 46 $46^{\circ} 19^{\prime} \mathrm{W}$, distando cerca de $20 \mathrm{~km}$ da costa a partir da entrada do porto de Santos. Este local vem sendo utilizado para a disposição do material dragado em mar aberto desde 1996. As direções das correntes na zona de descarte tendem a predominar na direção nordeste, porém apresenta variações em direção a sudeste e sudoeste (HARARI et al., 2001; LEITAO et al., 2001).

A Companhia Docas do Estado de São Paulo (CODESP) está realizando desde fevereiro de 2005, o acompanhamento ambiental de dragagem. A área está sendo monitorada através de análises químicas e biológicas, de água e de sedimentos, em pontos distribuídos na região sob a influência do lançamento. A dragagem é executada para manter as profundidades do canal de navegação, bacias de evolução e berços de atracação, quando a lâmina d'água estiver sendo significativamente reduzida, devido ao assoreamento. O projeto da dragagem de manutenção, para o porto de Santos, tem cotas de 13 a $14 \mathrm{~m}$. Já a dragagem de aprofundamento, em processo de licenciamento ambiental, tem por finalidade aprofundar o canal existente visando receber navios com maiores calados.

O número de pesquisas abordando a contaminação química e ecotoxicológica na zona marinha adjacente se restringe a área de disposição dos sedimentos dragados do porto de Santos. Estudos realizados por Lamparelli et al., (2001), Abessa (2002), Torres (2007) e Lia (2008), apontam indícios de contaminação por metais, hidrocarbonetos, bifenilas policloradas entre outros contaminantes, nas águas e nos sedimentos, o que influencia a adsorção e acumulação desses contaminantes nessa região. 


\subsection{Baia de Santos}

A Baía de Santos tem cerca de $7 \mathrm{~km}$ de largura na parte central e $11 \mathrm{~km}$ na parte final, entre as pontas de Itaipu, a oeste, e do Monduba, a leste, e apresentando uma profundidade média de 5 a 10 m (FIG 6). Ao norte, é delimitada pelas praias de São Vicente, constituindo uma área de mistura de água do mar com as águas salobras vindas do continente. Além da poluição causada pelo Porto de Santos e pelas indústrias da região de Cubatão, a qual é carreada até a baía pelos canais de Santos e de São Vicente, outra fonte de poluição são os efluentes domésticos descartados sem tratamento adequado no ambiente através do emissário submarino cuja saída está localizada a $4 \mathrm{~km}$ da costa, no centro da baía. Em épocas de veraneio a população flutuante chega a triplicar o número da população local agravando ainda mais o quadro (CETESB, 2006).

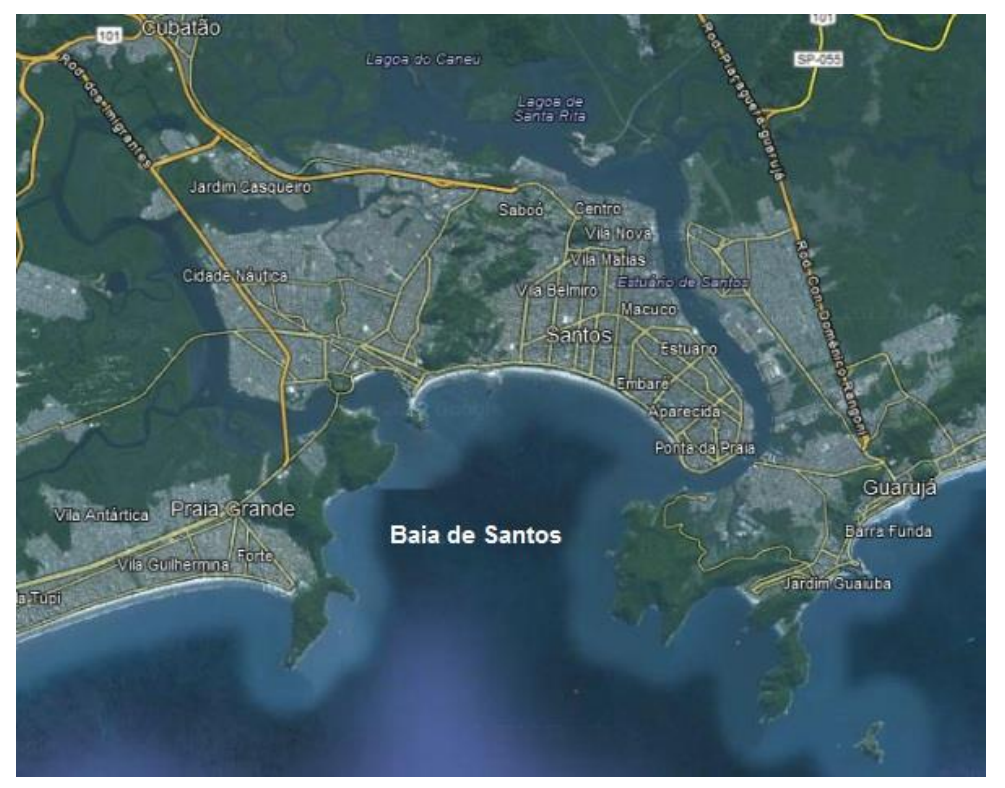

FIGURA 6 Mapa demonstrando a localização da Baia de Santos (Fonte: Google Earth).

Estudos realizados nessa região concluíram que o emissário submarino de Santos é uma fonte potencial de poluição, alterando as características 
químicas, etocoxicológicas e granulométricas da baia de Santos (LAMPARELLI et al., 2001; ABESSA et al., 2005; CESAR et al., 2006) e zona marinha adjacente, através do transporte pelas correntes marinhas como reportado por Martins et al. (2008).

\subsection{Sistema Estuarino de Santos e São Vicente}

O SESSV tem sido caracterizado por uma intensa e crescente atividade antropogênica nos últimos 100 anos, onde as atividades industriais e a combustão de combustíveis fósseis contribuíram para a introdução de uma grande quantidade de material particulado rico em poluentes (TAB 1). $O$ aumento da industrialização e ocupação desordenada sobre os bancos do estuário, principalmente nos últimos 60 anos (FIG 7), têm sido responsáveis pela degradação da vegetação de manguezal, a emissão de efluentes industriais, domésticos e resíduos sólidos, além das atividades portuárias que envolvem introdução de petróleo, dragagem e atividades de pesca. (MARTINS et al., 2007).

Desde a década de 1950, quando foi inaugurado, o Complexo Industrial de Cubatão tem sido o responsável pela degradação da vegetação de manguezal, pelas emissões dos efluentes industriais e domésticos e por resíduos sólidos, que impactam o SESSV (MARTINS et al., 2010). 
TABELA 1 Principais fontes de contaminação industrial para os corpos hídricos da Baixada Santista (Adaptado de Lamparelli et al., 2001)

\begin{tabular}{|c|c|c|}
\hline Indústria & Produção Principal & Contaminante * \\
\hline $\mathrm{Alba}^{(1)}$ & Resinas, formol & $\mathrm{N}$, Fenóis, $\mathrm{Cr}$ \\
\hline Carbocloro & Cloro, soda, EDC & Fenóis, Solventes halogenados, $\mathrm{Cr}, \mathrm{Hg}, \mathrm{Zn}$ \\
\hline $\mathrm{CBE}$ & Estireno & $\mathrm{N}$, Fenóis, Solventes aromáticos, $\mathrm{Cu}, \mathrm{Cr}, \mathrm{Hg}, \mathrm{Zn}$ \\
\hline Cia Santista de Papel & Papel & Fenóis, $\mathrm{Cd}, \mathrm{Cl}, \mathrm{Cr}, \mathrm{Mn}, \mathrm{Hg}, \mathrm{Ni}, \mathrm{Zn}$ \\
\hline CIEL & Coque verde & Mn, Ni, Zn \\
\hline Columbia & Negro de fumo & \\
\hline Copebrás & Ácido fosfórico, fertilizantes & P, N, Fluoreto \\
\hline Cosipa & $\mathrm{Acços}$ & $\begin{array}{l}\mathrm{N}, \mathrm{CN} \text {, Fluoreto, Fenóis, Solventes aromáticos, Ar, Cd, } \\
\mathrm{Pb}, \mathrm{Cu}, \mathrm{Cr}, \mathrm{Mn}, \mathrm{Hg}, \mathrm{Ni}, \mathrm{Zn}\end{array}$ \\
\hline Dow Química & Látex, polióis, poliestireno & $\begin{array}{l}\text { N, CN, Fluoreto, Fenóis, Solventes aromáticos, Solventes } \\
\text { halogenados, } \mathrm{Ar}, \mathrm{Cd}, \mathrm{Pb}, \mathrm{Cl}, \mathrm{Cr}, \mathrm{Mn}, \mathrm{Hg}, \mathrm{Ni}, \mathrm{Zn}\end{array}$ \\
\hline IFC & Fertilizantes & P, N, Fluoreto \\
\hline Liquid Química & Ácido benzóico & N, Fenóis, Solventes aromáticos, Mn, Hg \\
\hline Manah & Fertilizantes & P, N, Fluoreto \\
\hline Petrobrás/RPBC & Derivados de petróleo & $\begin{array}{l}\mathrm{N}, \mathrm{CN} \text {, Fluoreto, Fenóis, Solventes aromáticos, } \mathrm{Cd}, \mathrm{Pb} \text {, } \\
\mathrm{Cu}, \mathrm{Hg}, \mathrm{Ni}, \mathrm{Zn}\end{array}$ \\
\hline Petrocoque & Coque verde & $\mathrm{N}$, Fenóis, $\mathrm{Ar}, \mathrm{Cu}, \mathrm{Cr}, \mathrm{Ni}, \mathrm{Zn}$ \\
\hline Rhodia $-A g r 0^{(1)}$ & Pesticidas carbamatos & Carbamatos \\
\hline Rhodia - UQC ${ }^{(1)}$ & Organoclorados & $\begin{array}{l}\text { Fenóis, Solventes halogenados, Organoclorados } \\
\text { aromáticos, pesticidas organoclorados }\end{array}$ \\
\hline Serrana & Fertilizantes & P, N, Fluoreto \\
\hline Solorrico & Fertilizantes & P, N, Fluoreto, $\mathrm{Cd}$ \\
\hline Ultrafértil - CB & Fertilizantes & P, N, Fluoreto, Fenóis, Ar, Pb, Cu, Cr, Ni, Zn \\
\hline Ultrafértil - PG & Fertilizantes & P, N, Fluoreto \\
\hline Union Carbide & Polietileno & Fluoreto, Fenóis, Carbamatos, Mn, Zn \\
\hline
\end{tabular}

(1) - Indústrias desativadas

* - O contaminante constitui matéria prima, produto ou insumo do processo produtivo, ou é resíduo obrigatório do processo produtivo, ou foi verificado em análises químicas dos efluentes entre 1979 e 1999.

No começo da década de 1980 devido às emissões de gases líquidos e sólidos de indústrias químicas, petroquímicas, siderúrgicas e de fertilizantes a cidade de Cubatão apresentou um cenário seriamente contaminado por múltiplas fontes de poluição. Além disso, o crescimento urbano desordenado na região agravou ainda mais a qualidade ambiental pelo descarte dos efluentes domésticos. Programas governamentais conduzidos em 1984, pela Companhia de Tecnologia de Saneamento Ambiental (CETESB) associada 
com o Ministério do Meio Ambiente, iniciaram o controle de emissões de efluentes industriais e domésticos para melhoria da qualidade ambiental do SESSV.

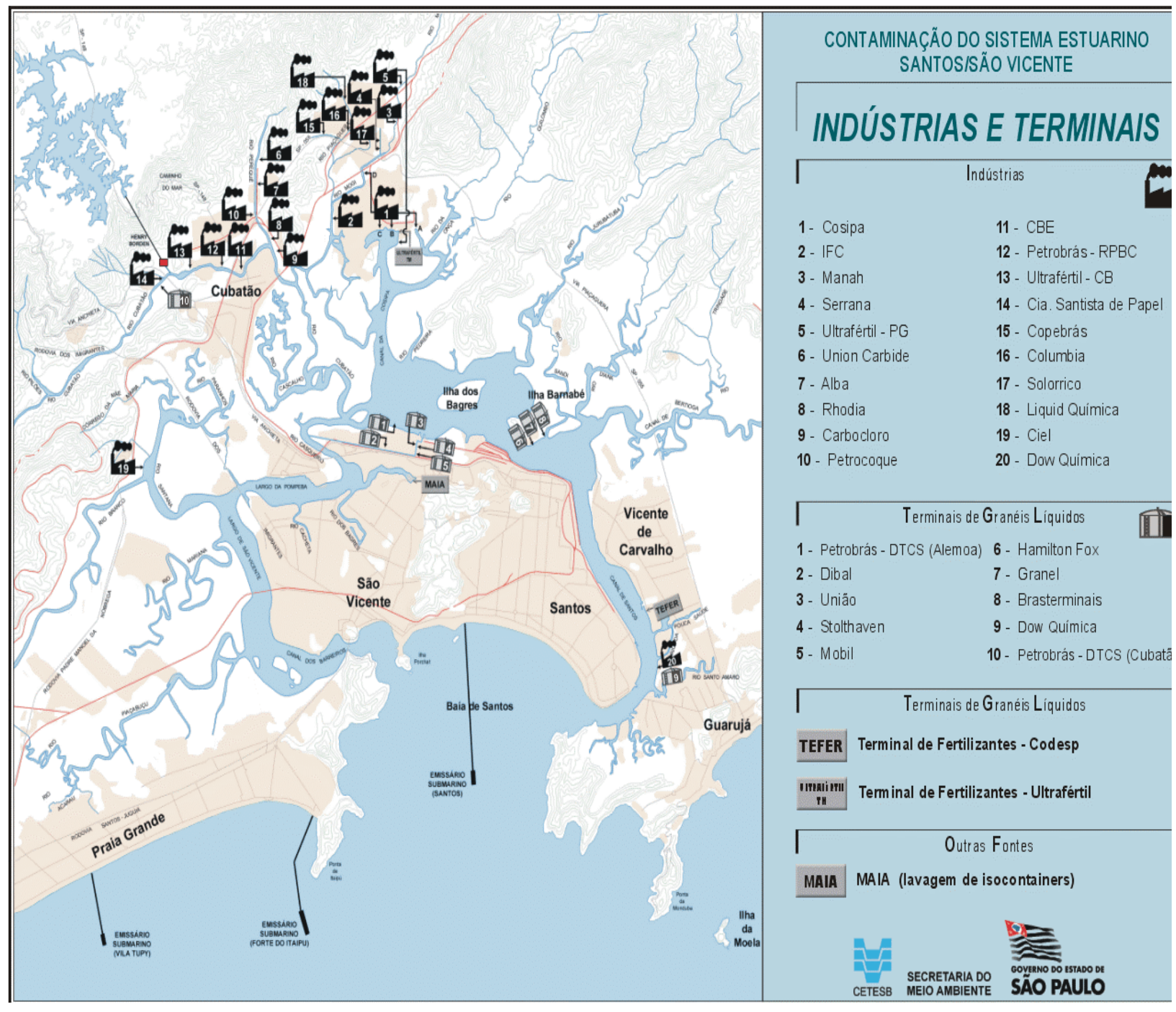

FIGURA 7 Localização das principais fontes poluidoras no SESSV (LAMPARELLI et al., 2001)

Como resultado, uma gradual recuperação dos ecossistemas aquáticos foi observada. Contudo, estudo conduzido em 1988, depois da implementação do programa de controle de poluição, foi concluído que a região continua impactada apresentando altas concentrações de contaminantes tais como metais e hidrocarbonetos nos três principais compartimentos ambientais: água, sedimentos e biota (LAMPARELLI et al., 2001). 
Com as continuas ações para controle da poluição, nos anos 1990 esperava-se uma redução da exposição do meio ambiente aos contaminantes. Entretanto, estudos conduzidos em 1997 e 1998 indicaram que a acumulação de poluentes nos sedimentos estava intimamente relacionada à bioacumulação na biota aquática colocando em risco a saúde pública e o equilibro ecológico do ecossistema costeiro da região (PRÓSPERI, 2002).

Além da grande importância econômica, o SESSV possui uma grande relevância ambiental pelo fato de estar cercado por manguezais, abrigando cerca de $43 \%$ do total de manguezais do estado de São Paulo (LAMPARELLI et al., 2001).

Recentemente, muitos estudos foram realizados no SESSV e indicaram contaminação elevada por metais (BORDON et al., 2010; HORTELLLANI et al., 2005; 2008; LUIZ-SILVA et al., 2006; QUINÁGLIA, 2006), compostos orgânicos como hidrocarbonetos (BICEGO et al., 2006; MEDEIROS E BICEGO, 2004; NISHIGIMA et al., 2001; MARTINS et al., 2007; 2011), alquilbenzenos lineares (MARTINS et al., 2010), toxicidade (ABESSA et al., 2005; 2008; CESAR et al., 2006; 2007; CHOUERI, et al., 2009; SOUSA et al., 2007) assim como bioacumulação nos organismos (LAMPARELLI et al., 2001; SEMMELER., 2007; PEREIRA., 2008; MAGALHÃES et al., 2012), indicando impactos significativos ao ecossistema da região os quais podem chegar ao homem através da transferência pela cadeia alimentar. 


\section{MATERIAL E MÉTODOS}

\subsection{Amostragem}

\subsubsection{Sistema Estuarino de Santos e São Vicente}

Durante o inverno de 2010, amostras de sedimentos superficiais estuarinos foram coletadas em 16 locais distribuídos ao longo do SESSV, com auxílio de um amostrador tipo Elckman. A partir do material retido, somente a camada superficial de $2 \mathrm{~cm}$ do sedimento foi coletada. As amostras foram homogeneizadas, em seguida, foram divididas em sub-amostras para análises químicas e granulométricas.

Alguns locais foram escolhidos estrategicamente para coleta de sedimento visando amostrar toda a área de estudo e abordar as principais fontes de contaminação para a região. Os locais estão descritos abaixo e apresentados na FIG 8.

O ponto 1 está localizado na entrada do canal de São Vicente próximo às diversas marinas instaladas no local. $O$ ponto 2 está localizado no meio do canal de São Vicente, no deságue do rio Mariana, onde há um intenso trafego de barcos a motor. O ponto 3 está situado próximo ao lixão da Alemoa, no Largo da Pompeba. O ponto 4 localizado próximo ao terminal petrolífero, no Largo do Canel. O ponto 5 situado no meio do canal da Piaçaguera, no deságue do rio Cubatão o qual recebe efluentes industriais provenientes do complexo industrial de Cubatão. Os pontos 6, 13, 14 e 15 estão localizados perto da principal indústria siderúrgica e os pontos 10,11 e 12 próximos a companhia de petróleo no Brasil. O ponto 7 está localizado no deságue do canal de Bertioga e tem como principais fontes de contaminação os efluentes domésticos e o trafego de barcos a motor. O ponto 8 no meio do canal do porto de Santos e o ponto 9, próximo a área contaminada de uma indústria química e na entrada do canal do porto de Santos. Esse ponto foi amostrado com o objetivo de se avaliar a influência das atividades portuárias e o tráfego de navios. 


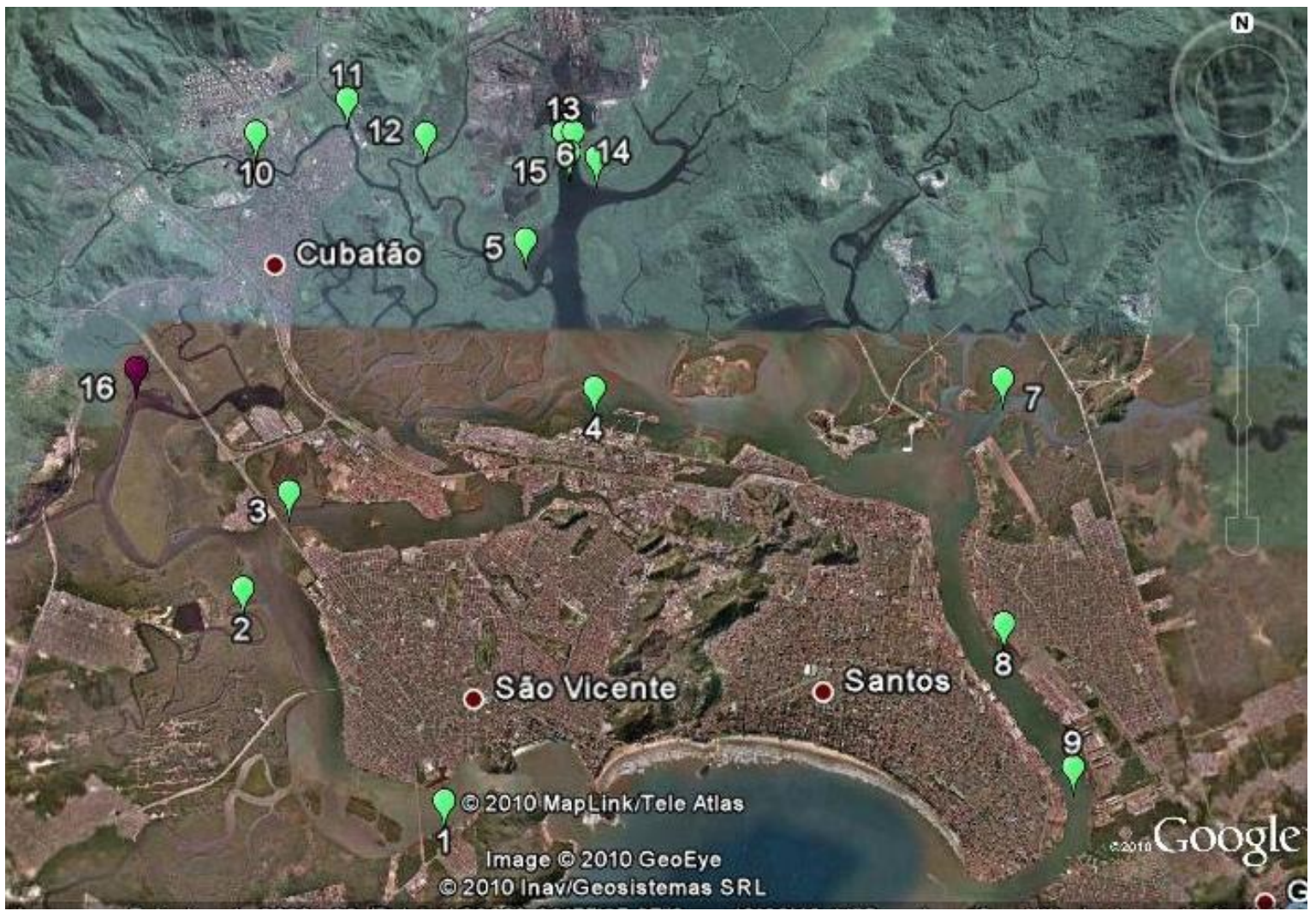

FIGURA 8 Localização do Sistema Estuarino de Santos e a distribuição dos pontos amostrais (Fonte: Google Earth).

Finalmente, o ponto 16, localizado no rio Casqueiro, foi amostrado como uma possível área de referência pelo fato de que o rio Casqueiro é uma região protegida, geograficamente distante das atividades metropolitanas da Baixada Santista.

\subsubsection{Baía de Santos, zona marinha adjacente e PEMLS}

As amostras de sedimentos referentes à baia de Santos, zona marinha adjacente e ao PEMLS foram coletadas durante o verão de 2011. Com auxilio de um amostrador de sedimento do tipo Van Veen, um total de 8 amostras de sedimentos superficiais foi coletado desde o PEMLS até a baia de Santos, distribuídos estrategicamente, de maneira a englobar áreas possivelmente 
impactadas em relação à contaminação e verificar um possível gradiente de contaminação (FIG 9 e 10).

O ponto 1 está localizado no pequeno porto da Laje de Santos, "Portinho", próximo à face norte da Laje de Santos, voltado para o continente. É no local onde os barcos das operadoras de mergulho e de turismo atracam, pois normalmente oferece melhor abrigo do vento, ondas e correnteza. O ponto 2 está localizado a cerca de 500 metros em direção ao continente em relação ao ponto 1 . O ponto 3 está localizado no lado oeste da Laje de Santos, próximo ao local conhecido como "Piscinas" pelas operadoras de mergulho. É um local muito apropriado para o mergulho, pois apresenta muitas formações rochosas.

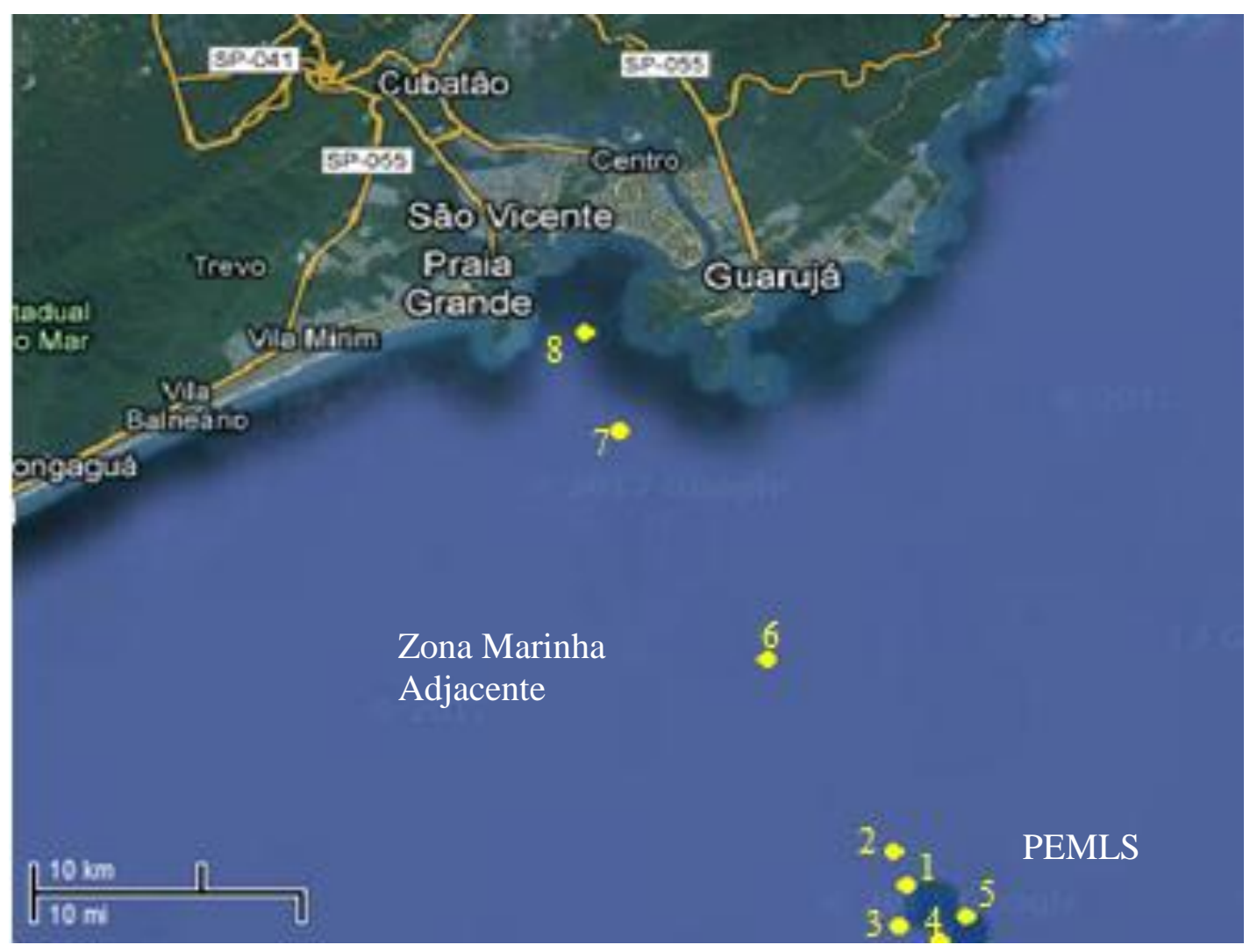

FIGURA 9 Localização dos pontos amostrais desde o PEMLS até a Baia de Santos (Fonte: Google Earth)

O ponto 4 está situado a sudeste da Laje de Santos, próximo ao "Parcel Novo". Um local que abriga uma grande diversidade de peixes e de invertebrados marinhos. O ponto 5 está localizado ao sul da Laje de Santos, conhecido como paredão da face sul. Na zona marinha adjacente, foram 
coletadas amostras de sedimentos em um ponto equidistante entre o PEMLS e o continente (ponto 6) e um ponto próximo a ilha da Moela (ponto 7), onde se encontra a área de descarte do material dragado do canal do Porto de Santos. Por fim, foi coletada uma amostra de sedimento na região central da baia de Santos (ponto 8), onde está Instalado o emissário submarino de Santos.

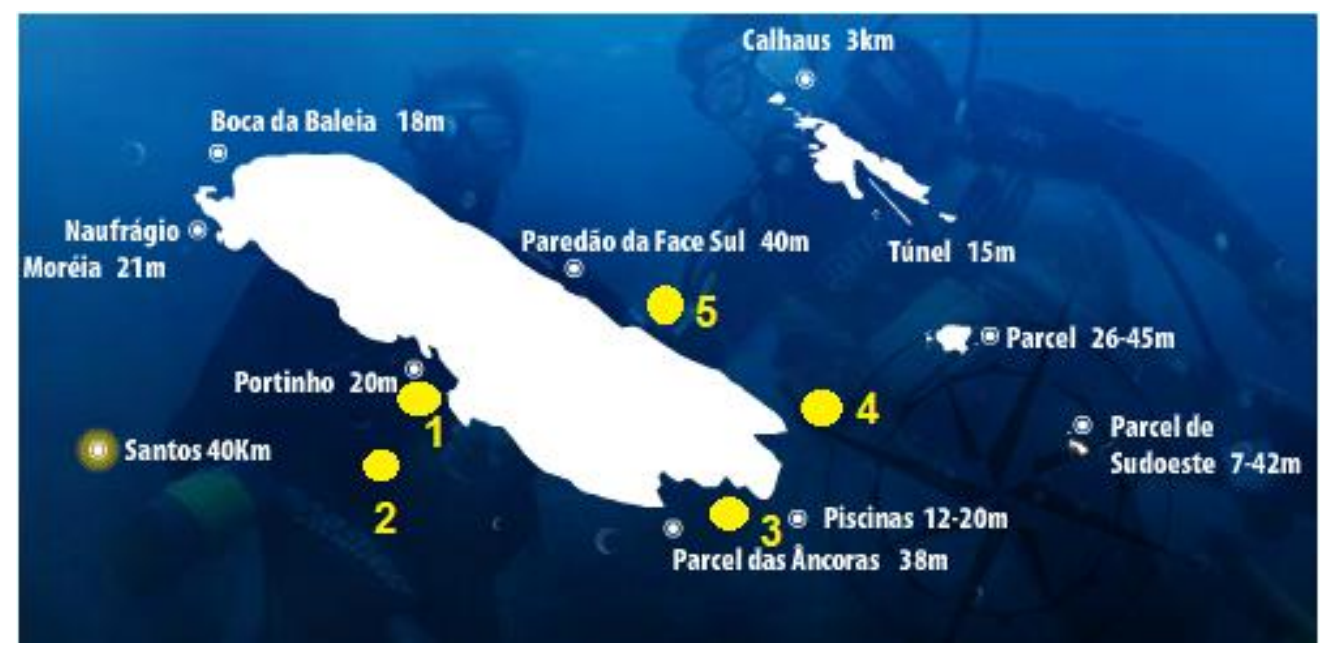

FIGURA 10 Localização dos pontos amostrais no interior do PEMLS e as respectivas profundidades (Fonte: Lajedesantos.com)

Todos os pontos foram georeferenciados com o auxilio de um Global Position System (GPS) e as coordenadas estão apresentadas na TAB 2.

TABELA 2. Coordenadas dos pontos amostrais dos sedimentos do PEMLS, zona marinha adjacente e Baia de Santos.

\begin{tabular}{ccc}
\hline & \multicolumn{2}{c}{ Coordenadas } \\
\hline Pontos & Latitude & Longitude \\
\hline 1 & $24^{\circ} 19.033^{\prime} S$ & $46^{\circ} 10.936^{\prime} \mathrm{O}$ \\
2 & $24^{\circ} 19.033^{\prime} \mathrm{S}$ & $46^{\circ} 10.936^{\prime} \mathrm{O}$ \\
3 & $24^{\circ} 19.103^{\prime} \mathrm{S}$ & $46^{\circ} 11.082^{\prime} \mathrm{O}$ \\
4 & $24^{\circ} 19.420^{\prime} \mathrm{S}$ & $46^{\circ} 10.900^{\prime} \mathrm{O}$ \\
5 & $24^{\circ} 19.274^{\prime} \mathrm{S}$ & $46^{\circ} 10.723^{\prime} \mathrm{O}$ \\
6 & $24^{\circ} 11.410^{\prime} \mathrm{S}$ & $46^{\circ} 17.619^{\prime} \mathrm{O}$ \\
7 & $24^{\circ} 07.561^{\prime} \mathrm{S}$ & $46^{\circ} 20.171^{\prime} \mathrm{O}$ \\
8 & $23^{\circ} 05.757^{\prime} \mathrm{S}$ & $46^{\circ} 22.179^{\prime} \mathrm{O}$ \\
\hline
\end{tabular}


Imediatamente após a coleta, as amostras destinadas as análises de metais foram armazenadas em recipientes plásticos, previamente descontaminados com ácido nítrico destilado e diluído a 10\% e devidamente identificados. As amostras destinadas a análises de hidrocarbonetos foram armazenadas em recipientes de alumínio previamente muflados a $600^{\circ} \mathrm{C} \mathrm{e}$ identificadas. Para as análises sedimentológicas, uma quantidade de aproximadamente $100 \mathrm{~g}$ foi separada. Após a coleta as amostras foram levadas ao laboratório e armazenadas a $-20^{\circ} \mathrm{C}$.

\subsection{Análise Granulométrica}

A granulometria foi analisada pelo método do peneiramento seco. Alíquotas de sedimento $(30 \mathrm{~g})$ foram secas à temperatura ambiente por $72 \mathrm{~h}$ e então, peneiradas por 15 minutos, utilizando um conjunto de peneiras seguindo a escala de Wenth-Worth. A fração retida em cada peneira será pesada e anotada. Com os resultados forão calculadas as classificações granulométricas de SHEPARD (1954) e obtidos os teores de areia e lama, segundo classificação de FOLK \& WARD (1957). A balança utilizada é calibrada frequentemente pelo INMETRO e tem a sensibilidade de 0,001g.

\subsection{Análise de Carbono Orgânico Total}

O Carbono Orgânico Total (TOC) foi mensurado pela técnica de infraververmelho utilizando o equipamento LECO CS-400 com precisão de $0,001 \%$. As amostras foram submetidas à combustão total e um sensor de infravermelho que detecta o dióxido de carbono $\left(\mathrm{CO}_{2}\right)$ gerado pela combustão, que imediatamente conecta com a quantidade de carbono elementar na amostra. A analise de TOC foi realizada no Laboratório de Gases do Instituto de Pesquisas Energéticas e Nucleares, coordenado pelo Prof. Dr. Jose Oscar William Vega Bustillos. 


\subsection{Análise da Matéria Orgânica}

Uma massa seca de $50 \mathrm{~g}$ de cada sedimento analisado foi colocada em mufla por aproximadamente 24 horas a $600^{\circ} \mathrm{C}$. O teor de matéria orgânica nos sedimentos foi calculado pela diferença entre o peso inicial e o final após ignição em mufla.

Essa análise foi realizada somente nos sedimentos provenientes do PEMLS, zona marinha adjacente e baia de Santos.

\subsection{Determinação do teor de Carbonato de Cálcio $\left(\mathrm{CaCO}_{3}\right)$}

Uma massa seca de $50 \mathrm{~g}$ de cada sedimento analisado foi colocada em uma solução de $\mathrm{HCl} 10 \%$ por aproximadamente 24 horas ou até que a decomposição do carbonato de cálcio se completasse. Em seguida, as amostras foram filtradas, lavadas com água de Milli $-\mathrm{Q}$ para a remoção de $\mathrm{HCl}$ residual e do $\mathrm{CaCl}_{2}$, e secas em estufas a $60^{\circ} \mathrm{C}$ por 24 horas. O teor de carbonato é calculado pela diferença entre o peso inicial e o final.

O teor de $\mathrm{CaCO}_{3}$ foi determinado somente para os sedimentos provenientes do PEMLS, zona marinha adjacente e baia de Santos.

\subsection{Preparação do Material Sedimentológico}

Aproximadamente $50 \mathrm{~g}$ de amostras de sedimentos foram secas em temperatura ambiente para evitar a perda de alguns elementos voláteis que poderiam ser sub avaliados. A etapa de secagem até massa constante é procedimento comum para amostras de sedimentos, pois amostras dessa 
natureza apresentam água em quantidade variável e em forma não determinada (Hortellani et al., 2008).

Após a secagem das amostras de sedimentos, o material grosseiro ( $>2 \mathrm{~mm}$ ) foi removido por peneiramento. Geralmente esse material é composto de pedregulhos, folha, carcaças de mariscos e outros materiais que não fazem parte da constituição do sedimento. As amostras de sedimentos foram maceradas em gral de ágata e homogeneizadas. Desse modo, assume-se que a fração total é todo material que passar na abertura $<2,00 \mathrm{~mm}$ uma vez que países como Brasil, Canadá, Austrália e Estados Unidos, através de sua agência ambiental EPA (U.S EPA, 2001), recomendam esse tipo de fração para os seus valores orientadores para fins de comparação.

As amostras foram acondicionadas em sacos de polietileno hermeticamente fechados para evitar contaminação das amostras antes do início das análises.

\subsection{Análises de Elementos Metálicos}

As análises de metais foram realizadas no Instituto de Pesquisas Energéticas e Nucleares no Laboratório de Caracterização Química e Isotópica o qual é acreditado pelo INMETRO no Sistema da Qualidade pela norma ISO/IEC 17025/2005. Foram determinados os seguintes elementos nas amostras de sedimentos proveniente do SESSV: Alumínio (Al), Cobalto (Co), Cromo (Cr), Cobre (Cu), Ferro (Fe), Manganês (Mn), Mercúrio (Hg), Níquel (Ni), Chumbo (Pb) e Zinco (Zn).

Esses metais foram selecionados para análise, baseados em estudos pretéritos na literatura e porque são conhecidos como potencialmente tóxicos e uma vez encontrados no meio ambiente em altas concentrações, podem causar efeitos adversos aos organismos que habitam a região. 


\subsubsection{Método de solubilização de amostras de sedimento}

A digestão foi realizada em sistema de microondas (CEM - modelo MARK 5). As soluções ácidas consistiam em uma mistura de $9 \mathrm{~mL}$ de ácido nítrico concentrado e destilado e $3 \mathrm{~mL}$ de ácido clorídrico concentrado destilado de acordo com as recomendações da metodologia USEPA 3051a (2007). 0,5 $1,0 \mathrm{~g}$ de cada amostra de sedimento e de materiais de referência certificados foram adicionados aos tubos de Teflon do microondas, os quais foram apropriadamente selados e aquecidos no microondas. A digestão foi feita de acordo com as condições a seguir: Potência: $600 \mathrm{~W}$; Tempo de rampa: 9 minutos; Temperatura: 175ํㅜ; Pressão: 1200 psi. Tempo mantido: 4.5 minutos. Depois do esfriamento, os conteúdos de dentro do tubo foram transferidos para tubos de centrifuga de $50 \mathrm{~mL}$ e o avolumado para $40 \mathrm{~g}$ de água Milli-Q. As análises de metais foram realizadas após as partículas dos resíduos decantarem no interior dos tubos. Para o $\mathrm{Al}$ e o $\mathrm{Fe}$ o extrato original foi diluído em 100 vezes antes de ser analisado devido a sua alta concentração no ambiente.

Segundo a metodologia USEPA 3051a, esse método não pretende realizar a digestão total das amostras e a extração dos analítos não pode refletir o conteúdo total nas amostras. Assim, nem todos os potenciais contaminantes disponíveis nas amostras de sedimentos podem ser acessados por qualquer extração ácida. Portanto, o uso de métodos como o 3051a, utilizando-se ácidos como $\circ \mathrm{HNO}_{3}$ e $\mathrm{HCl}$ (que extrai metais fortemente adsorvidos a matéria orgânica e pelas particulas finas) é muito útil para estimar a capácidade de sedimentos para transferência de metais para a biota. Esse tipo de metodologia de extração permite a comparação dos valores obtidos aos limites estabelecidos nos Valores da Qualidade do Sedimento. 


\subsubsection{Quantificação dos Elementos Metálicos]}

As concentrações de $\mathrm{Al}, \mathrm{Cr}$, Co, $\mathrm{Cu}, \mathrm{Fe}, \mathrm{Hg}, \mathrm{Mn}$, Ni, Pb e $\mathrm{Zn}$ foram determinados utilizando um espectrômetro de absorção atômica com chama, marca Varian (modelo-Spectra AA-220-Fast Sequencial).

O mercúrio foi analisado utilizando-se um sistema de injeção em fluxo, FIA-UP-AAS, onde uma válvula de injeção manual injeta $500 \mu \mathrm{L}$ da amostra digerida em um fluxo de $10 \mathrm{~mL} \min ^{-1}$ de água Milli-Q, que se encontra $30 \mathrm{~cm}$ à frente, conectado por um tubo de PTFE $(30 \mathrm{~cm})$, com um fluxo de $1 \mathrm{~mL} \mathrm{~min}^{-1}$ de $\mathrm{SnCl}_{2} 25 \%(\mathrm{~m} / \mathrm{v})$ em $\mathrm{HCl} 25 \%(\mathrm{v} / \mathrm{v})$ que reduz o $\mathrm{Hg}^{2+}$ para $\mathrm{Hg}^{0}$. O mercúrio reduzido encontra-se $30 \mathrm{~cm}$ a frente, conectado por um tubo de politetrafluoetileno $(30 \mathrm{~cm}$ ), com um fluxo de gás de arraste (argônio a $200 \mathrm{~mL}$ $\min ^{-1}$ ), utilizado para separar o vapor de $\mathrm{Hg}^{0}$ no separador de fases gás-líquido localizado $10 \mathrm{~cm}$ a frente, conectado por um tubo de PTFE $(10 \mathrm{~cm})$ e finalmente conduzir o vapor de $\mathrm{Hg}^{0}$ por um tubo de PTFE de $30 \mathrm{~cm}$ até a célula de quartzo acoplada ao espectrômetro de absorção atômica.

\subsubsection{Validação dos procedimentos analíticos para análise de metais}

Como garantia da qualidade foi feita a verificação do método, a partir de análises comprobatórias com material de referência certificado "Standard Reference Materials - SRM 2704 Buffalo River Sediment”, proveniente do National Institute of Standards and Technology (NIST) dos EUA. Brancos foram determinados sistematicamente e descontados em todas as amostras. $O$ material de referência foi analisado em 3 replicatas.

Os limites de detecção (LD) e de determinação (LQ) foram avaliados analisando-se as provas em branco da preparação, baseado nas orientações sobre Validação de Métodos de Ensaios Químicos do INMETRO (2003). O LD foi obtido através da média de determinações de 7 preparações distintas de provas em branco mais 3 vezes a estimativa do desvio padrão. O limite de 
determinação (LQ) foi obtido através da média de determinações de 7 preparações distintas de provas em branco mais 5 vezes a estimativa do desvio padrão, enquanto que os limites finais de determinação (LQf) foram obtidos considerando a massa das amostras e as diluições utilizadas. Os limites de detecção foram Al $\left(1,16 \mu \mathrm{g} \mathrm{g}^{-1}\right)$, Fe $\left(0,02 \mu \mathrm{g} \mathrm{g}^{-1}\right)$, Co $\left(0,02 \mu \mathrm{g} \mathrm{g}^{-1}\right), \mathrm{Cr}$ $\left(0,04 \mu \mathrm{g} \mathrm{g}{ }^{-1}\right), \mathrm{Cu}\left(0,02 \mu \mathrm{g} \mathrm{g}^{-1}\right), \mathrm{Hg}\left(0,001 \mu \mathrm{g} \mathrm{g}^{-1}\right), \mathrm{Mn}\left(0,05 \mu \mathrm{g} \mathrm{g}{ }^{-1}\right), \mathrm{Ni}(0,03 \mu \mathrm{g} \mathrm{g}$ $\left.{ }^{1}\right), \mathrm{Pb}\left(0,03 \mu \mathrm{g} \mathrm{g}^{-1}\right)$ e $\mathrm{Zn}\left(0,03 \mu \mathrm{g} \mathrm{g}^{-1}\right)$.

\subsection{Análises de Hidrocarbonetos}

As análises dos hidrocarbonetos foram realizadas nas dependências do Instituto Oceanográfico, no Laboratório de Química Orgânica Marinha. Foram analisados os hidrocarbonetos alifáticos e hidrocarbonetos policíclicos aromáticos.

A quantificação dos hidrocarbonetos foi realizada seguindo método descrito em UNEP (1992).

\subsubsection{Método de Extração e fracionamento}

As amostras de sedimento foram secas durante 72 horas em liofilizador. Em seguida, as amostras foram maceradas e homogeneizadas em almofariz com pistilo e armazenadas em frascos de vidro previamente descontaminados com solvente.

Cerca de $20 \mathrm{~g}$ de sedimento seco foram extraídas em sistema Soxhlet durante 8 horas com $80 \mathrm{~mL}$ de $50 \%$ em volume de $\mathrm{n}$-hexano e diclorometano por 8 horas. A cada frasco de extração foi adicionado uma solução de padrões internos "surrogates" contendo n-hexadeceno (para análises de n-alcanos entre C12 e C19 pristano e fitano); n-ecosieno (para análise de n-alcanos entre C20 e C34) e aromáticos deuterados (naftaleno-d8 e acenafteno-d10 - para HPA 
com até dois anéis aromáticos; fenantreno-d10 - para HPA com três anéis aromáticos; criseno-d12 - para HPA com quatro e cinco anéis aromáticos e perileno-d12 - para HPA com cinco e seis anéis aromáticos).

O extrato foi concentrado até $1 \mathrm{~mL}$ em um evaporador rotativo a vácuo. $\mathrm{O}$ volume restante foi submetido à cromatografia de adsorção em uma coluna contendo $3,2 \mathrm{~g}$ de sílica, $1,8 \mathrm{~g}$ de alumina ( $5 \%$ desativadas) e sulfato de sódio. A coluna foi eluida com $10 \mathrm{~mL}$ de $\mathrm{n}$-hexano (Fração F1) e $15 \mathrm{~mL}$ de uma mistura de 3:7 diclorometano em n-hexano (Fração F2). Estas frações foram concentradas em evaporador rotativo a vácuo e transferidas para ampolas de 1 $\mathrm{mL}$. A fração $\mathrm{F} 1$ continha os hidrocarbonetos alifáticos e a fração $\mathrm{F} 2$ continha os HPA.

\subsubsection{Determinação dos Hidrocarbonetos}

Uma alíquota do extrato final foi injetada no cromatógrafo a gás equipado com detector de ionização de chama (GC-FID) para análise de HA. Os HPA foram analisados no cromatógrafo a gás equipado com espectrômetro de massas (GC-MS) no modo de seleção de monitoração de íon (SIM - single ion monitoring).

$\mathrm{Na}$ etapa anterior à injeção no cromatógrafo, um padrão interno foi adicionado aos extratos finais de cada amostra. As temperaturas do injetor e detector do GC-FID foram de $300^{\circ} \mathrm{C}$ e $325^{\circ} \mathrm{C}$, respectivamente. O gás de arraste foi o hidrogênio ultra puro e o gás auxiliar foi o nitrogênio. As temperaturas do GC-MS foram de 280,280 e $300^{\circ} \mathrm{C}$ no injetor, na interface e na fonte de íons, respectivamente. A coluna cromatográfica utilizada em ambos os equipamentos foi de 30 metros de comprimento, $0,25 \mathrm{~mm}$ de diâmetro interno e $0,25 \mu \mathrm{m}$ de espessura de filme de $5 \%$ fenilmetilsiloxana. A rampa para os HA (no GC-FID) e HPA (no GC-MS) teve início em $40^{\circ} \mathrm{C}$ com aumento da taxa de $20^{\circ} \mathrm{C}$ até $60^{\circ} \mathrm{C}$ e a $5^{\circ} \mathrm{C} \mathrm{min}^{-1}$ até $290^{\circ} \mathrm{C}$ onde permaneceu por 5 minutos e aumentou $10^{\circ} \mathrm{C}$ até $300^{\circ} \mathrm{C}$, onde permaneceu constante durante 10 minutos. 
A identificação dos HA e dos HPA foi feita por comparação dos tempos de retenção com padrões de referência da Accustandard e Supelco dos EUA. Os compostos analisados no GC-MS também foram identificados através dos respectivos íons de quantificação e confirmação $(\mathrm{m} / \mathrm{z})$.

\subsubsection{Validação dos procedimentos analíticos para análise de hidrocarbonetos}

A quantificação foi feita por razões entre os "surrogates" e os compostos de interesse, baseada nas curvas analíticas construídas com pelo menos 05 concentrações diferentes de cada grupo de compostos.

A garantia de qualidade/controle de qualidade foi baseada na recuperação dos "surrogate", brancos e amostras fortificadas e análise do material de referência certificado "Standard Reference Materials - SRM 1944 New York/New Jersey Waterway Sediment" proveniente da NIST dos EUA. Brancos foram determinados sistematicamente para avaliar os níveis de possíveis interferentes durante as análises e descontados em todas as amostras. A recuperação dos padrões variou de $60 \%$ a $120 \%$.

O Limite de Deteç̧ão do Método (LD) é definido como a menor concentração de analito que pode ser determinada como sendo estatisticamente diferente do branco. Amostras de sedimento podem apresentar uma série de interferentes que influenciam na análise. Dessa forma, sugere-se que a determinação do LD seja realizada utilizando-se amostras reais das matrizes em estudo, porém recomenda-se o uso de amostras limpas, ou seja, que apresentem baixas concentrações do analitos em estudo.

O LD foi determinado como sendo 3 vezes o desvio padrão dos resultados de análises de 7 replicatas de uma amostra que foi fortificada com uma solução contendo todos os analitos de interesse. 


\subsubsection{Determinação da Origem dos Hidrocarbonetos no meio ambiente}

Estudos têm sido conduzidos para determinar não somente o grau de contaminação nos diferentes compartimentos ambientais, mas também para identificar as fontes emissoras dos potenciais contaminantes para o ambiente aquático.

\subsubsection{Determinação da Origem dos Hidrocabonetos Alifáticos}

Para auxiliar na determinação da origem do HA, avaliar o grau de contaminação petrogênica e o estado de degradação desses compostos nas amostras de sedimentos dos locais estudados foram utilizados algumas razões e parâmetros descritos abaixo.

De acordo com Volkman et al. (1992) e Readman et al. (2002), sedimentos estuarinos e marinhos não poluídos apresentam HA totais inferior a $10 \mu \mathrm{g} \mathrm{g}^{-1}$, podendo ser duas ou três vezes maior em regiões com significativo aporte de n-alcanos de cadeia longa e número impar de carbono, como áreas de mangue. Por outro lado, concentrações de HA totais superiores a $100 \mu \mathrm{g} \mathrm{g}^{-1}$ e a presença de mistura complexa não resolvida (MCNR) são associadas à introdução de hidrocarbonetos no ambiente, geralmente petróleo degradado, sendo que valores superiores a $500 \mu \mathrm{g} \mathrm{g}^{-1}$ são indicativos de poluição crônica por hidrocarbonetos.

Pristano (2,6,10,14-tetrametilpentadecano) e fitano $(2,6,10,14$ tetrametilhexadecano) são hidrocarbonetos isoprenóides comumente detectados em sedimentos marinhos costeiros. Pristano é normalmente encontrado no zooplâncton e outros animais marinhos de grande porte (Rontani e Bonin, 2011), mas também podem ocorrer como resultado de processos diagenéticos. Ambos estão presentes na maioria dos constituintes do petróleo, geralmente como componentes principais dentro de uma gama muito maior de alcanos isoprenóides (NRC, 1985). Como regra, uma alta 
predominância de pristano sobre fitano no ambiente marinho indica a contribuição de uma fonte biogênica desses compostos. Em sedimentos não contaminados a razão pristano/fitano normalmente varia entre 3 e 5, valores inferiores ou próximos a 1,00 indicam origem petrogênica desses compostos (Steinhauer e Boehm, 1992).

A razão entre os $n$-alcanos e isoprenóides corresponde à razão entre a concentração do pristano e do fitano com o $\mathrm{n}$-alcano de massa molecular mais próximo, ou seja, n-C17 e n-C18 (razão pristano/n-C17 e fitano/n-C18). A razão n-alcanos e isoprenóides entre têm sido utilizados para indicar a degradação microbiana uma vez que as taxas de biodegradação de $n$-alcanos são mais rápidas que os da isoprenóides ocasionando um aumento nessas duas razões para valores bem maiores que 1 , quando a matéria orgânica sedimentar está intensamente degradada (GONZÁLEZ-VILA et al., 2003). Portanto, baixos índices desta razão sugerem a presença de óleo degradado. Por outro lado, altos índices dessa razão indicam a entrada de óleo recém introduzido.

Para identificar introdução de petróleo, em geral, a presença de um MCNR em cromatogramas de HA pode ser utilizada como critério de evidência (Readman et al., 2002), por ser considerada uma mistura de vários isômeros e homólogos estruturalmente complexos de hidrocarbonetos ramificados e cíclicos que não podem ser resolvidos por colunas capilares do cromatógrafo a gás (CG) e aparece como um morro nos cromatogramas do CG (Gough e Rowland, 1990). Este recurso é normalmente associado com resíduos de petróleo degradado porque estas moléculas são resistentes à biodegradação e acumulam-se nos sedimentos (Farrington et al, 1977;. Readman et al, 2002). Além disso, a abundância relativa da MCNR, em comparação com a razão entre as concentrações de HA não resolvidos e resolvidos (U/R) pode ser utilizada como uma razão de evidencia da poluição por petróleo.

Relacionar os $\mathrm{n}$-alcanos de maior massa molecular de cadeias carbônicas ímpares sobre as pares auxilia a indicar a origem biogênica ou antrópica dos HA em sedimentos marinhos. Os valores de IPC que se apresentam em torno de 1,00 indicam, geralmente, predominância de nalcanos de origem antrópica, provenientes de contaminação petrogênica 
(ABOUL-KASSIM \& SIMONEIT, 1996). Em contrapartida, os valores entre 4,00 e 7,00 indicam n-alcanos de origem biogênica e terrígena, podendo estar associados a processos de deposição de material continental.

\subsubsection{Determinação da Origem dos Hidrocarbonetos Policíclicos Aromáticos}

Para identificação das origens dos HPA para o SESSV fora calculadas algumas razões descritas a seguir.

Para identificar as possíveis fontes dos HPA nos sedimentos, de acordo com Yunker et al. (2002), é possível utilizar razões de pares de isômeros: Razão antraceno/antraceno + fenantreno (Ant/ $\Sigma$-178) corresponde a razão entre antraceno e a soma dos isômeros de peso molecular 178 (ou seja, fenantreno e antraceno). Se a razão Ant $/ \Sigma-178$ for menor que 0,10 , indica a predominância de petróleo (óleo cru, combustível, diesel, querosene), se a razão for maior que 0,10 indica a predominância de HPA proveniente da combustão (queima de diferentes tipos de carvão, biomassa e óleos crus).

A razão fluoranteno/fluoranteno + pireno $(F-a n t / \Sigma-202)$ corresponde à razão do composto fluoranteno e a soma dos isômeros de peso molecular 202 (fluoranteno e pireno). Se os valores da razão forem menores que 0,50 indicam HPA proveniente de petróleo e derivados. Se estiver no intervalo de $0,40-0,50$ os HPA são originários do petróleo e da combustão (gasolina, diesel, petróleo bruto e emissões provenientes de carros e caminhões). Maior que 0,50 são associados a processos de combustão de querosene, de biomassa vegetal e da maioria dos tipos de carvão (vegetal, coque e betuminoso)

A razão benzo[a]antraceno/benzo[a]antraceno + criseno $(\mathrm{BaA} / \Sigma-228)$ associa a concentração do benzo(a)antraceno com a soma das concentrações dos isômeros de peso molecular 228 (ou seja, benzo(a)antraceno e criseno). Os valores da razão $\mathrm{BaA} / \Sigma$-228 menores que 0.20 sugerem HPA provenientes do petróleo, se resultar no intervalo de 0,20-0,35 indica HPA do petróleo e da 
combustão (fontes mistas). Maiores que 0,35 sugerem a combustão de petróleo e derivados e biomassa como principais fontes.

Por fim, a razão indeno[1,2,3-c,d]pireno/indeno[1,2,3- c,d]pireno + benzo[g,h,i]perileno (IPIP/ $\Sigma-276$ ) ou seja, o indeno[1,2,3-c,d]pireno e a somatória dos isômeros de peso molecular 276 (indeno[1,2,3-c,d]pireno e benzo[g,h,i]perileno). Para a razão IPIP/ $\Sigma-276$, os valores menores que 0,20 são atribuídos a fontes petrogênicas (petróleo bruto e diferentes tipos de óleos derivados). Os valores entre 0,20 e 0,50 estão associados à combustão de gasolina querosene diesel e óleos crus, enquanto valores maiores que 0,50 correspondem a processos de combustão envolvendo biomassa vegetal e carvão.

Os HPA de maior peso molecular (228 e 276) geralmente não contribuem significativamente na composição dos produtos de refino do petróleo, estando presente apenas nas frações residuais como piche de asfalto. A presença desses compostos é frequentemente observada em amostras associadas a processos de combustão (Wang et al., 1999).

A utilização de razões entre HPA é uma ferramenta importante para o estudo da origem antrópica desses compostos no meio ambiente. Assim, com os resultados foi possível identificar as possíveis fontes de hidrocarbonetos nos sedimentos e avaliar o grau de contaminação na área de estudo.

\subsection{Valores Guia de qualidade de sedimentos (VGQS)}

Muitos estudos vêm sendo desenvolvidos para integrar os dados químicos e ecotoxicológicos disponíveis sobre os contaminantes ambientais, a fim de estabelecer Valores Guia de Qualidade de Sedimentos (VGQS). Os VGQS fornecem uma base para identificar a concentração de compostos químicos que podem causar efeitos biológicos adversos à biota aquática (LONG et al., 2006). Estas propostas destinam-se como informal, não- 
regulatória, baseados em efeitos biológicos auxiliando na interpretação de dados químicos complexos (LONG E MACDONALD, 1998).

No Brasil, ainda não há uma legislação que determina critérios de regulamentação de qualidade de sedimento marinhos e estuarinos, mas existe uma resolução, CONAMA 344/04, (Brasil, 2004), que classifica os níveis de alguns metais e HPA em sedimentos de águas salinas e salobras a serem dragados. Contudo, afim de estimar os potenciais efeitos negativos a biota que os contaminantes podem causar, os dados do presente estudo serão comparados com valores orientadores de qualidade dos sedimentos desenvolvido no Brasil e um outro desenvolvido no Canadá. Os limites dos respectivos VGQS para os metais e HPA estão expressos nas TAB 2 e 3 , respectivamente.

MacDonald et al. (1996) desenvolveram valores para os níveis limiar de efeitos (Threshold Effect Level - TEL) e os níveis de prováveis efeitos (Probabily Effect Leve - PEL) para o Conselho Canadense de Ministros do Meio Ambiente, que mais tarde foi publicado, em 2002, como "Valores Orientadores da Qualidade dos Sedimentos Canadenses para Proteção da Vida Aquática" (CCME, 2002). Os valores de TEL foram calculados como a média geométrica do percentil $15 \%$ e $50 \%$ dos efeitos tóxicos e não tóxicos, respectivamente. Os valores de PEL foram obtidos a partir do pelo cálculo da média geométrica dos percentil $50 \%$ e $85 \%$ dos efeitos e não efeitos dos dados apresentados. Os valores de TEL foram assumidos como concentrações abaixo os quais os efeitos adversos sobre os organismos bentônicos são raramente esperados. $O$ PEL foi destinado a representar as concentrações acima das quais efeitos biológicos adversos são frequentemente esperados (Bicego et al., 2006).

O Conselho Canadense de Ministros do Meio Ambiente (CCME, 2002) utiliza a abordagem TEL/PEL para comparação e orientação de estudos ambientais nos sedimentos marinhos e estuarinos (TAB 3). Esse critério foi adotado tambem pela CETESB em estudo conduzido por Lamparelli et al. (2001), para fins de comparação. 
TABELA 3 Valores da qualidade dos sedimentos estipulados pelo CCME (2002) e por Choueri et al., 2009 para metais $\left({\mu g^{-1}}^{-1}\right)$.

\begin{tabular}{cccccc}
\hline & \multicolumn{2}{c}{ CCME (2002) } & \multicolumn{3}{c}{ Choueri et al., (2009) } \\
\hline Metais & TEL & PEL & $\begin{array}{c}\text { Não } \\
\text { poluído }\end{array}$ & $\begin{array}{c}\text { Moderadamente } \\
\text { poluído }\end{array}$ & $\begin{array}{c}\text { Altamente } \\
\text { poluído }\end{array}$ \\
\hline $\mathrm{Al}(\%)$ & $\mathrm{x}$ & $\mathrm{x}$ & $\mathrm{x}$ & $\mathrm{x}$ & $\mathrm{x}$ \\
$\mathrm{Fe}(\%)$ & $\mathrm{x}$ & $\mathrm{x}$ & $\mathrm{x}$ & $\mathrm{x}$ & $\mathrm{x}$ \\
$\mathrm{Co}(\mathrm{ppm})$ & $\mathrm{x}$ & $\mathrm{x}$ & $\leq 4,1$ & $>4,1 \mathrm{e}<10,3$ & $\geq 10,3$ \\
$\mathrm{Cr}(\mathrm{ppm})$ & 52,3 & 160 & $\mathrm{x}$ & $\mathrm{x}$ & $\geq 65,8$ \\
$\mathrm{Cu}(\mathrm{ppm})$ & 18,7 & 108 & $\mathrm{x}$ & $\mathrm{x}$ & $\geq 69,0$ \\
$\mathrm{Hg}(\mathrm{ppm})$ & 0,130 & 0,70 & $\leq 0,08$ & $>0,08 \mathrm{e}<0,32$ & $\geq 0,32$ \\
$\mathrm{Mn}(\mathrm{ppm})$ & $\mathrm{x}$ & $\mathrm{x}$ & $\mathrm{x}$ & $\mathrm{x}$ & $\mathrm{x}$ \\
$\mathrm{Ni}(\mathrm{ppm})$ & 15,9 & 42,8 & $\leq 5,9$ & $>5,9 \mathrm{e}<21,2$ & $\geq 21,2$ \\
$\mathrm{~Pb}(\mathrm{ppm})$ & 30,2 & 112 & $\leq 10,3$ & $>10,3 \mathrm{e}<19,2$ & $\geq 19,2$ \\
$\mathrm{Zn}(\mathrm{ppm})$ & 124 & 271 & $\leq 37,9$ & $>37,9 \mathrm{e}<61,7$ & $\geq 61,7$ \\
\hline
\end{tabular}

Baseados em estudos recentes abordando análises químicas, ecotoxicológicas e da comunidade bentônica do SESSV, VGQS estabelecidos por Choueri et al., (2009) definem 2 limiares de concentrações químicas para metais e HPAs em sedimentos locais, "VGQS baixo" e "VGQS altos" (TAB 4).

Concentrações químicas inferiores ao "VGQS baixo" são consideradas como não prejudiciais à biota aquática, assim como os sedimentos que apresentarem concentrações químicas abaixo desse nível são considerados como não poluídos. Por outro lado, as concentrações de contaminantes acima dos "VGQS alto" são potencialmente prejudiciais ao ecossistema; se os sedimentos apresentarem níveis de químicos superiores a este nível, será considerado como poluído para estes contaminantes. Por último, efeitos biológicos não são previsíveis entre a faixa de concentração destes dois limiares de sedimentos ("zona de incerteza") e os contaminantes que se enquadrarem neste intervalo, são considerados como moderadamente poluídos. 
TABELA 4 Valores da qualidade dos sedimentos estipulados pelo CCME (2002) e por Choueri et al., 2009 para HPA $\left(\mathrm{ng} \mathrm{g}^{-1}\right)$.

\begin{tabular}{cccccc}
\hline & \multicolumn{2}{c}{ CCME (2002) } & \multicolumn{3}{c}{ Choueri et al., (2009) } \\
\hline HPA & TEL & PEL & $\begin{array}{c}\text { Não } \\
\text { Poluído }\end{array}$ & $\begin{array}{c}\text { Moderadamente } \\
\text { Poluído }\end{array}$ & $\begin{array}{c}\text { Altamente } \\
\text { Poluído }\end{array}$ \\
\hline Naftaleno & 34,6 & 391 & $\mathrm{x}$ & $\mathrm{x}$ & $\mathrm{x}$ \\
Acenaftileno & 5,9 & 128 & $\mathrm{x}$ & $\mathrm{x}$ & $\mathrm{x}$ \\
Acenafteno & 6,7 & 88,9 & $\mathrm{x}$ & $\mathrm{x}$ & $\mathrm{x}$ \\
Fluoreno & 21,2 & 144 & $\mathrm{x}$ & $\mathrm{x}$ & $\mathrm{x}$ \\
Fenantreno & 86,7 & 544 & $\mathrm{x}$ & $\mathrm{x}$ & $\mathrm{x}$ \\
Antraceno & 46,9 & 245 & $\mathrm{x}$ & $\mathrm{x}$ & $\mathrm{x}$ \\
Fluoranteno & 113 & 1494 & $\mathrm{x}$ & $\mathrm{x}$ & $\mathrm{x}$ \\
Pireno & 153 & 1398 & $\mathrm{x}$ & $\mathrm{x}$ & $\mathrm{x}$ \\
Benzo(a)antraceno & 74,8 & 693 & $\mathrm{x}$ & $\mathrm{x}$ & $\mathrm{x}$ \\
Criseno & 108 & 846 & $\mathrm{x}$ & $\mathrm{x}$ & $\mathrm{x}$ \\
Benzo(a)pireno & 88.8 & 763 & $\mathrm{x}$ & $\mathrm{x}$ & $\mathrm{x}$ \\
Dibenzo(a,h)antraceno & 6,22 & 135 & $\mathrm{x}$ & $\mathrm{x}$ & $\mathrm{x}$ \\
HPA totais & 1684 & 16770 & $\leq 15$ & $>15 \mathrm{a}<1660$ & $\geq 1660$ \\
\hline
\end{tabular}

Assim, em uma tentativa de se estimar potenciais efeitos biológicos adversos dos metais e hidrocarbonetos nos sedimentos, os dados foram comparados com VGQS do CCME e por Choueri et al., (2009).

\subsection{Análises Estatísticas e Multivariada}

\subsubsection{Correlação de Pearson}

Com o objetivo de se estudar possíveis relações entre os teores dos metais, dos HA, dos HPA e das características sedimentológicas encontradas nos sedimentos, foram calculadas correlações de Pearson, de acordo com Zar (1996), a um nível de significância $p=0,01$, verificando a existência de uma possível relação linear entre dois dos valores quantitativos através do coeficiente $r$. As correlações foram geradas no programa estatístico BioStat 5.0 . 


\subsubsection{Análise de Componentes Principais e Agrupamento}

Para se identificar grupos de elementos com comportamento similar e o comportamento geral dos dados, foram utilizadas duas técnicas multivariada de classificação, a análise de componentes principais (ACP) e a análise de agrupamentos, usando o programa computacional Statistica 6. $0^{\circledR}$ (Stat Soft, Inc. 2001; versão 6).

Para análise de ACP e análise de agrupamento nos resultados de sedimentos provenientes de ambas as regiões, primeiramente, os dados foram padronizados aplicando o valor de $Z$ dado pela fórmula:

$$
Z_{i j}=\frac{X_{i j}-\bar{X}_{j}}{S_{j}}
$$

onde :

$\mathrm{j}=1,2,3 \ldots \mathrm{p}$, atributos

$\mathrm{i}=1,2,3 \ldots \mathrm{n}$, objetos

$Z_{i j=} 0$ valor padronizado de $X_{i} X_{j}$

$S_{\mathrm{j}}=\mathrm{a}$ média e o desvio padrão da coluna $\mathrm{j}$.

Assim, as variáveis padronizadas apresentam média nula e variância única.

A ACP é recomendada para integração dos resultados, verificando suas combinações, de modo a facilitar a interpretação destes dados. As técnicas multivariadas investigam problemas associados às medidas múltiplas. Assim, o tratamento das várias características dos sedimentos permite a verificação da existência, ou não, de correlação entre os diversos fatores estudados (HORTELLANI et al., 2005).

A ACP consiste numa manipulação da matriz de dados com o objetivo de simplificar as variações presentes em muitas variáveis, representando-as 
em um número menor de fatores, componentes principais, contendo informações para representar as amostras sobre como cada variável se relaciona com as demais variáveis. Assim, a natureza multivariada dos dados pode ser representada em poucas dimensões (FERREIRA et al. 1999).

A análise de agrupamento pode classificar as variáveis e as amostras de sedimentos de acordo com a similaridade da composição química. Nessa análise, inicialmente cada amostra é tratada individualmente e, então, a matriz similaridade é analisada; em cada passo se diminui uma dimensão da matriz, isto é, as amostras são gradativamente fundidas em grupos. O processo é repetido até que todas as amostras se reúnam em um único grupo de acordo com o grau de similaridade (DA SILVA et al., 2005). O resultado dessa análise é expresso na forma de dendrogramas, que são gráficos bidimensionais de fácil visualização. 


\section{RESULTADOS E DISCUSSÃO}

\subsection{Validação do método}

\subsubsection{Metais}

Validação do método foi realizada por meio das análises do Material de Referência Certificado (SRM 2704 - Buffalo River Sediments). A recuperação do material de referência, Buffalo River Sediment para a maioria dos metais durante o processo de validação foi > 80\% e estão expressos nas TAB 5 e 6 .

O Buffalo River Sediment é certificado para a extração total de metais, 0 que explica a baixa recuperação de $\mathrm{Cr}$ nas análises dos sedimentos provenientes da primeira campanha e da segunda campanha (52,1\% e 53,5\% respectivamente) e do $\mathrm{Al}(27,3 \%$ e $23,0 \%$ respectivamente). Para o elemento Fe, obteve-se uma recuperação de 55,4\% nas amostras de sedimento da segunda campanha (TAB 6). Cr, Al e Fe são conhecidos como elementos refratários e estão fortemente ligados aos silicatos que são difíceis de digerir e explica a baixa recuperação destes metais.

De acordo com o método 3051a, silicatos não podem ser dissolvidos e, em alguns casos, podem isolar elementos alvo analisados. Estes resultados estão de acordo com outros estudos com baixa recuperação para o elemento Cr (Cook, et al.1997; Cox et al, 2003; Hortellani et al, 2008).

TABELA 5. Valores mensurados, valores certificados e valores de recuperação para o material de referencia Buffalo River Sediment, para as análises das amostras de sedimentos do SESSV.

\begin{tabular}{|c|c|c|c|c|c|}
\hline \multicolumn{4}{|c|}{ Buffalo River Sediment $\left(\mu \mathrm{g} \mathrm{g}^{-1}\right)$} & \multirow[b]{2}{*}{$\begin{array}{c}\text { Valores } \\
\text { certificados } \\
\text { (USEPA, 3051a) } \\
\left(\mu \mathrm{g} \mathrm{g}^{-1}\right) \\
\end{array}$} & \multirow[b]{2}{*}{$\begin{array}{c}\text { Recuperação } \\
(\%)\end{array}$} \\
\hline Metais & $\begin{array}{l}\text { Valores mensurados }{ }^{a} \\
\qquad\left(\mu \mathrm{g} \mathrm{g}^{-1}\right)\end{array}$ & $\begin{array}{l}\text { Valores Certificados } \\
\left(\mu \mathrm{g} \mathrm{g}^{-1}\right)\end{array}$ & $\begin{array}{c}\text { Recuperação } \\
(\%)\end{array}$ & & \\
\hline $\mathrm{Al}$ & $1,67 \pm 0.45^{\star}$ & $6,11 \pm 0,16^{*}$ & 27,3 & - & - \\
\hline Co & $15,7 \pm 2.1$ & $14,0 \pm 0,6$ & 112 & - & - \\
\hline $\mathrm{Cr}$ & $70,4 \pm 6.5$ & $135 \pm 5$ & 52,1 & $77,1 \pm 12,6$ & 91,3 \\
\hline $\mathrm{Cu}$ & $90,6 \pm 3.8$ & $98,6 \pm 5,0$ & 91,9 & - & - \\
\hline $\mathrm{Fe}$ & $3,43 \pm 0.03^{*}$ & $4,11 \pm 0,10^{*}$ & 83,5 & - & - \\
\hline $\mathrm{Hg}$ & $1,65 \pm 0.04$ & $1,47 \pm 0,07$ & 112 & - & - \\
\hline $\mathrm{Mn}$ & $516 \pm 15$ & $555 \pm 19$ & 93,0 & - & - \\
\hline $\mathrm{Ni}$ & $36,0 \pm 1,9$ & $44,1 \pm 3,0$ & 80,7 & $42,2 \pm 3,20$ & 85,3 \\
\hline $\mathrm{Pb}$ & $149 \pm 11$ & $161 \pm 17$ & 93,0 & $161 \pm 17$ & 93,0 \\
\hline $\mathrm{Zn}$ & $431 \pm 34$ & $438 \pm 12$ & 98,4 & - & - \\
\hline
\end{tabular}


TABELA 6 Valores mensurados, valores certificados e valores de recuperação para amostras do material de referencia Buffalo River Sediments para as análises das amostras de sedimentos do PEMLS e Zona Marinha Adjacente Buffalo River Sediment $\left(\mu \mathrm{g} \mathrm{g}^{-1}\right)$

\begin{tabular}{|c|c|c|c|c|c|}
\hline Metais & $\begin{array}{l}\text { Valores mensurados }{ }^{a} \\
\qquad\left(\mu \mathrm{g} \mathrm{g}^{-1}\right)\end{array}$ & $\begin{array}{c}\text { Valores Certificados } \\
{ }^{b}\left(\mu \mathrm{g} \mathrm{g}^{-1}\right)\end{array}$ & $\begin{array}{l}\text { Recuperação } \\
(\%)\end{array}$ & $\begin{array}{l}\text { Valores certificados } \\
\left(\text { USEPA, 3051a } \mathrm{gg} \mathrm{g}^{-1} \text { ) }\right.\end{array}$ & $\begin{array}{c}\text { Recuperação } \\
(\%)\end{array}$ \\
\hline $\mathrm{Al}$ & $1,41 \pm 0,05^{*}$ & $6,11 \pm 0,16^{*}$ & 23,0 & - & - \\
\hline Co & $12,5 \pm 0,5$ & $14,0 \pm 0,6$ & 89,4 & - & - \\
\hline $\mathrm{Cr}$ & $72,3 \pm 1,4$ & $135 \pm 5$ & 53,5 & $77,1 \pm 12,6$ & 93,8 \\
\hline $\mathrm{Cu}$ & $83,7 \pm 0,8$ & $98,6 \pm 5,0$ & 84,8 & - & - \\
\hline $\mathrm{Fe}$ & $2,28 \pm 0,01^{*}$ & $4,11 \pm 0,10^{*}$ & 55,4 & - & - \\
\hline $\mathrm{Hg}$ & $1,37 \pm 0,18$ & $1,47 \pm 0,07$ & 93,1 & - & - \\
\hline $\mathrm{Mn}$ & $433 \pm 14$ & $555 \pm 19$ & 78,1 & - & - \\
\hline $\mathrm{Ni}$ & $36,6 \pm 0,3$ & $44,1 \pm 3,0$ & 83,1 & $42,2 \pm 3,20$ & 86,9 \\
\hline $\mathrm{Pb}$ & $152 \pm 5$ & $161 \pm 17$ & 94,7 & $161 \pm 17,0$ & 94,7 \\
\hline $\mathrm{Zn}$ & $435 \pm 11$ & $438 \pm 12$ & 99,5 & - & - \\
\hline
\end{tabular}
expressos em porcentagem

Apesar da recuperação do $\mathrm{Cr}$ ter sido 91,3\% para as análises dos sedimentos provenientes do SESSV e 93,8\% para as análises dos sedimentos referentes a baia de Santos, zona marinha adjacente e PEMLS, esses resultados foram considerados apropriados, bem como os valores de recuperação do $\mathrm{Ni}$ e $\mathrm{Pb}$.

\subsubsection{Hidrocarbonetos}

A tabela 7 expressa a porcentagem de recuperação para cada composto analisado no branco fortificado e na matriz fortificada e a analise d'o material de referência SRM 1944(“New York/New Jersey Waterway Sediment”). O limite de detecção (LD) do método foi 0,001-0,034 $\mu \mathrm{g} \mathrm{g}^{-1}$ para os n-alcanos e 1,00-3,70 $n g g^{-1}$, para os HPA. 
Tabela 7 Resultados das análises do branco fortificado, matriz forticada e material de referência SRM 1944 para validação do método analítico.

\begin{tabular}{|c|c|c|c|c|c|}
\hline & $\begin{array}{c}\text { Branco } \\
\text { fortificado }\end{array}$ & \%Recuperação & $\begin{array}{c}\text { Matriz } \\
\text { fortificada }\end{array}$ & \%Recuperação & $\begin{array}{l}\text { SRM } \\
1944\end{array}$ \\
\hline Naftaleno & 20,13 & 80,52 & 22,81 & 73,12 & 840,83 \\
\hline Metilnaftaleno & 47,65 & 95,3 & 48,67 & 88,76 & 297,22 \\
\hline Bifenil & 22,89 & 91,56 & 23,81 & 87,76 & 195,28 \\
\hline Etilnaftaleno & 59,62 & 119,24 & 55,32 & 108,09 & 232,47 \\
\hline Dimetilnaftaleno & 201,77 & 100,885 & 189,26 & 91,065 & 476,14 \\
\hline Acenaftileno & 25,34 & 101,36 & 25,64 & 93,96 & 591,67 \\
\hline Acenafteno & 25,68 & 102,72 & 25,46 & 97,44 & 273,07 \\
\hline Trimetilnaftaleno & $<$ LDM & - & 3,97 & 1,26 & 346,09 \\
\hline Fluoreno & 28,64 & 114,56 & 27,96 & 104,56 & 252,54 \\
\hline Metilfluoreno & $<$ LDM & - & 12,59 & 75,28 & 173,26 \\
\hline Dibenzotiofeno & 34,25 & 137 & 29,23 & - & 907,84 \\
\hline Fenantreno & 20,45 & 81,8 & 25,36 & 78,58 & 3568,45 \\
\hline Antraceno & 21,02 & 84,08 & 22,23 & 82,34 & 715,5 \\
\hline Dimetilfluoreno & $<$ LDM & - & 3,78 & 1,64 & 120,89 \\
\hline Metildibenzotiofeno & $<$ LDM & - & 0,86 & 0,22 & 302,52 \\
\hline Metilfenantreno & 46,06 & 61,41 & 49,47 & 57,72 & 930,28 \\
\hline Dimetildibenzotiofeno & $<$ LDM & - & 0,01 & 0 & 19,39 \\
\hline Dimetilfenantreno & $<$ LDM & - & 5,06 & 2,22 & 457,05 \\
\hline Fluoranteno & 17,69 & 70,76 & 28 & 62,22 & 5021,24 \\
\hline Pireno & 17,34 & 69,36 & 28,15 & 62,7 & 5010,82 \\
\hline Metilfluoranteno & 16,6 & 66,4 & 14,58 & 58,32 & 407,18 \\
\hline Renteno & 7,18 & 28,72 & 6,29 & 24,66 & 188,02 \\
\hline Metilpireno & 16,24 & 64,96 & 14,18 & 56,72 & 452,26 \\
\hline Criseno & 16,27 & 65,08 & 25,48 & 65,26 & 2313,28 \\
\hline Metilcriseno & 13,6 & 54,4 & 23,77 & 56,14 & 4030,89 \\
\hline Dimetilcriseno & $<$ LDM & - & 5,67 & 0,24 & 1213,3 \\
\hline Benzo(b)fluoranteno & 29,34 & 117,36 & 46,99 & 119,34 & 171,48 \\
\hline Benzo(j)fluoranteno & 25,51 & 102,04 & 34,85 & 94,76 & 2572,23 \\
\hline Benzo(k)fluoranteno & 24,93 & 99,72 & 37,51 & 109,34 & 2546,45 \\
\hline Benzo(e)pireno & 26,23 & 104,92 & 39,34 & 94,64 & 3132,08 \\
\hline Benzo(a)pireno & 23,34 & 93,36 & 37,88 & 92,5 & 3133,05 \\
\hline Perileno & 25,49 & 101,96 & 91,77 & 118,28 & 3283,63 \\
\hline indeno[123-c,d]pireno & 24,62 & 98,48 & 52,99 & 120,42 & 1232,67 \\
\hline dibenzo(a,h)antraceno & 25,5 & 102 & 36,06 & 112,28 & 3991,66 \\
\hline benzo(b)criseno & 24,67 & 98,68 & 28,57 & 100,48 & 942,23 \\
\hline benzo(g,h,i)perileno & 25,84 & 103,36 & 49,55 & 108,32 & 695,07 \\
\hline coroneno & 18,78 & 75,12 & 25,59 & 81,06 & 4008,78 \\
\hline
\end{tabular}


No processo analítico referente aos sedimentos originários do SESSV, o composto reteno não apresentou valores compatíveis com as faixas de valores aceitáveis de recuperação.

O ponto 15 apresentou interferências analíticas durante o procedimento de analise e não apresentou valores de recuperação acima dos aceitáveis para o método para todos os compostos de HPA ao final das análises.

Portanto, o composto HPA reteno e o ponto 15 não serão discutidos em relação aos HPA proveniente das amostras de sedimentos do SESSV.

\subsection{Sistema Estuarino de Santos e São Vicente}

\subsubsection{Análises sedimentológicas}

\subsubsection{Granulometria e TOC}

Os resultados das análises de granulometria e TOC estão expressas na TAB 8

A fração granulométrica silte e argila (fina) acima de $10 \%$ foi encontrada nos pontos localizados no fundo do estuário nos locais 5, 6, 12, 13 e 15, os quais apresentaram valores mais elevados quando em comparação com outros pontos. Uma vez que a concentração de metais pode vir a se acumular nos sedimentos que apresentam uma grande porcentagem de finos, devido ao aumento da área superficial disponível do grão (Hortellani et al., 2005), os resultados confirmaram as altas concentrações de metais nesses pontos, especialmente a concentração do elemento $\mathrm{Hg}$ nos pontos situados próximo às fontes industriais.

TABELA 8 Porcentagem de \% silte e argila $(<63 \mu \mathrm{m})$ e de carbono orgânico total (TOC) nas amostras de sedimentos do SESSV.

\begin{tabular}{ccccccccccccccccc}
\hline & 1 & 2 & 3 & 4 & 5 & 6 & 7 & 8 & 9 & 10 & 11 & 12 & 13 & 14 & 15 & 16 \\
\hline $\begin{array}{c}\text { Silte } e \\
\text { argila (\%) }\end{array}$ & 4.51 & 1.46 & 3.23 & 3.68 & 36.65 & 10.67 & 0.00 & 0.71 & 5.96 & 0.78 & 8.61 & 16.53 & 15.54 & 1.17 & 10.18 & 0.77 \\
TOC (\%) & 1.90 & 2.20 & 5.43 & 2.40 & 4.20 & 7.79 & 5.67 & 1.19 & 1.33 & 0.43 & 1.58 & 5.00 & 4.86 & 2.65 & 3.02 & 2.62 \\
\hline
\end{tabular}


Embora não seja comum encontrar baixa \% de silte e argila em um sistema estuarino, Cesar et al. (2007) reportaram baixo teor de \% silte e argila na mesma área utilizando um método granulométrico semelhante ao utilizado neste estudo. Devido à hidrodinâmica do sistema estuarino, a quantiade de finos nos sedimentos superficiais varia até mesmo em áreas próximas. Silva et al., 2006 registraram uma variação considerável nos dados de granulometria, nos mesmos pontos de amostragem desse estudo. A \% silte e argila encontrada no ponto 14 foi menor do que aquelas encontrada nos pontos $13 \mathrm{e}$ 15 , mesmo eles estando muito proximos uns aos outros.

O TOC variou de $0,43 \%$ (ponto 10) para $7,79 \%$ (ponto 6). As maiores concentrações foram encontradas nos sedimentos dos pontos 3, 6, 7 e 12. De acordo com a USEPA, (2007) em muitos estudos anteriores que avaliaram esta disponibilidade em areia e silte e argila com valores de TOC acima de 0,5\% foram responsáveis pela maior parte da precipitação metal. Comparando os valores TOC com conteúdo \% silte e argila, não há uma tendência aparente de distribuição entre os dois parâmetros. No entanto, de acordo com Yu et al., (2001) variáveis quelantes diferentes podem competir de forma dinâmica para absorver metais tornando-se difícil a compreensão dos processos de absorção e liberação de metais.

\subsection{Metais Sistema Estuarino de Santos e São Vicente}

As concentrações de metais nas amostras de sedimentos do SESSV estão expressos na TAB 9. De acordo com os resultados, os pontos localizados na porção interna do estuário $(5,10,11,12,13$ e 15), próximos ao complexo industrial de Cubatão, foram os que apresentaram as maiores concentrações de metais reportadas neste estudo. 
TABELA 9 Concentrações de metais nas amostras de sedimentos provenientes do SESSV $\left(\mu \mathrm{g} \mathrm{g}^{-1}\right)$

\begin{tabular}{|c|c|c|c|c|c|c|c|c|c|c|c|c|c|c|c|c|}
\hline Metais/ Pontos & 1 & 2 & 3 & 4 & 5 & 6 & 7 & 8 & 9 & 10 & 11 & 12 & 13 & 14 & 15 & 16 \\
\hline Al \% & 1.06 & 0.56 & 1.22 & 1.15 & 4.59 & 0.95 & 0.48 & 0.77 & 1.54 & 1.22 & 3.58 & 3.63 & 3.71 & 1.36 & 3.99 & 1.52 \\
\hline $\mathrm{Cd} \mu \mathrm{g} \mathrm{g}^{-1}$ & 0.08 & 0.05 & 0.10 & 0.11 & 0.27 & 0.10 & 0.07 & 0.05 & 0.05 & 0.04 & 0.09 & 0.23 & 0.34 & 0.06 & 0.29 & 0.06 \\
\hline $\mathrm{Cr} \mu \mathrm{g} \mathrm{g}^{-1}$ & 13.17 & 6.48 & 10.72 & 14.54 & 33.02 & 11.46 & 10.57 & 8.10 & 19.22 & 15.88 & 36.03 & 30.83 & 42.50 & 12.54 & 41.35 & 13.98 \\
\hline $\mathrm{Cu} \mu \mathrm{g} \mathrm{g}^{-1}$ & 15.84 & 2.88 & 7.29 & 9.24 & 29.53 & 5.95 & 6.88 & 3.88 & 7.24 & 15.07 & 19.08 & 35.43 & 38.39 & 6.44 & 27.50 & 6.90 \\
\hline Co $\mu g g^{-1}$ & 14.03 & 1.07 & 5.48 & 7.43 & 27.72 & 4.14 & 5.07 & 2.07 & 5.43 & 12.05 & 17.09 & 20.14 & 16.59 & 9.57 & 13.50 & 6.57 \\
\hline $\mathrm{Fe} \%$ & 1.20 & 0.58 & 1.12 & 1.59 & 3.87 & 1.64 & 0.85 & 0.81 & 95 & 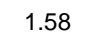 & 35 & 45 & 3.99 & .45 & 3.59 & 1.32 \\
\hline $\mathrm{Hg}_{\mu} \mathrm{g} \mathrm{g}^{-1}$ & 0.20 & 0.14 & 0.20 & 0.34 & $\underline{1.33}$ & 0.19 & 0.15 & 0.19 & 0.16 & $<0.03$ & 0.18 & 0.55 & 0.42 & 0.03 & 0.57 & $<0.03$ \\
\hline $\mathrm{Mn} \mu \mathrm{g} \mathrm{g}^{-1}$ & 212.60 & 78.17 & 91.48 & 168.77 & 255.19 & 136.76 & 93.70 & 104.33 & 366.68 & 160.70 & 889.47 & 316.33 & 593.99 & 165.66 & 610.11 & 115.99 \\
\hline $\mathrm{Ni} \mu \mathrm{g} \mathrm{g}^{-1}$ & 5.26 & $<2.00$ & 5.88 & 5.59 & 21.53 & 6.44 & 1.05 & 2.76 & 7.65 & 9.65 & 17.41 & 23.53 & 23.61 & 5.50 & 17.03 & 3.52 \\
\hline $\mathrm{Pb} \mu \mathrm{g} \mathrm{g}^{-1}$ & 13.44 & 1.37 & 6.59 & 7.04 & 24.70 & 3.10 & 5.53 & 3.72 & 1.08 & 4.44 & 15.04 & 18.37 & 37.78 & 3.71 & 26.67 & 6.95 \\
\hline $\mathrm{Zn} \mu \mathrm{g} \mathrm{g}^{-1}$ & 54.04 & 20.36 & 39.17 & 59.91 & 114.86 & 42.30 & 26.85 & 32.56 & 40.78 & 51.14 & 95.09 & 180.27 & 231.36 & 46.25 & 143.39 & 39.63 \\
\hline
\end{tabular}

\section{Alumínio}

O Al é considerado o terceiro elemento mais abundante na crosta terrestre. Devido a sua reatividade, o Al não ocorre naturalmente no seu estado fundamental $\left(\mathrm{Al}^{\circ}\right)$, porem, é amplamente distribuído na crosta terrestre em forma combinada com o flúor, em feldspato, caulim e, de uma maneira mais geral, nos chamados alumíniossilicatos. O valor basal da concentração de Al nos sedimentos da região do SESSV é de 2,7\% (Quináglia, 2006).

Nos sedimentos do SESSV, as concentrações de Al variaram entre 0,480 a $4,59 \%$ (FIG 11) 


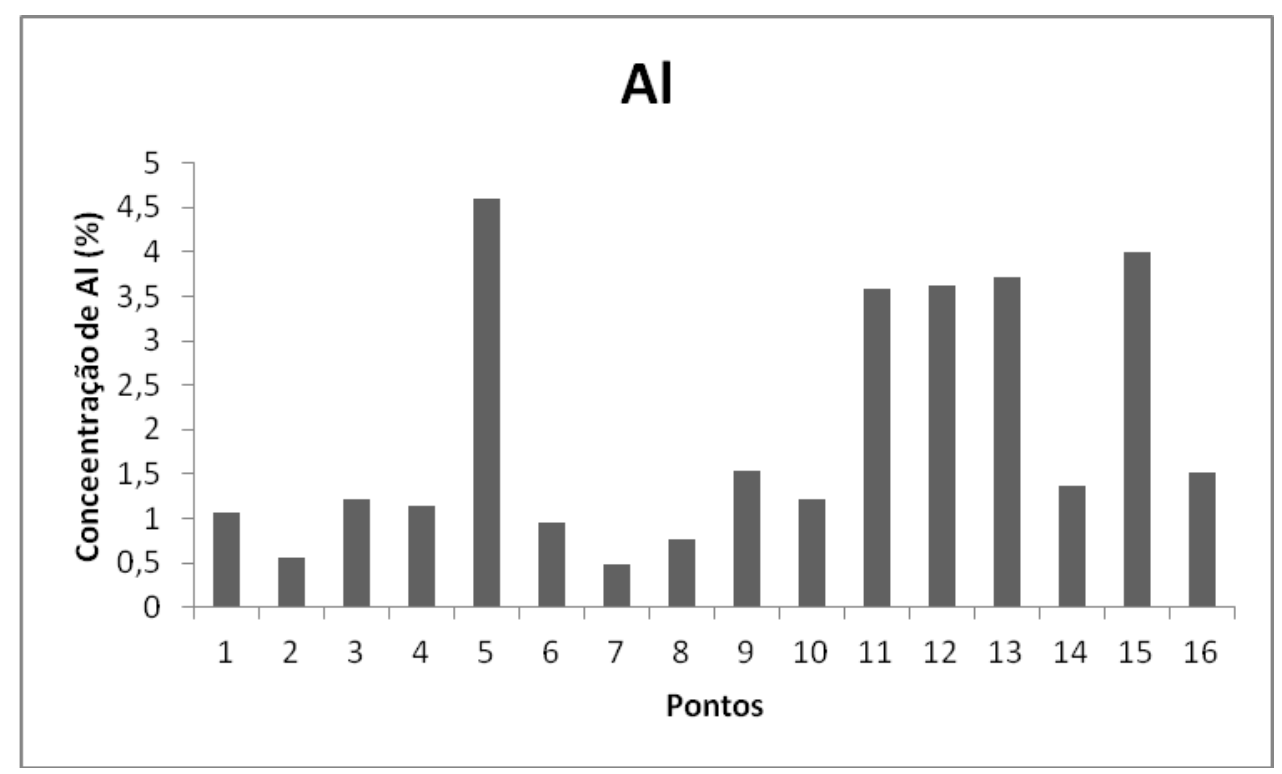

FIGURA 11 Concentração de Al (\%) nos pontos de coleta.

As concentrações mais elevadas foram observadas no interior do estuário, formando um gradiente em direção a baia de Santos. As maiores concentrações foram encontradas nos sedimentos dos pontos 5 (4,59\%), 15 $(3,99 \%)$ e $13(3,71 \%)$ localizados na parte interna do estuário. As menores concentrações foram observadas nos sedimentos dos pontos $7(0,480 \%)$ e 2 $(0,560 \%)$ na altura do desague do canal de Bertioga e do rio Mariana, respectivamente. Resultados semelhantes aos do presente estudo foram encontrados por Abessa (2002), que registrou concentrações entre 0,6 e 7,9\% e por Luiz-Silva et al., (2006) que reportou concentrações variando de 1,3 a $4,1 \%$.

Os teores de Al encontrados no presente estudo estão acima dos valores basais devido ao aporte de efluentes industriais da siderurgica, porem sugerem uma diminuição em relação à introdução desse elemento em comparação com os estudos pretéritos.

Em termos gerais verificou-se que a concentração de Al é maior no interior do estuário, próximo ao complexo industrial de Cubatão e decrescendo em relação a entrada dos canais de Santos e São Vicente que finalmente, voltando a aumentar Al nos sedimentos de ambos os canais. 


\section{Ferro}

O Fe é o quarto elemento químico mais abundante no planeta depois do oxigênio, silício e alumínio. O Fe compõe cerca de $30 \%$ da massa total do planeta. As fontes antrópicas de Fe são inúmeras como as industrias de aço, ligas em geral, soldas, magnéticos, transformadores elétricos, catálise de amônia, fabricação de maquinas, trilhos, atividades de mineração entre outras. Outra forma introduzir o $\mathrm{Fe}$ ao meio ambiente é o uso excessivo de fertilizantes.

Os teores de $\mathrm{Fe}$ variaram entre 0,58 e $3,99 \%$ nos sedimentos do SESSV (FIG 12) As maiores concentrações foram observadas no interior do estuário nos sedimentos dos pontos 13 (3,99\%), 5 (3,87\%), e 15 (3,59\%) próximo a principal siderúrgica da região. As menores concentrações foram encontradas nos sedimentos dos pontos 2,7 e 8 (0,58\%, 0,85\% e 0,81\% respectivamente).

Estudos anteriores realizados por Abessa (2002) encontraram concentrações de Fe variando de 0,2 a $8 \%$ nos sedimentos. Luiz-Silva et al., (2006) observaram concentrações de Fe variando entre 1,9 a 10\%. As maiores concentrações para ambos os estudos foram reportadas próximo à siderúrgica, na parte interna do estuário. 


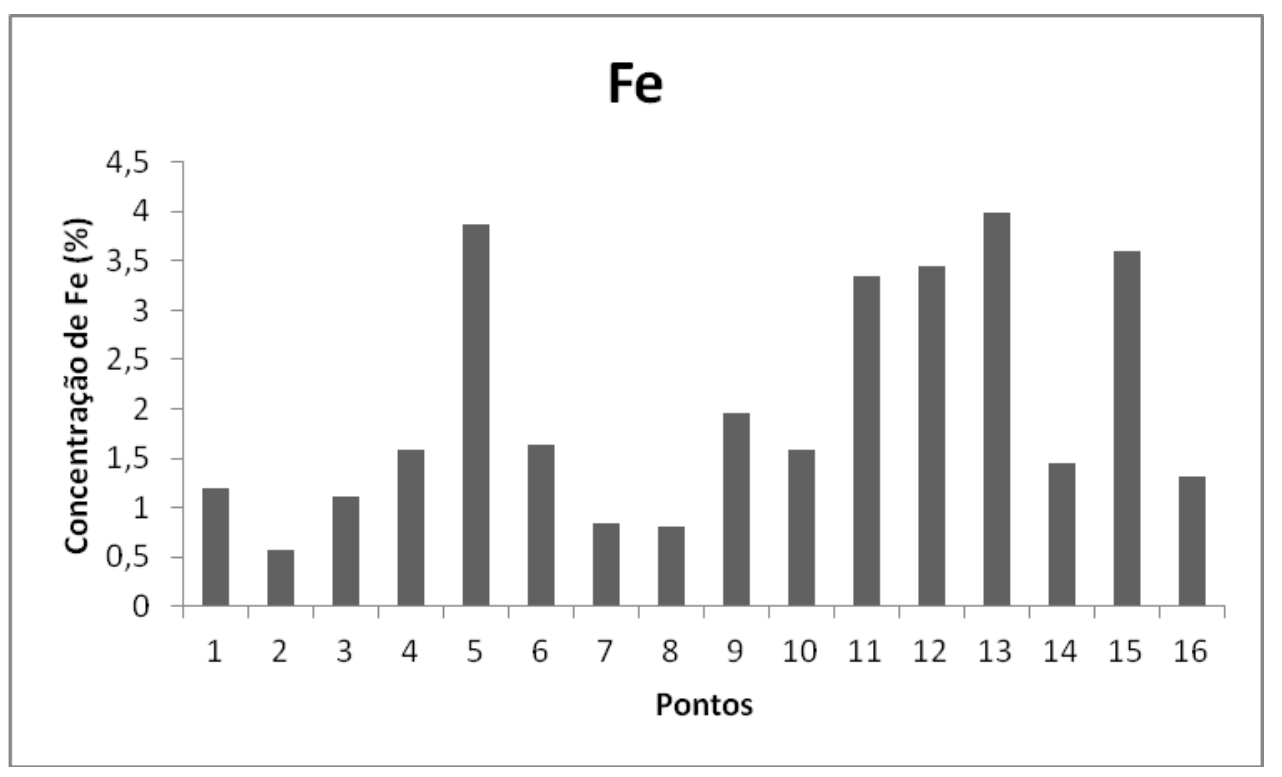

FIGURA 12 Concentração de $\mathrm{Fe}(\%)$ nos pontos de coleta.

O presente estudo também registrou as maiores concentrações de Fe na porção interna do estuário, porem houve uma diminuição da concentração desse elemento nos sedimentos do SESSV quando comparados com os dados pretéritos.

O Fe não possui níveis estabelecidos nos VGQS para possíveis estimativas de efeito a biota aquática.

Em linhas gerais, o $\mathrm{Fe}$ apresentou o mesmo comportamento do $\mathrm{Al}$, apresentando concentrações elevadas pelo aporte continental e industrial (embora haja uma influência das industrias de fertilizantes e do esgoto doméstico) no fundo do estuário e evidenciando um grandiente em direção as saídas dos canais de Santos e São Vicente, com aumento de concentração de ambos os canais.

\section{Cobalto}

Os minérios de Co economicamente importantes são a cobalita, CoAs, a esmaltita, $\mathrm{CoAs}_{2}$ e a lineíta, $\mathrm{Co}_{3} \mathrm{~S}_{4}$. As fontes antrópicas de Co são: a fabricação de imãs, instrumentos e ferramentas de alta velocidade e de serviço 
pesado, em ligas de corte, no aço inoxidável, na eletrodeposição de metais. Nos sedimentos e solos o Co esta associado às partículas sólidas por adsorção ou na água intersticial. De acordo com Quináglia (2006), o valor da concentração basal de Co nos sedimentos da região do SESSV é de 6,70 $\mu \mathrm{gg} \mathrm{g}^{-}$ 1 .

No presente estudo foram encontradas concentrações de Co nos sedimentos do SESSV variando de 1,7 a $27,7 \mu \mathrm{g} \mathrm{g}^{-1}$ (FIG 13). Os maiores valores foram observados nos sedimentos dos pontos $5\left(27,7 \mu \mathrm{g} \mathrm{g}^{-1}\right), 15(27,5$ $\left.\mu \mathrm{g} \mathrm{g}{ }^{-1}\right), 12\left(20,1 \mu \mathrm{g} \mathrm{g}{ }^{-1}\right), 11\left(17,09 \mu \mathrm{g} \mathrm{g}^{-1}\right), 13\left(16,5 \mu \mathrm{g} \mathrm{g}^{-1}\right)$, e $10\left(12,05 \mu \mathrm{g} \mathrm{g}^{-1}\right)$, localizados próximos ao polo industrial de Cubatão e o ponto1 $\left(14,03 \mu \mathrm{g} \mathrm{g}^{-1}\right)$ localizado na entrada do canal de São Vicente. As menores concentrações ocorreram nos sedimentos dos pontos $2\left(1,07 \mu \mathrm{g} \mathrm{g}{ }^{-1}\right)$ e $8\left(2,07 \mu \mathrm{g} \mathrm{g}^{-1}\right)$ localizados na porção central dos canais de São Vicente e Santos, respectivamente.

Em comparação com os VGQS o Co não possui valor estabelecido para TEL e PEL, porem Choueri et al., (2009) estipularam valores limites para esse elemento. De acordo com esses limites, os sedimentos dos pontos 3, 4, 6, 7, 9 e 14 foram classificados como moderadamente poluídos ao passo que os pontos 1, 5, 10,11, 12, 13 e 15 foram classificados como altamente poluídos por Co. Isso indica que há uma fonte de introdução de Co para todo o SESSV.

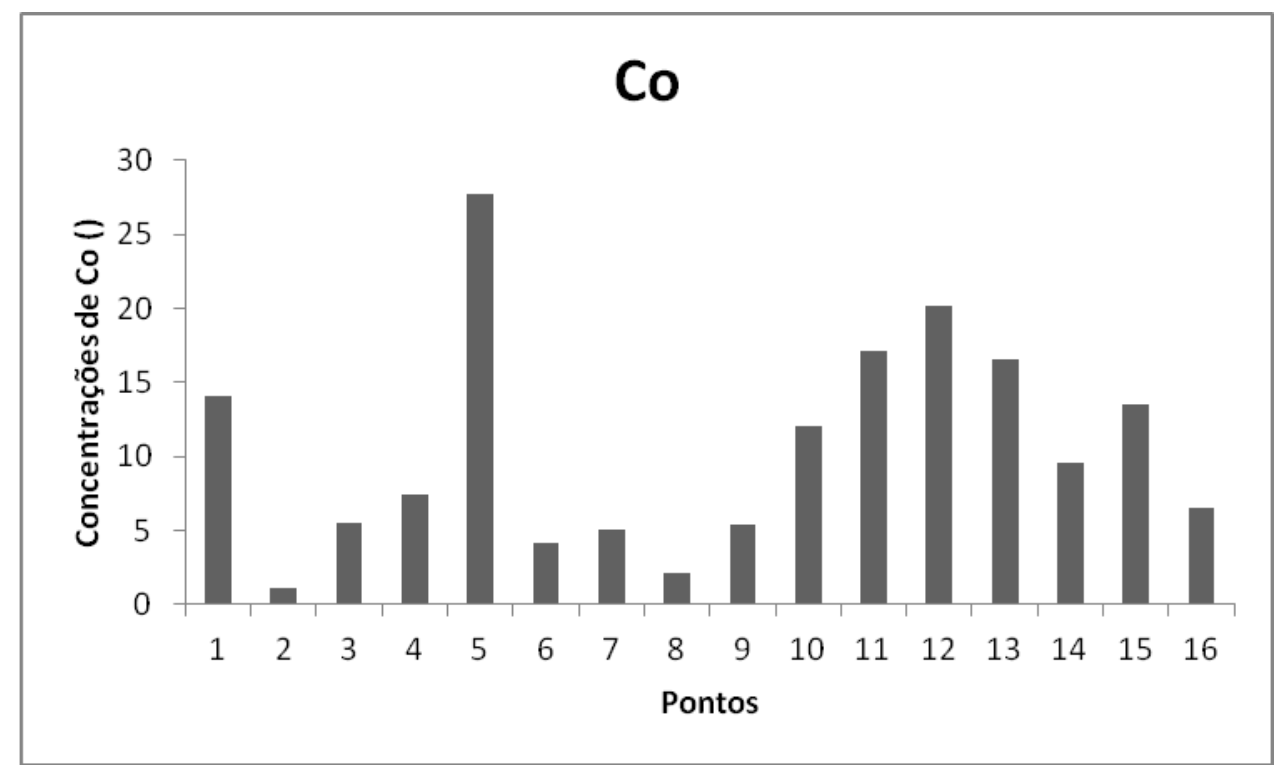

FIGURA 13 Concentração de Co $\left(\mu \mathrm{g} \mathrm{g}^{-1}\right)$ nos pontos de coleta. 
Estudo pretérito realizado por Abessa, (2002) apresentou concentrações de Co variando de 0,9 a $17 \mu \mathrm{g} \mathrm{g}^{-1}$. Em 2006, Luiz-Silva e colaboradores registraram concentrações de Co variando de 4 a $14 \mu \mathrm{g} \mathrm{g}^{-1}$. Em ambos, os trabalhos e os sedimentos foram classificados como altamente poluídos nos locais próximos ao polo industrial de Cubatão.

O presente estudo registrou um aumento na concentração de Co nos sedimentos do SESSV, principalmente nos sedimentos próximos às atividades industriais que apresentaram valores bem acima dos basais propostos por Quinaglia (2006) e no VGQS proposto por Choueri et al., (2009).

Em resumo, o Co apresentou-se em concentrações elevadas no interior do estuário próximo as fontes industriais e apresentou concentrações menores nos pontos situados no meio do estuário e na saída do canal de Santos. Notouse um aumento acentuado das concentrações de Co nos sedimentos da saída do canal de São Vicente o que sugere uma fonte pontual de Co, influenciando esse local.

\section{Cromo}

O Cr ocorre na natureza em vários minerais, frequentemente associado a outros metais. É o sétimo metal mais abundando na Terra. O metal está presente como contaminante ou insumo em diversos processos industriais, uma vez que é utilizado como anti-corrosivo em sistemas de resfriamento, está presente em tijolos refratários utilizados no revestimento de fornos, em ligas metálicas em efluentes líquidos de siderúrgicas, refinarias, indústrias de fertilizantes e de celulose e papel bem como em curtumes, laboratórios e na indústria química em geral.

$\mathrm{Na}$ região da Baixada Santista, sais de cromo foram largamente utilizados como anti-corrosivo nos sistemas de resfriamento de grande parte das indústrias, provocando um aporte significativo do metal para o sistema hídrico. Em Cubatão, os sais de cromo foram substituídos por outras substâncias menos nocivas ao ambiente, a partir da implantação do programa 
de controle da poluição, em 1984. Mesmo após sua substituição, o cromo ainda foi detectado em efluentes das petroquímicas e siderúrgicas bem como os resíduos depositados nos Lixões (Lamparelli et al., 2001).

O valor basal de $\mathrm{Cr}$ estabelecido para os sedimentos da região do SESSV por Quináglia (2006) foi de 27,8 $\mu \mathrm{g} \mathrm{g}^{-1}$.

Neste estudo, as concentrações de $\mathrm{Cr}$ nos sedimentos variaram de 6,48 a $42,5 \mu \mathrm{g} \mathrm{g}^{-1}$ (FIG 14). As maiores concentrações foram encontradas nos pontos $13\left(42,5 \mu \mathrm{g} \mathrm{g}^{-1}\right), 15\left(41,3 \mu \mathrm{g} \mathrm{g}{ }^{-1}\right)$ e $11\left(36,03 \mu \mathrm{g} \mathrm{g} \mathrm{g}^{-1}\right)$, localizados próximos ao local de lançamento dos efluentes da siderúrgica e da petroquímica. As menores concentrações ocorreram na porção central dos canais de São Vicente, ponto $2\left(6,48 \mu \mathrm{g} \mathrm{g}^{-1}\right)$ e de Santos, ponto $8\left(8,1 \mu \mathrm{g} \mathrm{g}^{-1}\right)$.

Nos sedimentos do SESSV o Cr não ocorreu em concentrações acima dos limites estabelecidos por TEL, PEL e por Choueri et al., (2009), o que significa que efeitos adversos a biota aquática não são esperados.

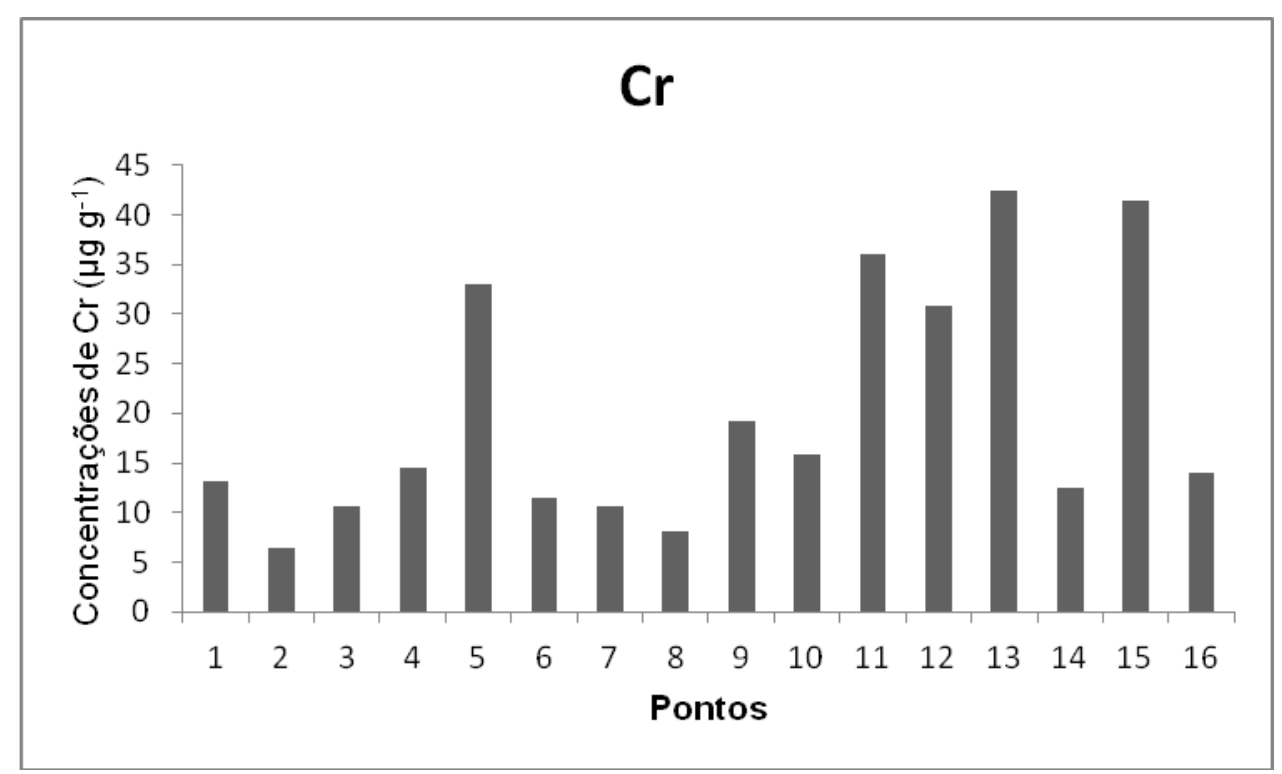

FIGURA 14 Concentração de $\mathrm{Cr}\left(\mu \mathrm{g} \mathrm{g}^{-1}\right)$ nos pontos de coleta.

Estudos anteriores apresentaram concentrações acima das encontradas no presente estudo nos sedimentos do SESSV. Lamparelli et al., (2001) 
registraram concentrações de $\mathrm{Cr}$ variando entre 1,7 e $70 \mu \mathrm{g} \mathrm{g}^{-1}$ sendo os valores mais elevados, acima de TEL, encontrados próximos as atividades industriais. Em 2002, Abessa e colaboradores apresentaram concentrações de $\mathrm{Cr}$ de $<5,0$ até $69 \mu \mathrm{g} \mathrm{g} \mathrm{g}^{-1} \mathrm{em}$ sedimentos localizados na porção interna do estuário, acima dos limites de TEL. Luiz-Silva et al., (2006) encontraram teores de $\mathrm{Cr}$ entre 23 e $138 \mu \mathrm{g} \mathrm{g}{ }^{-1}$, acima de TEL.

Em relação a dados anteriores, historicamente parece estar havendo uma diminuição na contaminação por $\mathrm{Cr}$ nos sedimentos da região do SESSV, porém os valores continuam muito acima dos valores basais da região.

Em termos gerais, verificou-se que a concentração de $\mathrm{Cr}$ é maior no interior do estuário, próximo ao complexo industrial de Cubatão diminuindo em direção a entrada dos canais de Santos e São Vicente, voltando a aumentar em ambos os canais.

\section{Cobre}

O Cu é um metal de ampla distribuição pela crosta terrestre, ocorrendo nas rochas magmáticas. Por tratar-se de metal de amplo emprego industrial e doméstico, inclusive como fungicida e algicida para piscinas (na forma solúvel de sulfato de cobre) e na forma metálica (tubulações, utensílios e fiação), o Cu está presente no lixo doméstico e nos esgotos em geral.

Na Baixada Santista o Cu é encontrado habitualmente em refinarias, siderúrgicas, indústrias de papel e celulose e terminais portuários de granéis líquidos. O metal também está presente no chorume de lixões e aterros sanitários e nos esgotos lançados no mar e nos estuários. O caráter difuso das fontes potenciais de cobre reflete-se sobre a distribuição do metal nos ecossistemas do SESSV (Lamparelli et al., 2001). O valor basal estabelecido por Quinaglia (2006) para a concentração de Cu nos sedimentos da região é de $11,0 \mu g^{-1}$.

As concentrações de Cu nos sedimentos do SESSV variaram de 2,88 a $38,39 \mu \mathrm{g} \mathrm{g}^{-1}$ (FIG 15). Os pontos $13\left(38,39 \mu \mathrm{g} \mathrm{g}^{-1}\right), 12\left(35,43 \mu \mathrm{g} \mathrm{g}^{-1}\right), 5(29,53$ 
$\left.\mu \mathrm{g} \mathrm{g}{ }^{-1}\right), 15\left(27,5 \mu \mathrm{g} \mathrm{g}^{-1}\right)$ e $11\left(19,08 \mu \mathrm{g} \mathrm{g}^{-1}\right)$, localizados na porção interna do estuário próximos ao polo industrial de Cubatão, foram os que apresentaram as maiores concentrações. O ponto 1 , localizado na entrada do canal de São Vicente, apresentou uma concentração de $15,84 \mu \mathrm{g} \mathrm{g}^{-1}$ sugerindo a influência das marinas que estão localizadas próximas a esse ponto. As menores concentrações ocorreram nos sedimentos dos pontos $2\left(2,88 \mu \mathrm{g} \mathrm{g}^{-1}\right)$ e $8(3,88$ $\mu \mathrm{g} \mathrm{g}^{-1}$ ) localizados na porção central dos canais de Santos e São Vicente.

Quando comparados com os VGQS, os pontos 5, 11, 12, 13 e 15 excederam os valores de TEL, o que significa que possíveis efeitos biológicos adversos podem ocorrer. Nenhum ponto esteve acima dos limites estabelecidos por Choueri et al., (2009).

Estes resultados indicam a existência de níveis de concentração de cobre podendo ser de origem industrial ou contribuições por esgotos e de aterros sanitários uma vez que os pontos mais contaminados estão localizados próximos a essas fontes.

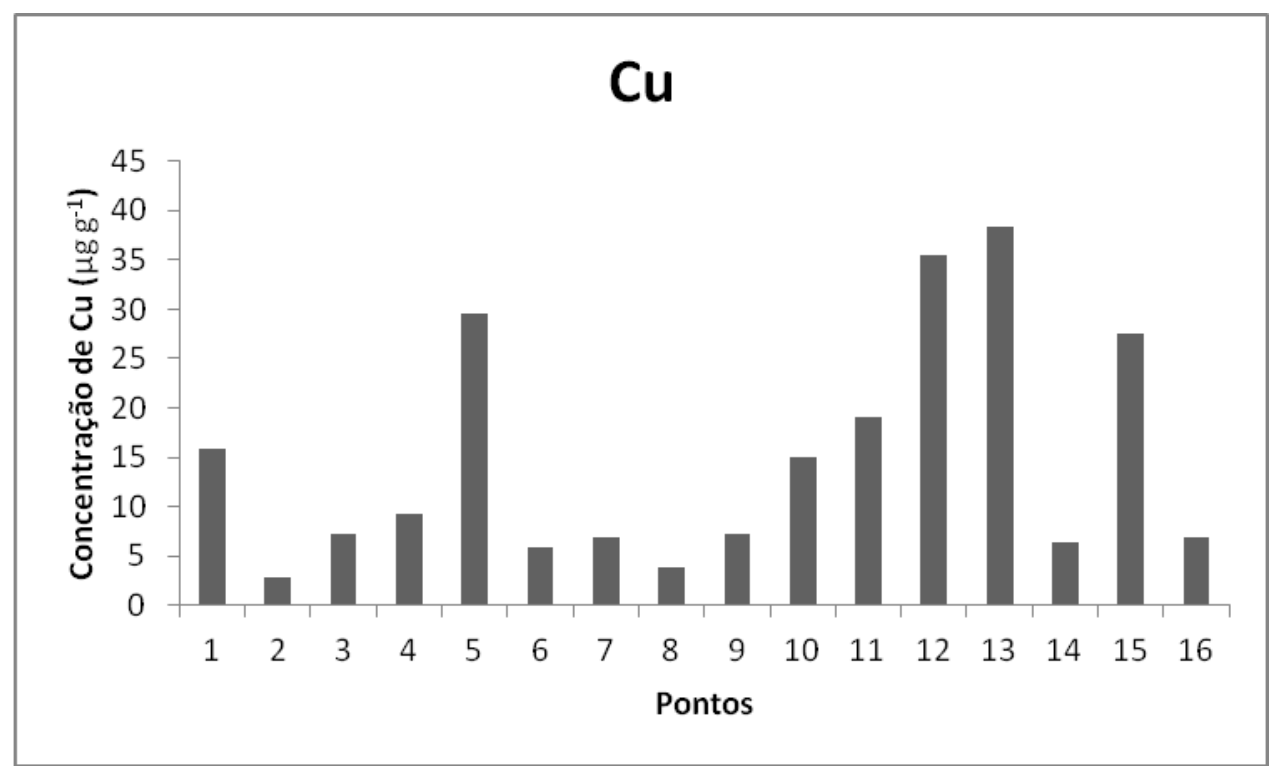

FIGURA 15 Concentração de $\mathrm{Cu}\left(\mu \mathrm{g} \mathrm{g}^{-1}\right)$ nos pontos de coleta.

A contaminação por $\mathrm{Cu}$ nos sedimentos do SESSV foi registrada por Lamparelli et al., (2001) apresentando valores que variaram de 0,68 a $100 \mu \mathrm{g} \mathrm{g}$ ${ }^{1}$ excedendo os valores de TEL e classificados como altamente poluídos 
quando comparados com VGQS proposto por Choueri et al., (2009). As maiores concentrações ocorreram em amostras de sedimentos coletadas próximas ao complexo industrial de Cubatão. Em 2006, Luiz-Silva e colaboradores registraram valores de 13 a $109 \mu \mathrm{g} \mathrm{g} 1$, valores esses próximos aos encontrados por Lamparelli et al., (2001), sendo as maiores concentrações detectadas na parte interna do estuário, acima dos valores de PEL e novamente classificados como altamente poluídos por Choueri et al., (2009). Cesar et al., (2007) apresentaram concentrações de $\mathrm{Cu}<0,1$ a $167 \mu \mathrm{g} \mathrm{g}^{-1}$, os quais excederam os valores de PEL, sendo as maiores concentrações encontradas também próximas ao pólo industrial de Cubatão e os sedimentos classificadas como altamente poluídos.

Quando comparados com os valores de contaminação histórica por $\mathrm{Cu}$ nos SESSV os valores do presente estudo demonstraram uma diminuição na concentração desse elemento nos sedimentos. Entretanto, os pontos localizados próximo às atividades industriais revelaram valores elevados acima dos valores de TEL e muito acima dos estabelecidos por Quináglia (2006), o que significa que ainda está havendo a introdução desse elemento por parte das atividades industriais no SESSV.

Em linhas gerais, o $\mathrm{Cu}$ apresentou uma alta concentração no interior do estuário próximo das fontes industriais e ao se distanciar das fontes na porção central dos canais de Santos e São Vicente e decrescendo ao chegar à entrada dos canais. Isso se deve ao fato de muitas marinas estarem localizadas próximas a esses pontos e o desague do rio Santo Amaro na entrada do canal de Santos, podem estar causando um aumento na concentração desse elemento.

\section{Mercúrio}

O $\mathrm{Hg}$ é encontrado na crosta terrestre em concentrações muito reduzidas em rochas magmáticas, podendo concentrar-se em rochas sedimentares e sedimentos argilosos. As principais fontes de contaminação ambiental são as indústrias de processamento de metais, produção de cloro- 
soda, fabricação de pilha, lâmpadas fluorescentes, aparelhos de medição e fungicidas contendo $\mathrm{Hg}$. Lodos de esgoto e outros resíduos também podem ser fontes de contaminação. Em Cubatão, a principal fonte de mercúrio são as unidades eletrolíticas de fabricação de cloro-soda, que utilizam eletrodos à base de mercúrio. Outras fontes potenciais do metal na região são as petroquímicas e siderúrgicas, além de indústrias químicas que estão instaladas na região (Lamparelli et al., 2001). ). Quináglia (2006) estabeleceu como valor de concentração basal de $\mathrm{Hg}$ nos sedimentos da região do SSESV de $<0,02 \mu \mathrm{g}$ $g^{-1}$.

No presente estudo, foram obtidas concentrações de $\mathrm{Hg}$ nos sedimentos do SESSV variando entre $\angle \mathrm{LD}$ e $1,33 \mathrm{\mu g} \mathrm{g}^{-1}$ (FIG 16). As menores concentrações foram registradas nos pontos 10, 14 e 16 que apresentaram concentrações de $\mathrm{Hg}$ abaixo do LD do método.

Entretanto, concentrações elevadas foram registradas nos sedimentos dos pontos 1, 2, 3, 4, 5, 6, 7, 8, 9, 11, 12, 13 e 15. Com exceção do ponto 5 que apresentou valores acima de PEL $\left(0,70 \mu \mathrm{g} \mathrm{g}{ }^{-1}\right)$, os demais pontos estudados apresentaram concentrações de $\mathrm{Hg}$ acima dos valores de TEL $(0,13$ $\left.\mu \mathrm{g} \mathrm{g}^{-1}\right)$. Quando comparados com os valores estabelecidos por Choueri et al., (2009) os sedimentos dos pontos 1, 2, 3, 6, 7, 8, 9, 11 e 12 foram classificados como moderadamente poluídos por $\mathrm{Hg}$, ao passo que os pontos 4, 513 e 15, foram classificados como altamente poluídos por $\mathrm{Hg}$.

Foi observada contaminação elevada nos sedimentos coletados em todo o SESSV, com as maiores concentrações ocorrendo nos pontos localizados próximo às atividades industriais e lixões, na parte interna do estuário e na porção central dos canais de Santos e São Vicente e na saída dos mesmos.

A contaminação histórica por $\mathrm{Hg}$ no SESSV foi reportada por Lamparelli et al., (2001) e Abessa (2002), que registraram concentrações similares de $\mathrm{Hg}$ nos sedimentos do SESSV em relação ao presente estudo, reportando concentrações que variam de <0,005 a 0,97 e <0,003 a 0,92 $\mu \mathrm{g} \mathrm{g} \mathrm{g}^{-1}$, respectivamente, com valores elevados em pontos localizados na porção 
interna do SESSV, acima de PEL e considerando o estuário novamente como altamente poluído.

Hortellani et al., (2005) em um estudo sistemático sobre a contaminação por $\mathrm{Hg}$ nos sedimentos do SESSV registrou concentrações variando de 0,04 a $1,19 \mathrm{\mu g} \mathrm{g}^{-1}$, com registro de aumento nas concentrações desse elemento em relação aos estudos anteriores excedendo os valores de PEL e novamente considerando os sedimentos como altamente poluído.

Luiz-Silva et al., (2006) detectaram um aumento significativo na concentração de $\mathrm{Hg}$ nos sedimentos do SESSV, apresentando concentrações elevadas de $\mathrm{Hg}$ entre 0,1 e 6,77 $\mu \mathrm{g} \mathrm{g}{ }^{-1}$, concentrações essas que excedem os valore de PEL e considerados altamente poluídos por Choueri et al., (2009). Esses valores foram os mais elevados reportados na literatura e a maior concentração foi encontrada no rio Cubatão, mesmo local onde foi registrada a maior concentração no presente estudo $\left(1,31 \mu \mathrm{g} \mathrm{g}^{-1}\right.$, ponto 5$)$.

A comparação dos níveis atuais de mercúrio nos sedimentos com aqueles encontrados em trabalhos anteriores indicam uma redução nos sedimentos do SESSV. No entanto, o $\mathrm{Hg}$ ocorreu em níveis elevados considerados capazes de provocar efeitos severos à biota aquática e em concentrações muito acima dos valores basais.

O Hg apresentou uma ampla distribuição por toda a área de estudo, indicando uma diversidade de fontes pontuais e difusas com as maiores concentrações ocorrendo próximo às atividades industriais. Esse padrão de distribuição é muito preocupante, pois o $\mathrm{Hg}$ assume a forma orgânica (metilmercurio $-\mathrm{CH}_{3} \mathrm{Hg}^{+}$) no ambiente o que pode biomagnificar na cadeia trófica. Os terminais portuários e poluição atmosférica também contribuem para introdução de $\mathrm{Hg}$ no meio ambiente. 


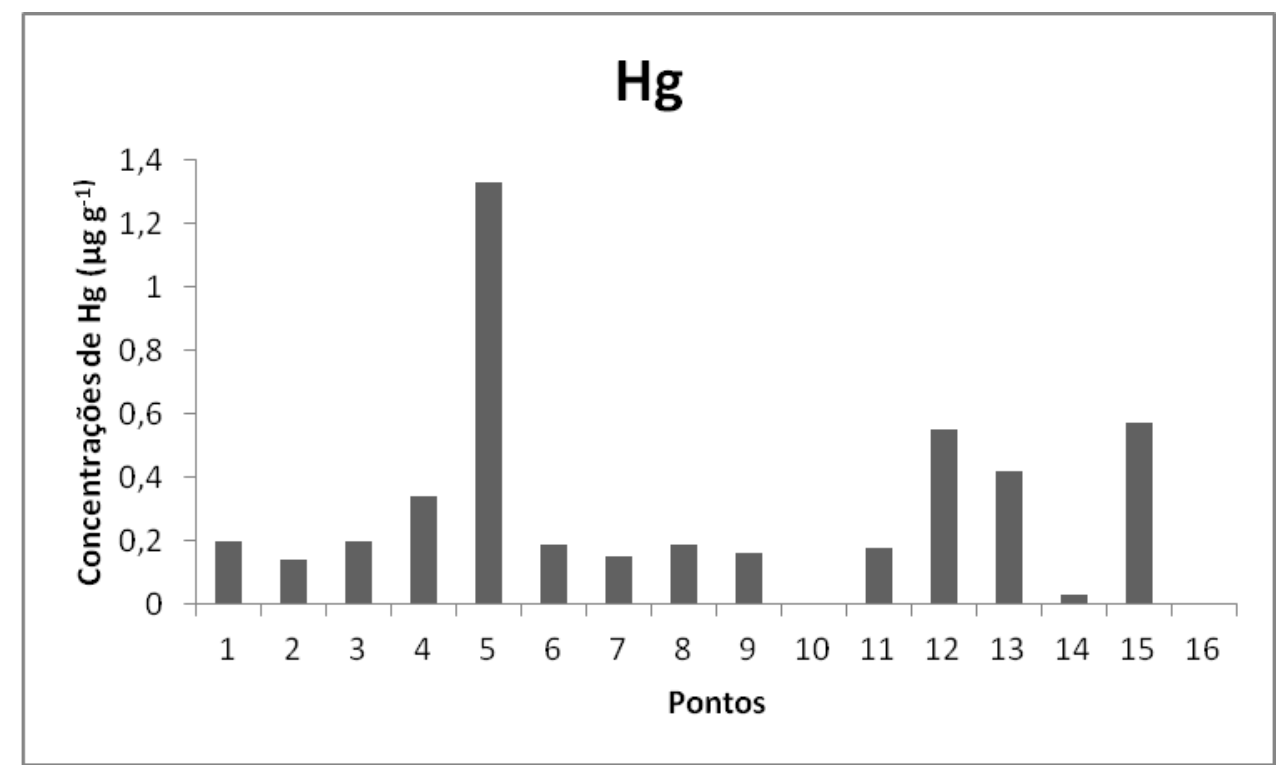

FIGURA 16 Concentração de $\mathrm{Hg}\left(\mu \mathrm{g} \mathrm{g}^{-1}\right)$ nos pontos de coleta.

Em linhas gerais, os resultados indicaram que existe uma contaminação generalizada por $\mathrm{Hg}$ nos sedimentos do SESSV e que esse é um contaminante prioritário na região por ser persistente no meio ambiente, pela contaminação histórica e por apresentar alta toxicidade e bioacumular na biota aquática.

\section{Manganês}

O Mn é o $11^{\circ}$ elemento mais abundante da crosta terrestre e ocorre naturalmente em vários tipos de rocha, estando presente nos solos em concentrações que variam de acordo com o material de origem (Quináglia, 2006). Freqüentemente está associado ao ferro com o qual possui grandes semelhanças de comportamento químico no ambiente. As principais fontes de manganês na Baixada Santista são as indústrias, os diversos terminais que lançam seus efluentes no estuário os lixões, bem como os aterros sanitários da região (Lamparelli et al., 2001). O valor da concentração basal de Mn nos sedimentos da região do SESSV encontrado por Quinaglia (2006) foi de $300 \mu \mathrm{g}$ $g^{-1}$.

As concentrações de Mn nos sedimentos do SESSV variaram de 78 a $889 \mu^{-1} g^{-1}$ (FIG 17). Os pontos 11 (889 $\left.\mu g^{-1}\right), 15\left(610 \mu g g^{-1}\right)$ e $13\left(593 \mu g^{-1}\right)$ 
foram os que apresentaram as maiores concentrações. Os pontos localizados na porção interna do SESSV, próximos ao polo industrial de Cubatão, foram os que apresentaram as maiores concentrações. $O$ ponto 1 , localizado na entrada do canal de São Vicente e o ponto 9, na entrada do canal do porto de Santos, apresentaram concentrações de 212 e $366 \mu^{-1} g^{-1}$, respectivamente, sugerindo a influência antrópica principalmente das marinas que estão localizadas próximas a esses pontos e dos navios que trafegam pelo canal de Santos. As menores concentrações ocorreram nos sedimentos dos pontos $2\left(78,1 \mu^{-1}\right)$, $3\left(91,4 \mu \mathrm{g} \mathrm{g}^{-1}\right), 7\left(93,7 \mu \mathrm{g} \mathrm{g}^{-1}\right)$ e $8\left(104 \mu \mathrm{g} \mathrm{g}{ }^{-1}\right)$ todos localizados na porção central dos canais de Santos e São Vicente e na porção central do estuário.

Estes resultados indicaram que a introdução desse elemento nos sedimentos do SESSV pode ser de origem industrial ou contribuições pelos lixões, esgotos e aterros sanitários.

As concentrações de Mn nos sedimentos do SESSV foi registrada por Lamparelli et al., (2001) e Luiz-Silva et al., (2006), apresentando valores bem mais elevados do que os registrados nesse estudo, que variaram de 7,9 a 1561 $\mu \mathrm{g} \mathrm{g}{ }^{-1}$ e 160 a $5699 \mu \mathrm{g} \mathrm{g}^{-1}$, respectivamente. Esses estudos apresentaram as concentrações de $\mathrm{Mn}$ acima dos valores basais da região. As maiores concentrações registradas por esses estudos também foram encontradas próximas às atividades industriais do complexo industrial de Cubatão.

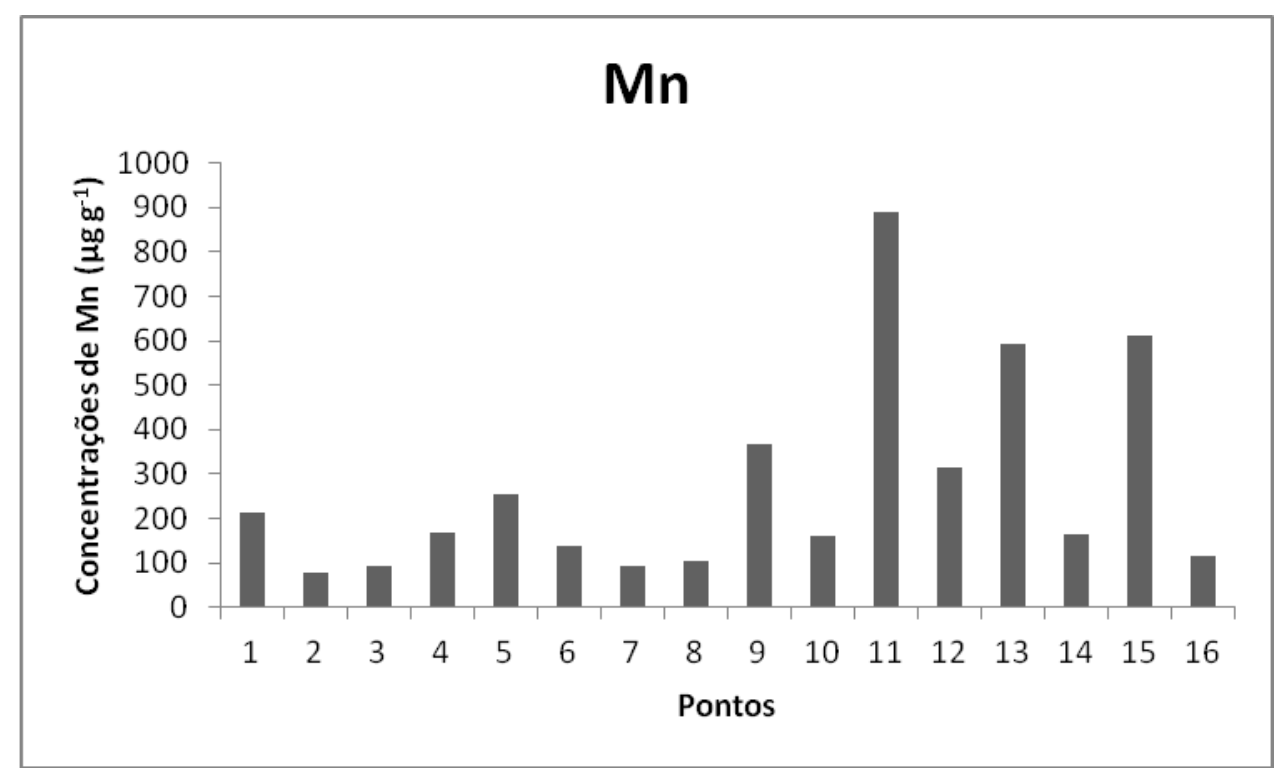

FIGURA 17 Concentração de $\mathrm{Mn}\left(\mu \mathrm{g} \mathrm{g}{ }^{-1}\right)$ nos pontos de coleta. 
O manganês não possui critérios para sua classificação nos VGQS, indicando não ser um poluente prioritário.

Em síntese, o Mn ocorreu em altas concentrações próximo ao complexo industrial de Cubatão e com diminuição em direção a saída dos canais de Santos e São Vicente e finalmente um aumento da concentração de $\mathrm{Mn}$ em ambos os canais.

\section{Níquel}

O Ni é um metal prateado com ocorrência natural na crosta terrestre e em sua maioria, ocorre em associação com o $\mathrm{Fe}$ e o $\mathrm{Mg}$. O metal é normalmente encontrado em efluentes líquidos industriais, principalmente em refinarias de petróleo, siderúrgicas e fábricas de fertilizantes e de papel e celulose e papel. Essas são as principais fontes desse poluente para o SESSV (Lamparelli et al, 2001). O valor basal de Ni registrado por Quináglia (2006) nos sedimentos da região do SESSV é de 11,2 $\mu \mathrm{g} \mathrm{g}^{-1}$.

Nos sedimentos do SESSV, as concentrações de Ni variaram de 1,05 a $23,61 \mathrm{Mg} \mathrm{g}^{-1}$ (FIG 18). As maiores concentrações foram encontradas nos pontos12 (23,53 $\left.\mu \mathrm{g} \mathrm{g}^{-1}\right), 13\left(23,61 \mu \mathrm{g} \mathrm{g}^{-1}\right), 5\left(21,53 \mu \mathrm{g} \mathrm{g}{ }^{-1}\right), 11\left(17,41 \mu \mathrm{g} \mathrm{g}{ }^{-1}\right) \mathrm{e}$ $15\left(17,03 \mathrm{\mu g} \mathrm{g}^{-1}\right)$, localizados próximos a siderúrgica e a petroquímica, no polo industrial de Cubatão. As menores concentrações ocorreram na porção central dos canais de São Vicente, ponto $2\left(2,00 \mu \mathrm{g} \mathrm{g}^{-1}\right)$, de Santos, ponto $8(2,76 \mu \mathrm{g}$ $\left.\mathrm{g}^{-1}\right)$, no ponto $7\left(1,05 \mu \mathrm{g} \mathrm{g}^{-1}\right)$, localizado no desague do canal de Bertioga e no ponto $16\left(3,52 \mu \mathrm{g} \mathrm{g}^{-1}\right)$.

Nos sedimentos do SESSV o Ni ocorreu em concentrações acima do TEL para os pontos 5, 11, 12, 13 e 15 o que significa que possíveis efeitos negativos a biota podem ocorrer. Quando comparados com os limites estabelecidos por Choueri et al., (2009), os sedimentos dos pontos 6, 9, 10, 11 e 15 foram classificados como moderadamente poluídos e os pontos 5, 12 e 13 foram classificados como altamente poluídos. Dentre as fontes de $\mathrm{Ni}$ no SESSV, vale ressaltar os efluentes industriais, terminais portuários e poluição atmosférica (Lamparelli et al., 2001; Luiz-Silva et al., 2006). 
Estudos anteriores apresentaram concentrações acima das encontradas no presente trabalho nos sedimentos do SESSV. Lamparelli et al., (2001) registraram concentrações de $\mathrm{Ni}$ variando entre 0,97 a $34 \mathrm{\mu g} \mathrm{g}^{-1}$ sendo os valores mais elevados encontrados próximos às atividades industriais acima de TEL e considerados altamente poluídos por Choueri et al., (2009). Em 2002, Abessa apresentou concentrações de Ni de 2,4 até 44,2 $\mathrm{mg} \mathrm{g}^{-1}$ em sedimentos localizados na porção interna do estuário, excedendo os valores de PEL e classificados como altamente poluídos. Luiz-Silva et al., (2006) encontraram

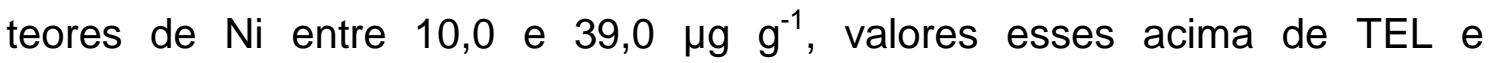
classificados como altamente poluídos.

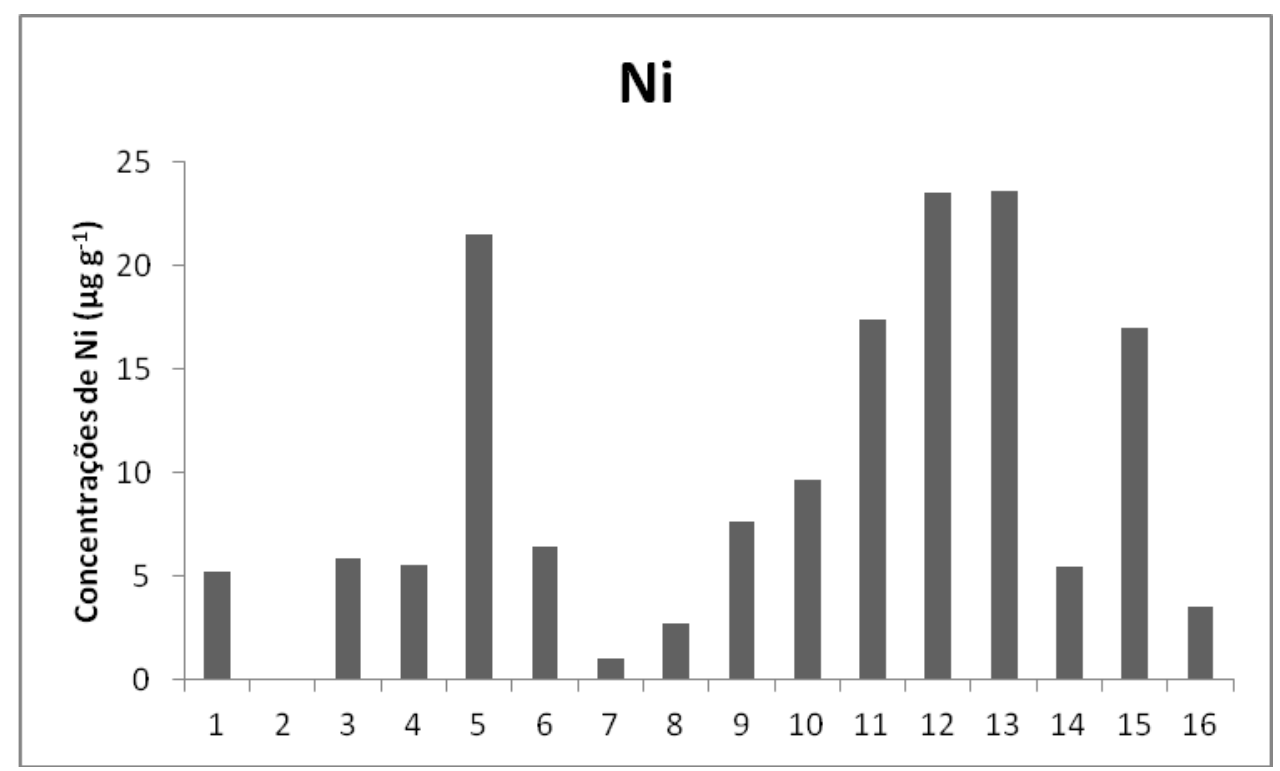

FIGURA 18 Concentração de Ni $\left(\mu \mathrm{g} \mathrm{g}^{-1}\right)$ nos pontos de coleta.

Em relação a dados anteriores, historicamente houve uma diminuição na contaminação por $\mathrm{Ni}$ nos sedimentos da região do SESSV porem as concentrações se mantiveram elevadas acima dos limites estabelecidos nos VGQS.

Em resumo verificou-se que a concentração de $\mathrm{Ni}$ é maior no interior do estuário, próximo ao complexo industrial de Cubatão e decresce a medida que se desloca para a entrada dos canais, evidenciando um gradiente (mais 
acentuado no canal de Santos do que no de São Vicente que apresenta uma concentração maior nos pontos 2 e 3 quando comparados aos pontos 7 e 8) até a entrada dos canais de Santos e São Vicente, onde as concentrações voltam a aumentar.

\section{Chumbo}

$\mathrm{O} \mathrm{Pb}$ tem sua ocorrência natural em rochas magmáticas e outros tipos de rocha. Está geralmente associado à indústria de extração, beneficiamento e fundição do metal e ocorre como contaminante em efluentes de indústrias de refino de petróleo, petroquímicas e siderúrgicas, entre outras. Em Cubatão, as principais fontes industriais são as siderúrgicas, petroquímicas e de fertilizantes, que lançam seus efluentes no SESSV. Como outras fontes potenciais, existem os lixões e os aterros que possuem resíduos de chumbo enterrados de forma irregular (Lamparelli et al., 2001). O valor basal de $\mathrm{Pb}$ para os sedimentos da região do SESSV estabelecido por Quinaglia (2006) foi de $<0,26 \mu \mathrm{g} \mathrm{g}^{-1}$.

Os valores de $\mathrm{Pb}$ encontrados nos sedimentos do SESSV variaram entre 1,37 e $37,78 \mu \mathrm{g} \mathrm{g}^{-1}$ (FIG 19). As maiores concentrações ocorreram na parte interna do estuário nos pontos $13\left(37,78 \mu \mathrm{g} \mathrm{g}^{-1}\right)$ e $15\left(26,67 \mu \mathrm{g} \mathrm{g}^{-1}\right)$. As menores concentrações foram encontradas nos sedimentos dos pontos $2(1,37$ $\left.\mu g g^{-1}\right)$ e $9\left(1,08 \mu g g^{-1}\right)$.

Valores acima de TEL $\left(30,2 \mu \mathrm{g} \mathrm{g}^{-1}\right)$ foram obtidos somente para o ponto 13. Quando comparados com os valores estabelecidos por Choueri et al., (2009), o Pb apresentou concentrações classificadas como moderadamente poluídas, nos sedimentos dos pontos 1, 11 e 12 e altamente poluídas nos sedimentos dos pontos 5, 13 e 15. Com exceção do ponto 1, localizado na entrada do canal de São Vicente, os demais pontos estão próximos ao complexo industrial de Cubatão, o que sugere a origem industrial desse elemento para o SESSV. O ponto 1 apresentou concentração de $\mathrm{Pb}$ elevada pelo fato de estar sob influência do tráfego de embarcações que acessam as marinas das região. 
Estudos conduzidos por Lamparelli et al., (2001) apresentaram valores de $\mathrm{Pb}$ variando de 1,8 a $295 \mu \mathrm{g} \mathrm{g}^{-1}$, sendo que os teores de $\mathrm{Pb}$ mais altos foram encontrados na parte interna do estuário, bem acima do valor de PEL e os sedimentos foram considerados altamente poluídos.

Abessa (2002), encontrou concentrações de $\mathrm{Pb}$ variando entre $\angle \mathrm{LD}$ e $204 \mathrm{\mu g} \mathrm{g}^{-1}$, com as maiores concentrações ocorrendo na porção central e interna do estuário, sob influência das atividades industriais da região, excedendo os limites mais altos de ambos os VGQS.

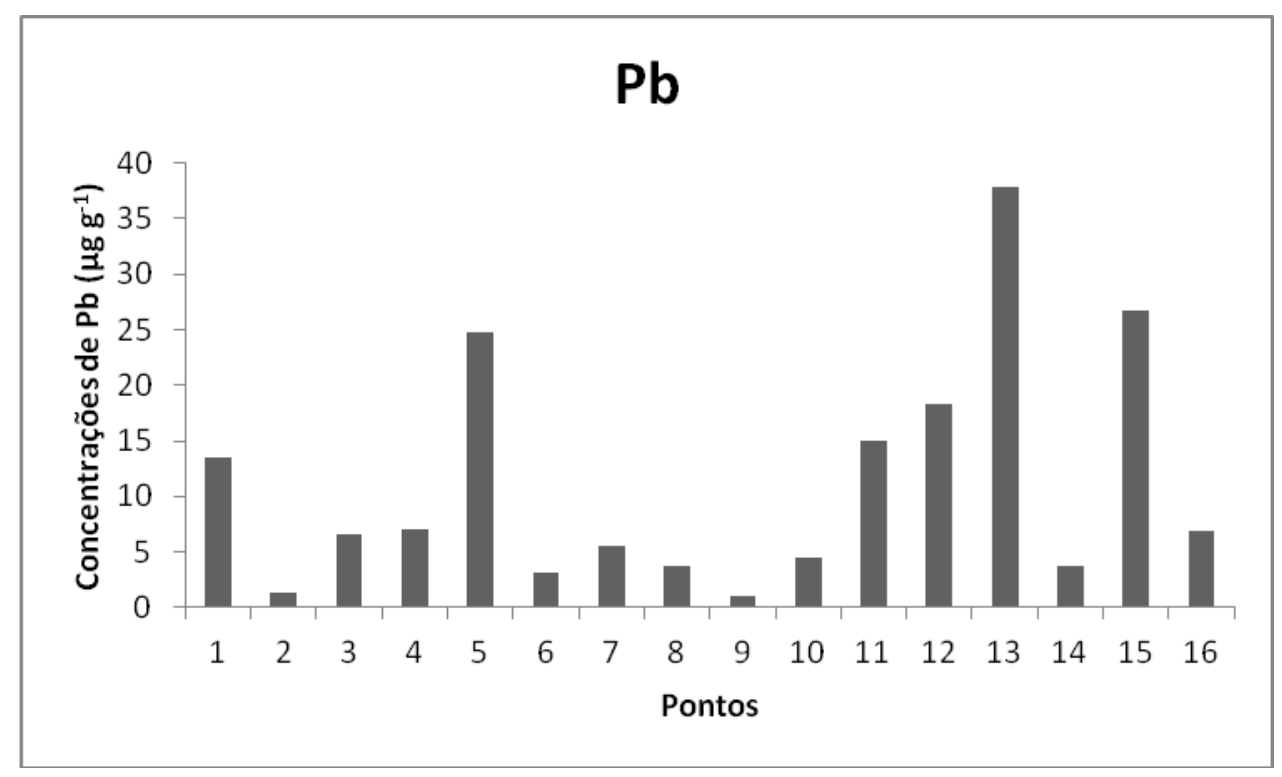

FIGURA 19 Concentração de $\mathrm{Pb}\left(\mu \mathrm{g} \mathrm{g}^{-1}\right)$ nos pontos de coleta.

Luiz-Silva et al., (2006) encontraram valores de $\mathrm{Pb}$ variando de 9 a $127 \mu \mathrm{g}$ $\mathrm{g}^{-1}$ também na parte interna do estuário excedendo os valores estabelecidos nos VGQS. Cesar e colaboradores (2007) registraram valores de $\mathrm{Pb}$ variando de 8,6 a $66,2 \mu \mathrm{g} \mathrm{g}^{-1}$ sendo que as maiores concentrações ocorreram próximo as atividades industriais, novamente acima dos limites máximos para ambos os VGQS.

Os estudos anteriores revelaram concentrações de $\mathrm{Pb}$ mais elevadas que as encontradas no presente estudo, o que registrou um decréscimo nos teores 
desse metal. Entretanto, as concentrações ainda se mantem elevadas acima dos níveis basais da região e as maiores concentrações foram encontradas próximas as fontes industriais.

Em linhas gerais, o Pb apresentou um gradiente em direção aos canais de Santos com as maiores concentrações registradas na parte interna do estuário. O canal de São Vicente apresentou um aumento significativo nas concentrações de $\mathrm{Pb}$ na entrada do mesmo, sugerindo uma fonte pontual desse elemento nessa região.

\section{Zinco}

O Zn é um metal amplamente distribuído na natureza, ocorrendo como nutriente essencial. O uso do $\mathrm{Zn}$ em sua forma metálica ou na forma de sais do metal é comum nos mais diversos ramos industriais. Na Baixada Santista, o Zn é encontrado nos efluentes de grande parte das indústrias, dos terminais e em áreas contaminadas da região. Além do uso industrial, o Zn está presente nas habitações (telha, utensílios) e em produtos diversos, ocorrendo, portanto, no lixo e nos esgotos domésticos (Lamparelli et al., 2001). Segundo Quinaglia (2006), o valor basal da concentração de Zn nos sedimentos da região do SESSV é de $63,8 \mu \mathrm{g} \mathrm{g}^{-1}$.

Nos sedimentos do SESSV, foram observadas concentrações de Zn variando de 20,36 a $231 \mu^{g^{-1}}$ (FIG 20). Maiores valores foram observados na porção interna do SESSV, nos pontos $13\left(231 \mu \mathrm{g} \mathrm{g}{ }^{-1}\right), 12\left(180 \mu \mathrm{g} \mathrm{g}^{-1}\right)$ e 15 $\left(143 \mu \mathrm{g} \mathrm{g}^{-1}\right)$ onde os teores de Zn ultrapassaram o valor de TEL $\left(124 \mu \mathrm{g} \mathrm{g}^{-1}\right)$. Quando comparados com os limites estabelecidos por Choueri et al (2009), o $\mathrm{Zn}$ foi encontrado em concentrações classificadas como moderadamente poluídas nos sedimentos dos pontos 1, 3, 4, 6, 9, 10, 14 e 16 e altamente poluído nos pontos 5, 11, 12, 13 e 15 . 


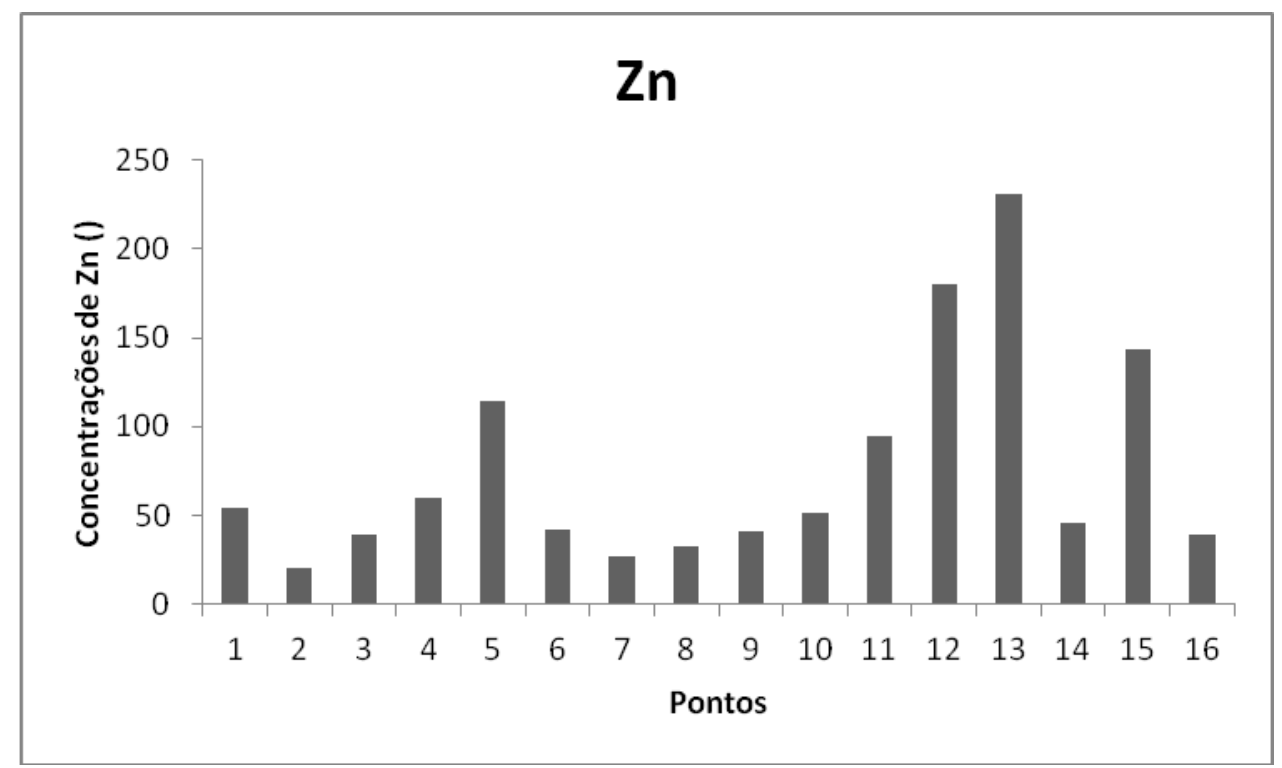

FIGURA 20 Concentração de $Z n\left(\mu \mathrm{g} \mathrm{g}^{-1}\right)$ nos pontos de coleta.

As menores concentrações ocorreram nos sedimentos dos pontos 2 $\left(20,3 \mu \mathrm{g} \mathrm{g}^{-1}\right)$ e 7 ( 26,8 $\left.\mu \mathrm{g} \mathrm{g}^{-1}\right)$ localizados na porção central dos Canais de São Vicente e no desague do canal de Bertioga, respectivamente.

Estudos anteriores realizados por Lamparelli et al., (2001) registraram concentrações de $\mathrm{Zn}$ variando de 7,4 a $957 \mu \mathrm{g} \mathrm{g}{ }^{-1}$, ultrapassando os valores mais altos de ambos os VGQS. Abessa (2002) encontrou concentrações de 6 a $312 \mu \mathrm{g} \mathrm{g}^{-1}$, excedendo os limites mais altos dos VGQS. Em 2006, Luiz-Silva e colaboradores encontraram concentrações de $\mathrm{Zn}$ entre 54,0 e $476 \mu \mathrm{g} \mathrm{g}^{-1}$ novamente as concentrações estiveram acima dos limites mais elevados estipulados nos VGQS. Todos os estudos anteriores encontraram as maiores concentrações na porção interna do estuário, sugerindo o acúmulo desse elemento próximo as fontes de contaminação.

No presente estudo, foi registrada uma diminuição na concentração de Zn nos sedimentos do SESSV quando comparados com os dados pretéritos. Porem, as concentrações se mantiveram altas nas proximidades do polo industrial de Cubatão e apresentaram-se acima do valor basal de Zn para a região e excedendo os limites estabelecidos nos VGQS.

Em síntese, os sedimentos no SESSV apresentaram valores de $\mathrm{Zn}$ mais elevados na porção interna do estuário o que pode ser decorrente das 
atividades industriais e de efluentes domésticos e observou um gradiente em direção ao canal de Santos e São Vicente. A concentração de Zn decresce ao chegar na entrada do canal de Santos ao passo que no canal de São Vicente, a concentração de $\mathrm{Zn}$ se manteve elevada, possivelmente pela presença de marinas no local, influenciando a introdução desse elemento, uma vez que está presente na composição de tintas anti-incrustante.

\subsection{Hidrocarbonetos - Sistema Estuarino de Santos e São Vicente}

\subsubsection{Hidrocarbonetos Alifáticos}

Os HA em sedimentos incluem todos os compostos resolvidos da fração 1, principalmente $\mathrm{n}$-alcanos e isoprenóides e da mistura complexa não resolvida (MCNR). As concentrações de hidrocarbonetos alifáticos nos sedimentos do SESSV estão apresentadas na TAB 10.

A concentração total de HA nos sedimentos do SESSV variou de 41 a $370 \mu \mathrm{g} \mathrm{g}^{-1}$. Os maiores níveis de HA $\left(<100 \mu \mathrm{g} \mathrm{g}^{-1}\right)$ foram encontrados no ponto 15 (370 $\left.\mu \mathrm{g} \mathrm{g}^{-1}\right)$, localizado no canal onde operações de carga e descarga são realizadas por várias indústrias do Polo Industrial de Cubatão. Os pontos 13 $\left(357,0 \mu \mathrm{g} \mathrm{g}^{-1}\right), 5\left(188 \mu \mathrm{g} \mathrm{g}^{-1}\right), 10\left(187 \mu \mathrm{g} \mathrm{g}^{-1}\right), 12\left(110 \mu \mathrm{g} \mathrm{g}{ }^{-1}\right), 8\left(109 \mu \mathrm{g} \mathrm{g}^{-1}\right), 6$ $\left(109 \mu \mathrm{g} \mathrm{g}^{-1}\right)$ e $14\left(102 \mu \mathrm{g} \mathrm{g}^{-1}\right)$ também são afetados pelas atividades industriais de Cubatão.

Os sedimentos do ponto 11, localizado próximo a indústria petroquímica, apresentou uma concentração relativamente baixa de HA totais, apesar de ser próximo ao complexo industrial de Cubatão. Uma possível explicação pode ser a elevada percentagem de areia na amostra, que não favorece a adsorção de contaminantes orgânicos. A concentração relativamente elevada no sedimento do ponto de $8\left(109 \mathrm{\mu g} \mathrm{g}^{-1}\right)$ pode estar relacionada com a proximidade do porto e de tráfego intenso de navios. 
TABELA 10 Concentrações de hidrocarbonetos alifáticos $\left(\mu \mathrm{g} \mathrm{g}{ }^{-1}\right)$ em amostras de sedimento do SESSV e as razões entre os compostos

\begin{tabular}{|c|c|c|c|c|c|c|c|c|c|c|c|c|c|c|c|c|}
\hline $\begin{array}{l}\text { Compostos/Po } \\
\text { ntos }\end{array}$ & 1 & 2 & 3 & 4 & 5 & 6 & 7 & 8 & 9 & 10 & 11 & 12 & 13 & 14 & 15 & 16 \\
\hline C12 & 0,034 & 0,008 & 0,018 & 0,015 & 0,035 & 0,023 & 0,016 & 0,055 & 0,261 & 0,017 & 0,031 & 0,043 & 0,326 & 0,077 & 0,235 & $<L D$ \\
\hline C13 & 0,062 & 0,016 & 0,024 & 0,026 & 0,039 & 0,032 & 0,029 & 0,108 & 0,336 & 16,2 & 0,064 & 0,061 & 0,427 & 0,113 & 0,343 & $<L D$ \\
\hline C14 & 0,049 & 0,016 & 0,018 & 0,019 & 0,035 & 0,027 & 0,028 & 0,083 & 0,231 & 0,016 & 0,052 & 0,058 & 0,381 & 0,078 & 0,25 & $<\mathrm{LD}$ \\
\hline C15 & 0,046 & 0,018 & 0,03 & 0,031 & 0,072 & 0,043 & 0,037 & 0,088 & 0,159 & 0,050 & 0,148 & 0,236 & 0,392 & 0,061 & 0,233 & 0,021 \\
\hline C16 & 0,026 & 0,015 & 0,017 & 0,021 & 0,038 & 0,026 & 0,016 & 0,046 & 0,088 & 0,026 & 0,068 & 0,054 & 0,307 & 0,034 & 0,137 & $<\mathrm{LD}$ \\
\hline C17 & 0,071 & 0,036 & 0,083 & 0,085 & 0,183 & 0,059 & 0,044 & 0,102 & 0,130 & 0,249 & 0,322 & 0,513 & 0,435 & 0,066 & 0,287 & 0,037 \\
\hline Pristano & 0,049 & 0,019 & 0,026 & 0,048 & 0,056 & 0,027 & 0,015 & 0,053 & 0,142 & 0,146 & 0,451 & 0,366 & 0,238 & 0,037 & 0,173 & $<\mathrm{LD}$ \\
\hline C18 & 0,027 & 0,015 & 0,016 & 0,020 & 0,042 & 0,035 & 0,013 & 0,042 & 0,065 & 0,044 & 0,096 & 0,109 & 0,216 & 0,029 & 0,125 & $<L D$ \\
\hline Fitano & 0,035 & 0,026 & 0,021 & 0,033 & 0,044 & 0,031 & 0,014 & 0,052 & 0,092 & 0,121 & 0,324 & 0,296 & 0,119 & 0,025 & 0,128 & $<\mathrm{LD}$ \\
\hline C19 & 0,045 & 0,026 & 0,043 & 0,062 & 0,165 & 0,084 & 0,031 & 0,077 & 0,100 & 0,127 & 0,277 & 0,309 & 0,322 & 0,046 & 0,225 & 0,029 \\
\hline C20 & 0,031 & 0,021 & 0,028 & 0,032 & 0,040 & 0,058 & 0,023 & 0,042 & 0,075 & 0,021 & 0,024 & 0,054 & 0,193 & 0,035 & 0,112 & 0,024 \\
\hline C21 & 0,07 & 0,065 & 0,091 & 0,079 & 0,215 & 0,121 & 0,082 & 0,118 & 0,132 & 0,052 & 0,081 & 0,163 & 0,300 & 0,083 & 0,277 & 0,068 \\
\hline C22 & 0,055 & 0,044 & 0,067 & 0,051 & 0,163 & 0,086 & 0,057 & 0,105 & 0,148 & 0,082 & 0,151 & 0,186 & 0,275 & 0,07 & 0,207 & 0,051 \\
\hline C23 & 0,155 & 0,321 & 0,449 & 0,177 & 0,799 & 0,433 & 0,478 & 0,43 & 0,339 & 0,019 & 0,129 & 0,156 & 0,697 & 0,532 & 0,833 & 0,372 \\
\hline C24 & 0,134 & 0,243 & 0,372 & 0,263 & 1,15 & 0,625 & 0,259 & 0,222 & 0,366 & 0,049 & 0,194 & 0,520 & 0,827 & 0,378 & 0,878 & 0,98 \\
\hline C25 & 0,394 & 0,859 & 1,31 & 0,627 & 2,25 & 1,28 & 1,40 & 1,25 & 0,748 & 0,067 & 0,511 & 0,437 & 1,81 & 2,00 & 2,55 & 1,21 \\
\hline C26 & 0,106 & 0,156 & 0,224 & 0,116 & 0,376 & 0,279 & 0,148 & 0,209 & 0,214 & 0,040 & 0,157 & 0,197 & 0,523 & 0,259 & 0,453 & 0,264 \\
\hline $\mathrm{C} 27$ & 0,709 & 1,21 & 1,60 & 0,790 & 3,06 & 2,096 & 1,35 & 1,24 & 0,887 & 0,095 & 0,720 & 0,902 & 2,74 & 1,87 & 3,32 & 2,00 \\
\hline C28 & 0,213 & 0,321 & 0,411 & 0,209 & 0,718 & 0,600 & 0,227 & 0,313 & 0,297 & $<\mathrm{LD}$ & 0,223 & 0,444 & 0,865 & 0,281 & 0,878 & 0,500 \\
\hline C29 & 1,56 & 2,41 & 3,36 & 1,46 & 6,36 & 4,07 & 1,95 & 2,02 & 1,79 & 0,320 & 1,99 & 2,98 & 0,494 & 2,45 & 6,57 & 4,28 \\
\hline C30 & 0,233 & 0,348 & 0,489 & 0,287 & 0,848 & 0,496 & 0,185 & 0,380 & 0,383 & 0,327 & 0,740 & 0,775 & 1,08 & 0,277 & 0,978 & 0,594 \\
\hline C31 & 0,867 & 1,21 & 1,59 & 0,807 & 2,79 & 1,46 & 0,795 & 1,14 & 1,32 & 0,389 & 2,54 & 3,40 & 4,45 & 1,15 & 4,25 & 2,08 \\
\hline C32 & 0,114 & 0,163 & 0,221 & 0,112 & 0,324 & 0,180 & 0,079 & 0,188 & 0,222 & 0,074 & 0,335 & 0,527 & 0,619 & 0,089 & 0,570 & 0,285 \\
\hline C33 & 0,480 & 0,622 & 0,746 & 0,413 & 1,22 & 0,624 & 0,383 & 0,569 & 0,725 & 0,138 & 1,06 & 1,35 & 2,00 & 0,477 & 1,99 & 0,908 \\
\hline C34 & 0,037 & 0,053 & 0,084 & 0,037 & 0,098 & 0,082 & 0,053 & 0,088 & 0,055 & 0,039 & 0,069 & 0,207 & 0,179 & 0,186 & 0,149 & 0,068 \\
\hline C35 & 0,123 & 0,145 & 0,186 & 0,113 & 0,267 & 0,149 & 0,083 & 0,192 & 0,239 & 0,060 & 0,263 & 0,430 & 0,448 & 0,092 & 0,42 & 0,191 \\
\hline $\begin{array}{l}\text { Alifáticos } \\
\text { totais }\end{array}$ & 51,3 & 41,0 & 67,6 & 75,4 & 188 & 109 & 45,0 & 109 & 77,0 & 187 & 84,0 & 110 & 357 & 102 & 370 & 56,9 \\
\hline $\begin{array}{l}\text { Alifáticos } \\
\text { Resolvidos }\end{array}$ & 9,78 & 11,7 & 16,7 & 11,6 & 41,7 & 23,3 & 12,6 & 16,2 & 18,6 & 15,9 & 36,4 & 47,4 & 54,8 & 17,4 & 50,5 & 19,7 \\
\hline $\begin{array}{l}\text { n-Alcanos } \\
\text { totais }\end{array}$ & 5,64 & 8,35 & 11,4 & 5,85 & 21,3 & 12,9 & 7,78 & 9,11 & 9,32 & 18,5 & 10,2 & 14,1 & 20,3 & 10,7 & 26,2 & 13,9 \\
\hline Pristano/Fitan & 1,38 & 0,741 & 1,24 & 1,47 & 1,28 & 0,848 & 1,08 & 1,03 & 1,54 & 1,20 & 1,39 & 1,23 & 2,00 & 1,44 & 1,35 & $\mathrm{n}, \mathrm{c}$ \\
\hline Pristano/C17 & 0,690 & 0,528 & 0,313 & 0,565 & 0,306 & 0,458 & 0,341 & 0,520 & 1,09 & 0,586 & 1,40 & 0,713 & 0,547 & 0,561 & 0,603 & n.c. \\
\hline Fitano/C18 & 1,30 & 1,65 & 1,32 & 1,67 & 1,04 & 0,897 & 1,05 & 1,23 & 1,41 & 2,76 & 3,36 & 2,71 & 0,540 & 0,872 & 1,02 & n.c. \\
\hline MCNR & 41,5 & 29,2 & 50,9 & 63,8 & 146 & 85,8 & 31,9 & 92,5 & 58,6 & 171 & 47,5 & 62,3 & 302 & 84,4 & 319 & 37,2 \\
\hline U/R & 4,24 & 2,48 & 3,04 & 5,48 & 3,50 & 3,67 & 2,53 & 5,68 & 3,14 & 10,7 & 1,30 & 1,31 & 5,51 & 4,83 & 6,32 & 1,89 \\
\hline IPC & 5,4 & 5,6 & 5,5 & 4,8 & 5,6 & 5,1 & 7,6 & 5,0 & 4,2 & 1,9 & 4,3 & 4,0 & 3,2 & 6,8 & 5,6 & 5,1 \\
\hline
\end{tabular}


Historicamente, dados sobre os níveis de HA nos sedimentos do SESSV registraram baixa concentração encontrada em 2001 (Nishigima et al. 2001, variando de 1.08 - $4.29 \mathrm{\mu g} \mathrm{g}^{-1}$ ). Em 2002, Abessa, (2002) registrou um pequeno aumento nas concentrações de HA totais variando de 0,280 a $14,30 \mu \mathrm{g} \mathrm{g}^{-1}$. Medeiros e Bicego (2004), mensuraram a concentração de HA totais nos sedimentos e reportaram um aumento nas concentrações em um intervalo de 0,7 a $170 \mu \mathrm{g} \mathrm{g}^{-1}$. Dois anos depois, Bicego et al. (2006) encontraram um aumento acentuado nas concentrações de HA totais, apresentando os maiores valores registrados, de 17.1 a $2508 \mu \mathrm{g} \mathrm{g}^{-1}$, na porção interna do estuário. $\mathrm{O}$ presente estudo registrou concentração mais baixa de HA nos sedimentos do SESSV.

Foi observado um gradiente de concentração dos HA nos sedimentos do SESSV partindo da parte mais interna do estuário, próximo ao complexo industrial de Cubatão em direção as saídas dos canais de Santos e São Vicente (pontos 1 e 9), o que evidencia a contribuição das fontes industriais para essa região.

\subsection{Identificação de Fontes dos HA para o Sistema Estuarino de Santos e São Vicente}

Para determinar as possíveis fontes de HA para o ambiente estuarino, foram utilizadas algumas razões entre os compostos.

Sedimentos de todos os pontos apresentaram valores da razão pristano/fitano que variaram de 0,7 a 2,0 indicando a predominância da introdução de hidrocarbonetos de origem petrogênica, uma vez que o petróleo apresenta uma razão de aproximadamente 1. Entretanto, a presença de manguezais por todo o SESSV podem contribuir com HA biogênicos.

Os valores das razões pristano/n-C17 e fitano/n-C18 nos sedimentos dos locais estudados, variaram entre 0,3 - 1,4 e 0,8 - 3,3 respectivamente, indicando principalmente a introdução recente de petróleo. Bicego et al. (2006) relataram valores elevados para as razões pristano/n-C17 e fitano/n-C18 ratios 
(0,2 - 7,9 e 0,3 - 12,3 respectivamente) revelando a presença de óleo degradado no canal do porto causado pelo tráfego de navios.

A MCNR apresentou valores mais elevados nos sedimentos de locais onde há tráfego intensivo de navios, descartes de efluentes provenientes de processos metalúrgicos e de indústrias petroquímicas, próximos ao Complexo Industrial de Cubatão, nos ponto 15 e ponto $13\left(319 \mu \mathrm{g} \mathrm{g}^{-1} \mathrm{dw}\right.$ e $302 \mu \mathrm{g} \mathrm{g}^{-1} \mathrm{dw}$ respectivamente). Além disso, os valores de $U / R>4$ nos sedimentos dos pontos $1,4,8,10,14$ e 15, os quais variaram de 4,23 a 10,73 mostraram contribuições significativas de petróleo ao meio ambiente aquático. Em contrapartida, a taxa U/R nos sedimentos dos pontos $2,3,5,6,7,9,11,12$ e 16 , variando de 1,30 a 3,66, indicou menor contribuição de petróleo.

O IPC apresentou um padrão de distribuição com índices variando de 3,2 a 7,6 em todas as amostras, com exceção do sedimento do ponto 10, que apresentou índice de 1,9. Esse padrão é um indicativo da introdução de HA de origem terrígena proveniente da vegetação que compõem a densa floresta da Mata Atlântica e os manguezais que compõe o estuário. No entanto, a possibilidade de contaminação por petróleo não deve ser excluída, porém sugere um aporte contínuo e significativo de material terrígeno, rico em nalcanos de cadeia longa e número ímpar de carbono, predominando sobre introduções de origem antrópica (HOSTETTLER et al., 1999).

\subsection{Hidrocarbonetos Policíclicos Aromáticos - Sistema Estuarino de Santos e São Vicente}

Os valores das concentrações dos HPA individuais e totais encontradas no presente estudo estão apresentados na TAB 11. O sedimento do ponto 15 não apresentou valores de recuperação acima dos aceitos pelo método (60$120 \%$ ) e pela garantia de qualidade/controle de qualidade, portanto os resultados dessa amostra não serão discutidos para os HPA.

De acordo com os resultados do presente estudo, as concentrações de HPA totais variaram de $<$ LD a $41758 \mathrm{ng} \mathrm{g}^{-1}$ (peso seco). Segundo Notar et al. 
(2001), o sedimento pode ser considerado contaminado quando os valores da concentração total dos HPA estão acima de $500 \mathrm{ng} \mathrm{g}^{-1}$, ao passo que sedimentos que apresentam valores da HPA totais entre 250 e $500 \mathrm{ng} \mathrm{g}^{-1}$ são considerados moderadamente contaminados. No presente estudo, as baixas concentrações (entre 250 e $500 \mathrm{ng} \mathrm{g}^{-1}$ ) foram observadas nos sedimentos dos pontos 1, 2 e 16, localizados no canal de São Vicente. As concentrações mais elevadas (> $500 \mathrm{ng} \mathrm{g}^{-1}$ ) ocorreram nos pontos $3,4,5,6,7,8,9,10,11,12,13 \mathrm{e}$ 14 onde há intensa influência antrópica.

A contaminação por HPA nos sedimentos do SESSV tem sido estudada por diversos autores. Nos últimos anos, os resultados demonstraram valores elevados devido à presença das múltiplas fontes de contaminação.

As maiores concentrações de HPA já registradas nos sedimentos do SESSV foram encontradas em um estudo sistemático, realizado pela CETESB, (LAMPARELLI et al., 2001), apresentando valores que variaram de 11.62 a $733700 \mathrm{ng} \mathrm{g}^{-1}$, concentrações estas muito elevadas quando comparadas com trabalhos anteriores e com os VGQS, encontradas na porção interna do estuário próximo ao Complexo Industrial de Cubatão.

Abessa, (2002) registrou concentrações do total de HPA variando de 1 a $42390 \mathrm{ng} \mathrm{g}^{-1}$, e concentrações de HPA individuais elevadas destacando 0 composto naftaleno e o pireno.

Em 2004, foram registradas menores concentrações de HPA totais nos sedimentos do SESSV (MEDEIROS E BÍCEGO, 2004) com valores variando de 79,6 a $15389 \mathrm{ng} \mathrm{g}^{-1}$ nos sedimentos próximos ao complexo industrial de Cubatão.

Bicego et al., (2006) registrou concentrações mais altas de HPA totais nos sedimentos, com valores variando de 22,6 a $68130 \mathrm{ng} \mathrm{g}^{-1}$, sendo que as maiores concentrações foram medidas no material coletado próximo das atividades industriais. Cesar et al., (2007) observaram valores de HPA variando de 106 a $950 \mathrm{ng} \mathrm{g}^{-1}$. Os resultados do presente estudo foram similares às concentrações reportadas pelos estudos anteriores na região. 


\section{TABELA 11 Concentrações de HPA em amostras de sedimento do SESSV (ng}

$\mathrm{g}^{-1}$ ) e razões entre pares de isômeros. (n.c - Não calculado)

\begin{tabular}{|c|c|c|c|c|c|c|c|c|c|c|c|c|c|c|c|}
\hline Compostos/ Pontos & 1 & 2 & 3 & 4 & 5 & 6 & 7 & 8 & 9 & 10 & 11 & 12 & 13 & 14 & 16 \\
\hline Naftaleno & 2,61 & 6,58 & 18,9 & 374 & 92,8 & 16,8 & 11,7 & 8,00 & 16,8 & 45,5 & 177 & 1548 & 150 & 784 & $<L D$ \\
\hline Metilnaftaleno & 2,23 & 5,02 & 13,6 & 237,7 & 53,3 & 7,63 & 8,90 & 11,4 & 35,9 & 95,71 & 203 & 739 & 60,4 & 358 & $<L D$ \\
\hline Bifenil & 1,01 & 2,32 & 40,96 & 151 & 27,4 & 4,83 & 4,37 & 5,56 & 3,67 & 30,3 & 67,4 & 421 & 34,0 & 161 & $<L D$ \\
\hline Etilnaftaleno & 0,490 & 1,07 & 4,27 & 49,1 & 10,2 & 1,37 & 2,20 & 3,98 & 6,86 & 20,4 & 32,6 & 138 & 11,0 & 71,2 & $<L D$ \\
\hline Dimetilnaftaleno & 3,67 & 8,05 & 23,1 & 305 & 120 & 13,1 & 19,0 & 45,2 & 45,2 & 129 & 264 & 971 & 74,8 & 429 & $<L D$ \\
\hline Acenaftileno & 1,15 & 3,37 & 14,7 & 454 & 167 & 32,2 & 20,1 & 12,5 & 13,5 & 64,6 & 94,5 & 496 & 77,4 & 211 & $<L D$ \\
\hline Acenafteno & 0,750 & 1,94 & 6,04 & 75,3 & 34,0 & 3,54 & 5,47 & 2,07 & 1,87 & 12,2 & 33,5 & 830 & 78,8 & 409 & $<L D$ \\
\hline Trimetilnaftaleno & 3,48 & 8,31 & 28,0 & 123 & 93,4 & 14,4 & 17,7 & 34,5 & 16,2 & 85,1 & 122 & 522 & 50,2 & 259 & $<L D$ \\
\hline Fluoreno & 1,14 & 2,96 & 7,73 & 111 & 63,3 & 10,1 & 6,82 & 6,46 & 10,2 & 28,2 & 92,0 & 1042 & 105 & 400 & $<L D$ \\
\hline Metilfluoreno & 1,44 & 6,99 & 10,0 & 94,8 & 60,4 & 45,1 & 16,2 & 16,3 & 8,36 & 83,3 & 85,9 & 388 & 52,9 & 196 & $<L D$ \\
\hline Dibenzotiofeno & 1,30 & 1,30 & 1,30 & 57,1 & 48,9 & 3,35 & 1,30 & 1,30 & 1,30 & 20,8 & 45,8 & 378 & 36,1 & 144 & $<L D$ \\
\hline Fenantreno & 4,52 & 11,8 & 29,5 & 232 & 217 & 53,2 & 31,6 & 13,1 & 38,3 & 76,1 & 201 & 1747 & 203 & 968 & $<L D$ \\
\hline Antraceno & 1,47 & 3,11 & 11,2 & 152 & 119 & 14,4 & 10,9 & 4,30 & 17,3 & 23,8 & 46,6 & 562 & 89,8 & 288 & $<L D$ \\
\hline Dimetilfluoreno & 1,80 & 3,25 & 10,3 & 36,7 & 23,9 & 6,64 & 8,27 & 7,49 & 21,2 & 185 & 47,6 & 313 & 28,4 & 169 & $<L D$ \\
\hline Metildibenzotiofeno & 0,970 & 1,57 & 4,87 & 31,2 & 10,4 & 3,13 & 2,89 & 1,70 & 1,22 & 10,2 & 11,9 & 152 & 14,4 & 84,9 & $<L D$ \\
\hline Metilfenantreno & 4,75 & 10,5 & 32,5 & 188 & 172 & 48,9 & 44,1 & 14,8 & 37,8 & 120 & 190 & 887 & 109 & 483 & $<L D$ \\
\hline Dimetildibenzotiofeno & 1,30 & 0,160 & 0,220 & 1,86 & 1,29 & 0,520 & 0,350 & 0,150 & 0,240 & 3,64 & 0,980 & 3,06 & 0,420 & 2,74 & $<L D$ \\
\hline Dimetilfenantreno & 2,20 & 5,72 & 18,8 & 72,9 & 44,4 & 15,0 & 15,4 & 8,24 & 24,6 & 119 & 130 & 287 & 29,7 & 165 & $<L D$ \\
\hline Fluoranteno & 12,3 & 30,2 & 89,8 & 684 & 916 & 221 & 137 & 28,3 & 85,8 & 251 & 273 & 2051 & 380 & 1884 & $<L D$ \\
\hline Pireno & 12,6 & 29,9 & 88,5 & 688 & 950 & 224 & 138 & 28,4 & 87,0 & 258 & 279 & 2155 & 398 & 1874 & $<L D$ \\
\hline Metilfluoranteno & 3,62 & 8,28 & 43,0 & 359 & 341 & 99,9 & 56,0 & 13,2 & 45,8 & 173 & 122 & 897 & 179 & 519 & $<L D$ \\
\hline Metilpireno & 3,79 & 7,77 & 35,6 & 171 & 140 & 46,3 & 42,6 & 8,30 & 119 & 328 & 254 & 422 & 65,1 & 317 & $<L D$ \\
\hline Benzo[a]antraceno & 5,40 & 13,6 & 48,3 & 446 & 462 & 151 & 71,4 & 18,2 & 50,3 & 89,7 & 139 & 1017 & 234 & 537 & $<L D$ \\
\hline Criseno & 6,99 & 17,9 & 65,3 & 586 & 536 & 171 & 85,4 & 21,1 & 92,4 & 200 & 235 & 1729 & 319 & 1181 & $<L D$ \\
\hline Metilcriseno & 5,12 & 13,4 & 80,4 & 355 & 101 & 76,4 & 62,7 & 14,6 & 126 & 624 & 409 & 1229 & 121 & 828 & $<L D$ \\
\hline Dimetilcriseno & 4,12 & 10,8 & 76,6 & 225 & 127 & 23,3 & 47,2 & 12,2 & 181 & 692 & 505 & 637 & 61,7 & 477 & $<L D$ \\
\hline Benzo[b]fluoranteno & 14,9 & 27,1 & 108 & 889 & 576 & 177 & 179 & 40,4 & 83,0 & 170 & 180 & 1981 & 305 & 1141 & $<L D$ \\
\hline Benzo[j]fluoranteno & 8,80 & 15,0 & 90,7 & 648 & 472 & 152 & 107 & 37,5 & 71,6 & 147 & 196 & 1986 & 280 & 1162 & $<L D$ \\
\hline Benzo[k]fluoranteno & 8,19 & 16,9 & 76,0 & 643 & 534 & 202 & 114 & 22,4 & 51,3 & 148 & 165 & 1762 & 283 & 1412 & $<L D$ \\
\hline Benzo[e]pireno & 9,82 & 24,0 & 99,4 & 724 & 546 & 175 & 137 & 30,3 & 139 & 316 & 358 & 2006 & 324 & 1642 & $<L D$ \\
\hline Benzo[a]pireno & 9,65 & 24,6 & 132 & 952 & 761 & 251 & 192 & 31,1 & 138 & 252 & 339 & 2519 & 461 & 1870 & $<L D$ \\
\hline Perileno & 40,3 & 36,4 & 90,1 & 426 & 351 & 157 & 94,7 & 149 & 38,9 & 624 & 142 & 2698 & 320 & 736 & $<L D$ \\
\hline Indeno[123-cd]pireno & 13,5 & 32,9 & 148 & 960 & 831 & 291 & 235 & 122 & 77,7 & 151 & 219 & 2784 & 508 & 1250 & $<L D$ \\
\hline Dibenzo[ah]antraceno & 2,71 & 8,52 & 33,2 & 275 & 188 & 54,7 & 38,8 & 18,3 & 62,7 & 146 & 127 & 798 & 135 & 286 & $<L D$ \\
\hline Benzo[b]criseno & 1,73 & 4,29 & 26,2 & 174 & 131 & 46,1 & 35,8 & 15,0 & 39,5 & 101 & 99,9 & 581 & 100 & 161 & $<L D$ \\
\hline Benzo[ghi]perileno & 14,1 & 32,6 & 132 & 935 & 701 & 234 & 194 & 105 & 117 & 232 & 320 & 2685 & 431 & 1312 & $<L D$ \\
\hline Coroneno & 2,94 & 6,78 & 19,1 & 147 & 137 & 32,9 & 32,6 & 28,1 & 22,4 & 34,1 & 14,8 & 398 & 72,9 & 192 & $<L D$ \\
\hline HPA totais & 217 & 445 & 1722 & 13033 & 10161 & 3080 & 2226 & 941 & 1928 & 6089 & 6223 & 41759 & 6183 & 24363 & $<L D$ \\
\hline$\sum \mathbf{C}_{1} \mathbf{P} / \mathbf{P}$ & 0.39 & 0.42 & 0.37 & 0.47 & 0.5 & 0.45 & 0.35 & 0.36 & 0.38 & 0.24 & 0.39 & 0.6 & 0.59 & 0.6 & n.c \\
\hline Ant/178 & 0.25 & 0.21 & 0.27 & 0.4 & 0.35 & 0.21 & 0.26 & 0.25 & 0.31 & 0.24 & 0.19 & 0.24 & 0.31 & 0.23 & n.c \\
\hline $\mathrm{BaA} / 228$ & 0.44 & 0.43 & 0.43 & 0.43 & 0.46 & 0.47 & 0.46 & 0.46 & 0.35 & 0.31 & 0.37 & 0.37 & 0.42 & 0.31 & n.c \\
\hline IP/IP+BghiP & 0.48 & 0.50 & 0.52 & 0.50 & 0.54 & 0.55 & 0.54 & 0.53 & 0.39 & 0.39 & 0.40 & 0.50 & 0.54 & 0.48 & n.c \\
\hline $\mathrm{Fl} / \mathrm{FI}+\mathrm{Py}$ & 0.49 & 0.5 & 0.5 & 0.5 & 0.49 & 0.5 & 0.5 & 0.5 & 0.5 & 0.49 & 0.49 & 0.49 & 0.49 & 0.5 & n.c \\
\hline
\end{tabular}


Em resumo, os níveis de HPA nos sedimentos apresentaram gradiente de concentração desde a parte interna do estuário até a entrada dos canais de Santos e São Vicente. Os sedimentos localizados na porção mediana do estuário (pontos 3, 4, 7 e 8) apresentaram valores elevados de HPA totais os quais decresceram até a saída do canal de São Vicente (ponto 1). Porém, na saída do canal de Santos, local onde está instalado o porto de Santos e algumas marinas, os HPA totais apresentaram um aumento na concentração evidenciando a influência dessas atividades nesse ponto.

Quando comparados com os VGQS, os sedimentos dos pontos 1 e 16 não revelaram HPA individuais e nem totais acima de TEL, sugerindo que efeitos tóxicos a biota aquática nos sedimentos não são esperados nesses locais devido aos HPA. Sedimentos dos pontos 2, 3 e 8 apresentaram no máximo dois HPA individuais acima de TEL, enquanto que os sedimentos dos pontos $4,5,6,7,9,13$ apresentaram nove, dez, sete, quatro, três e 11 compostos individuais acima de TEL, respectivamente. Os sedimentos dos pontos 12 e 14 apresentaram as maiores concentrações de HPA individuais e totais, todas acima de PEL, com exceção do benzo[a]antraceno, que excedeu apenas TEL no ponto 14. Estes resultados evidenciam a introdução desses compostos no ambiente estuarino através das atividades antrópicas. O sedimento do ponto 5 apresentou concentrações de acenaftileno e dibenzo[a,h]antraceno acima de PEL.

Os compostos acenaftileno, benzo[a]pireno e benzo[ah]antraceno foram os mais freqüentes a aparecer nas amostras em concentrações que excediam os limites do VGQS. Os sedimentos dos pontos 4, 5, 12 e 14 apresentaram concentrações de acenaftileno acima de PEL. Por sua vez, o composto benzo(a)pireno apresentou valores acima de TEL nos sedimentos dos pontos $3,5,6,7,9,10,11$ e 13 e apresentou valores acima de PEL nos sedimentos dos pontos 4, 12 e 14. O dibenzo[ah]antraceno apresentou concentrações acima do PEL nas amostras provenientes de 4, 5, 10, 11, 12, 13 e 14 e de TEL nos sedimentos dos pontos $2,3,6,7,8$ e 9 . Tais resultados sugerem a ocorrência de introdução de HPA de origem antrópica pelo Complexo Industrial de Cubatão, os quais podem ocasionar possíveis efeitos adversos a comunidade bentônica local. 
As concentrações de HPA em pontos que se estendem a partir da porção central dos canais em torno de Santos e São Vicente apresentaram concentrações acima do TEL para alguns HPA individuais. De acordo com Medeiros e Bicego (2004) isso ocorre, provavelmente, devido às emissões atmosféricas provenientes do complexo industrial de Cubatão.

A concentração de HPA totais nos sedimentos dos pontos 1, 2 e 8 foram classificadas como moderadamente poluídas ao passo que os pontos $3,4,5,6$, $7,9,10,11,12,13$ e 14 foram consideradas como altamente poluídas quando comparadas com os VGQS estabelecidos por Choueri et al., (2009).

Em geral, observou-se que os contaminantes orgânicos são depositados, principalmente perto de sua origem por causa da limitada circulação de água, alta porcentagem de finos e transporte de partículas no SESSV (HARARI E CAMARGO, 1998).

De acordo com os valores estabelecidos no VGQS, os altos níveis de HPA no ambiente estuarino representam um risco para a biota aquática e saúde pública, pois podem bioacumular e são potencialmente carcinogênicos e mutagênicos para os habitantes da região que estão em contato direto com o ambiente aquático, bebem água contaminada por HPA e se alimentam de espécies alvo da pesca (peixes, crustáceos e bivalves) provenientes do estuário (WALKER, 2009).

\subsubsection{Identificação de Fontes de HPA para o SESSV}

Algumas das razões entre compostos individuais foram calculados para a identificação de origem HPA. Estas relações são baseadas na temperatura de formação dos compostos. Formação dos combustíveis fósseis requer temperaturas baixas, e alteração térmica dos resultados da matéria orgânica em HPA com estrutura de 2 ou 3 anéis e grande proporção de homólogos alquilados. Por outro lado, a combustão de alta temperatura produz HPA com estrutura de 4 - 5 ou 6 anéis e mínimo de produtos alquilados. Alguns pares de isômeros também são utilizados para distinguir as diversas origens dos HPA, 
pois apresentam estabilidades diferentes e também dependem da temperatura de formação (Colombo et al., 1989; Yunker et al., 2002).

Os valores das razões entre pares de isômeros de HPA determinados para as amostras de sedimentos neste estudo, são apresentados na TAB 8.

A razão Ant/178 demonstra que os HPA são derivados predominantemente da combustão (Ant/178> 0,10 em todos os locais) (FIG 21). A combustão de petróleo bruto é possivelmente a principal fonte de HPA em sedimentos, pelo fato do SESSV estar situado em uma área de refinarias, terminais petrolíferos e de tráfego marítimo intenso.

A razão $\mathrm{Fl} / \mathrm{Fl}+\mathrm{Py}$ mostrou que são introduzidos HPA diretamente da combustão de petróleo das refinarias e dos navios, predominando a introdução por combustão. 


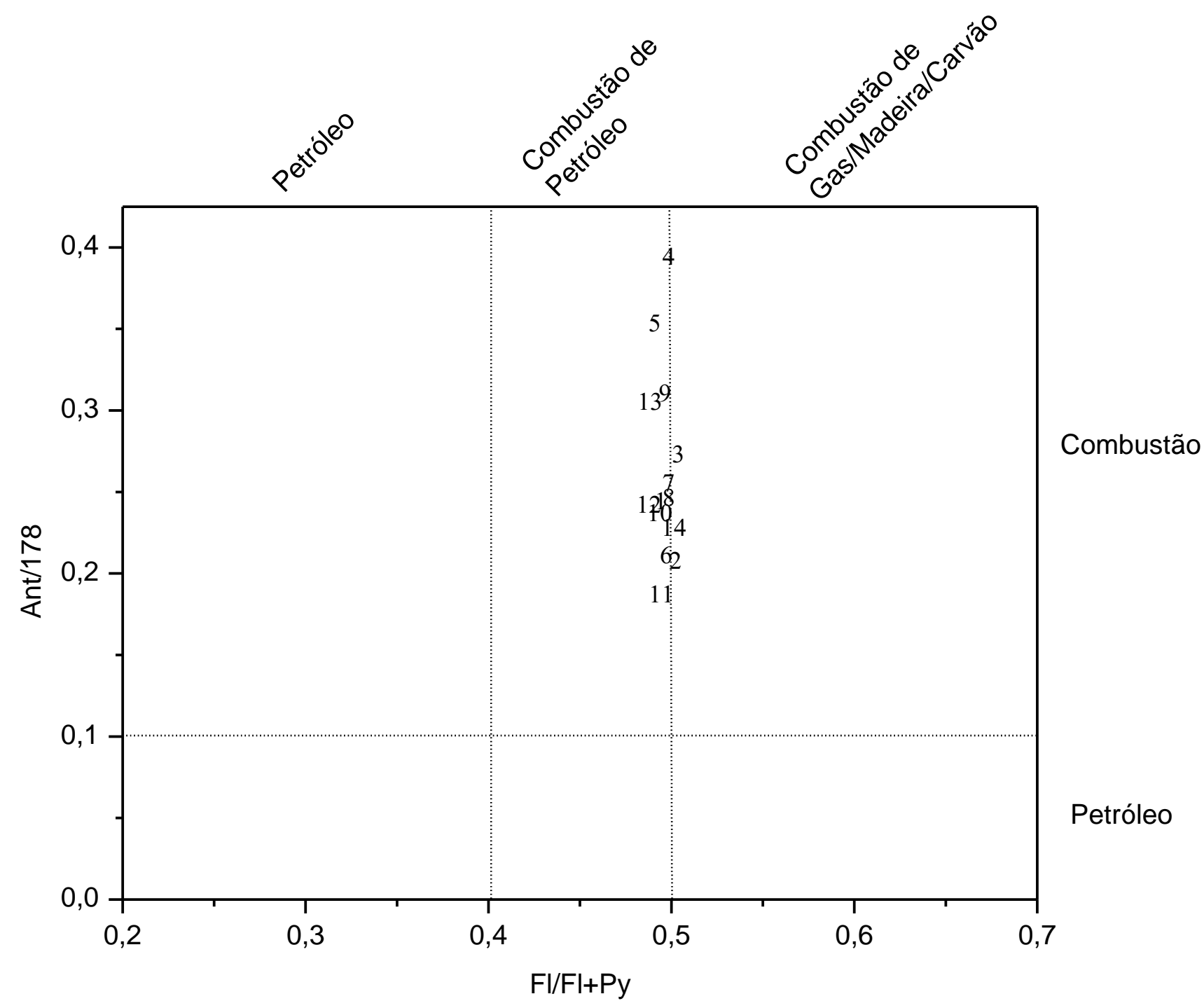

FIGURA 21 Gráfico da razão de Ant/178 vs. FIFI+Py

A razão entre $\mathrm{BaA} / 228$ mostrou que os HPA são derivados da combustão do carvão e biomassa vegetal para todos os locais, exceto para os pontos 10 e 14 que apresentaram fontes de petróleo e de combustão (fontes mistas) (FIG 22). 


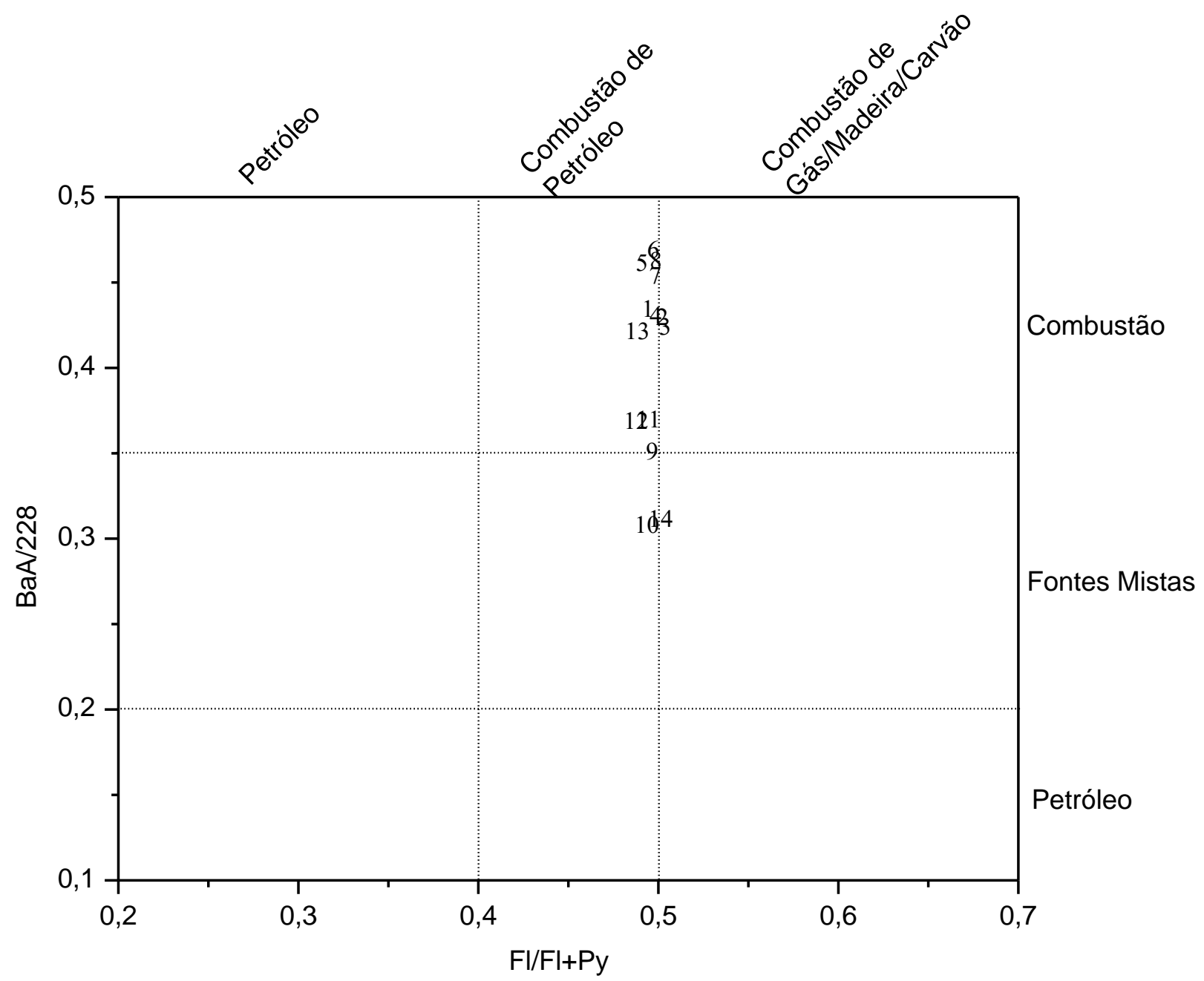

FIGURA 22 Gráfico da razão BaA/228 vs. Fl/FI+Py

A razão $\mathrm{IP} / \mathrm{IP}+$ BghiP mostrou que os HPA são derivados da combustão do petróleo nos pontos 1, 2, 9, 10, 11 e 14. Nos pontos 3, 4, 5, 6, 7, 8, 12 e 13 os índices apresentaram resultados de fontes de queima da biomassa vegetal e de carvão. O complexo industrial, que utiliza grandes quantidades de carvão em suas atividades e com a presença de refinarias, é a principal fonte de HPA provenientes do petróleo e da combustão. A queima de biomassa ocorre ao longo das margens do estuário, onde a população está concentrada (FIG 23). 


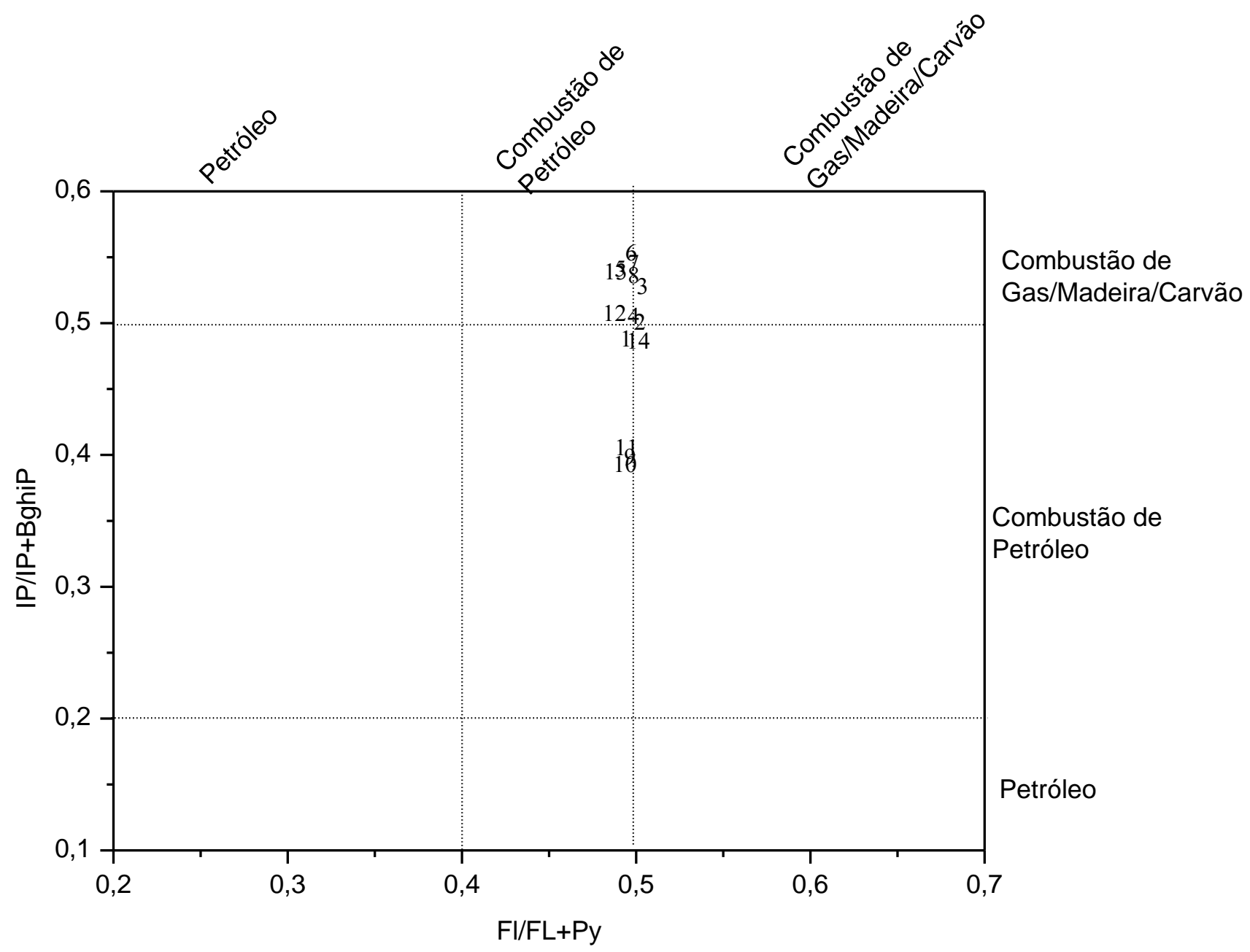

FIGURA 23 Gráfico da razão IP/IP+BghiP vs. Fl/FI+Py

Apesar de identificar fontes distintas de contaminação a partir de razões de pares de isômeros de HPA, é bem documentado que, em zonas urbanas e industriais os HPA podem ser provenientes de uma variedade de fontes e ser transportadas por vias diferentes. De acordo com as razões de pares de isômeros de HPA e a predominância de HPA pirolíticos de alto peso molecular encontrados nos sedimentos do estuário, evidenciou a combustão de petróleo e seus derivados como as principais fontes de introdução desses compostos para o SESSV assim como observados anteriormente por Bicego et al. (2006) e Martins et al. $(2007 ; 2011)$. 


\subsubsection{Análise Estatistica e Multivariada}

\subsubsection{Correlação de Pearson}

Os resultados das correlações de Pearson estão resumidos na TAB 12.

A maioria dos metais se mostraram fortemente correlacionados entre si, com exceção do $\mathrm{Hg}$, que não se correlacionou com o $\mathrm{Mn}$ (com correlação não significativa $p>0,05)$. Os HA totais se correlacionaram fortemente com os metais $\mathrm{Al}, \mathrm{Cr}, \mathrm{Cu}, \mathrm{Fe}, \mathrm{Mn}, \mathrm{Ni}, \mathrm{Pb}$ e $\mathrm{Zn}$, não apresentando correlações significativas com as demais variáveis. A porcentagem de silte e argila apresentou correlação forte $(p<0,01)$ para todos os metais, exceto para 0 $\mathrm{Mn}, \mathrm{HA}$ totais, HPA totais e o TOC (com $\mathrm{p}>0,05$ ). A correlação do $\mathrm{Hg}$ com a porcentagem de silte e argila foi a maior entre os metais, confirmando 0 encontrado por Hortellani et al. (2005).

TABELA 12 Correlação de Pearson entre os metais, hidrocarbonetos e parâmetros sedimentológicos, analisados nos sedimentos do SESSV $(n=16)$.

$\begin{array}{cccccccccccccc} & \mathrm{Al} & \mathrm{Cr} & \mathrm{Cu} & \mathrm{Co} & \mathrm{Fe} & \mathrm{Hg} & \mathrm{Mn} & \mathrm{Ni} & \mathrm{Pb} & \mathrm{Zn} & \begin{array}{c}\mathrm{HA} \\ \text { totais }\end{array} & \begin{array}{c}\text { HPA } \\ \text { Totais }\end{array} \text { \%Silte } \\ \mathrm{Al} & 1 & & & & & & & & & & & & \\ \mathrm{Cr} & 0.948 & 1 & & & & & & & & & & & \\ \mathrm{Cu} & 0.886 & 0.896 & 1 & & & & & & & & & & \\ \mathrm{Co} & 0.865 & 0.769 & 0.858 & 1 & & & & & & & & & \\ \mathrm{Fe} & 0.973 & 0.972 & 0.911 & 0.838 & 1 & & & & & & & & \\ \mathrm{Hg} & 0.746 & 0.585 & 0.656 & 0.750 & 0.689 & 1 & & & & & & & \\ \mathrm{Mn} & 0.732 & 0.854 & 0.612 & 0.519 & 0.771 & 0.219 & 1 & & & & & & \\ \mathrm{Ni} & 0.946 & 0.925 & 0.951 & 0.861 & 0.970 & 0.673 & 0.696 & 1 & & & & & \\ \mathrm{~Pb} & 0.852 & 0.891 & 0.923 & 0.753 & 0.863 & 0.643 & 0.637 & 0.849 & 1 & & & & \\ \text { Zn } & 0.840 & 0.891 & 0.957 & 0.714 & 0.891 & 0.541 & 0.642 & 0.921 & 0.921 & 1 & & & \\ \text { HA totais } & 0.660 & 0.762 & 0.709 & 0.455 & 0.708 & 0.435 & 0.523 & 0.668 & 0.789 & 0.751 & 1 & & \\ \text { HPA Totais } & 0.339 & 0.232 & 0.421 & 0.445 & 0.353 & 0.234 & 0.046 & 0.456 & 0.157 & 0.427 & -0.010 & 1 & \\ \text { \%Silte e } & 0.803 & 0.655 & 0.718 & 0.815 & 0.785 & 0.933 & 0.332 & 0.782 & 0.670 & 0.620 & 0.434 & 0.288 & 1 \\ \text { Argila } & 0.109 & 0.075 & 0.181 & 0.053 & 0.165 & 0.259 & 0.135 & 0.173 & 0.215 & 0.237 & 0.085 & 0.159 & 0.346\end{array}$


Os HPA totais e o TOC não apresentaram correlações significativas com nenhuma das variáveis estudadas.

A fim de identificar prováveis grupos correlacionados e estudar as interrelações entre as variáveis (metais, hidrocarbonetos, características sedimentológicas e os pontos amostrais) e também o comportamento geral dos dados, a análise de componentes principais (ACP), foi aplicada.

\subsubsection{Análise de componentes principais (ACP)}

Neste estudo, a ACP indicou que 13 variáveis e 16 amostras de sedimentos podem ser representados por três CP significativos, que apresentaram \% total de variância acima ou próximo de $10 \%$ ou autovalor acima ou próximo de 1. Desses componentes, o primeiro (CP1) sintetiza $68,33 \%$ das informações originais e o segundo (CP2) 10,95\%. Os 2 primeiros componentes somados explicam $79,28 \%$ da variabilidade dos dados. Somente eles podem ser usados para uma análise, pois apresentam uma variância acima ou próxima de $10 \%$, e o autovalor acima de 1, como mostra a TAB 13.

A CP1 concentrou informações sobre todos os metais, HA totais e \% silte e argila. As correlações da CP1 com cada variável estão apresentadas na tabela 14. Estes resultados explicam o fato da CP1 ser predominante e responsável por cerca de $68,33 \%$ da variância total podem indicar fontes comuns a esses contaminantes. Os locais mais contaminados por metais tendem a ser mais contaminados por HA totais. 
TABELA 13 Autovalor, \% de variância, Autovalor acumulativo e \% acumulativa referente a cada componente gerada.

Matriz de correlação dos autovalores e estatística relacionada SESSV

\begin{tabular}{ccccc}
\hline Número & Autovalor & $\begin{array}{r}\text { \% Total de } \\
\text { Variância }\end{array}$ & $\begin{array}{c}\text { Autovalor } \\
\text { Acumulativo }\end{array}$ & $\begin{array}{c}\% \\
\text { acumulativa }\end{array}$ \\
\hline 1 & 9,5670 & 68,335 & 9,567 & 68,339 \\
2 & 1,5336 & 10,954 & 11,100 & 79,290 \\
3 & 1,0387 & 7,419 & 12,139 & 86,709 \\
4 & 0,8676 & 6,197 & 13,007 & 92,907 \\
5 & 0,4948 & 3,534 & 13,501 & 96,442 \\
& 0,2259 & 1,614 & 13,727 & 98,056 \\
\hline
\end{tabular}

A CP2 (que explicou 10,95\% da variância) concentra apenas informações sobre o $\mathrm{Mn}, \mathrm{Hg}$, HPA totais \% silte e argila e TOC e os valores de correlação com CP2 estão expressos na TAB 14. O Mn apresentou correlação positiva com a CP2 enquanto que o $\mathrm{Hg}$, HPA e TOC tiveram correlação negativa com a CP2. Isso ocorre pelo fato dos HPA apresentarem grande afinidade pelo TOC e o $\mathrm{Hg}$ em sua forma orgânica (metilmercúrio), tende a ficar associado com o TOC. 
TABELA 14 Correlação das variáveis (metais, hidrocarbonetos e parâmetros sedimentológicas) com cada componente principal.

\begin{tabular}{|c|c|c|}
\hline Variável & Fator 1 & Fator 2 \\
\hline $\mathrm{Al}$ & -0.96 & 0.03 \\
\hline $\mathrm{Cr}$ & -0.95 & 0.25 \\
\hline $\mathrm{Cu}$ & -0.96 & -0.01 \\
\hline Co & -0.87 & -0.17 \\
\hline $\mathrm{Fe}$ & -0.98 & 0.06 \\
\hline $\mathrm{Hg}$ & -0.74 & -0.42 \\
\hline $\mathrm{Mn}$ & -0.69 & 0.55 \\
\hline $\mathrm{Ni}$ & -0.97 & -0.02 \\
\hline $\mathrm{Pb}$ & -0.92 & 0.11 \\
\hline $\mathrm{Zn}$ & -0.92 & 0.05 \\
\hline HA totais & -0.73 & 0.34 \\
\hline HPA totais & -0.36 & -0.49 \\
\hline \%silte+argila & -0.81 & -0.42 \\
\hline$\%$ TOC & -0.19 & -0.61 \\
\hline
\end{tabular}

Os resultados referentes às correlações entre os pontos e as CPs estão expressos na TAB 15 e o gráfico bidimensional referente aos valores de CP1 $\mathrm{x}$ CP2 estão expressos na FIG 24. Como pode ser observado, a contaminação no SESSV também aumentou com o aumento dos valores obtidos pelo CP1. Os pontos 5, 11, 12, 13 e 15 (que estão próximos ao polo industrial de Cubatão) estavam separados dos demais pontos devido à elevada 
contaminação por metais. $\mathrm{O}$ ponto 5 apresentou a maior concentração de $\mathrm{Hg}$, acima de PEL. Como previamente relatado, as concentrações de $\mathrm{Cu}, \mathrm{Hg}, \mathrm{Ni}$ e $\mathrm{Zn}$, foram acima de TEL em locais 12, 13 e 15 e a concentração de $\mathrm{Pb}$ foi acima de TEL, apenas no local 13. O ponto 11 também apresentou concentrações de $\mathrm{Cu}, \mathrm{Hg}$ e $\mathrm{Ni}$ acima de TEL.

TABELA 15 Correlação dos casos (pontos amostrais) com cada componente principal.

\begin{tabular}{ccc}
\hline Casos & Fator 1 & Fator 2 \\
\hline 1 & 1.16 & 0.26 \\
2 & 3.35 & 0.02 \\
3 & 1.99 & -0.74 \\
4 & 1.32 & -0.33 \\
5 & -5.25 & -2.24 \\
6 & 1.62 & -1.41 \\
7 & 2.71 & -0.74 \\
8 & 2.81 & 0.53 \\
9 & 1.36 & 0.88 \\
10 & 1.09 & 1.00 \\
11 & -2.36 & 1.87 \\
12 & -4.05 & -2.03 \\
13 & -5.58 & 1.15 \\
14 & 1.64 & -0.43 \\
15 & -3.98 & 1.81 \\
16 & 2.14 & 0.35 \\
\hline
\end{tabular}

Os pontos 5 e 12 se separaram dos pontos 11,13 e 15 pelo fato de apresentarem concentrações relativamente diferentes de Mn, HPA, TOC e Hg, justamente as variáveis que mais se correlacionaram com a CP2. Os pontos 5 , 
$11,12,13$ e 15 se separaram dos demais pontos o que sugere que eles devem ser os locais mais contaminados, justificando os resultados dessa análise.

\section{Projection of the cases on the factor-plane ( $\left.1 \begin{array}{ll}1 x & 2\end{array}\right)$ \\ Cases with sum of cosine square $>=0.00$ \\ Labelling variable: Locais}

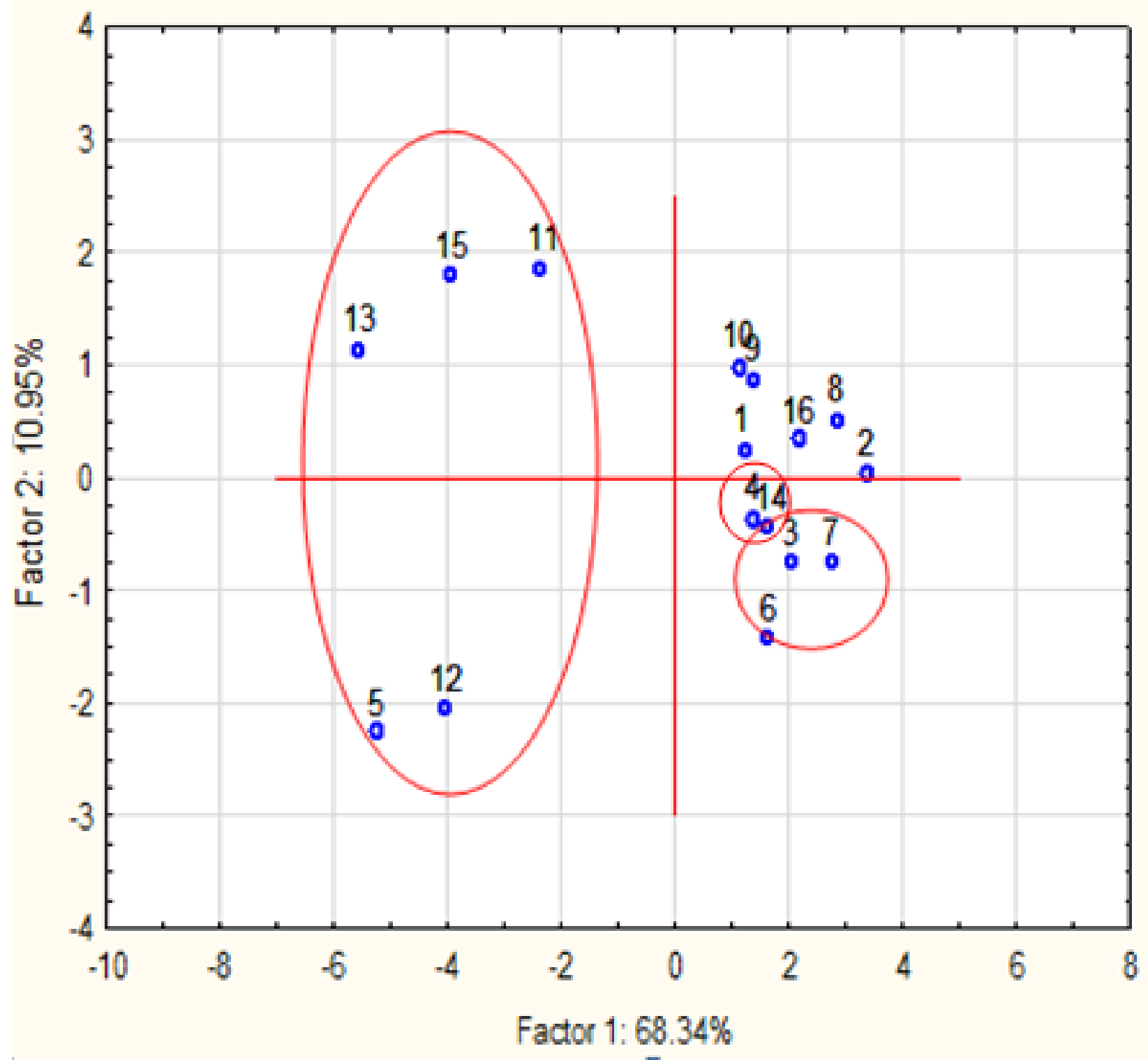

FIGURA 24 Gráfico de dispersão dos casos referente as CP1 x CP2

O ponto 4 e 14 se agruparam formando um grupo por apresentarem similaridade nas concentrações da maioria dos metais, HPAs e TOC. Também pode ser observado que, entre os locais com baixa contaminação, um subgrupo, incluindo os locais de 3, 6 e 7, foi separado dos outros locais. 
Nos resultados apresentados na FIG 25, um grupo formado por Al, Fe, $\mathrm{Co}, \mathrm{Cr}, \mathrm{Cu}, \mathrm{Ni}, \mathrm{Pb}$ e $\mathrm{Zn}$ foi observado, o que sugere a mesma fonte de origem para esses elementos.

Projection of the variables on the factor-plane $\left(\begin{array}{ll}1 x & 2\end{array}\right)$

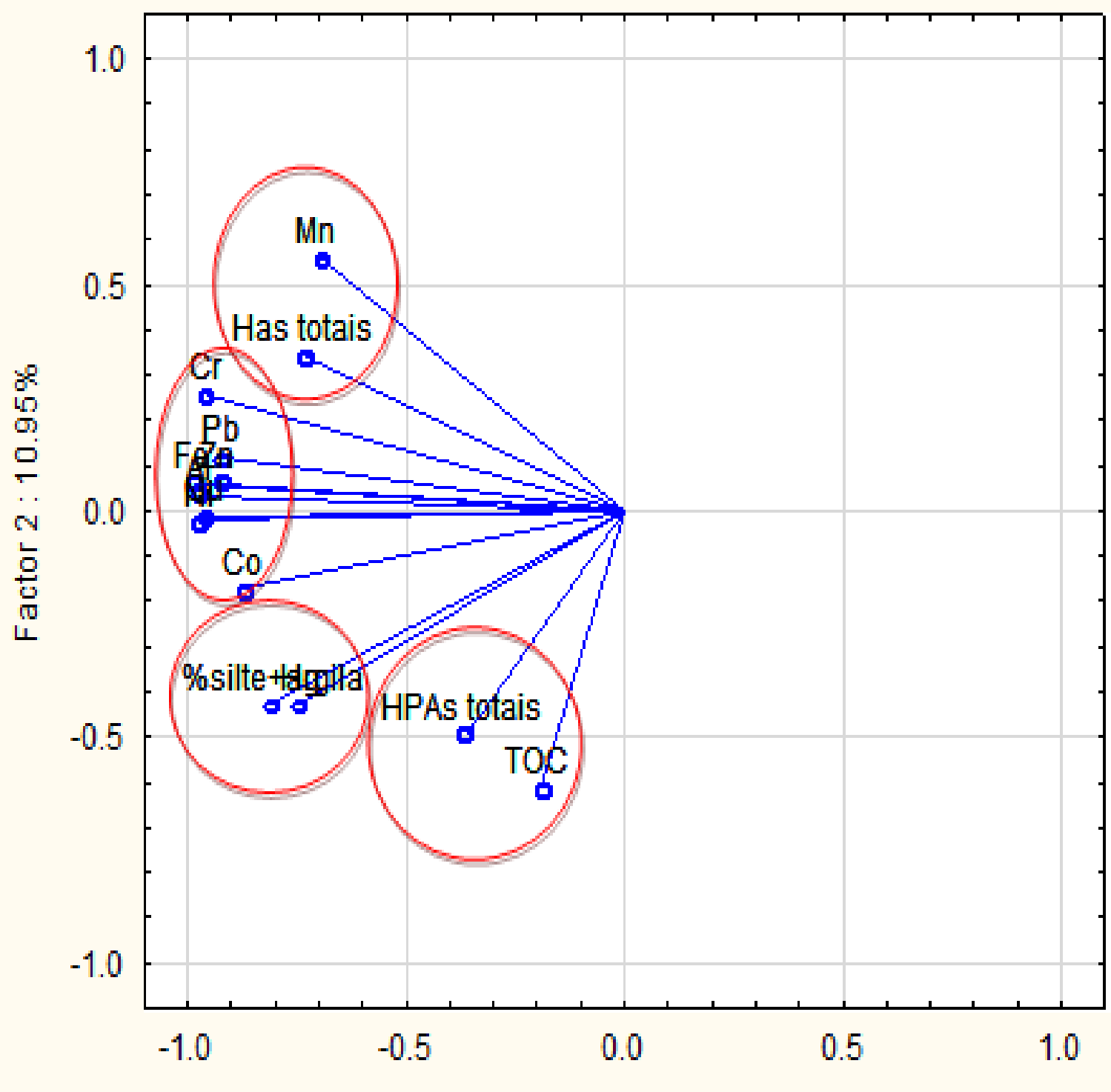

Factor $1: 68.34 \%$

FIGURA 25 Gráfico de dispersão das variáveis referentes a CP1 x CP2

Um outro grupo formado pelo $\mathrm{Hg}$ e a \% silte e argila mostrou estar correlacionados, provavelmente, não só por causa da contaminação nos pontos (uma vez que todos os valores de concentração de $\mathrm{Hg}$ foram acima dos limites do TEL), mas também por causa da grande afinidade do $\mathrm{Hg}$ com a \% de silte e argila. 
O Mn e os HA totais formaram outro grupo, pois esses dois elementos apresentam como fontes para o meio ambiente aquático antrópicas e naturais o que influenciam nas concentrações desses contaminantes nos sedimentos.

O mesmo aconteceu com os HPA totais e O TOC que formaram um grupo pelo fato de apresentarem altas concentrações em pontos semelhantes e também, pela afinidade dos HPA com a fração orgânica dos sedimentos.

\subsubsection{Análise de Agrupamento}

A análise de agrupamento é uma ferramenta útil para a análise de conjuntos de dados. Os pontos mais semelhantes são agrupados formando um aglomerado e o processo é repetido até que todos os pontos formem um agrupamento. Esta análise examina as distâncias entre as amostras e os conjuntos de dados. Um dendrograma, apresentando semelhanças entre as amostras, é detalhado na FIG 26. 
Ward's method

Eudidean distanos

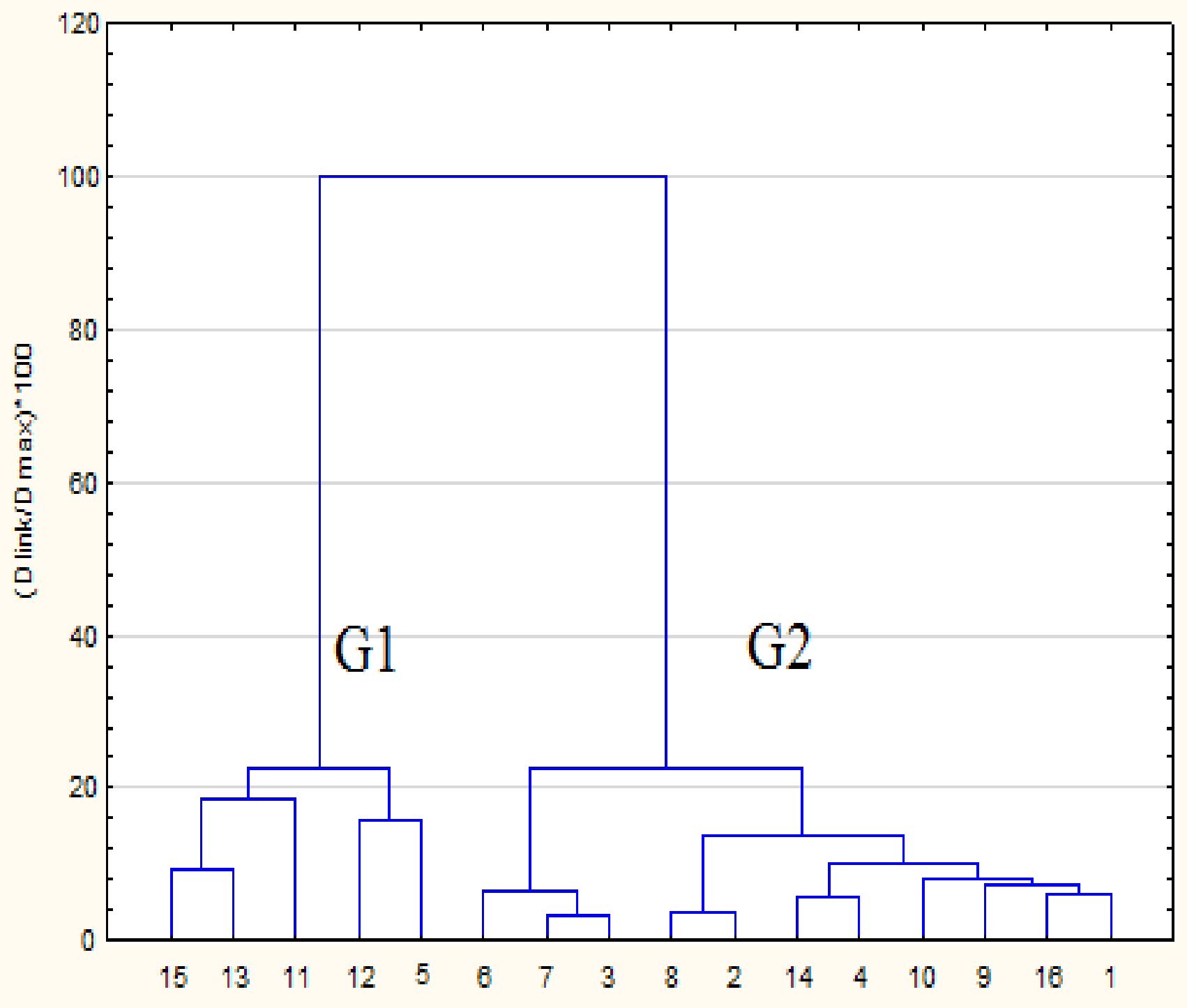

FIGURA 26 Dendrograma das analises de agrupamento referente aos pontos coletados no SESSV.

As ligações horizontais correspondem aos locais e os números no topo do dendrograma correspondem ao nível de similaridade, em uma escala de 0 (identidade no máximo) a 100 (dissimilaridade máxima). Os pontos foram agrupados em dois grandes grupos (G1 e G2), separados por máxima dissemelhança entre $o$ teor de metais das amostras.

O G1 agrupou os pontos que apresentaram as concentrações de metais e hidrocarbonetos mais elevadas, na parte interna do estuário onde estão 
localizados as atividades do polo industrial de Cubatão o que sugere mesma fonte de origem para esses contaminantes.

Por outro lado o G2 apresentou o agrupamento dos pontos menos contaminados, localizados por todo o SESSV. OS pontos 3,6 e 7 se agruparam demonstrado menor dissimilaridade entre eles. O mesmo aconteceu com os pontos 2 e 8 que se agruparam e com os pontos 14 e o 4 devido a similaridade nas concentrações da maioria dos metais e hidrocarbonetos.

A análise de agrupamento corroborou a ACP, evidenciando a separação dos pontos mais contaminados dos pontos menos contaminados e um agrupamento dos pontos moderadamente contaminados em relação aos demais locais do estudo.

\subsection{PEMLS, Zona Marinha Adjacente e Baia de Santos}

\subsubsection{Análises sedimentológicas}

Os resultados das análises sedimentológicas (\% silte e argila e \% de areia), TOC, M.O e $\mathrm{CaCO}_{3}$ estão expressos na TAB 16.

Os resultados revelaram uma similaridade entre os pontos 2, 3, 6, 7 e 8 que apresentaram uma alta porcentagem de areia e uma menor porcentagem de $\mathrm{TOC}$ e $\mathrm{CaCO}_{3}$ quando comparados com os demais pontos. Os pontos $1,4 \mathrm{e}$ 5 apresentaram uma porcentagem de $\mathrm{TOC}$ e $\mathrm{CaCO}_{3}$ mais elevada e uma porcentagem de areia menor.

Em relação a matéria orgânica, o ponto 7 foi o que apresentou a maior concentração de $0,2 \%$, enquanto que os outros pontos ficaram entre 0 e $0,1 \%$ de matéria orgânica. 
TABELA 16 Classificação da porcentagem de \% de areia $(>63 \mu \mathrm{m})$, silte e argila $(<63 \mu \mathrm{m})$, TOC, $\mathrm{M} . \mathrm{O}$ e $\mathrm{CaCO}_{3}$ nos sedimentos dos pontos de coleta.

\begin{tabular}{ccccccccc}
\hline Variáveis/Pontos & 1 & 2 & 3 & 4 & 5 & 6 & 7 & 8 \\
\hline \%Areia & 82,8 & 93,3 & 97,6 & 84 & 84,1 & 99,2 & 98,3 & 99,1 \\
\%silte e argila & 17,2 & 16,7 & 2,4 & 16 & 15,1 & 0,8 & 1,7 & 0,9 \\
TOC (\%) & 9.79 & 5.71 & 4.02 & 8.93 & 10.35 & 0.34 & 0.64 & 0.1 \\
M.O & 0,1 & 0,1 & 0 & 0,1 & 0,1 & 0 & 0,2 & 0,1 \\
$\mathrm{CaCO}_{3}$ & 17,1 & 6,60 & 2,40 & 16,0 & 15,8 & 0,700 & 1,50 & 0,800 \\
\hline
\end{tabular}

Sendo assim, os pontos 1, 4 e 5 apresentam características que proporcionam o acumulo de metais e hidrocarbonetos devido a grande afinidade que esses contaminantes apresentam com a granulometria fina, alta porcentagem de $\mathrm{TOC}$ e de $\mathrm{CaCO}_{3}$ (Bicego et al., 2006; Harari et al., 2000; Hortellani et al., 2005; Martins et al., 2007)

\subsubsection{Metais - PEMLS, Zona Marinha Adjacente e Baia de Santos}

Os resultados das análises químicas de metais nas amostras de sedimentos provenientes do PEMLS, zona marinha adjacente e Baia de Santos estão expressos na TAB 17.

TABELA 17 Concentrações de metais nas amostras de sedimentos provenientes do PEMLS $\left(\mu \mathrm{g} \mathrm{g}^{-1}\right)$

\begin{tabular}{ccccccccc}
\hline Metais/Pontos & 1 & 2 & 3 & 4 & 5 & 6 & 7 & 8 \\
\hline $\mathbf{A l}(\%)$ & 0,21 & 0,53 & 0,69 & 0,46 & 0,48 & 0,29 & 1,63 & 0,68 \\
$\mathbf{F e ~ ( \% )}$ & 0,13 & 0,31 & 0,39 & 0,27 & 0,40 & 0,21 & 1,15 & 0,82 \\
$\mathbf{C o}$ & 2,48 & 2,71 & 2,80 & 1,94 & 3,06 & 3,22 & 6,14 & 4,15 \\
$\mathbf{C r}$ & 7,31 & 6,00 & 9,45 & 8,58 & 8,77 & 5,54 & 18,0 & 10,7 \\
$\mathbf{C u}$ & 1,51 & 1,41 & 1,53 & 1,67 & 1,44 & $<\mathrm{LD}$ & 3,81 & 1,45 \\
$\mathbf{H g}$ & $<\mathrm{LD}$ & $<\mathrm{LD}$ & 0,076 & $<\mathrm{LD}$ & $<\mathrm{LD}$ & $<\mathrm{LD}$ & 0,142 & $<\mathrm{LD}$ \\
$\mathbf{~ M n}$ & 62,4 & 134 & 99,1 & 199 & 234 & 68,3 & 219 & 115 \\
$\mathbf{~ N i}$ & 3,72 & 3,86 & 4,68 & 6,09 & 5,5 & 3,1 & 9,52 & 5,54 \\
$\mathbf{P b}$ & $<\mathrm{LD}$ & $<\mathrm{LD}$ & 3,9 & 8,74 & 5,13 & 4,84 & 8,36 & $<\mathrm{LD}$ \\
$\mathbf{~ Z n}$ & 21,1 & 14,1 & 14,3 & 8,03 & 8,92 & 6,03 & 32,9 & 18,9 \\
\hline
\end{tabular}




\section{Alumínio}

Nos sedimentos do PEMLS zona marinha adjacente e baia de Santos, os valores de Al foram encontrados variando entre 0,210 a 1,63\% (FIG 27).

As concentrações no interior do PEMLS foram relativamente mais altas no sedimento do ponto $3(0,692 \%)$ seguidas dos pontos $5(0,482 \%)$ e 4 $(0,462 \%)$. A menor concentração ocorreu no sedimento do ponto $1(0,21 \%)$, localizado no pequeno porto da Laje de Santos, a qual foi similar a encontrada no sedimento do ponto $6(0,29 \%)$.

O sedimento do ponto 7 , localizado na área de descarte do material dragado do porto de Santos, apresentou a concentração mais elevada $(1,63 \%)$ e o sedimento do ponto 8 , localizado na baia de Santos, apresentou a concentração de $0,684 \%$.

Estudo realizado por Abessa, (2002) registrou concentrações de 3,6 \% de Al na baia de Santos e de 4,15\% na área de descarte do material dragado. No presente trabalho a concentração de $\mathrm{Al}$ nessa região foi menor que a registrada anteriormente.

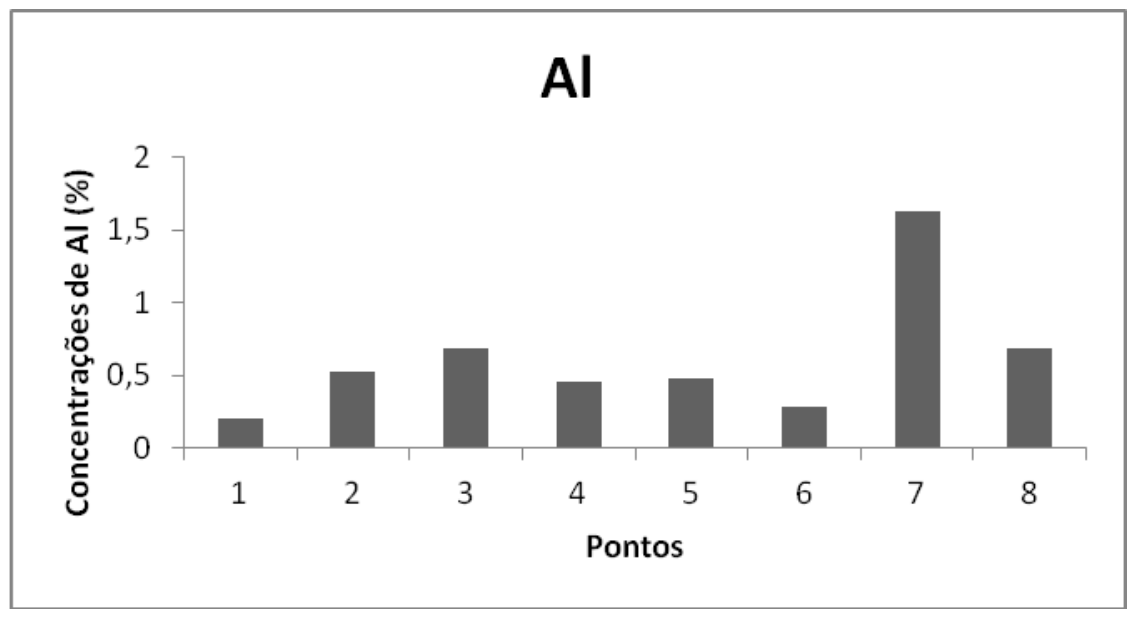

FIGURA 27 Concentração de Al (\%) nos pontos de coleta 
O Al não possui valores estabelecidos nos VGQS por ser um elemento constituinte natural dos sedimentos.

Em termos gerais, o Al não apresentou gradiente evidente da concentração desde a baia de Santos até o PEMLS.

\section{Ferro}

As concentrações de $\mathrm{Fe}$ nos sedimentos do PEMLS, zona marinha adjacente e baia de Santos variaram de 0,135 a 1,15\% (FIG 28). Nos sedimentos provenientes do PEMLS, o ponto 5 foi o que apresentou a maior concentração $(0,403 \%)$ seguido do sedimento do ponto $3(0,396 \%)$. Os sedimentos dos ponto $1(0,135 \%), 4(0,276 \%)$ e $6(0,214 \%)$ foram os que apresentaram as menores concentrações. Em geral as concentrações de $\mathrm{Fe}$ foram baixas nos sedimentos do PEMLS e sem fontes potenciais de introdução desse elemento no ambiente do PEMLS.

Os sedimentos do ponto 6 apresentou a concentração de 0,214\%, similar às encontradas no sedimento do ponto 1 , localizado no PEMLS

As maiores concentrações foram registradas nos sedimentos dos pontos $7(1,15 \%)$ e $8(0,823 \%)$, sob influência das atividades na costa.

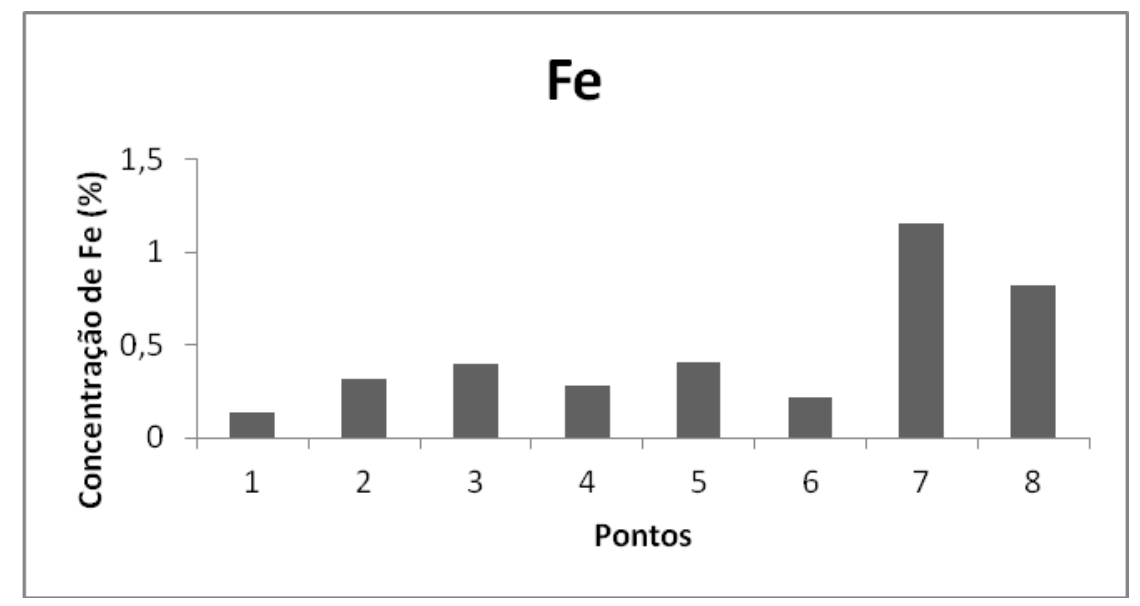

FIGURA 28 Concentração de $\mathrm{Fe}(\%)$ nos pontos de coleta. 
Em trabalho pretérito, Abessa (2002) encontrou concentrações de 1,6\% de Fe nos sedimentos da baia de Santos e de 1,1\% na área de descarte do material dragado, o que sugere que as concentrações de $\mathrm{Fe}$ estão se mantendo nessas regiões quando comparadas com as concentrações reportadas nesse estudo.

O Fe não possui VGQS estabelecido para ser comparado e não foi observado gradiente de concentração desde a zona costeira até o PEMLS.

\section{Cobalto}

As concentrações de Co variaram de 1,94 a 6,14 $\mathrm{\mu g} \mathrm{g}^{-1}$ nos sedimentos do PEMLS, zona marinha adjacente e baia de Santos (FIG 29). Os sedimentos dos pontos $5\left(3,06 \mu \mathrm{g} \mathrm{g}^{-1}\right), 3\left(2,80 \mu \mathrm{g} \mathrm{g}^{-1}\right)$ e $2\left(2,71 \mu \mathrm{g} \mathrm{g}^{-1}\right)$ foram os que apresentaram as maiores concentrações e os sedimentos dos pontos 1 (2,48 $\left.\mu \mathrm{g} \mathrm{g}^{-1}\right)$ e $4\left(1,94 \mu \mathrm{g} \mathrm{g}^{-1}\right)$, as menores concentrações. Os teores mais elevados foram reportados nos sedimentos dos pontos $7\left(6,14 \mu \mathrm{g} \mathrm{g}^{-1}\right)$ e $8\left(4,15 \mu \mathrm{g} \mathrm{g}^{-1}\right)$ evidenciando a influencia antrópica nesses pontos.

Estudo conduzido por Abessa (2002) encontrou resultados de Co próximos aos registrados no presente estudo para baia de Santos $\left(7,10 \mathrm{\mu g} \mathrm{g}^{-1}\right)$. Entretanto, as concentrações de Co na área de descarte do material dragado, mostraram-se baixas $\left(3,8 \mu \mathrm{g} \mathrm{g}^{-1}\right.$ de Co). 


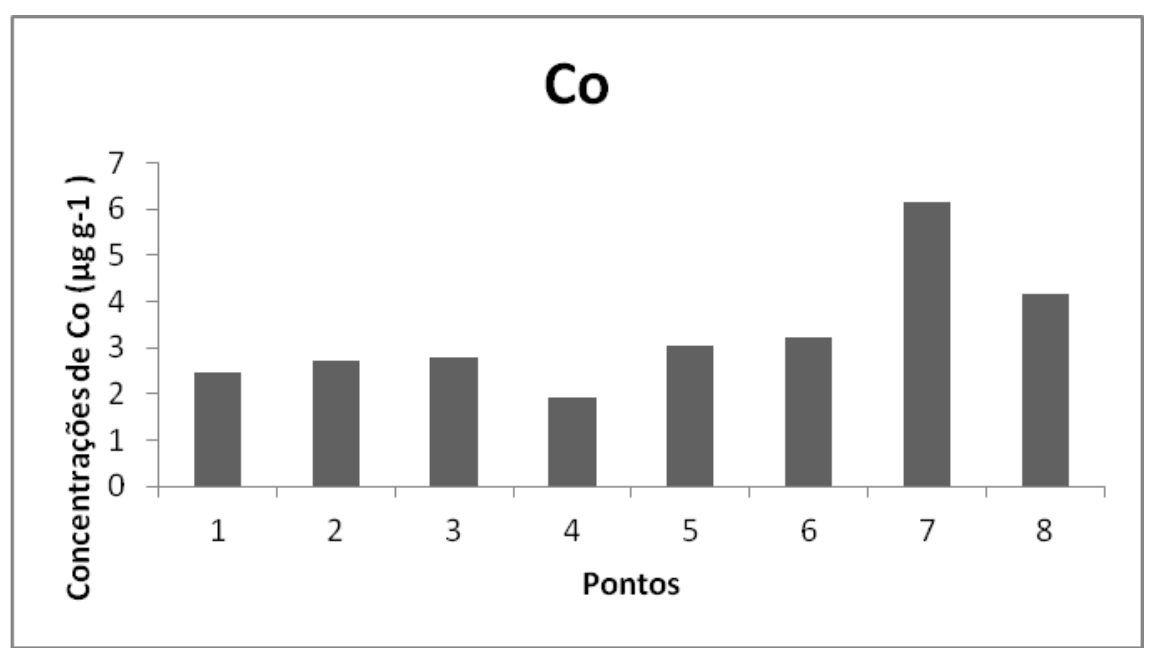

FIGURA 29 Concentração de Co $\left(\mu \mathrm{g} \mathrm{g}^{-1}\right)$ nos pontos de coleta.

Quando comparados com os VGQS, nenhuma amostra apresentou concentrações de Co nos sedimentos acima dos limites de TEL e PEL. Contudo, os sedimentos dos pontos 7 e 8 apresentaram valores acima dos limites estabelecidos por Choueri et al., (2009), sendo classificados como moderadamente poluídos por Co o que significa um alerta sobre a contaminação desse elemento nesses pontos.

Em resumo, o Co apresentou uma concentração relativamente elevada nos sedimentos dos pontos 7 e 8 e observou-se um gradiente em direção ao PEMLS. Devido ao sedimento do ponto 6 apresentar a concentração de Co mais elevada que os sedimentos localizados no interior do PEMLS, sugere que - Co encontrado no PEMLS seja de origem antrópica e proveniente de fontes localizadas no continente incluindo também a área de descarte do material dragado, que atinge o PEMLS através do transporte de sedimentos contaminados pelas correntes marinhas de fundo que chegam no PEMLS.

\section{Cromo}

O $\mathrm{Cr}$ ocorreu em concentrações que variaram de 6,0 a $18,0 \mu \mathrm{g} \mathrm{g}^{-1}$ (FIG 30. Os sedimentos dos pontos $3\left(9,45 \mu g^{-1}\right), 5\left(8,77 \mu g^{-1}\right)$ e $4\left(8,58 \mu g^{-1}\right)$ 
foram os que apresentaram as maiores concentrações de $\mathrm{Cr}$. Na área de descarte do material dragado, ponto $7\left(18,0 \mu \mathrm{g} \mathrm{g}^{-1}\right)$ e na baia de Santos, ponto $8\left(10,7 \mu \mathrm{g} \mathrm{g}^{-1}\right)$ os sedimentos apresentaram as maiores concentrações de $\mathrm{Cr}$.

Estudo realizado por Lamparelli et al., (2001) encontraram concentrações de $\mathrm{Cr}$ para os sedimentos da baia de Santos e área de descarte do material dragado de $26,0 \mu \mathrm{g} \mathrm{g}^{-1}$ e $42,0 \mu \mathrm{g} \mathrm{g}^{-1}$ respectivamente. Abessa (2002) registrou concentrações maiores do que as do presente estudo para baia de Santos, e abaixo para a área de descarte do material dragado $(28,4 \mu \mathrm{g}$ $\mathrm{g}^{-1}$ e $5 \mu \mathrm{g} \mathrm{g}{ }^{-1}$, respectivamente).

Em 2005, Torres (2007) registrou um aumento nas concentrações de $\mathrm{Cr}$ nos sedimentos na área de descarte do material dragado com valores de 31,4

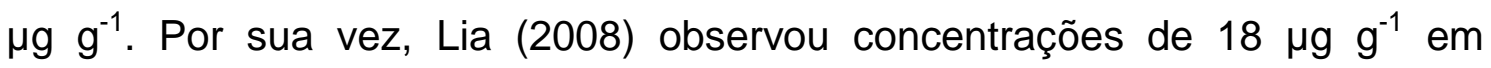
amostragens realizadas em 2006 e em 2007 na área de descarte do material dragado.

Os resultados do presente estudo sugerem a possibilidade de estar havendo um decréscimo nas concentrações de $\mathrm{Cr}$ na região da baia de Santos. Entretanto, na área de descarte do material dragado os teores de $\mathrm{Cr}$ estão se mantendo quando comparados com os dados na literatura.

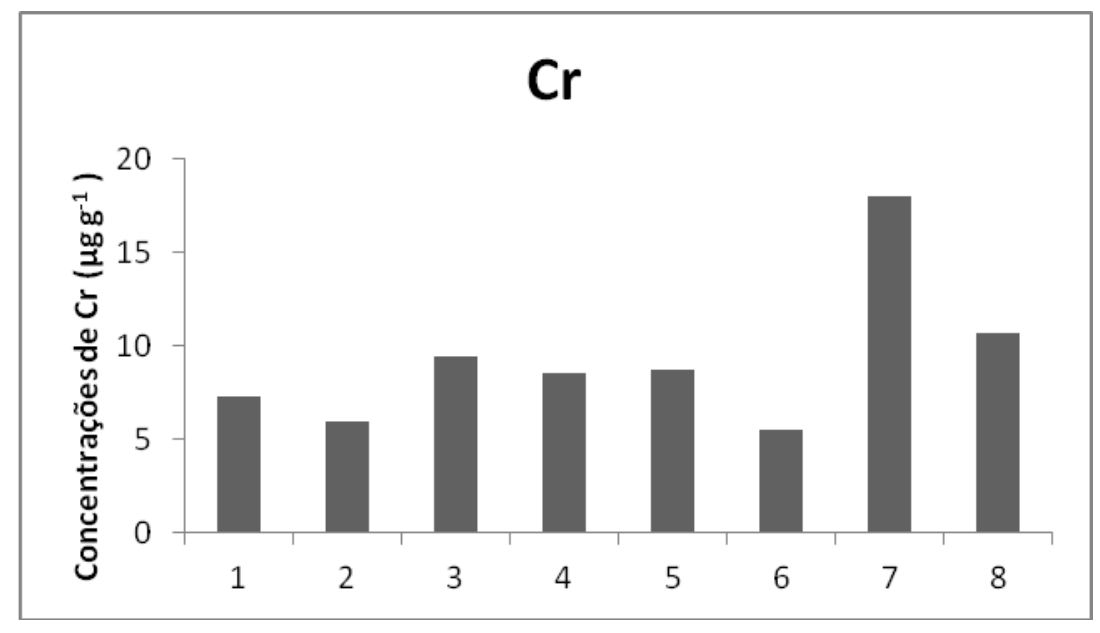

FIGURA 30 Concentração de $\mathrm{Cr}\left(\mu \mathrm{g} \mathrm{g}^{-1}\right)$ nos pontos de coleta 
Quando comparados com os valores estabelecidos nos VGQS, o Cr não excedeu os limites estipulados por ambos VGQS.

O $\mathrm{Cr}$ apresentou-se mais elevado nos pontos localizados mais próximos do continente (pontos 7 e 8). Ao se distanciar das fontes sofre diluição nas águas zona marinha adjacente, apresentando um gradiente de concentração no ponto 6, o qual voltando a aumentar nos sedimentos do PEMLS, principalmente nos pontos 3, 4 e 5 . Sendo assim, fontes provenientes da costa podem estar influenciando negativamente através do transporte pelas correntes marinhas e/ou fontes locais como as embarcações de turismo e pesqueiras que podem estar causando a introdução desse contaminante para o ambiente aquático.

\section{Cobre}

Os teores de $\mathrm{Cu}$ ocorreram nos sedimentos em concentrações que variaram de $<L D$ até $3,81 \mu \mathrm{g} \mathrm{g}^{-1}$ (FIG 31). Nos sedimentos do PEMLS as concentrações variaram de 1,41 a $1,67 \mu^{\prime} \mathrm{g} \mathrm{g}^{-1}$. As maiores concentrações ocorreram nos sedimentos dos pontos 4 e $3\left(1,67\right.$ e $1,53 \mu \mathrm{g} \mathrm{g}^{-1}$, respectivamente). Os sedimentos do ponto 7 apresentaram concentração de $3,81 \mu \mathrm{g} \mathrm{g}^{-1}$, a mais elevada entre os pontos amostrais. A concentração de $\mathrm{Cu}$ encontrada no sedimento do ponto 8 localizado na baia de Santos foi de 1,45 $\mu \mathrm{g} \mathrm{g}^{-1}$, similar as concentrações encontradas nos sedimentos do PEMLS.

Estudos anteriores conduzidos por Lamparelli et al. (2001) encontraram valores de $\mathrm{Cu}$ acima dos encontrados nos sedimentos da baia de Santos e área de descarte do material dragado $\left(19,0 \mu \mathrm{g} \mathrm{g}^{-1}\right.$ e $16 \mu \mathrm{gg} \mathrm{g}^{-1}$, respectivamente). Torres (2007) registrou concentrações de $10,5 \mu \mathrm{g} \mathrm{g}^{-1} \mathrm{na}$ região da área de descarte do material dragado. Lia (2008) observou

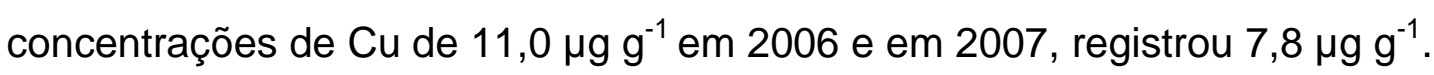




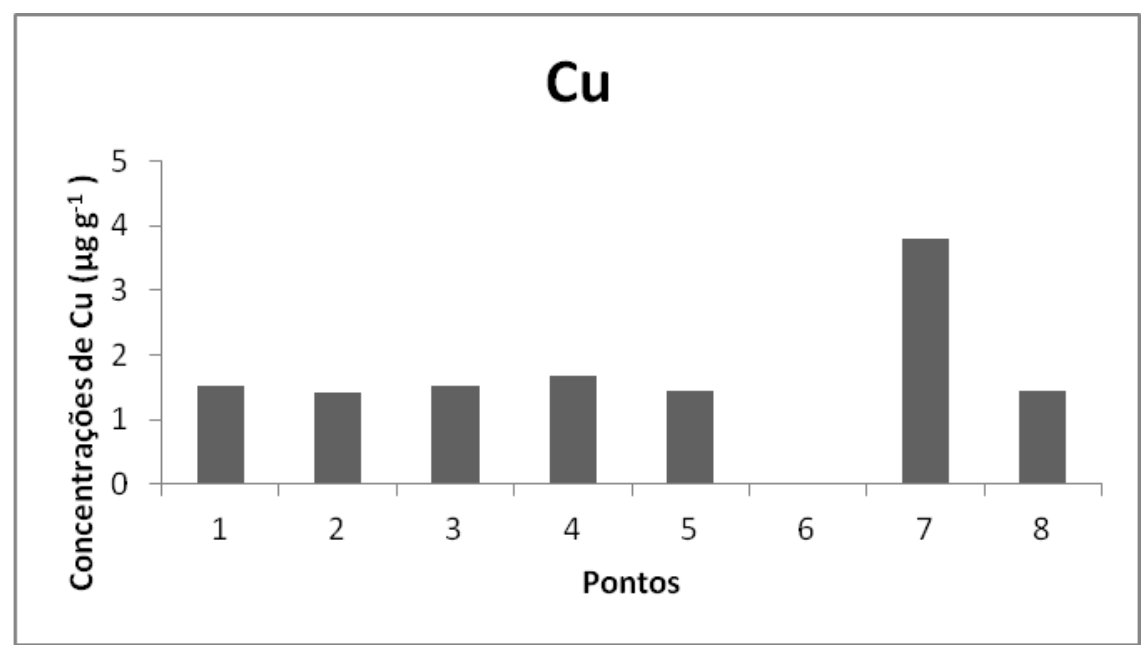

FIGURA 31 Concentração de $\mathrm{Cu}\left(\mu \mathrm{g} \mathrm{g}^{-1}\right)$ nos pontos de coleta.

As concentrações de Cu registradas nos sedimentos da baia de Santos e na área de descarte do material dragado sugerem estar havendo uma diminuição nos níveis ambientais. As concentrações foram relativamente baixas e não ultrapassaram os valores estabelecidos nos VGQS.

Como o $\mathrm{Cu}$ é utilizado em algumas tintas anti-incrustantes a visitação por barcos de pesca e de operadoras de mergulho pode influenciar na introdução desse elemento nessa região, porém não foi observado gradiente evidente de concentração para Cu desde a zona costeira até o PEMLS bem como altos níveis na região.

\section{Mercúrio}

Os sedimentos do PEMLS zona marinha adjacente e baia de Santos, a concentração de $\mathrm{Hg}$ variou de $<\mathrm{LD}$ até $0,142 \mu \mathrm{g} \mathrm{g}^{-1}$ (FIG 32). Com exceção dos pontos 3 e 7 , todos os sedimentos apresentaram as concentrações de $\mathrm{Hg}$ abaixo do LD do método.

O ponto 7 apresentou a concentração de $\mathrm{Hg}$ de $0,142 \mu \mathrm{g} \mathrm{g}{ }^{-1}$, acima do valor de TEL e os sedimentos considerados como moderadamente poluídos 
(Choueri et al., 2009), refletindo a influência da área de descarte do material dragado do porto de Santos nesse local, tendo em vista que a contaminação por $\mathrm{Hg}$ nos sedimentos do canal do porto de Santos é elevada. O ponto 3 , localizado no interior do PEMLS, apresentou concentração de $\mathrm{Hg}$ de $0,076 \mu \mathrm{g}$ $\mathrm{g}^{-1}$, o que sugere um aporte desse elemento nessa região.

A concentração de $\mathrm{Hg}$ encontrada nos sedimentos do PEMLS (ponto 3) aparenta não ser natural e sugere a influência de fontes antrópicas que podem ser oriundas da zona costeira atingindo a área do PEMLS através do transporte pelas correntes. Como a área de descarte apresentou a concentração de $\mathrm{Hg}$ elevada, acima de TEL, pode estar ocorrendo o transporte de sedimento contaminado desde a área de descarte do material dragado até o PEMLS. As correntes predominantes na região podem permitir ou facilitar a introdução desse elemento nos sedimentos do PEMLS. O Hg também apresenta $\mathrm{O}$ transporte atmosférico como uma via de deposição em outras regiões, o que reforça a hipótese de origem industrial.

Estudos pretéritos da concentração de $\mathrm{Hg}$ na baia de Santos revelaram concentrações de $\mathrm{Hg}$ elevada nos pontos da baia de Santos. Lamparelli et al., (2001) registraram $0,11 \mathrm{\mu g} \mathrm{g}^{-1}$ de $\mathrm{Hg}$ nos sedimentos, ultrapassando os valores de TEL. Abessa (2002) encontrou 0,19 $\mu \mathrm{g} \mathrm{g}^{-1}$, excedendo o valor de TEL. Hortellani et al., (2005) registraram valores de 0,31 $\mu \mathrm{g} \mathrm{g}{ }^{-1}$, acima das encontradas no presente estudo.

$\mathrm{Na}$ área de descarte do material dragado, os valores de $\mathrm{Hg}$ registrados por Lamparelli et al., (2001) foi de $0,13 \mu \mathrm{g} \mathrm{g}^{-1}$. Abessa (2002) encontrou teores de $\mathrm{Hg}$ em $0,03 \mu \mathrm{g} \mathrm{g}^{-1}$. Lia (2008) apresentou concentrações abaixo do limite do método.

As concentrações de $\mathrm{Hg}$ nos sedimentos da baia de Santos registradas nesse estudo foram inferiores as encontradas em trabalhos pretéritos. Em contra partida, na área de descarte do material dragado, as concentrações de $\mathrm{Hg}$ estiveram acima dos resultados registrados na literatura, excedendo o valor de TEL. 


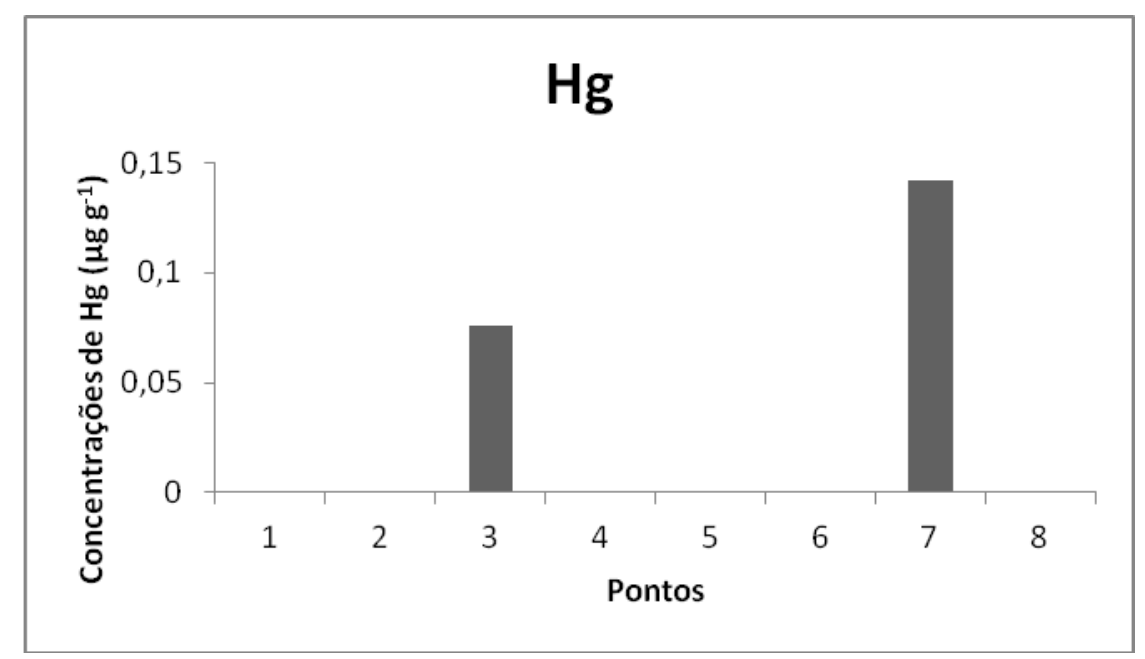

FIGURA 32 Concentração de $\mathrm{Hg}\left(\mu \mathrm{g} \mathrm{g}{ }^{-1}\right)$ nos pontos de coleta.

A contaminação por $\mathrm{Hg}$ no ponto 7 foi elevada (acima de TEL) pois no SESSV o $\mathrm{Hg}$ está presente em concentrações altas em todo o estuário e devido a sua alta persistência no meio ambiente, a disposição dos sedimentos dragados contaminados pode estar influenciando a qualidade ambiental dos sedimentos nessa região e de zonas adjacentes, como o PEMLS. A concentração relativamente elevada no ponto 3 , indica que a área de descarte do material dragado pode estar influenciando a região do PEMLS, o que pode alterar a qualidade ambiental e causa possíveis impactos significativos para a biota.

\section{Manganês}

Os teores de Mn nos sedimentos referentes ao PEMLS zona marinha adjacente e baia de Santos, ocorreram em concentrações que variaram de 62,4 até $234 \mu \mathrm{g} \mathrm{g}^{-1}$ (FIG 33). As maiores concentrações ocorreram no ponto 5 (234 $\left.\mu \mathrm{g} \mathrm{g}^{-1}\right)$, seguido pelo ponto $7\left(219 \mu \mathrm{g} \mathrm{g}^{-1}\right)$ e pelo ponto $4\left(199 \mu \mathrm{g} \mathrm{g}^{-1}\right)$.

As concentrações relativamente elevadas nos sedimentos dos pontos 4 e 5, localizados no PEMLS, chamam a atenção principalmente pelo fato das 
concentrações no ponto 5, terem excedido as encontradas na área de descarte do material dragado. $O$ ponto 4 também apresentou uma concentração relativamente elevada para esse elemento. Isso significa que pode estar ocorrendo um aporte de Mn na região do PEMLS, provavelmente oriunda do transporte de sedimento pelas correntes provenientes da área de descarte do material dragado e das atividades industriais localizadas na região costeira, pois o $\mathrm{Mn}$ é fortemente associado com a origem continental, porém pode estar presente nos efluentes industriais.

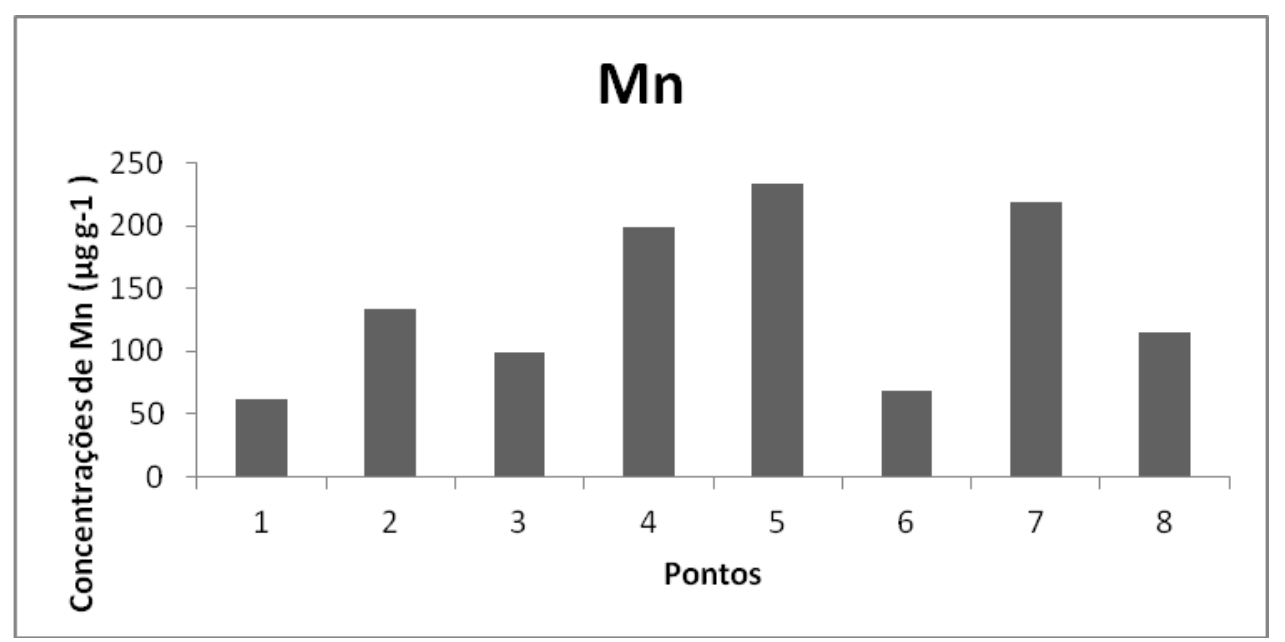

FIGURA 33 Concentração de $\mathrm{Mn}\left(\mu \mathrm{g} \mathrm{g}^{-1}\right)$ nos pontos de coleta

No sedimento do ponto 6 , o Mn ocorreu na concentração de $68 \mu \mathrm{g} \mathrm{g}^{-1} \mathrm{e}$ no sedimento da baia de Santos (ponto 8), o valor foi de $115 \mu \mathrm{g} \mathrm{g}^{-1}$.As principais fontes antrópicas de $\mathrm{Mn}$ são as atividades indústrias de produção de fertilizantes agrícolas, aços, pilha elétrica e vidros (Quinaglia, 2006) que estão instaladas no SESSV, podendo ser exportado para zonas marinha adjacentes.

Lamparelli et al. (2001) encontraram valores acima dos encontrados nesse estudo para a baia de Santos $\left(435 \mu \mathrm{g} \mathrm{g}^{-1}\right)$ e na área de descarte do material dragado do Porto de Santos $\left(629 \mu \mathrm{g} \mathrm{g}^{-1}\right)$. O presente estudo registrou concentrações mais baixas de $\mathrm{Mn}$ em relação aos dados pretéritos em ambas as regiões, baia de Santos e área de descarte do material dragado. Em 2006,

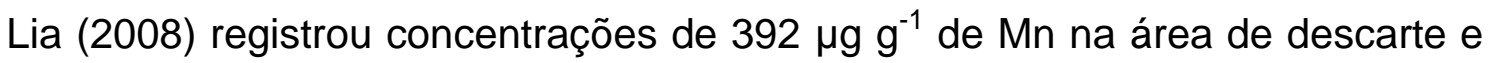
em 2007, houve um pequeno decréscimo para $327 \mu \mathrm{g} \mathrm{g}^{-1}$. 
O Mn não possui critérios para sua classificação nos VGQS e não apresentou gradiente definido desde a zona costeira até o PEMLS.

\section{Níquel}

O Ni ocorreu em concentrações que variaram de 3,1 a 9,52 $\mu \mathrm{g} \mathrm{g}^{-1}$ nos sedimentos referentes ao PEMLS, zona marinha adjacente e baia de Santos (FIG 34). Nos sedimentos do PEMLS as concentrações variaram de 3,52 a $6,09 \mu \mathrm{g} \mathrm{g}^{-1}$. As maiores concentrações ocorreram no sedimento dos pontos 4 $\left(6,09 \mu \mathrm{g} \mathrm{g}^{-1}\right), 5\left(5,50 \mu \mathrm{g} \mathrm{g}^{-1}\right)$ e $3\left(, 68 \mu \mathrm{g} \mathrm{g}^{-1}\right)$. As menores concentrações foram encontradas nos pontos $6\left(3,10 \mu \mathrm{g} \mathrm{g}^{-1}\right)$ e $1\left(3,52 \mu \mathrm{g} \mathrm{g}^{-1}\right)$.

Assim como observado para outros metais, os sedimentos dos pontos 4 e 5 apresentaram as maiores concentrações de $\mathrm{Ni}$ quando comparados com os sedimentos dos outros pontos no interior do PEMLS. Devido aos padrões de correntes predominantes nessa região (HARARI et al., 2001) e as características sedimentológicas desses pontos tais como a alta \% de silte e argila, de $\mathrm{CaCO}_{3}$ e de TOC favorecem o acúmulo de Ni na porção na porção sul da Laje de Santos.

As concentrações de Ni nos sedimentos da área de descarte do material dragado (ponto 7) e na baia de Santos (ponto 8) foram, respectivamente, 9,52 $\mu g g^{-1}$ e $5,54 \mu g g^{-1}$.

Quando comparados com os VGQS, as concentrações de $\mathrm{Ni}$ nos sedimentos não excederam os limites de TEL e PEL. Entretanto, quando comparados com os valores estabelecidos por Choueri et al., (2009) os sedimentos dos pontos 4 e 7 foram classificados como moderadamente poluídos. Os sedimentos dos pontos 5 e 8 apresentaram concentrações de $\mathrm{Ni}$ relativamente elevadas, muito próximas de serem classificadas como moderadamente poluídas, o que representa indícios de contaminação desse metal nos sedimentos do PEMLS. 


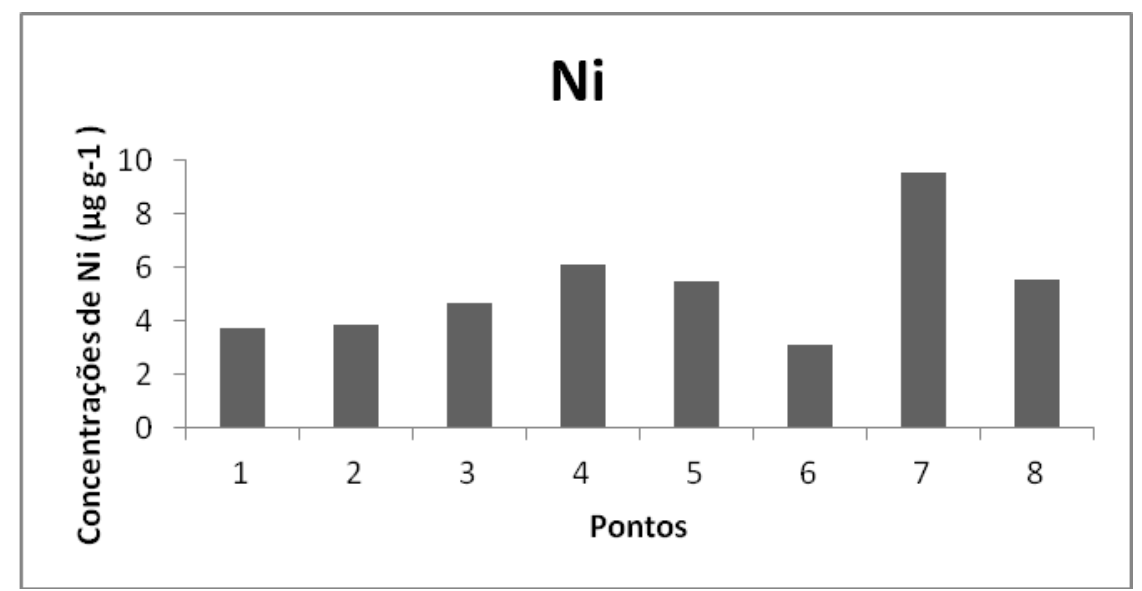

FIGURA 34 Concentração de $\mathrm{Ni}\left(\mu \mathrm{g} \mathrm{g}^{-1}\right)$ nos pontos de coleta.

A concentração de Ni nos sedimentos da baia de Santos encontrada por Lamparelli et al., (2001) e por Abessa (2002), foram similares em $13 \mu \mathrm{g} \mathrm{g}^{-1} \mathrm{e}$ $12,5 \mathrm{\mu g} \mathrm{g}^{-1}$, respectivamente. $\mathrm{Na}$ área de descarte do material dragado foi de $21 \mu \mathrm{g} \mathrm{g}^{-1}$ e $8,1 \mu \mathrm{g} \mathrm{g}^{-1}$, respectivamente. Torres (2007), a partir de coleta realizada em 2005 registrou concentrações de 10,4 $\mu_{\mathrm{g} \mathrm{g}} \mathrm{g}^{-1}$ de $\mathrm{Ni}$ na área de descarte do material dragado. Lia (2008) encontrou valores de $6,9 \mu^{-1} \mathrm{em}$ 2006 e $7,1 \mu \mathrm{g} \mathrm{g}^{-1}$ em 2007, o que sugere uma diminuição dos teores de Ni nos sedimentos dessa região.

De acordo com os resultados do presente estudo, as concentrações de $\mathrm{Ni}$ foram mais baixas na baia de Santos e levemente mais elevadas nos sedimentos da área de descarte do material dragado, quando comparados com os dados da literatura.

A concentração de Ni nos sedimentos da baia de Santos, apresentou-se em aproximadamente $5 \mathrm{\mu g} \mathrm{g}^{-1}$ e aumentou ao chegar à zona de descarte do material dragado $\left(9,52 \mu \mathrm{g} \mathrm{g}^{-1}\right)$. Ao se distanciar da área de descarte do material dragado no caminho até o PEMLS (ponto 6) houve decréscimo de concentração. Ao chegar no PEMLS, ocorreu um aumento nas concentrações, principalmente nos pontos 4 e 5 (6,09 e $5,50 \mathrm{\mu g} \mathrm{g}^{-1}$, respectivamente). 
Portanto, os valores elevados de Ni nos sedimentos do PEMLS sugerem que há uma fonte local influenciando na concentração desse elemento uma vez que as concentrações aumentaram ao chegar no interior do PEMLS. Atividades turísticas e de pesca bem como pelos navios que fundeiam o largo a espera para entrar no porto de Santos podem estar influenciando esse aumento nas concentrações.

\section{Chumbo}

Nos sedimentos do PEMLS, zona marinha adjacente e da baia de Santos os valores das concentrações de $\mathrm{Pb}$ variaram $\angle \mathrm{LD}$ a $8,74 \mu \mathrm{g} \mathrm{g}^{-1}$ (FIG 35). O sedimento do ponto $4\left(8,74 \mu \mathrm{g} \mathrm{g}^{-1}\right)$ apresentou a maior concentração de $\mathrm{Pb}$, seguido do sedimento do ponto $5\left(5,13 \mu \mathrm{g} \mathrm{g}^{-1}\right)$, ambos situados na face sul da Laje de Santos. As menores concentrações foram detectadas nos sedimentos dos pontos 1,2 e 8 , os quais apresentaram valores abaixo do LD do método.

O sedimento do ponto 7 apresentou a concentração de $\mathrm{Pb}$ de $8,36 \mu \mathrm{g} \mathrm{g}^{-1}$ similar a do ponto 4 , o que sugere uma influência da área de descarte do material dragado, ainda que baixa, sobre os sedimentos do PEMLS. Nota-se que no ponto 6 a concentração de $\mathrm{Pb}$ decresce para $4,84 \mu \mathrm{g} \mathrm{g}^{-1}$, voltando a aumentar, o que sugere o transporte pelas correntes de fundo e de sedimento contaminado em direção ao PEMLS, ainda que diluído e sofrendo processos de troca com a coluna d'água. As características sedimentológicas da amostra do ponto 4 favorecem o acúmulo de $\mathrm{Pb}$.

Os teores de $\mathrm{Pb}$ registrados nos sedimentos não excederam os limites de TEL e PEL para nenhum ponto. No entanto, os sedimentos dos pontos 4 e 7 foram classificados como moderadamente poluídos por $\mathrm{Pb}$ de acordo com Choueri et al., (2009) o que reforça a exportação do sedimento contaminado da área de descarte do material dragado. 


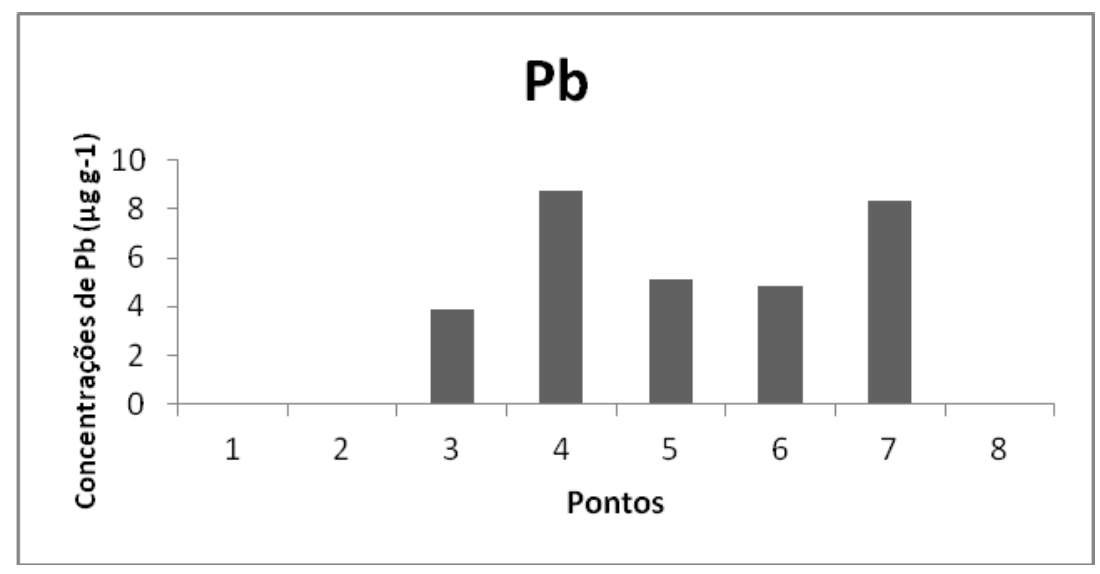

FIGURA 35 Concentração de $\mathrm{Pb}\left(\mu \mathrm{g} \mathrm{g}^{-1}\right)$ nos pontos de coleta.

Estudos pretéritos realizados por Lamparelli et al. (2001) encontraram valores acima dos encontrados no presente estudo, na baia de Santos $(18 \mu \mathrm{g}$ $\mathrm{g}^{-1}$ ) classificados como moderadamente poluídos, e na área de descarte do material dragado a concentração de $\mathrm{Pb}$ foi de $35 \mu \mathrm{g} \mathrm{g}^{-1}$, considerado como sedimentos altamente poluídos.

Abessa (2002) reportou concentrações de $\mathrm{Pb}$ em sedimentos da baia de Santos de $16,8 \mu \mathrm{g} \mathrm{g}^{-1}$, classificado como moderadamente poluído e área de descarte do material dragado de $5,5 \mu \mathrm{g} \mathrm{g}^{-1}$.

Torres (2007) registrou concentrações de $\mathrm{Pb}$ nos sedimentos da área de descarte do material dragado de $27,8 \mu^{-1} \mathrm{~g} \mathrm{~g}^{-1}$ em 2005, sendo os sedimentos considerados como altamente poluídos. Lia (2008) registrou concentrações mais baixas de $\mathrm{Pb}$ nos sedimentos da área de descarte do material dragado, $12 \mu \mathrm{g} \mathrm{g}^{-1}$ em 2006 e 11,5 $\mathrm{\mu g} \mathrm{g}^{-1}$ em 2007, sendo os sedimentos classificados como moderadamente poluídos.

Em comparação com estudos anteriores houveram valores mais baixos nas concentrações de $\mathrm{Pb}$ referentes aos sedimentos da baia de Santos e na área de descarte do material dragado

Sendo assim, os resultados do presente estudo registraram uma concentração relativamente alta nos sedimentos do PEMLS, o que evidencia indícios de impactos negativos para essa região. A concentração relativamente alta no sedimento do ponto 7, diminuição das concentrações de $\mathrm{Pb}$ no ponto 6 
e o aumento nos sedimentos do PEMLS evidenciam a introdução desse elemento por uma fonte local de $\mathrm{Pb}$ para o PEMLS ou através do transporte de sedimentos contaminados através das correntes.

\section{Zinco}

Nos sedimentos do PEMLS, zona marinha adjacente e baia de Santos, as concentrações de $\mathrm{Zn}$ nos sedimentos variaram de 6,03 a 21,1 $\mathrm{gg} \mathrm{g}^{-1}$ (FIG 36). Nos sedimentos do PEMLS as concentrações variaram de 8,03 a $21,1 \mu \mathrm{g}$ $\mathrm{g}^{-1}$. As maiores concentrações ocorreram nas amostras dos pontos $1(21,1 \mu \mathrm{g}$ $\left.g^{-1}\right) 3\left(14,3 \mu g g^{-1}\right)$ e $2\left(14,1 \mu g g^{-1}\right)$.

O ponto 1, localizado no pequeno porto da Laje de Santos, evidenciou a introdução desse elemento pelos barcos que fundeiam essa região para turismo e mergulho subaquático, pois o $\mathrm{Zn}$ é utilizado na composição de tintas anti-incrustante nos cascos das embarcações (Almeida et al., 2007). Os sedimentos dos pontos 2 e 3 também apresentaram concentrações relativamente elevadas e podem estar sendo influenciados por essas atividades, uma vez que as embarcações navegam por toda a área do PEMLS. Os sedimentos dos pontos $6\left(6,03 \mu \mathrm{g} \mathrm{g}^{-1}\right), 4\left(8,03 \mu \mathrm{g} \mathrm{g} \mathrm{g}^{-1}\right)$ e $5\left(8,92 \mu \mathrm{g} \mathrm{g}^{-1}\right)$ apresentaram as menores concentrações de $\mathrm{Zn}$ nos sedimentos.

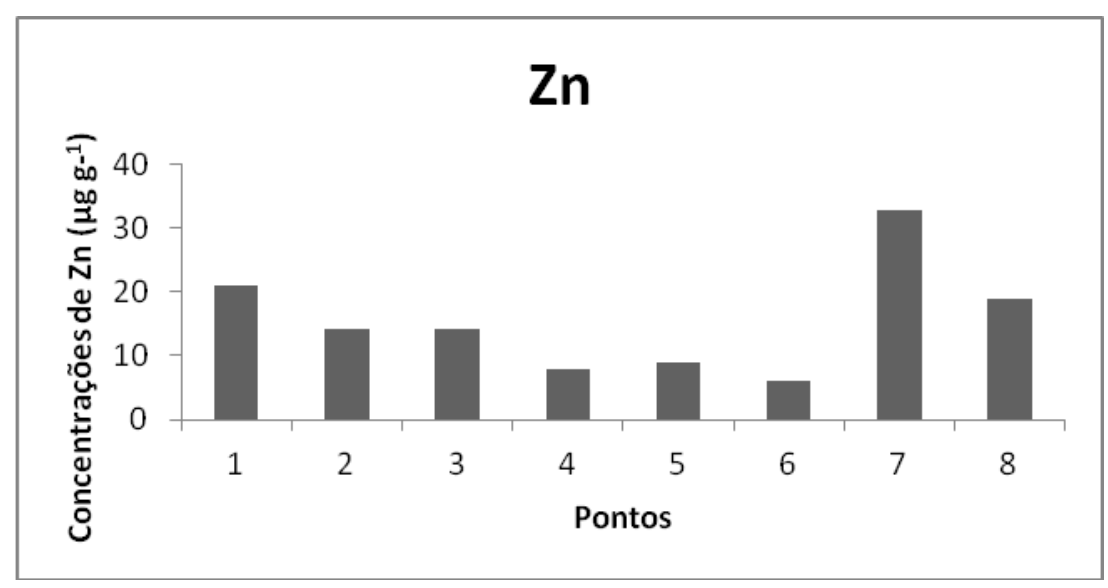

FIGURA 36 Concentração de $\mathrm{Zn}\left(\mu \mathrm{g} \mathrm{g}^{-1}\right)$ nos pontos de coleta. 
As maiores concentrações ocorreram nos sedimentos dos pontos 7 (32,0 $\left.\mu \mathrm{g} \mathrm{g}^{-1}\right)$ e $8\left(18,9 \mu \mathrm{g} \mathrm{g}^{-1}\right)$ evidenciando a influência das atividades antrópicas na região.

De acordo com estudos pretéritos, Lamparelli et al. (2001) encontraram valores de $\mathrm{Zn}$ baia de Santos de $42 \mu \mathrm{g} \mathrm{g}^{-1}$ e de $21 \mu \mathrm{g} \mathrm{g}{ }^{-1}$ na área de descarte do material dragado. Abessa (2002) registrou concentrações de 61,7 $\mu \mathrm{g} \mathrm{g}^{-1} 1 \mathrm{na}$ baia de Santos e de 29,7 $\mathrm{g} \mathrm{g} \mathrm{g}^{-1}$ na área de descarte do material dragado. Torres (2007) registrou concentrações de $\mathrm{Pb}$ nos sedimentos da área de descarte do material dragado de $98,7 \mu \mathrm{g} \mathrm{g}^{-1}$. Lia (2008) registrou concentrações de $\mathrm{Pb}$ de 36,0 $\mathrm{\mu g} \mathrm{g}^{-1}$ em 2006 e 58,8 $\mu \mathrm{g} \mathrm{g}{ }^{-1}$, em 2007.

Em comparação com os estudos anteriores, as concentrações de $\mathrm{Zn}$ nessas regiões foram mais baixas. Vale ressaltar que, as maiores concentrações de $\mathrm{Zn}$ ocorreram nos sedimentos localizados no PEMLS (principalmente ponto 1 , local onde esta localizado o local onde as embarcações atracam conhecido como "Portinho"), o que sugere indícios de contaminação nessa região. Porém, em comparação com ambos os VGQS, nenhum ponto apresentou concentração de $\mathrm{Zn}$ acima dos limites estabelecidos.

Em resumo, na baia de Santos o $\mathrm{Zn}$ apresentou uma concentração de $18,9 \mu \mathrm{g} \mathrm{g}^{-1}$ com aumento de concentrações na área de descarte do material dragado. No caminho até o PEMLS, a concentração de Zn decresceu, conforme observado no sedimento do ponto 6 . Um aumento significativo foi observado nos sedimentos do PEMLS, principalmente no ponto 1 , no pequeno porto da Laje de Santos, o qual apresentou as maiores concentrações.

\subsubsection{Hidrocarbonetos - PEMLS, Zona Marinha Adjacente e Baia de Santos}

\subsubsection{Hidrocarbonetos Alifáticos}

Os HA totais em sedimentos incluem todos os compostos resolvidos da fração 1 , principalmente n-alcanos e isoprenóides e da mistura complexa não 
resolvida (MCNR). As concentrações de hidrocarbonetos alifáticos nos sedimentos do PEMLS, zona marinha adjacente e Baia de Santos estão apresentadas na TAB 18.

As concentrações de HA totais, no geral, apresentaram-se baixas, variando de 0,564 a $1,813 \mu \mathrm{g} \mathrm{g}^{-1}$. As concentrações nos sedimentos do interior do PEMLS variaram de 0,564 a $0,895 \mathrm{\mu g} \mathrm{g}^{-1}$, sendo observadas as maiores concentrações nos pontos 2 e 5 . O ponto 7 apresentou a maior concentração de HA totais evidenciando a introdução desses compostos provenientes dos sedimentos dragados do SESSV. No ponto 8 a concentração de HA totais foi de $0,729 \mu \mathrm{g} \mathrm{g}^{-1}$ o que indica a introdução desses compostos de origem natural como a mata atlântica e os manguezais situado no SESSV ou das atividades industriais situadas na região.

Abessa (2002) encontrou concentração de HA totais de $13,12 \mu \mathrm{g} \mathrm{g}^{-1} \mathrm{em}$ sedimentos da baia de Santos e de $1,71 \mu \mathrm{g} \mathrm{g}^{-1} \mathrm{em}$ sedimentos próximos à área de descarte do material dragado. Medeiros e Bicego, (2004) encontraram valores de 9,23 $\mathrm{mg} \mathrm{g}^{-1}$ nos sedimentos da baia de Santos e a presença de MCNR foi detectada. Sendo assim, no presente trabalho, os valores registrados para as concentrações de HA nos sedimentos da baia de Santos e área de descarte do material dragado foram levemente maiores dos que os reportados na literatura.

Para auxiliar na determinação da origem do HA, avaliar o grau de contaminação petrogênica e o estado de degradação desses compostos nas amostras de sedimentos dos locais estudados, foram utilizadas algumas razões entre compostos e parâmetros descritos no item 4.8.4.1. Vale ressaltar que as razões foram calculadas somente para os compostos que apresentaram concentrações acima do LD do método. 
TABELA 18 Concentrações de n-Alcanos, isoprenóides, MCNR, HA resolvidos e HA totais $\left(\mu \mathrm{g} \cdot \mathrm{g}^{-1}\right)$ e razões entre os compostos.

\begin{tabular}{|c|c|c|c|c|c|c|c|c|}
\hline Composto /Pontos & 1 & 2 & 3 & 4 & 5 & 6 & 7 & 8 \\
\hline C12 & $<0.003$ & $<0.003$ & $<0.003$ & $<0.003$ & $<0.003$ & $<0.003$ & 0,004 & $<0.003$ \\
\hline C13 & $<0.001$ & $<0.001$ & $<0.001$ & $<0.001$ & $<0.001$ & $<0.001$ & $<0.001$ & 0,005 \\
\hline C14 & 0,004 & 0,007 & 0,005 & 0,005 & 0,012 & 0,007 & 0,007 & 0,010 \\
\hline C15 & 0,009 & 0,011 & 0,006 & 0,009 & 0,018 & 0,012 & 0,007 & 0,009 \\
\hline C16 & $<0.001$ & $<0.001$ & $<0.001$ & $<0.001$ & $<0.001$ & $<0.001$ & $<0.001$ & $<0.001$ \\
\hline C17 & 0,044 & 0,014 & 0,008 & 0,008 & 0,019 & 0,015 & 0,011 & 0,011 \\
\hline Pristano & $<0.008$ & $<0.008$ & $<0.008$ & $<0.008$ & 0,012 & 0,008 & 0,008 & $<0.008$ \\
\hline $\mathrm{C} 18$ & 0,004 & 0,009 & $<0.002$ & 0,004 & 0,013 & 0,013 & $<0.002$ & 0,010 \\
\hline Fitano & $<0.002$ & 0,006 & $<0.002$ & $<0.002$ & 0,008 & 0,009 & 0,005 & $<0.002$ \\
\hline C19 & 0,006 & 0,010 & $<0.005$ & $<0.005$ & 0,014 & 0,013 & 0,006 & 0,010 \\
\hline $\mathrm{C} 20$ & $<0.008$ & $<0.008$ & $<0.008$ & $<0.008$ & $<0.008$ & $<0.008$ & $<0.008$ & $<0.008$ \\
\hline C21 & $<0.011$ & 0,017 & $<0.011$ & $<0.011$ & 0,020 & 0,016 & 0,013 & 0,013 \\
\hline C22 & 0,005 & 0,021 & $<0.003$ & 0,007 & 0,030 & 0,024 & 0,007 & 0,022 \\
\hline C23 & 0,008 & 0,036 & $<0.006$ & 0,013 & 0,051 & 0,040 & 0,027 & 0,037 \\
\hline $\mathrm{C} 24$ & 0,009 & 0,043 & $<0.006$ & 0,013 & 0,058 & 0,046 & 0,017 & 0,045 \\
\hline C25 & $<0.027$ & 0,031 & $<0.027$ & $<0.027$ & 0,044 & 0,031 & 0,089 & 0,033 \\
\hline $\mathrm{C} 26$ & 0,007 & 0,016 & $<0.007$ & 0,009 & 0,02 & 0,017 & 0,021 & 0,016 \\
\hline C27 & $<0.034$ & $<0.034$ & $<0.034$ & $<0.034$ & $<0.034$ & $<0.034$ & 0,116 & $<0.034$ \\
\hline C28 & $<0.034$ & $<0.034$ & $<0.034$ & $<0.034$ & $<0.034$ & $<0.034$ & 0,036 & $<0.034$ \\
\hline C29 & $<0.028$ & $<0.028$ & $<0.028$ & $<0.028$ & 0,028 & $<0.028$ & 0,207 & $<0.028$ \\
\hline C30 & $<0.028$ & $<0.028$ & $<0.028$ & $<0.028$ & $<0.028$ & $<0.028$ & 0,038 & $<0.028$ \\
\hline C31 & $<0.026$ & $<0.026$ & $<0.026$ & $<0.026$ & $<0.026$ & $<0.026$ & 0,154 & $<0.026$ \\
\hline C32 & $<0.026$ & $<0.026$ & $<0.026$ & $<0.026$ & $<0.026$ & $<0.026$ & 0,032 & $<0.026$ \\
\hline C33 & $<0.012$ & 0,012 & 0,013 & 0,015 & 0,020 & $<0.012$ & 0,087 & $<0.012$ \\
\hline C34 & $<0.012$ & $<0.012$ & $<0.012$ & $<0.012$ & $<0.012$ & $<0.012$ & $<0.012$ & $<0.012$ \\
\hline C35 & $<0.012$ & $<0.012$ & $<0.012$ & $<0.012$ & 0,016 & $<0.012$ & 0,025 & $<0.012$ \\
\hline Alifáticos totais & 0,682 & 0,786 & 0,564 & 0,639 & 0,895 & 0,727 & 1,813 & 0,729 \\
\hline Alifáticos resolvidos & 0,682 & 0,786 & 0,564 & 0,639 & 0,895 & 0,727 & 1,813 & 0,729 \\
\hline n-Alcanos totais & 0,096 & 0,228 & 0,031 & 0,082 & 0,364 & 0,235 & 0,905 & 0,221 \\
\hline Pristano/Fitano & n.c & n.c & n.c & n.c & 1,52 & 1,62 & 0,88 & n.c \\
\hline Pristano/C17 & n.c & n.c & n.c & n.c & 0,62 & 0,53 & 0,78 & n.c \\
\hline Fitano/C18 & n.c & 0,67 & n.c & n.c & 0,57 & 0,72 & n.c & n.c \\
\hline MCNR & $<5.337$ & $<5.337$ & $<5.337$ & $<5.337$ & $<5.337$ & $<5.337$ & $<5.337$ & $<5.337$ \\
\hline
\end{tabular}

De acordo com Volkman et al. (1992) e Readman et al. (2002), sedimentos estuarinos e marinhos não poluídos apresentam a concentraçãp de HA totais inferior a $10 \mu \mathrm{g} \mathrm{g}^{-1}$. Em nenhum ponto a concentração de $\mathrm{HA}$ totais foi superior a $10 \mu \mathrm{g} \mathrm{g}^{-1}$. A inexistencia da MCNR e os valores de HA totais abaixo de $10 \mu \mathrm{g} \mathrm{g}^{-1}$ sugerem que os sedimentos estão classificados como não poluídos por HA. 
De acordo com os resultados da razão pristano/fitano o sedimento do ponto 5, localizado no PEMLS apresentou o valor de 1,52, o sedimento do ponto $6,1,62$ e do ponto 7 de 0,88 . Esses resultados indicam a predominância de hidrocarbonetos de origem petrogênica, o que sugere que há a introdução de petróleo nos sedimentos do PEMLS provavelmente originária das embarcações que frequentam o local.

Os valores da razão pristano/n-C17 nos locais estudados, foram de 0,62 no sedimento do ponto 5 , de 0,53 no sedimento do ponto 6 e 0,78 no sedimento do ponto 7. Para a razão fitano/n-C18 os valores foram de 0,67 nos sedimentos do ponto 2 , de 0,57 no sedimento do ponto 5 e 0,72 no sedimentos do ponto 6 . Esses resultados indicam, principalmente, a introdução recente de petróleo nos sedimentos dessas regiões, uma vez que as taxas microbianas de decomposição influenciam positivamente essa razão para valores acima de 1. Vale ressaltar que apesar disso os valores são baixos, portanto essa influência é relativamente baixa.

A introdução desses compostos nos sedimentos do PEMLS pode ser oriunda de fontes naturais como os produtores primários ou de embarcações turísticas que frequentam o local.

Os HA totais, em resumo, apresentaram uma maior concentração na área de descarte do material dragado devido ao sedimento ser dragado do estuário, porém não se observou um gradiente de contaminação evidente desde a zona costeira até o PEMLS.

\subsubsection{Hidrocarbonetos Policíclicos Aromáticos - PEMLS, Zona Marinha Adjacente e Baia de Santos}

As concentrações dos HPA totais e individuais analisados nos sedimentos do PEMLS, zona marinha adjacente e baia de Santos estão expressas na TAB 19. A concentração de HPA totais nos sedimentos variaram de $<$ LD a 95,1 ng $g^{-1}$. 
Nos sedimentos do interior do PEMLS, as concentrações de HPA totais variaram de $<1,0$ a $16,5 \mathrm{ng} \mathrm{g}^{-1}$. As maiores concentrações ocorreram nos sedimentos do ponto 5 (16,5 $\left.\mathrm{ng} \mathrm{g}^{-1}\right)$, com a contribuição dos compostos trimetilnaftaleno $\left(2,13 \mathrm{ng} \mathrm{g}^{-1}\right)$, pireno $\left(1,41 \mathrm{ng} \mathrm{g}^{-1}\right)$ e reteno $\left(12,87 \mathrm{ng} \mathrm{g}^{-1}\right)$, o que sugere que as características sedimentológicas e o regime das correntes favorecem o acúmulo desses compostos nos sedimentos desse ponto. O ponto 2 apresentou concentração de HPA totais nos sedimentos de 5,64 $\mathrm{ng} \mathrm{g}^{-1}$, o trimetilnaftaleno contribuiu com $1,38 \mathrm{ng} \mathrm{g}^{-1}$ e o reteno com 4, $26 \mathrm{ng} \mathrm{g}^{-1}$. No sedimento do ponto 4 somente o reteno apresentou a concentração acima do LD do método apresentando a concentração de HPA totais de $2,65 \mathrm{ng} \mathrm{g}^{-1}$.

O sedimento do ponto 6 apresentou $8,61 \mathrm{ng} \cdot \mathrm{g}^{-1}$ de HPA totais nos sedimentos constituídos por trimetilnaftaleno $\left(1,55 \mathrm{ng} \mathrm{g}^{-1}\right)$ e reteno $\left(7,11 \mathrm{ng} \mathrm{g}^{-1}\right)$, o que sugere um aporte desses compostos nesse ponto, provavelmente provenientes da zona costeira.

Os sedimentos do ponto 7 , provenientes da área de descarte do material dragado, apresentou a maior concentração de HPA totais $\left(95,1 \mathrm{ng} \mathrm{g}^{-1}\right) \mathrm{com}$ a predominância dos compostos: perileno (16,58 $\left.\mathrm{ng} \mathrm{g}^{-1}\right)$, seguido pelo benzo[b]fluoranteno $\left(8,70 \mathrm{ng} \mathrm{g}^{-1}\right)$, indeno[1,2,3-cd]pireno $\left(8,19 \mathrm{ng} \mathrm{g}^{-1}\right)$, o benzo[a]pireno $\left(8,04 \mathrm{ng} \mathrm{g}^{-1}\right)$. Os demais HPA ficaram abaixo de $8 \mathrm{ng} \mathrm{g}^{-1}$. Pelo fato dos HPA de alto peso molecular não se degradarem facilmente e serem mais resistentes no meio aquático, apresentaram as maiores concentrações e foram os que predominaram nos sedimentos da área de descarte do material dragado. A origem pirolítica dos HPA é confirmada pela alta concentração de perileno nos sedimentos, devido a contribuição significativa proveniente dos manguezais na região. A contaminação por HPA nos sedimentos do canal do porto de Santos é muito elevada e refletem nas concentrações descritas acima pelo fato desses sedimentos serem descartados nesse local causando impactos negativos nessa região.

No sedimento do ponto 8 o valor de HPA totais foi de $7,14 \mathrm{ng} \mathrm{g}^{-1}$, inferior aquele encontrado nos sedimentos dos pontos 5 e 6 e os compostos foram 0 trimetilnaftaleno e o reteno $\left(2,23\right.$ e $4,91 \mathrm{ng} \mathrm{g}^{-1}$, respectivamente). 
Os compostos que predominaram nos sedimentos do PEMLS e das demais regiões foram o trimeltilnaftaleno e o reteno.

O trimetilnaftaleno está presente na maioria dos tipos de petróleo e seus derivados apresentam altas concentrações de HPAs alquilados, desta forma estes compostos são utilizados como indicadores da introdução de combustíveis fósseis, no entanto, menos frequentemente, também podem estar associados a processos de queima envolvendo carvão e biomassa vegetal (YUNKER et al., 2002).

O reteno tem sido proposto como marcador molecular de queima de biomassa vegetal, além disso, também pode ser formado por processos de diagênese de precursores naturais (LIU et al., 2008).

A origem do trimetilnaftaleno para os sedimentos do PEMLS está associada a introdução de petróleo pelos barcos que frequentam o PEMLS e em menor proporção, pela queima de biomassa vegetal que atinge o PEMLS através do transporte atmosfétrico.

A origem do reteno para os sedimentos do PEMLS e outras regiões está associada, em maior proporção, a produção natural pelo processo de diagênese e também proveniente do transporte atmosférico da combustão de biomassa vegetal nas industrias presentes no SESSV.

Lamparelli et al., (2001) registrou concentrações de HPA totais nos sedimentos da baia de Santos de 49,80 $\mathrm{ng} \mathrm{g}^{-1}$. Abessa (2002) encontrou concentrações de HPA totais mais elevadas $\left(511 \mathrm{ng} \mathrm{g}^{-1}\right)$, nos sedimentos da baia de Santos. 
TABELA 19 Concentrações de HPA (ng g ${ }^{-1}$ ) em amostras de sedimento do PEMLS, zona marinha adjacente e baia de Santos e razoes entre os compostos. N.C- Não Calculado

\begin{tabular}{|c|c|c|c|c|c|c|c|c|}
\hline Compoto/Pontos & 1 & 2 & 3 & 4 & 5 & 6 & 7 & 8 \\
\hline naftaleno & $<\mathrm{LD}$ & $<\mathrm{LD}$ & $<L D$ & $<\mathrm{LD}$ & $<\mathrm{LD}$ & $<\mathrm{LD}$ & $<\mathrm{LD}$ & $<L D$ \\
\hline metilnaftaleno & $<\mathrm{LD}$ & $<L D$ & $<\mathrm{LD}$ & $<\mathrm{LD}$ & $<\mathrm{LD}$ & $<\mathrm{LD}$ & $<\mathrm{LD}$ & $<L D$ \\
\hline bifenil & $<\mathrm{LD}$ & $<L D$ & $<L D$ & $<\mathrm{LD}$ & $<\mathrm{LD}$ & $<\mathrm{LD}$ & $<\mathrm{LD}$ & $<L D$ \\
\hline etilnaftaleno & $<\mathrm{LD}$ & $<L D$ & $<L D$ & $<\mathrm{LD}$ & $<\mathrm{LD}$ & $<\mathrm{LD}$ & $<\mathrm{LD}$ & $<L D$ \\
\hline dimetilnaftaleno & $<\mathrm{LD}$ & $<L D$ & $<L D$ & $<\mathrm{LD}$ & $<\mathrm{LD}$ & $<\mathrm{LD}$ & $<\mathrm{LD}$ & $<L D$ \\
\hline acenaftileno & $<\mathrm{LD}$ & $<L D$ & $<L D$ & $<\mathrm{LD}$ & $<\mathrm{LD}$ & $<\mathrm{LD}$ & $<\mathrm{LD}$ & $<L D$ \\
\hline acenafteno & $<\mathrm{LD}$ & $<L D$ & $<L D$ & $<\mathrm{LD}$ & $<\mathrm{LD}$ & $<\mathrm{LD}$ & $<\mathrm{LD}$ & $<L D$ \\
\hline trimetilnaftaleno & $<\mathrm{LD}$ & 1,38 & $<\mathrm{LD}$ & $<\mathrm{LD}$ & 2,13 & 1,5 & $<\mathrm{LD}$ & 2,23 \\
\hline fluoreno & $<\mathrm{LD}$ & $<L D$ & $<L D$ & $<\mathrm{LD}$ & $<\mathrm{LD}$ & $<\mathrm{LD}$ & $<\mathrm{LD}$ & $<L D$ \\
\hline metilfluoreno & $<\mathrm{LD}$ & $<L D$ & $<L D$ & $<\mathrm{LD}$ & $<\mathrm{LD}$ & $<\mathrm{LD}$ & $<\mathrm{LD}$ & $<L D$ \\
\hline dibenzotiofeno & $<\mathrm{LD}$ & $<L D$ & $<L D$ & $<\mathrm{LD}$ & $<\mathrm{LD}$ & $<\mathrm{LD}$ & $<\mathrm{LD}$ & $<L D$ \\
\hline fenantreno & $<\mathrm{LD}$ & $<\mathrm{LD}$ & $<L D$ & $<\mathrm{LD}$ & $<\mathrm{LD}$ & $<\mathrm{LD}$ & $<\mathrm{LD}$ & $<L D$ \\
\hline antraceno & $<\mathrm{LD}$ & $<L D$ & $<L D$ & $<\mathrm{LD}$ & $<\mathrm{LD}$ & $<\mathrm{LD}$ & $<\mathrm{LD}$ & $<L D$ \\
\hline dimetilfluoreno & $<\mathrm{LD}$ & $<L D$ & $<L D$ & $<\mathrm{LD}$ & $<\mathrm{LD}$ & $<\mathrm{LD}$ & $<\mathrm{LD}$ & $<L D$ \\
\hline metildibenzotiofeno & $<\mathrm{LD}$ & $<L D$ & $<L D$ & $<\mathrm{LD}$ & $<\mathrm{LD}$ & $<\mathrm{LD}$ & $<\mathrm{LD}$ & $<L D$ \\
\hline metilfenantreno & $<\mathrm{LD}$ & $<\mathrm{LD}$ & $<L D$ & $<\mathrm{LD}$ & $<\mathrm{LD}$ & $<\mathrm{LD}$ & 2,56 & $<\mathrm{LD}$ \\
\hline dimetildibenzotiofeno & $<\mathrm{LD}$ & $<L D$ & $<L D$ & $<\mathrm{LD}$ & $<\mathrm{LD}$ & $<\mathrm{LD}$ & $<\mathrm{LD}$ & $<L D$ \\
\hline dimetilfenantreno & $<\mathrm{LD}$ & $<L D$ & $<L D$ & $<\mathrm{LD}$ & $<\mathrm{LD}$ & $<\mathrm{LD}$ & $<\mathrm{LD}$ & $<L D$ \\
\hline fluoranteno & $<\mathrm{LD}$ & $<L D$ & $<L D$ & $<\mathrm{LD}$ & $<\mathrm{LD}$ & $<\mathrm{LD}$ & 4,7 & $<L D$ \\
\hline pireno & $<\mathrm{LD}$ & $<L D$ & $<L D$ & $<\mathrm{LD}$ & 1,41 & $<\mathrm{LD}$ & 4,24 & $<L D$ \\
\hline metilfluoranteno & $<\mathrm{LD}$ & $<\mathrm{LD}$ & $<L D$ & $<\mathrm{LD}$ & $<\mathrm{LD}$ & $<\mathrm{LD}$ & 2,89 & $<L D$ \\
\hline reteno & $<\mathrm{LD}$ & 4,26 & $<L D$ & 2,65 & 12,93 & 7,11 & $<\mathrm{LD}$ & 4,91 \\
\hline metilpireno & $<\mathrm{LD}$ & $<L D$ & $<L D$ & $<\mathrm{LD}$ & $<\mathrm{LD}$ & $<L D$ & 2,31 & $<L D$ \\
\hline benzo(c)fenantreno & $<\mathrm{LD}$ & $<L D$ & $<L D$ & $<\mathrm{LD}$ & $<\mathrm{LD}$ & $<L D$ & $<\mathrm{LD}$ & $<L D$ \\
\hline benzo(a)antraceno & $<\mathrm{LD}$ & $<L D$ & $<L D$ & $<\mathrm{LD}$ & $<L D$ & $<L D$ & 2,42 & $<L D$ \\
\hline criseno & $<\mathrm{LD}$ & $<\mathrm{LD}$ & $<L D$ & $<\mathrm{LD}$ & $<\mathrm{LD}$ & $<L D$ & 4,01 & $<L D$ \\
\hline metilcriseno & $<\mathrm{LD}$ & $<L D$ & $<L D$ & $<\mathrm{LD}$ & $<\mathrm{LD}$ & $<L D$ & 5,84 & $<L D$ \\
\hline dimetilcriseno & $<\mathrm{LD}$ & $<L D$ & $<L D$ & $<\mathrm{LD}$ & $<\mathrm{LD}$ & $<L D$ & 3,99 & $<L D$ \\
\hline benzo[b]fluoranteno & $<\mathrm{LD}$ & $<\mathrm{LD}$ & $<L D$ & $<\mathrm{LD}$ & $<\mathrm{LD}$ & $<L D$ & 8,7 & $<L D$ \\
\hline benzo[j]fluoranteno & $<\mathrm{LD}$ & $<L D$ & $<L D$ & $<\mathrm{LD}$ & $<\mathrm{LD}$ & $<L D$ & 1,85 & $<L D$ \\
\hline benzo[k]fluoranteno & $<\mathrm{LD}$ & $<L D$ & $<L D$ & $<\mathrm{LD}$ & $<\mathrm{LD}$ & $<L D$ & 3,9 & $<L D$ \\
\hline benzo[e]pireno & $<\mathrm{LD}$ & $<\mathrm{LD}$ & $<L D$ & $<\mathrm{LD}$ & $<\mathrm{LD}$ & $<\mathrm{LD}$ & 5,85 & $<\mathrm{LD}$ \\
\hline benzo[a]pireno & $<L D$ & $<L D$ & $<L D$ & $<L D$ & $<L D$ & $<L D$ & 8,04 & $<L D$ \\
\hline $\begin{array}{l}\text { perileno } \\
\text { indeno[1,2,3- }\end{array}$ & $<\mathrm{LD}$ & $<\mathrm{LD}$ & $<L D$ & $<\mathrm{LD}$ & $<L D$ & $<L D$ & 16,58 & $<\mathrm{LD}$ \\
\hline c,d]pireno & $<\mathrm{LD}$ & $<\mathrm{LD}$ & $<L D$ & $<\mathrm{LD}$ & $<L D$ & $<L D$ & 8,19 & $<L D$ \\
\hline dibenzo[a,h]antraceno & $<\mathrm{LD}$ & $<\mathrm{LD}$ & $<L D$ & $<\mathrm{LD}$ & $<L D$ & $<L D$ & 1,89 & $<L D$ \\
\hline benzo[b]criseno & $<\mathrm{LD}$ & $<L D$ & $<L D$ & $<\mathrm{LD}$ & $<L D$ & $<L D$ & 1,65 & $<L D$ \\
\hline benzo[g,h,i]perileno & $<\mathrm{LD}$ & $<L D$ & $<L D$ & $<\mathrm{LD}$ & $<L D$ & $<L D$ & 5,46 & $<L D$ \\
\hline coroneno & $<\mathrm{LD}$ & $<L D$ & $<L D$ & $<\mathrm{LD}$ & $<L D$ & $<L D$ & $<\mathrm{LD}$ & $<L D$ \\
\hline HPA totais & $<$ LD & 5,64 & $<L D$ & 2,65 & 16,5 & 8,61 & 95,1 & 7,14 \\
\hline Ant/178 & N.C & N.C & N.C & N.C & N.C & N.C & N.C & N.C \\
\hline $\mathrm{BaA} / 228$ & N.C & N.C & N.C & N.C & N.C & N.C & 0,37 & N.C \\
\hline IP/IP+BghiP & N.C & N.C & N.C & N.C & N.C & N.C & 0,60 & N.C \\
\hline $\mathrm{Fl} / \mathrm{FI}+\mathrm{Py}$ & N.C & N.C & N.C & N.C & N.C & N.C & 0,52 & N.C \\
\hline
\end{tabular}


No estudo conduzido por Medeiros e Bicego (2004), os HPA totais ocorreram em concentrações similares às encontradas por Abessa (2002), 394 $\mathrm{ng} \mathrm{g}^{-1}$. Em comparação com dados anteriores, os valores da concentração de HPA totais nos sedimentos da baia de Santos foram baixos.

$\mathrm{Na}$ área de descarte do material dragado, as concentrações de HPA totais encontradas por Lamparelli et al., (2001), foram as mais elevadas já registradas no local, atingindo $4816 \mathrm{ng} \mathrm{g}^{-1}$. Abessa (2002) registrou valores mais baixos nesses sedimentos $\left(1 \mathrm{ng} \mathrm{g}^{-1}\right)$. Essa diferença significativa na concentração de HPA totais nos sedimentos da área de descarte do material dragado entre os dois estudo pode ser explicada pela diferenças na amostragem e metodologias analíticas. Em 2005, Torres (2007) realizou uma única campanha nessa região e encontrou concentrações de HPA totais mais altas nos sedimentos, registrando a concentração de 414,1 $\mathrm{ng} \mathrm{g}^{-1}$. Lia (2008) em duas campanhas de amostragem na área de descarte registrou concentrações de 576,6 $\mathrm{ng} \mathrm{g}^{-1}$ em 2006 e 383,4 ng g $^{-1}$, em 2007.

O presente estudo registrou níveis mais baixos de HPA totais nos sedimentos da baia de Santos e da área de descarte do material dragado em comparação com estudos anteriores e a predominância de HPA de alto peso molecular o que indica a origem de processos industriais de combustão/pirólise de combustíveis fósseis, biomassa vegetal e carvão (YUNKER et AL., 2002). Esses compostos apresentam menor toxicidade aguda em relação aos HPA de menor massa molecular, no entanto muitos desses compostos são carcinogênicos, representando sérios riscos ao ambiente (WALKER, 2009).

Quando comparados com os VGQS estabelecidos pelo CCME (2002) e por Choueri et al., (2009), nenhuma das concentrações de HPA individuais e totais apresentaram-se acima dos valores estipulados. Assim, efeitos biológicos adversos aos organismos não são esperados em relação a esses compostos nesses pontos.

Os HPA em síntese apresentaram-se mais elevados na área de descarte do material dragado e decresceram nas concentrações do ponto 6. No PEMLS o ponto 5 demonstrou um aumento na concentração, porem não foi observado 
um gradiente evidente da contaminação por HPA desde a zona costeira até o PEMLS.

\subsubsection{Análise Estatística e Multivariada}

\subsubsection{Correlação de Pearson}

A matriz de correlação de Pearson entre os metais, hidrocarbonetos e parâmetros sedimentológicos está expressa na TAB 20. Em geral todos os metais, HA totais e HPA totais apresentaram correlações fortes entre si.

O Mn se correlacionou fortemente com o $\mathrm{Al}, \mathrm{Cr}, \mathrm{Cu}, \mathrm{Ni}, \mathrm{Pb}, \mathrm{HA}$ totais, HPA totais e M.O. Os HA totais se correlacionaram com todos os metais, com exceção do Pb, HPA totais e MO. Uma correlação forte também foi observada entre os HPA totais, os metais, HA totais e M.O. O Pb apresentou correlação forte somente com o Mn, Ni e os HPA totais.

TABELA 20 Correlação de Pearson entre os metais hidrocarbonetos e parâmetros sedimentológicos, analisados nos sedimentos do PEMLS, zona marinha adjacente e baia de Santos $(n=8)$

\begin{tabular}{|c|c|c|c|c|c|c|c|c|c|c|c|c|c|c|c|c|c|}
\hline & Al & $\mathrm{Fe}$ & Co & $\mathrm{Cr}$ & $\mathrm{Cu}$ & $\mathrm{Hg}$ & $\mathrm{Mn}$ & $\mathrm{Ni}$ & $\mathrm{Pb}$ & $\mathrm{Zn}$ & $\begin{array}{l}\mathrm{HA} \\
\text { totais }\end{array}$ & $\begin{array}{l}\text { HPA } \\
\text { totais }\end{array}$ & $\%$ Areia & $\begin{array}{c}\% \\
\text { silte e } \\
\text { argila }\end{array}$ & TOC & M.O & $\mathrm{CaCO}_{3}$ \\
\hline Al & 1 & --- & --- & --- & --- & --- & --- & --- & --- & --- & --- & --- & --- & --- & --- & --- & --- \\
\hline $\mathrm{Fe}$ & 0.920 & 1.000 & --- & --- & --- & --- & --- & --- & --- & --- & --- & --- & --- & --- & --- & --- & --- \\
\hline Co & 0.880 & 0.928 & 1.000 & --- & --- & --- & --- & --- & --- & --- & --- & --- & --- & --- & --- & --- & --- \\
\hline $\mathrm{Cr}$ & 0.946 & 0.919 & 0.859 & 1.000 & -- & -- & --- & --- & --- & --- & --- & --- & -- & --- & --- & --- & --- \\
\hline $\mathrm{Cu}$ & 0.878 & 0.765 & 0.678 & 0.908 & 1.000 & --- & --- & --- & --- & --- & --- & --- & --- & --- & --- & --- & --- \\
\hline $\mathrm{Hg}$ & 0.900 & 0.713 & 0.741 & 0.851 & 0.793 & 1.000 & --- & --- & --- & --- & --- & --- & --- & --- & --- & --- & --- \\
\hline $\mathrm{Mn}$ & 0.522 & 0.462 & 0.312 & 0.538 & 0.597 & 0.309 & 1.000 & --- & --- & --- & --- & --- & --- & --- & --- & --- & --- \\
\hline $\mathrm{Ni}$ & 0.901 & 0.852 & 0.744 & 0.951 & 0.910 & 0.748 & 0.743 & 1.000 & --- & --- & --- & --- & --- & --- & --- & --- & --- \\
\hline $\mathrm{Pb}$ & 0.445 & 0.263 & 0.239 & 0.467 & 0.388 & 0.473 & 0.648 & 0.623 & 1.000 & --- & --- & --- & --- & --- & --- & --- & --- \\
\hline $\mathrm{Zn}$ & 0.768 & 0.744 & 0.768 & 0.807 & 0.839 & 0.723 & 0.129 & 0.663 & $0 . \overline{023}$ & 1.000 & --- & --- & --- & --- & --- & --- & --- \\
\hline HA totais & 0.882 & 0.796 & 0.885 & 0.849 & 0.816 & 0.763 & 0.554 & 0.833 & 0.454 & 0.746 & 1.000 & --- & -- & --- & --- & --- & --- \\
\hline HPA totais & 0.913 & 0.816 & 0.896 & 0.886 & 0.826 & 0.824 & 0.535 & 0.860 & 0.516 & 0.747 & 0.992 & 1.000 & --- & --- & --- & --- & --- \\
\hline \%Areia & 0.474 & 0.530 & 0.590 & 0.307 & 0.041 & 0.452 & $0 . \overline{267}$ & 0.133 & 0.055 & 0.257 & 0.265 & 0.316 & 1.000 & --- & --- & --- & --- \\
\hline $\begin{array}{l}\% \text { silte e } \\
\text { argila }\end{array}$ & 0.510 & 0.559 & $0 . \overline{6} 21$ & $0 . \overline{344}$ & $0 . \overline{-}$ & $0 . \overline{485}$ & 0.241 & $0 . \overline{171}$ & 0.031 & $0 . \overline{291}$ & $0 . \overline{306}$ & $0 . \overline{357}$ & -0.999 & 1.000 & --- & --- & --- \\
\hline TOC & $0 . \overline{493}$ & $0 . \overline{594}$ & 0.668 & 0.376 & 0.080 & $0 . \overline{423}$ & 0.248 & 0.214 & $0 . \overline{-}$ & 0.321 & $0 . \overline{343}$ & $0 . \overline{392}$ & -0.963 & 0.966 & 1.000 & --- & --- \\
\hline M.O & 0.643 & 0.648 & 0.585 & 0.700 & 0.834 & 0.389 & 0.636 & 0.775 & 0.215 & 0.715 & 0.768 & 0.718 & -0.186 & 0.150 & 0.065 & 1.000 & --- \\
\hline $\mathrm{CaCO}_{3}$ & $\begin{array}{c}- \\
0.478\end{array}$ & $\begin{array}{c}- \\
0.534\end{array}$ & $\begin{array}{c}- \\
0.596\end{array}$ & $\begin{array}{c}- \\
0.311\end{array}$ & 0.045 & $\begin{array}{c}- \\
0.454\end{array}$ & 0.265 & $0 . \overline{-}$ & 0.055 & $0 . \overline{263}$ & $\begin{array}{c}- \\
0.272\end{array}$ & $\begin{array}{c}- \\
0.322\end{array}$ & -1.000 & 0.999 & 0.964 & 0.180 & 1 \\
\hline
\end{tabular}


Os parâmetros sedimentológicos apresentaram algumas correlações significativas com alguns metais, hidrocarbonetos e características sedimentológicas. A \% areia apresentou correlação significativa com o $\mathrm{Fe}, \mathrm{Co}$, \%silte e argila e TOC . A \% silte e argila apresentou correlação forte com ○ Al,

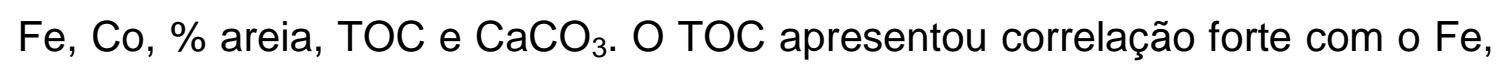
Co, \% areia, \% silte e argila e $\mathrm{CaCO}_{3}$. A M.O apresentou correlação forte com todos os metais e HA e HPA, com exceção do $\mathrm{Hg}$, do $\mathrm{Pb}$ e de todos os parâmetros sedimentológicos. $\mathrm{O} \mathrm{CaCO}_{3}$ apresentou correlação forte somente com o $\mathrm{Fe}, \mathrm{Co}, \mathrm{TOC}$ e com a $\%$ silte e argila. Importante ressaltar que parte significativa de $\mathrm{TOC}$ é $\mathrm{CaCO}_{3}$ e por isso que o TOC não se correlaciona com a M.O.

Analisando-se o conjunto de dados da correlação entre duas variáveis (TAB 10), nota-se similaridades no comportamento de pares de variáveis, mas não se identifica grupos de elementos com comportamento similar. Por isso foi utilizado a ACP, que é apropriada para se estudar as inter-relações entre as variáveis e também o comportamento geral dos dados.

\subsubsection{Análise de Componentes Principais}

Fazendo-se a análise das variâncias pelos parâmetros, cada componente principal apresenta uma variância distinta, cumulativa de componente para componente. Pela TAB 21, podemos observar que a variabilidade original foi sintetizada em 7 componentes principais das 8 amostras de sedimento. Desses componentes, o primeiro (CP1) sintetiza $65,16 \%$ das informações originais, o segundo (CP2) $14,55 \%$ e o terceiro (CP3) $12,47 \%$. Os 3 primeiros componentes somados explicam $92,18 \%$ da variabilidade dos dados. Somente eles podem ser usados para uma análise, pois apresentam uma \% de variância acima ou próxima de 10 \%, e o autovalor acima de 1. 
Do quarto componente em diante, podemos desprezá-los por apresentarem valores muito pequenos para que possam explicar alguma variabilidade, sendo considerados como resíduos de variância (Hortellani et al., 2008).

TABELA 21 Autovalor, \% de variância, Autovalor acumulativo e \% acumulativa referente a cada componente gerada

Matriz de Correlação e estatística relacionada PEMLS, zona marinha adjacente e baia de Santos

\begin{tabular}{ccccc}
\hline Número & Autovalor & $\begin{array}{c}\text { \% total de } \\
\text { variância }\end{array}$ & $\begin{array}{c}\text { Autovalor } \\
\text { acumulativo }\end{array}$ & $\begin{array}{c}\% \\
\text { acumulativa }\end{array}$ \\
\hline 1 & 11,077 & 65,164 & 11,077 & 65,164 \\
2 & 2,474 & 14,557 & 13,552 & 79,722 \\
3 & 2,120 & 12,474 & 15,673 & 92,196 \\
4 & 0,645 & 3,796 & 16,318 & 95,992 \\
5 & 0,309 & 1,818 & 16,627 & 97,810 \\
6 & 0,256 & 1,507 & 16,884 & 99,318 \\
7 & 0,115 & 0,682 & 17,000 & 100,000 \\
\hline
\end{tabular}

Analisando-se os dados da TAB 22, verifica-se que o eixo 1 da ACP mostrou correlações negativas com a maioria dos metais (exceto $\mathrm{Pb}$ ), M.O, silte-argila, HA e HPA, além de correlação positiva com a \% areia. Isto explica o porquê deste componente principal sintetizar cerca de $65,16 \%$ das informações sobre variabilidade e mostra a associação entre os contaminantes e finos. $\mathrm{O}$ eixo 2 apresentou correlação com o $\mathrm{Mn}, \mathrm{Pb}$, TOC e $\mathrm{CaCO}_{3}$, indicando associação entre essas variáveis. Por fim o eixo 3 , o menos significativo dos componentes principais, mas que ainda assim, caracteriza 0 sedimento, mostrou correlação positiva com o $\mathrm{Pb}$ e $\%$ areia e negativa com $\%$ silte-argila. 
TABELA 22 Correlação das variáveis (metais hidrocarbonetos e parâmetros sedimentológicas) com cada componente principal.

\begin{tabular}{ccc}
\hline Variável & Fator 1 & Fator 2 \\
\hline $\mathrm{Al}$ & -0.97 & -0.03 \\
$\mathrm{Cr}$ & -0.95 & 0.08 \\
$\mathrm{Cu}$ & -0.91 & 0.29 \\
$\mathrm{Co}$ & -0.89 & -0.29 \\
$\mathrm{Fe}$ & -0.89 & -0.16 \\
$\mathrm{Hg}$ & -0.89 & -0.06 \\
$\mathrm{Mn}$ & -0.48 & 0.71 \\
$\mathrm{Ni}$ & -0.90 & 0.32 \\
$\mathrm{~Pb}$ & -0.42 & 0.53 \\
$\mathrm{Zn}$ & -0.84 & -0.16 \\
$\mathrm{HA}$ totais & -0.97 & 0.03 \\
$\mathrm{HPA}$ totais & -0.95 & 0.06 \\
\%TOC & -0.43 & 0.80 \\
M.O & -0.97 & 0.03 \\
CaCO & -0.38 & 0.82 \\
\%silte+argila & -0.65 & -0.03 \\
\%areia & -0.65 & 0.03
\end{tabular}

Com relação aos pontos (casos), de acordo a TAB 23 os pontos 1, 2, 4, 5, e 7 foram explicados pela CP1. A CP2 concentrou informações sobre os pontos 3, 4, 5, 6 e 8 e a PC3 reuniu informações sobre os pontos 1, 2 e 6. A partir destas coordenadas podemos construir um gráfico bidimensional CP1 $\mathrm{x}$ CP2, (FIG 37), que representa a distribuição dos sedimentos explicada pelos componentes principais mais significativos. 
TABELA 23 Correlação dos pontos amostrais com cada componente principal.

\begin{tabular}{ccc}
\hline Pontos & Fator 1 & Fator 2 \\
\hline 2 & 1.67 & 0.26 \\
3 & 1.06 & -0.51 \\
4 & 0.38 & -0.80 \\
5 & 1.33 & 2.34 \\
6 & 1.21 & 2.11 \\
7 & 2.43 & -1.72 \\
8 & -8.01 & 0.15 \\
\hline
\end{tabular}

Com a distribuição dos casos estudados em CP1 x CP2, podemos notar claramente a separação entre a área de descarte do material dragado (ponto 7) pelo fato de apresentar as maiores concentrações de metais e hidrocarbonetos, evidenciando ser o local mais impactado. Um agrupamento formado pelos pontos 4 e 5 foi observado por representarem pontos com uma alta porcentagem de TOC (>8,0\%) e $\mathrm{CaCO}_{3}(>15 \%)$. 


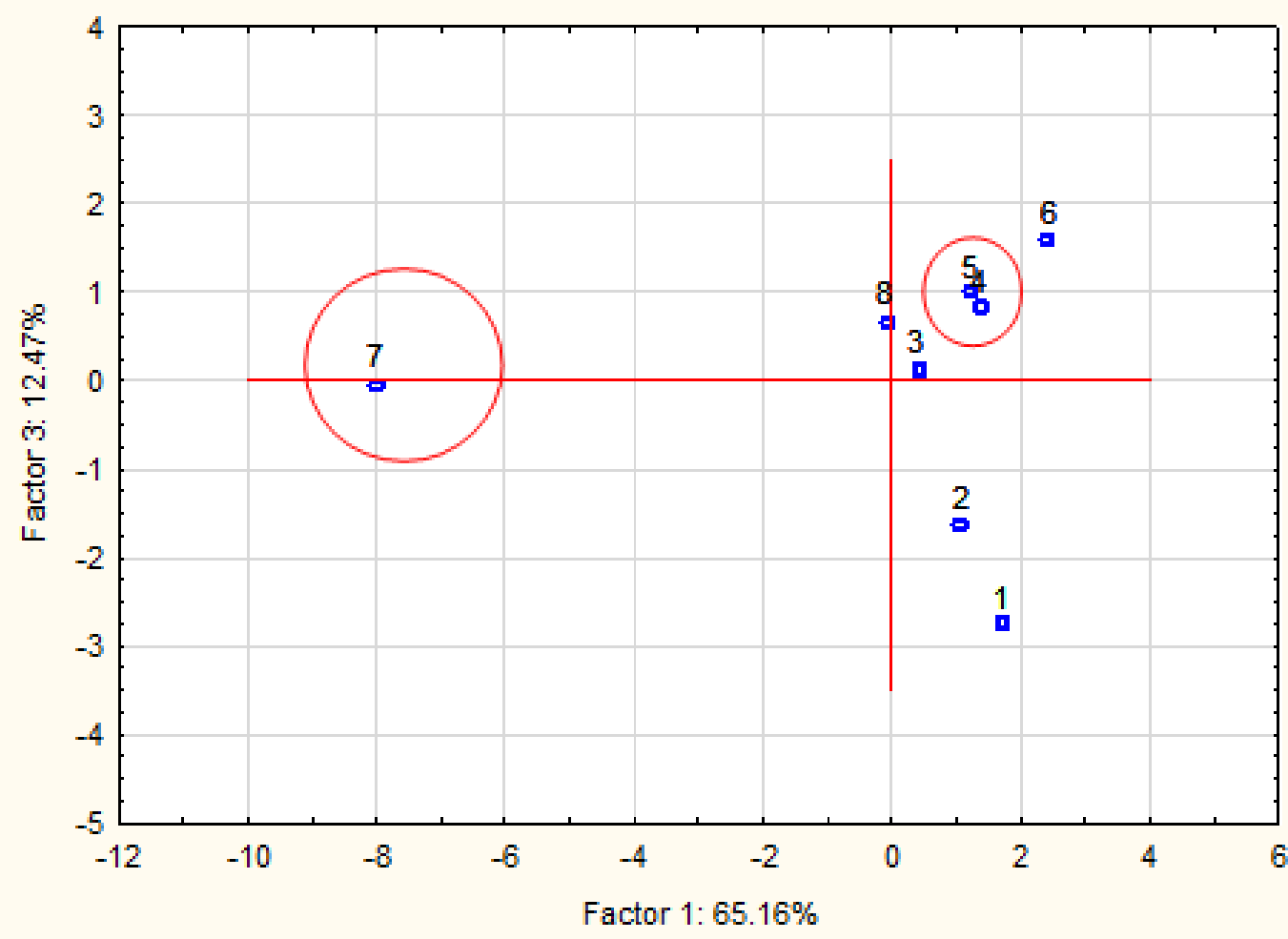

FIGURA 37 Gráfico de dispersão dos casos referentes a CP1 x CP3

Na FIG 38, o gráfico bidimensional CP1 x CP2 abordando as variáveis indicou um grupo formado pelos metais (Al, Fe, Co, Cr, Hg, Zn), hidrocarbonetos (HA totais, HPA totais), MO e \%silte e argila, ambos explicados pela CP1, o que sugere fontes comuns a esses contaminantes, principalmente antrópica. A presença de HPA e Hg nos sedimentos do PEMLS reforça essa afirmação.

As quantidade de M.O e de \% silte-argila e indicam locais de deposição e acúmulo de contaminantes e na disponibilidade desses metais e hidrocarbonetos no ambiente aquático, o qual é corroborado por Hortellani et al., (2005) e Bícego et al., (2006). Outro grupo formado pelo $\mathrm{TOC}_{\text {e } ~} \mathrm{CaCO}_{3}$ foi identificado pois além da maior parte do $\mathrm{TOC}$ ser $\mathrm{CaCO}_{3}$, esse último pode ter papel na adsorção de alguns metais que estiveram em concentrações similares nos pontos 4 e 5 . 
Por outro lado, um grupo foi formado pelo $\mathrm{Pb}$ e $\mathrm{Mn}$, pois ambos apresentaram correlação com a CP2, apresentaram comportamentos distintos dos demais metais o que sugere indicativo de uma fonte comum a ambos os elementos.

Projection of the variables on the factor-plane $\left(\begin{array}{ll}1 \times & 2\end{array}\right)$

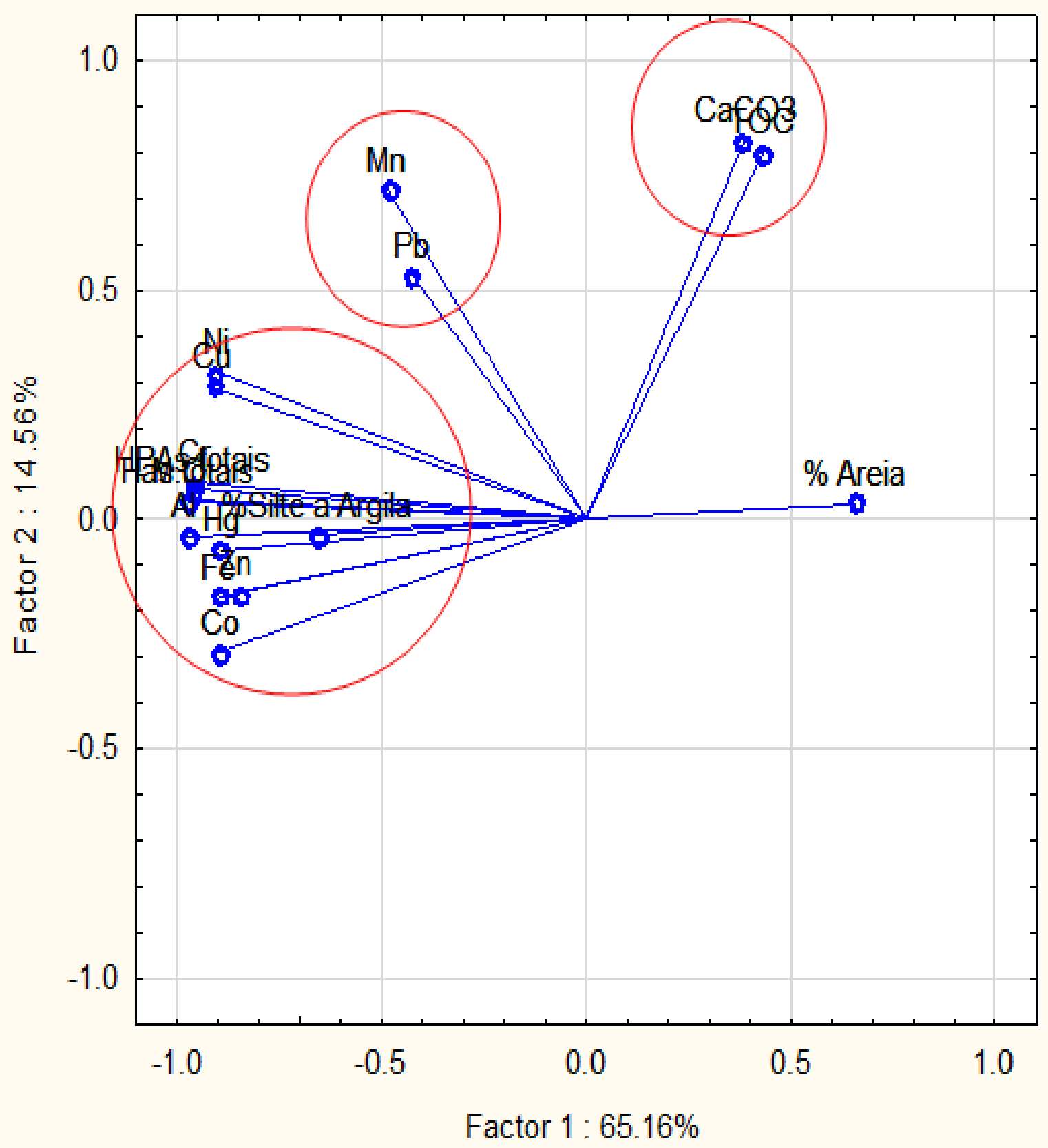

FIGURA 38 Gráfico de dispersão das variáveis referentes a CP1 x CP2 
Nos resultados apresentados no gráfico CP1 x CP3 (FIG 39) pode-se notar um grupo formado pela associação dos metais (Al, $\mathrm{Fe}, \mathrm{Co}, \mathrm{Cr}, \mathrm{Hg}, \mathrm{Ni}$ ) com os hidrocarbonetos (HA e HPA), o que sugere indícios de fontes antrópicas de origem comum. $O$ aporte de sedimentos contaminados provenientes da área de descarte do material dragado e a introdução desses compostos na zona costeira são as principais origens desses contaminantes. Um grupo formado pelo $\mathrm{Cu}$ e o $\mathrm{Zn}$, explicado pela $\mathrm{CP} 1$, sugere uma fonte comum a esses contaminantes, possivelmente de tintas anti-incrustantes utilizadas nas embarcações de pequeno porte que frequentam a região.

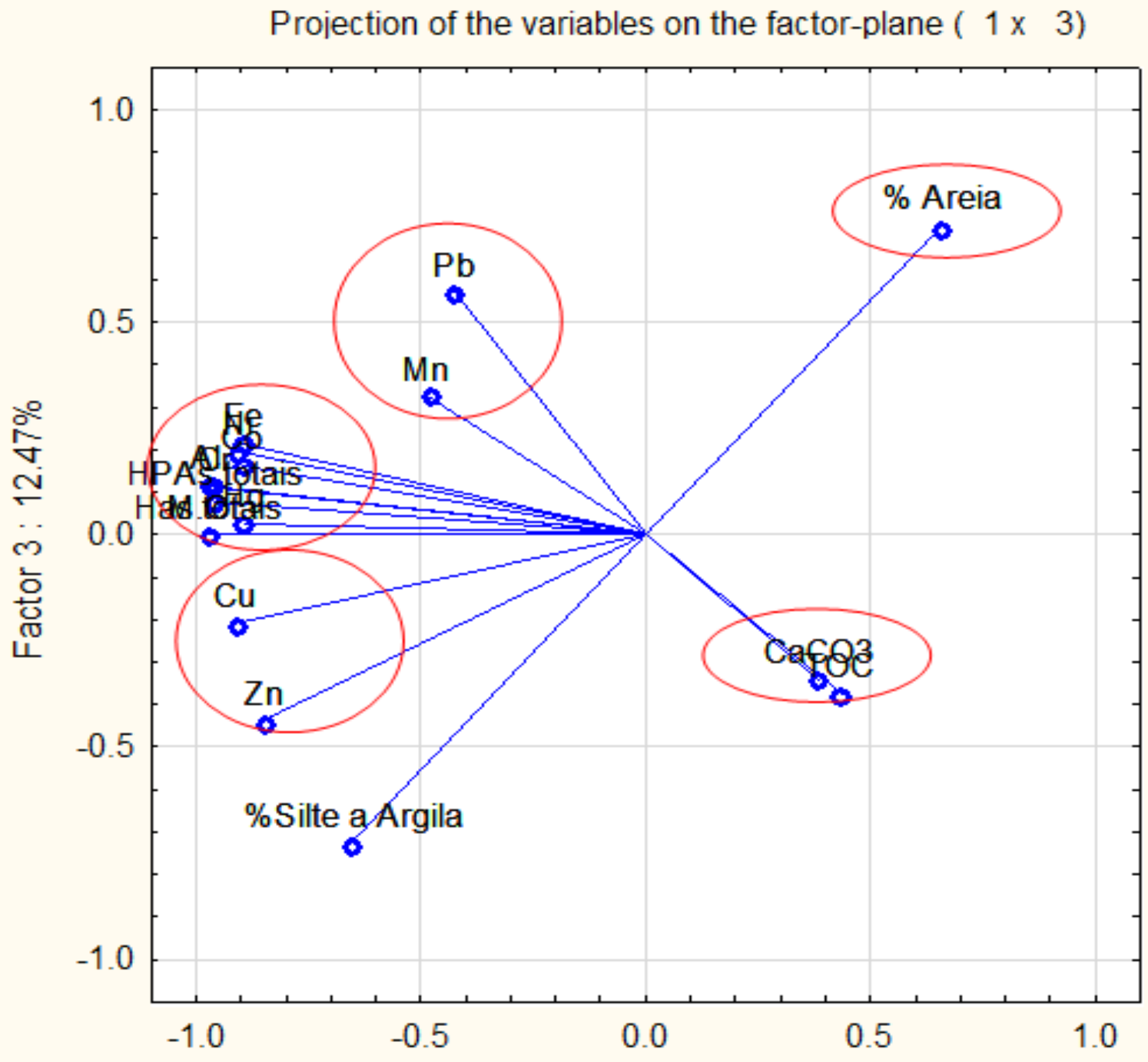

Factor $1: 65.16 \%$

FIGURA 39 Gráfico de dispersão das variáveis referentes a CP1 x CP3 
Verificou-se que na área amostrada a origem da maioria dos metais seja provavelmente proveniente do aporte continental (área de descarte do material dragado ou zona costeira), uma vez que as assinaturas marinha $\left(\mathrm{CaCO}_{3}, \mathrm{TOC}\right.$ e granulometria ) não se associam com as assinaturas terrestres ( $\mathrm{Al} \mathrm{e} \mathrm{o} \mathrm{Fe}$ ), o que sugere fontes antrópicas para esses contaminantes.

\subsubsection{Análise de Agrupamento}

Um dendrograma resumindo as semelhanças entre os pontos amostrados são apresentados na FIG 40.

As ligações horizontais correspondem aos locais e os números no topo do dendrograma correspondem ao nível de similaridade, em uma escala de 0 (identidade no máximo) a 100 (dissimilaridade máxima).

Como podemos observar no dendrograma dos pontos amostrados o $\mathrm{G} 1$ é representado somente pelo ponto 7 corroborando as análises de ACP, demonstrando que a concentração dos elementos analisados nos sedimentos se diferenciaram nesse ponto por apresentarem valores mais elevados em comparação com os sedimentos dos outros pontos estudados. 


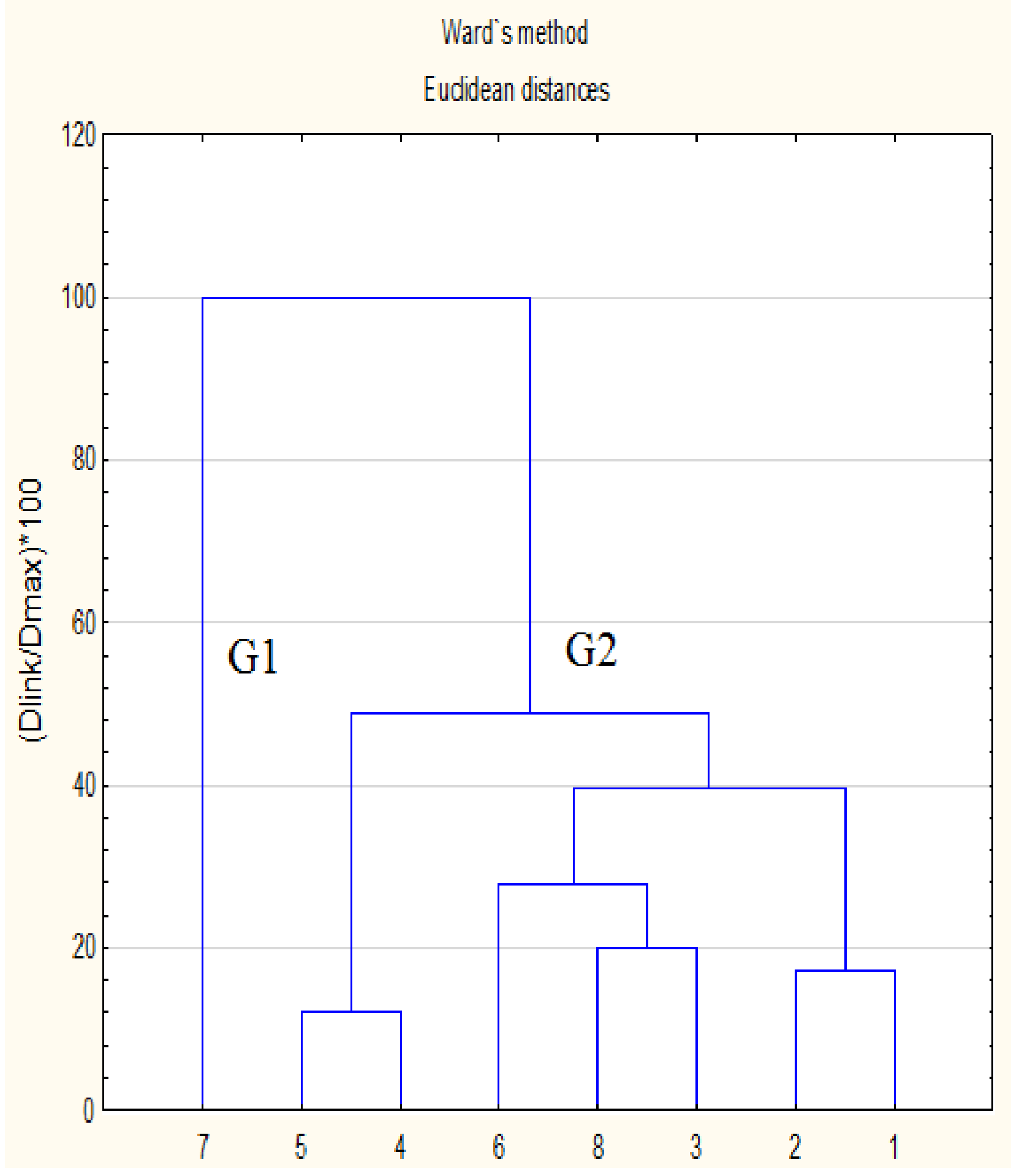

FIGURA 40 Dendrograma das analises de agrupamento referente aos pontos coletados no PEMLS (pontos de 1 a 5), zona marinha adjacente (ponto 6), área de descarte do material dragado (ponto 7) e baia de Santos (ponto 8). Legenda: G1 -Grupo 1. G2 Grupo 2 
O G2 agrupou os demais pontos, separando-os em subgrupos. Os pontos 4 e 5 se agruparam por seus sedimentos apresentarem a maior \% de silte e argila e as concentrações similares para alguns metais. $O$ sedimento do ponto 6 apresentou a maior \% de areia e menor contaminação e ficou separado dos demais. Os sedimentos dos pontos 3 e 8 se agruparam por causa da similaridade na $\% \mathrm{TOC}$ e $\% \mathrm{CaCO}_{3}$.

\section{Gradiente de Contaminação}

Conforme observado nos resultados do presente estudo, a contaminação por metais e HPA nos sedimentos das diferentes áreas de estudo seguiu um padrão de distribuição. Os pontos localizados na parte interna do SESSV, próximas as atividades industriais (pontos 4, 5, 11, 12,13 e 15), foram os que apresentaram as concentrações mais elevadas quando comparadas com os demais pontos de estudo. Ao se distanciar das principais fontes de contaminação, em direção aos canais de Santos e São Vicente, as concentrações dos contaminantes decresceram nos sedimentos dos pontos localizados na parte central do estuário e no meio dos canais de Santos e São Vicente (pontos 2, 3, 7 e 8). Nas entradas dos canais (pontos 1 e 9), as concentrações dos contaminantes voltaram a aumentar, o que reflete a influencia do porto e das marinas da região.

Ao chegar à baia de Santos (representado por BS e pelo número 17 nos gráficos), os níveis de contaminantes diminuem em relação aos pontos localizados na entrada dos canais, até a chegada a área de descarte do material dragado (representado por AD e pelo número 18 nos gráficos) onde as concentrações de metais e HPA voltam a aumentam, evidenciando a introdução de sedimentos contaminados nessa região. Mais à frente, localizada em mar aberto, está a zona marinha adjacente (representada por ZM e número 19 nos gráfico), um local longe das principais fontes potenciais de poluição, o que faz com que as concentrações dos metais e HPA decresçam nos sedimentos. Na medida em que esses contaminantes são transportados pelas 
correntes para outras regiões, podem se depositar em áreas adjacentes, que apresentam características físico-químicas propicias ao acúmulo dos contaminantes.

Nos pontos localizados dentro do PEMLS (representados no gráfico pelos númeors de 20 a 24 , sendo o 24 equivalente ao ponto 1 , o número 23 representa o ponto 2 , o número 22 o ponto 3 , o número 21 o ponto 4 e 0 número 20 o ponto 5 ) as concentrações de metais, apresentaram-se relativamente altas, iguais ou acima das registradas nos pontos localizados na baia de Santos e em pontos localizados na parte central do estuário. Entretanto as concentrações de HPA decresceram a tal ponto, apresentando valores abaixo do limite de detecção do método.

Para relacionarmos a contaminação nos diferentes locais de estudo e estabelecer um gradiente da contaminação por metais e HPA desde o SESSV até o PEMLS, foi adotado um gráfico de dispersão tridimensional utilizando 3 metais e HPA específicos para cada gráfico. Esses gráficos são representações de três variáveis organizadas em um gráfico tridimensional, uma em função da outra. Os metais escolhidos para confecção dos gráficos foram os que apresentaram correlações fortes entre si $(p<0,001)$ e para os os gráficos dos HPA foram separados por números de anéis aromáticos.

\subsection{Metais}

Na FIG 41 estão plotados todos os pontos do presente estudo referente aos metais $\mathrm{Fe}, \mathrm{Cr}$ e Zn e na FIG 42 estão plotados somente os pontos desde a baia de Santos até o PMLS para os mesmos metais. Como podemos observar na FIG 41 , os pontos $5,11,12,13$ e 15 (localizados no fundo do estuário) ficam separados dos demais pontos devido a contaminação elevada por esses 3 metais nos sedimentos próximos as atividades industriais. $O$ ponto 9 apresentou concentrações mais elevadas desses metais em relação aos outros pontos e ficou separado dos demais na área central do gráfico seguido dos 
pontos $1,4,6,10,14,16$ e 18 que se localizaram próximos uns aos outros, pois apresentaram uma contaminação moderada por esses metais. Os pontos 2, 3, 7,8 e 17 foram os menos contaminados em relação aos demais pontos localizados na região costeira. Os pontos localizados na ZM e no PEMLS se agruparam, pois apresentaram a contaminação menos elevada por esses metais.

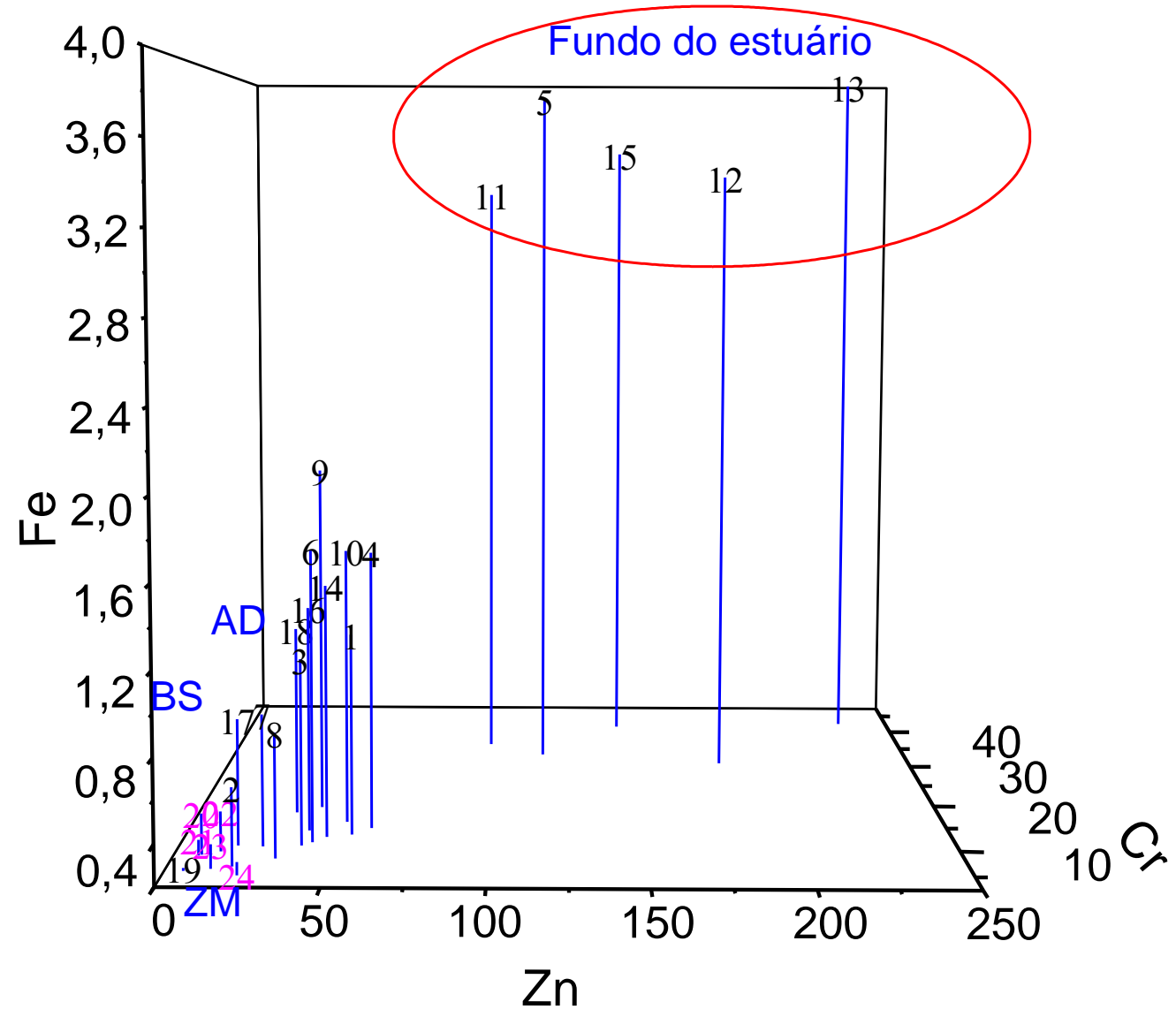

FIGURA 41 Gráfico de dispersão tridimensional abordando todos os pontos de estudo, referente ao $\mathrm{Zn}, \mathrm{Cr}$ e Fe. Legenda: Fundo do Estuário (pontos mais contaminados - 5, 11, 12, 13 e 15 ), BS - Baia de Santos (número 17), AD Área de descarte do material dragado (número 18), ZM - Zona marinha adjacente (número 19), Pontos em rosa - PEMLS (números 20 a 24). Os valores estão em ppm. 
Na FIG 42 podemos observar que a área de descarte do material dragado (AD - ponto 18) se distanciou dos demais pontos por apresentar a concentração desses 3 elementos superior as dos outros pontos, devido a introdução de contaminantes nessa região de mar aberto, sob influência das correntes marinhas que transportam os sedimentos contaminados para outras regiões. A baia de Santos (BS - ponto 17) apresentou concentração mais elevado que no PEMLS e na zona marinha para esses 3 metais e separou-se dos demais pontos, o que reflete o impacto causado pela disposição de efluentes domésticos pelo emissário submarino de Santos e São Vicente. Os pontos localizados na ZM e no PEMLS apresentaram as menores concentrações e se agruparam no gráfico.

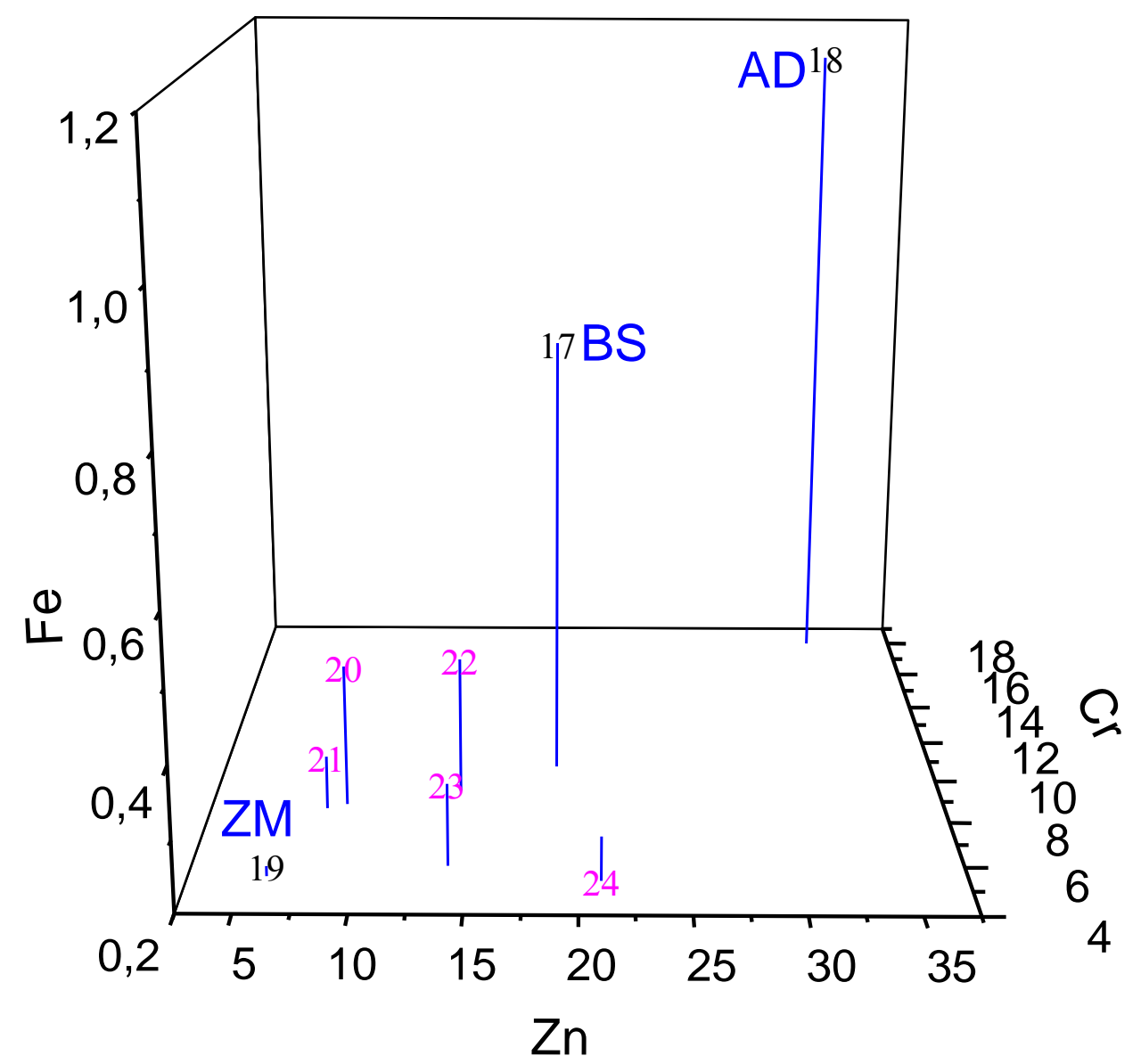

FIGURA 42. Gráfico de dispersão tridimensional desde a baia de Santos até o PEMLS referente ao Zn, Cr e Fe. Legenda: BS - Baia de Santos (ponto 17), AD - Área de descarte do material dragado (ponto 18), ZM - Zona marinha adjacente (ponto 19). PEMLS (pontos de 20 a 24). Os valores estão em ppm. 
Na FIG 43 estão plotados todos os pontos referentes aos metais $\mathrm{Zn}, \mathrm{Cr}$ e Al e na FIG 44 estão plotados somente os pontos desde a baia de Santos até o PEMLS para os mesmos metais.

Os pontos mais contaminados $(5,11,12,13$ e 15) se separaram, novamente, dos demais pontos do presente estudo. Os pontos 1, 3, 4, 6, 10, 16 e 18 se agruparam por apresentarem uma contaminação moderada nos sedimentos em relação a esses metais. Os pontos 2, 7 e 8 , localizados no SESSV, o ponto 17 (baia de Santos), o ponto 19 (zona marinha adjacente) se agruparam por serem os pontos menos contaminados do presente estudo.

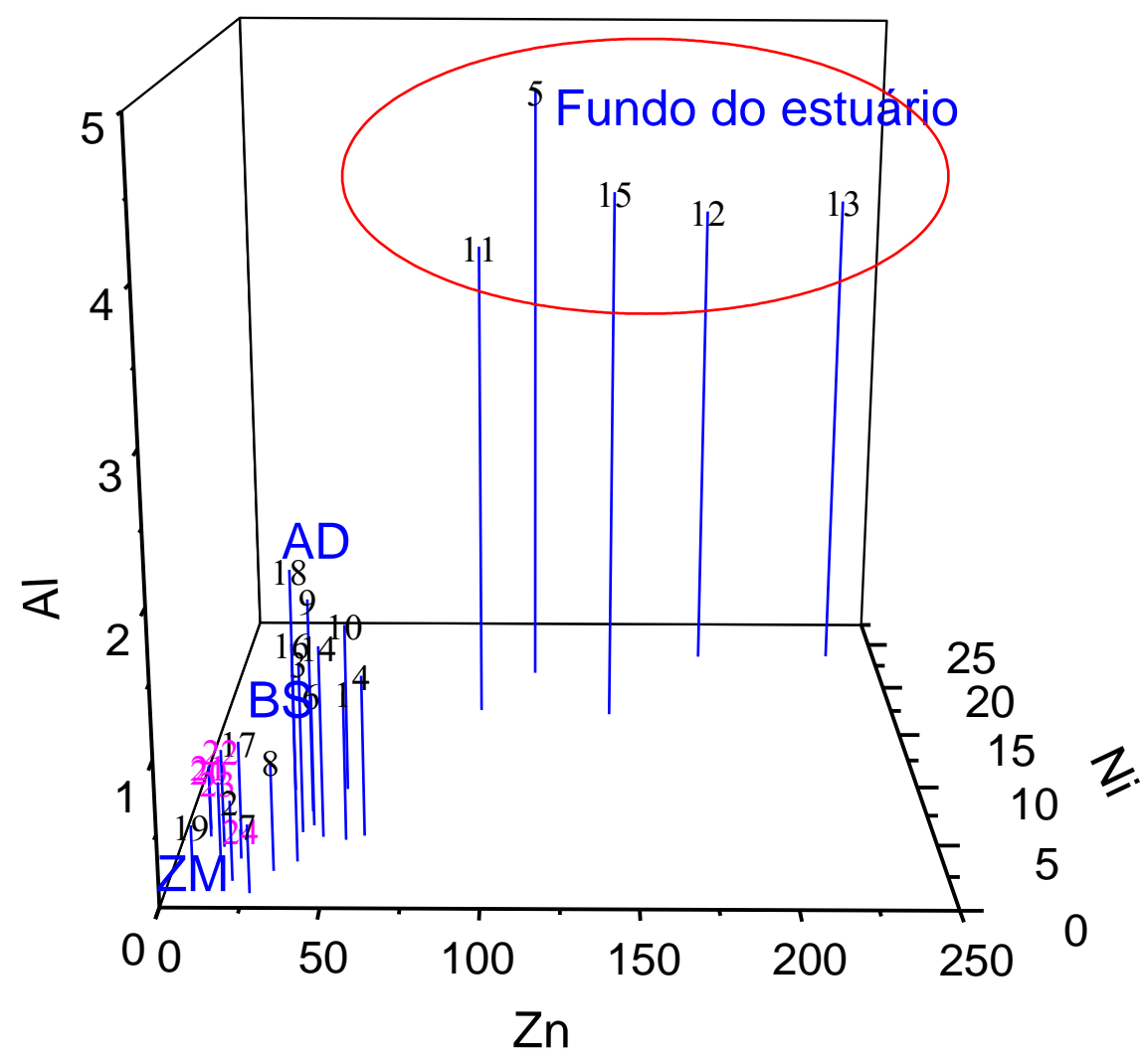

FIGURA 43. Gráfico de dispersão tridimensional abordando todos os pontos de estudo, referente ao $\mathrm{Al}, \mathrm{Ni}$ e $\mathrm{Zn}$. Legenda: Fundo do Estuário (pontos mais contaminados - 5, 11, 12, 13 e 15 ), BS - Baia de Santos (número 17), AD Área de descarte do material dragado (número 18), ZM - Zona marinha adjacente (número 19), Pontos em rosa - PEMLS (números 20 a 24). Os valores estão em ppm. 
A FIG 44 apresenta os pontos desde a baia de Santos até o PEMLS. A área de descarte do material dragado foi a que apresentou maior contaminação nos sedimentos para esses metais se distanciando dos demais pontos.

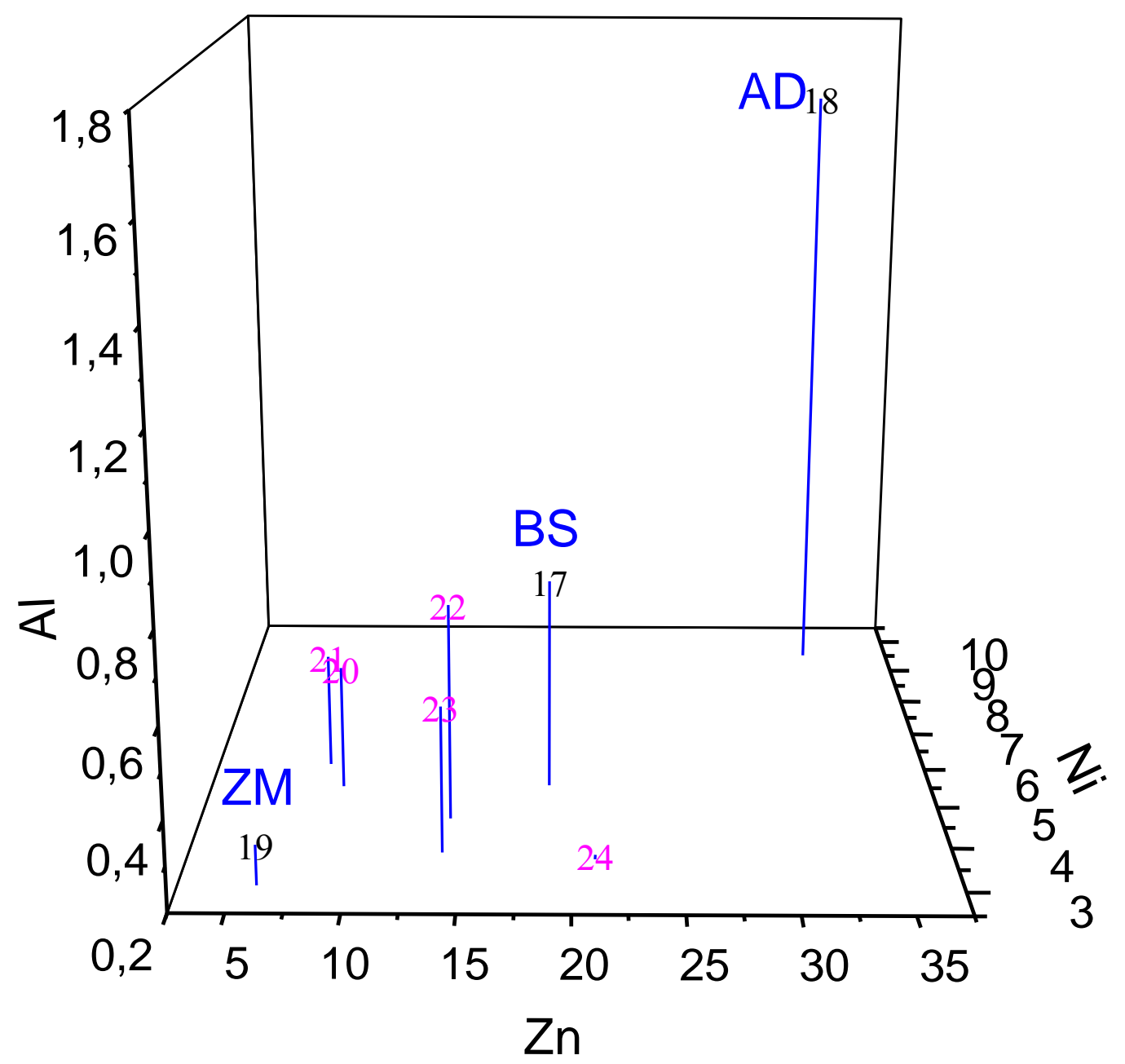

FIGURA 44. Gráfico de dispersão tridimensional desde a baia de Santos até o PEMLS referente ao Al, Ni e Zn. Legenda: BS - Baia de Santos (ponto 17), AD Área de descarte do material dragado (ponto 18), ZM - Zona marinha adjacente (ponto 19). PEMLS (pontos de 20 a 24). Os valores estão em ppm.

Os sedimentos da baia de Santos e do PEMLS se agruparam por apresentarem concentrações semelhantes em relação a esses metais. A zona marinha adjacente foi o local que apresentou a menor contaminação em relação aos demais pontos, ficando isolado dos outros pontos. 
O gráfico de dispersão tridimensional relacionando $\mathrm{O} \mathrm{Cu}, \mathrm{Pb}$ e Co com todos os pontos do presente estudo esta expresso na FIG 45 e na FIG 46 estão plotados esses mesmos metais somente para os pontos desde a baia de Santos até o PEMLS. Nesses gráficos podemos observar que há um gradiente acentuado em relação a esses 3 elementos. Os pontos mais contaminados (fundo do estuário) se separam dos demais. O ponto 1 (entrada do canal de São Vicente) e o ponto 10 , se distanciaram dos outros pontos por apresentarem valores mais elevados, próximos aos encontrados nos pontos ao fundo do estuário. Os pontos 3, 4, 7, 14 e 16 se agruparam juntamente com 0 ponto da área de descarte (representado pelo ponto 18) por apresentarem uma contaminação moderada para esses metais nos sedimentos.

Os pontos 2, 6, 8 e 9 se agruparam com os pontos referentes a baia de Santos, zona marinha adjacente e do PEMLS indicando que esses pontos estão na mesma ordem de grandeza em relação a concentração desses elementos, o que significa, mesmo que as concentrações sejam relativamente baixas, indícios de contaminação na região do PEMLS estão sendo detectados uma vez que os pontos do estuário ficaram próximos aos do parque. 


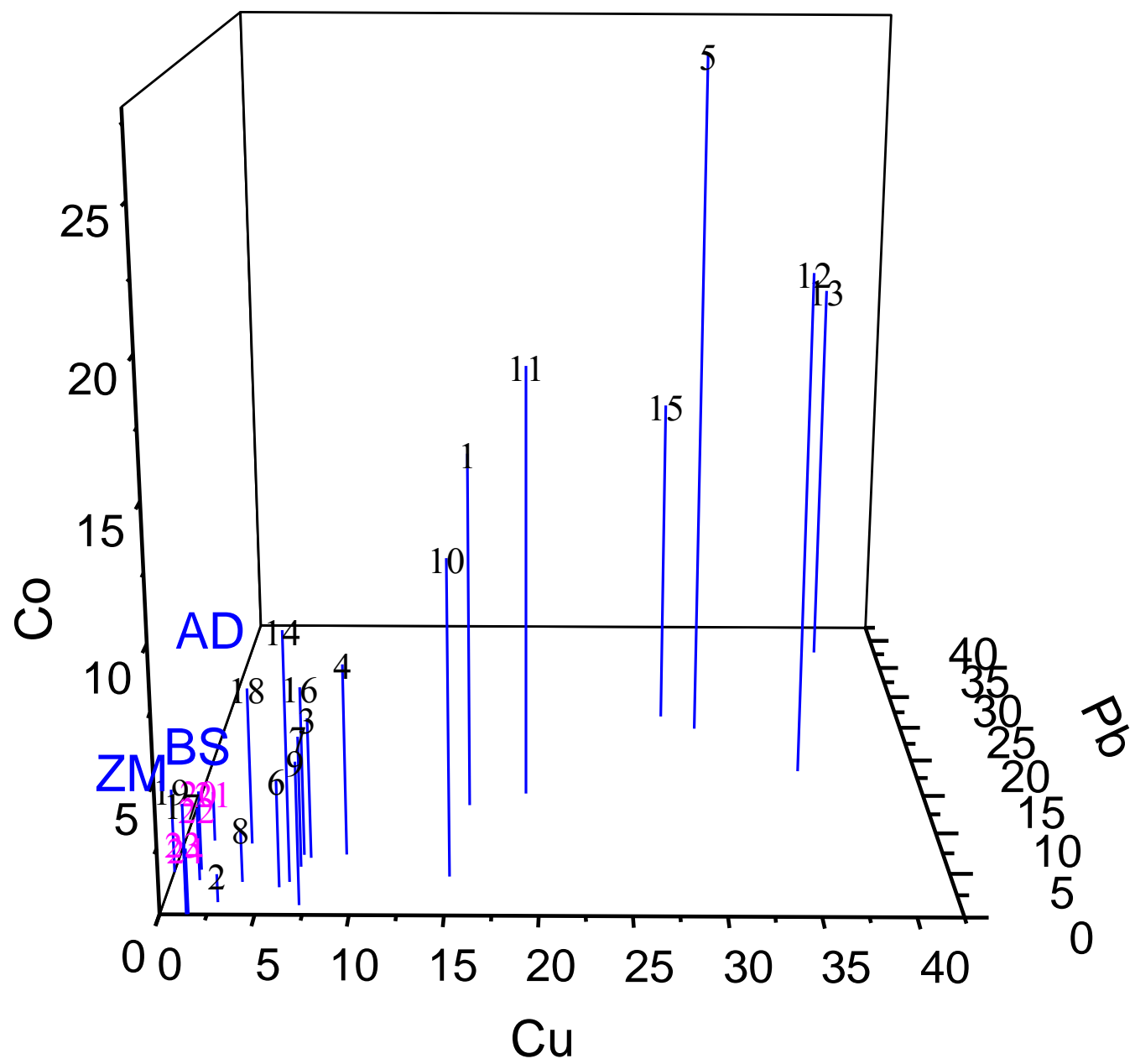

FIGURA 45 Gráfico de dispersão tridimensional abordando todos os pontos de estudo, referente ao $\mathrm{Cu}, \mathrm{Pb}$ e $\mathrm{Co}$. Legenda: Fundo do Estuário (pontos mais contaminados - 5, 11, 12, 13 e 15 ), BS - Baia de Santos (número 17), AD Área de descarte do material dragado (número 18), ZM - Zona marinha adjacente (número 19), Pontos em rosa - PEMLS (números 20 a 24). Os valores estão em ppm.

Na FIG 46 estão plotados somente os pontos desde a baia de Santos até o PEMLS. Como mostra a figura, o ponto 18 (área de descarte) apresentou as concentrações elevadas desses elementos, o que reflete na sua posição isolada na área do gráfico, em relação aos outros pontos. 


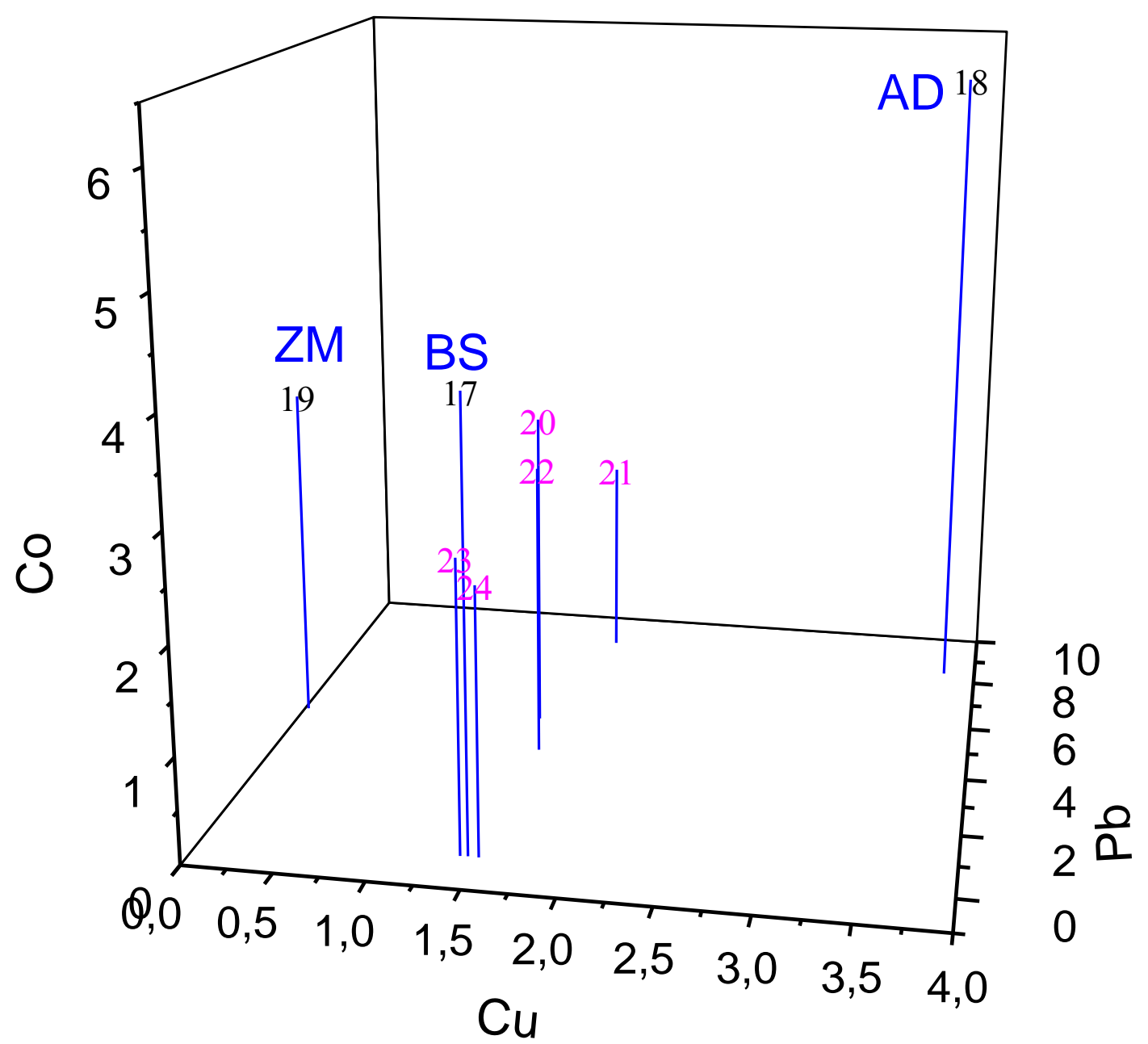

FIGURA 46. Gráfico de dispersão tridimensional desde a baia de Santos até o PEMLS referente ao $\mathrm{Cu}, \mathrm{Pb}$ e Co. Legenda: $\mathrm{BS}$ - Baia de Santos (ponto 17), AD - Área de descarte do material dragado (ponto 18), ZM - Zona marinha adjacente (ponto 19). PEMLS (pontos de 20 a 24). Os valores estão em ppm.

O ponto 4 (representado pelo número 21 no gráfico) apresentou a maior concentração de $\mathrm{Pb}$ e fez com que ele se distanciasse dos demais pontos. Os pontos da zona marinha adjacente (número 19), e pontos 3 e 5 (representados pelos números 22 e 20 respectivamente) se agruparam por apresentarem concentrações desses 3 elementos muito similares. Os pontos da baia de Santos (número 17) e os pontos 1 e 2 (representados pelos números 24 e 23 respectivamente) foram os que apresentaram concentrações mais baixas para esses elementos, ficando distantes dos demais pontos. 
Essa similaridade entre as concentrações de pontos no PEMLS e no SESSV sugere que os teores desses metais estão elevados e pode estar havendo uma introdução desses elementos nos sedimento do PEMLS. Os sedimentos localizados no PEMLS, apresentaram concentrações de Co, $\mathrm{Cu}$ e $\mathrm{Pb}$ elevadas, acima das concentrações registradas em alguns pontos do estuário o que sugere indícios de contaminação por esse metal nos sedimentos principalmente no ponto 4 localizado no PEMLS.

Na FIG 47, estão plotados todos os pontos referentes aos metais $\mathrm{Ni}, \mathrm{Hg}$ e Mn e na FIG 48, somente os pontos desde a baia de Santos até o PEMLS. Podemos observar que o ponto 5 se separa dos demais pontos no gráfico pelo fato de apresentar a concentração mais elevada de $\mathrm{Hg}$ nos sedimentos. Os pontos 11, 12, 13 e 15 se agruparam e se distanciaram dos pontos do SESSV. O ponto 9 se distanciou levemente dos demais pois apresentou concentrações desses 3 elementos mais elevada quando comparados com os outros pontos. Os pontos 1, 2, 3, 4, 6, 7 e 8 se agruparam por apresentarem concentrações similares desses elementos.

Entretanto, os pontos do PEMLS se localizaram juntos com os pontos do estuário 10, 14 e 16 e do ponto da baia de Santos (representado no gráfico pelo ponto 17). O sedimento do ponto 3 (representado pelo número 22) apresentou concentrações de $\mathrm{Hg}$ próximas as encontradas nos sedimentos do estuário. Os sedimentos dos pontos 4 e 5 (representado pelo numero 21 e 20) apresentaram concentrações de $\mathrm{Mn}$ relativamente elevadas o que influencia na dispersão dessses pontos próximos a área de descarte do material dragado e do ponto 14 . 


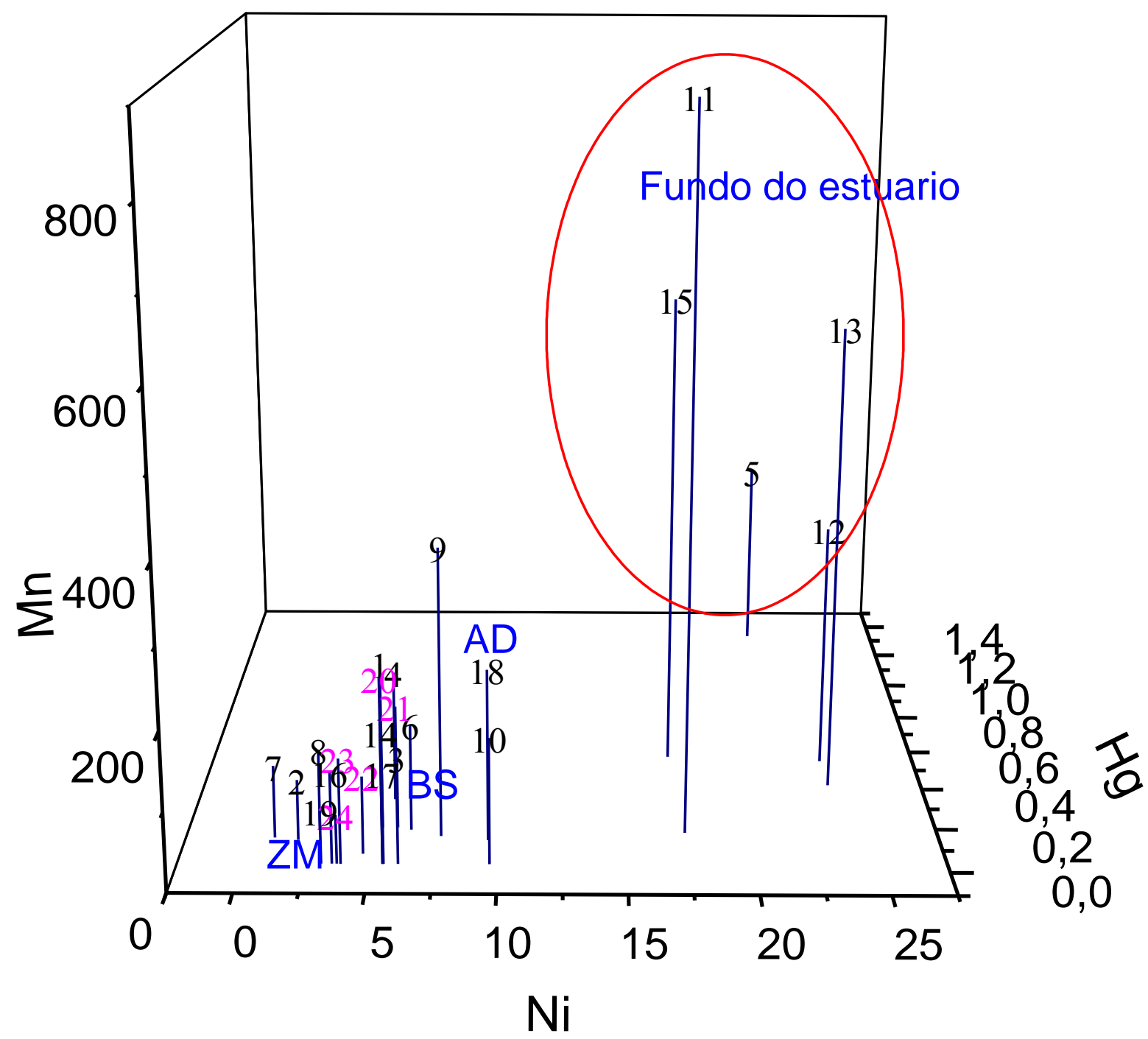

FIGURA 47 Gráfico de dispersão tridimensional abordando todos os pontos de estudo referente aos metais $\mathrm{Ni}, \mathrm{Mn}$ e $\mathrm{Hg}$. Legenda: Fundo do Estuário (pontos mais contaminados - 5, 11, 12, 13 e 15),BS - Baia de Santos (número 17), AD - Área de descarte do material dragado (número 18), ZM - Zona marinha adjacente (número 19), Pontos em rosa - PEMLS (números 20 a 24). Os valores estão em ppm.

Na FIG 48 estão expressos os pontos desde a baia de Santos até o PEMLS. O ponto 18 (área de descarte do material dragado) se separou dos demais pontos devido a concentração elevada dos metais. O ponto 4 e $5(21$ e 20 respectivamente) se agruparam pela similaridade nas concentrações e foram os mais contaminados dentre esses pontos. O ponto da baia de Santos 
(ponto 17) e o ponto 2 e 3 do PEMLS (representado por 24 e 23 respectivamente) se agruparam por apresentarem concentrações relativamente elevadas deferente dos pontos 19 (zona marinha adjacente) e do ponto 1 do PEMLS (representado por 24 no gráfico) que ficaram longe dos demais.

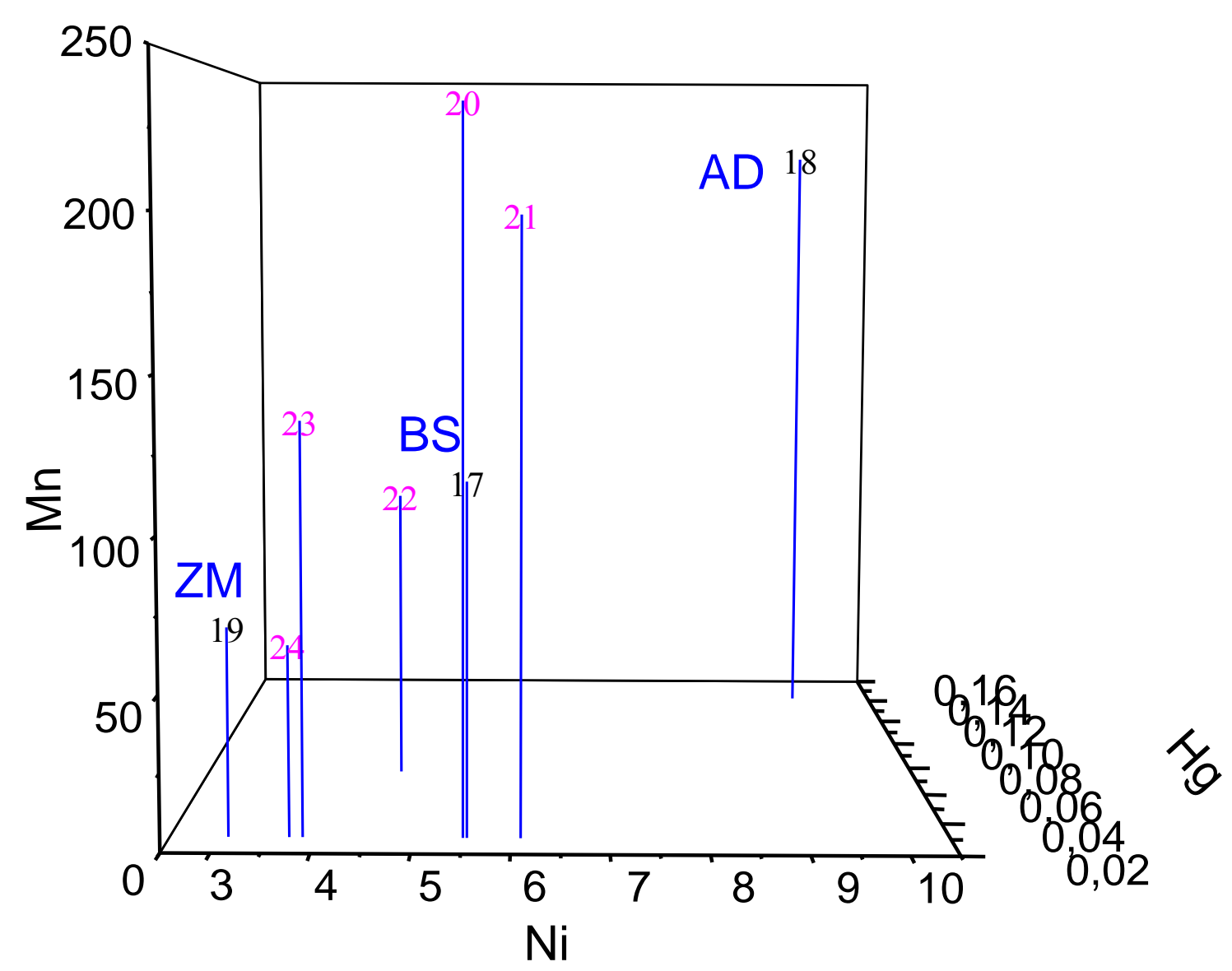

FIGURA 48. Gráfico de dispersão tridimensional desde a baia de Santos até o PEMLS referente ao Ni, Hg e Mn. Legenda: BS - Baia de Santos (ponto 17), AD - Área de descarte do material dragado (ponto 18), ZM - Zona marinha adjacente (ponto 19). PEMLS (pontos de 20 a 24). Os valores estão em ppm.

Sendo assim, não houve um gradiente definido para esses metais, o que significa que concentrações similares de $\mathrm{Ni}, \mathrm{Hg}$ e $\mathrm{Mn}$ foram encontradas nos sedimentos dessas áreas e são os principais indícios de contaminação para o PEMLS, uma vez que o Mn apresentou concentrações elevadas nos sedimentos acima das encontradas nos demais pontos, incluindo os localizados no estuário, na baia de Santos e da área de descarte do material 
dragado. O Ni foi classificado como moderadamente poluído nos sedimentos do PEMLS e foram registradas concentrações bem próximas as encontradas nos pontos moderadamente contaminados no SESSV.

Esses resultados evidenciam indícios de contaminação por esses metais nos sedimentos do PEMLS, uma vez que as concentrações de alguns metais estão na mesma ordem de grandeza quando comparados com pontos situados no estuário e na área de descarte do material dragado. Todavia, o PEMLS está localizado a $40 \mathrm{~km}$ de qualquer fonte pontual e as concentrações encontradas nos sedimentos indicam que pode estar havendo a introdução desses metais nessa região através do transporte pelas correntes marinhas provenientes da área de descarte do material dragado ou vindos do continente, uma vez que o SESSV apresenta uma contaminação elevada nos sedimentos. Esses dois processos são diferentes porem podem ocorre concomitantemente.

A área de descarte ficou próxima dos pontos moderadamente contaminados, localizados no interior do estuário, refletindo a influência do material dragado contaminado, disposto nessa região de mar aberto, uma vez que esses metais estão em concentrações elevadas nos sedimentos do SESSV e consequentemente, no material dragado.

Entretanto os sedimentos da baia de Santos se localizaram distante dos demais pontos, próximo a pontos do PEMLS, zona marinha adjacente e pontos menos contaminados no SESSV (pontos 2, 7 e 8), situados na porção inferior do gráfico, sugerindo que as concentrações desses metais são relativamente baixas. Porém os pontos 4 e 5 (representados pelos números 20 e 21) foram os que apresentaram os maiores valores de $\mathrm{Cr}$ e $\mathrm{Fe}$ em concentrações bem próximas as encontradas no ponto 2 , localizado no SESSV o que sugere os primeiros indícios de contaminação por esses metais. 


\subsection{Hidrocarbonetos Policíclicos Aromáticos}

A contaminação por HPA nos sedimentos do SESSV seguiu o mesmo padrão dos metais sendo as maiores concentrações registradas na parte mais interna do estuário, próximo às atividades industriais. Conforme se distancia das principais fontes de contaminação para o SESSV, a concentração dos HPA decresce até a chegada à entrada dos canais de Santos e São Vicente. Na baia de Santos não foi constatado concentrações de HPA nos sedimentos com exceção dos compostos trimetilnaftaleno e do reteno. $\mathrm{Na}$ área de descarte do material dragado, os sedimentos apresentaram concentrações somente de HPA de alto peso molecular (de 4, 5 e 6 anéis). Nos sedimentos da zona marinha adjacente a concentração de HPA apresentou-se abaixo do LD do método com exceção dos compostos pireno e reteno, que foram detectados nesses sedimentos. Em relação aos sedimentos do PEMLS, os HPA se apresentaram em concentrações abaixo do LD do método para a maioria dos HPA, sendo detectado somente os compostos trimetilnaftaleno, pireno e reteno.

Sendo assim, nos gráficos de dispersão tridimensional serão abordados somente os pontos do SESSV e da área de descarte do material dragado, que apresentaram a concentração dos 16 HPA prioritários, acima do LD do método, e serão separados pelo número de anéis aromáticos. Para avaliar o gradiente de contaminação desde o SESSV até o PEMLS será utilizado somente os compostos trimetilnaftaleno, pireno e reteno, os que apresentaram concentrações acima do LD do método.

Na FIG 49 estão plotados no gráfico de dispersão tridimensional os HPA de 2 e 3 anéis aromáticos (naftaleno, acenaftileno e acenafteno). Os pontos localizados no fundo do estuário $(4,5,10,11,12,13,14)$ se separam dos pontos localizados nos canais de Santos e São Vicente $(1,2,3,7,8,9)$. O ponto 12 foi o que apresentou maior concentração desses HPA nos sedimentos e se isola dos demais pontos no gráfico. Os pontos 4 e 14 , os quais apresentaram contaminação elevada, sendo superado somente pelo ponto 12 , 
se separaram dos demais pontos. Nos pontos 5,11 e 13 a concentração decresceu e ficaram agrupados, seguidos do ponto 10 e dos pontos nos canais de Santos e São Vicente os quais apresentaram contaminação inferior as dos pontos localizados no fundo do estuário. $\mathrm{Na}$ baia de Santos, zona marinha adjacente e PEMLS não foram encontradas concentrações desses compostos nos sedimentos.

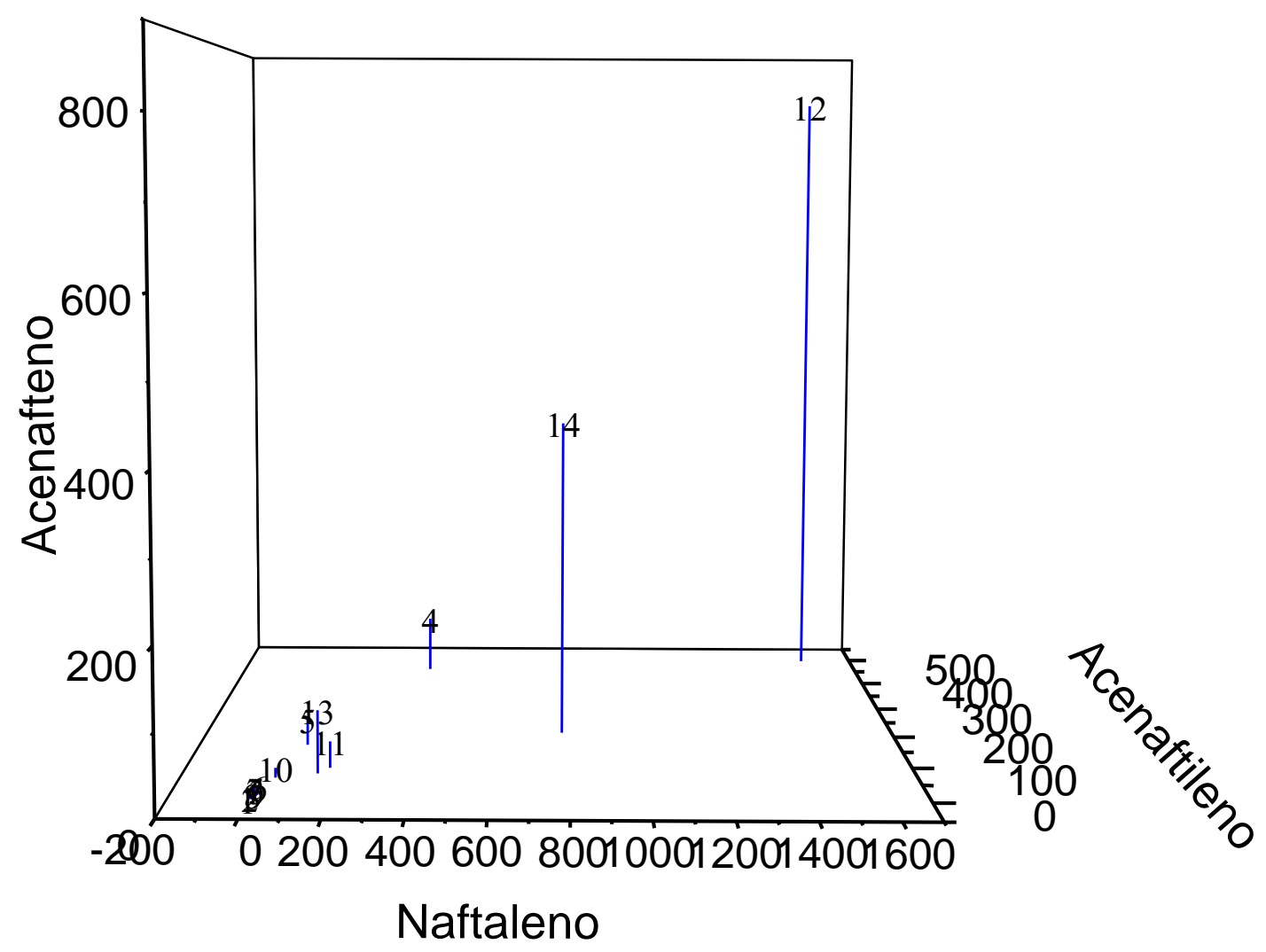

FIGURA 49 Gráfico de dispersão tridimensional abordando os pontos do SESSV referente aos HPA de 2 e 3 aneis aromáticos (naftaleno, acenaftileno e acenafteno). Os valores estão em ppb.

Sendo assim, evidencia-se um gradiente desde o fundo do estuário, próximo ao complexo industrial de Cubatão até os canais de Santos e São Vicente.

A FIG 50 expressa o gráfico de dispersão tridimensional em relação aos HPA de 3 anéis aromáticos (fenantreno, antraceno e acenaftileno). Pode-se 
observar que a distribuição aos pontos no gráfico segue o mesmo padrão dos apresentados na FIG 49. Os pontos mais contaminados localizados no fundo do estuário se distanciam dos demais. O ponto 12 se isola dos outros pontos, seguido pelo ponto 4 e 14 devido as altas concentrações desses HPA. O ponto 5 se destaca ligeiramente dos demais pontos que apresentaram contaminações inferiores dos citados anteriormente. Os pontos 6, 10, 11, 13 seguidos pelos pontos $1,2,3,7,8$, e 9, ficaram localizados na parte inferior esquerda, significando menor concentração desses HPA. Não foi detectada a presença desses HPA nos sedimentos desde a baia de Santos até o PEMLS.

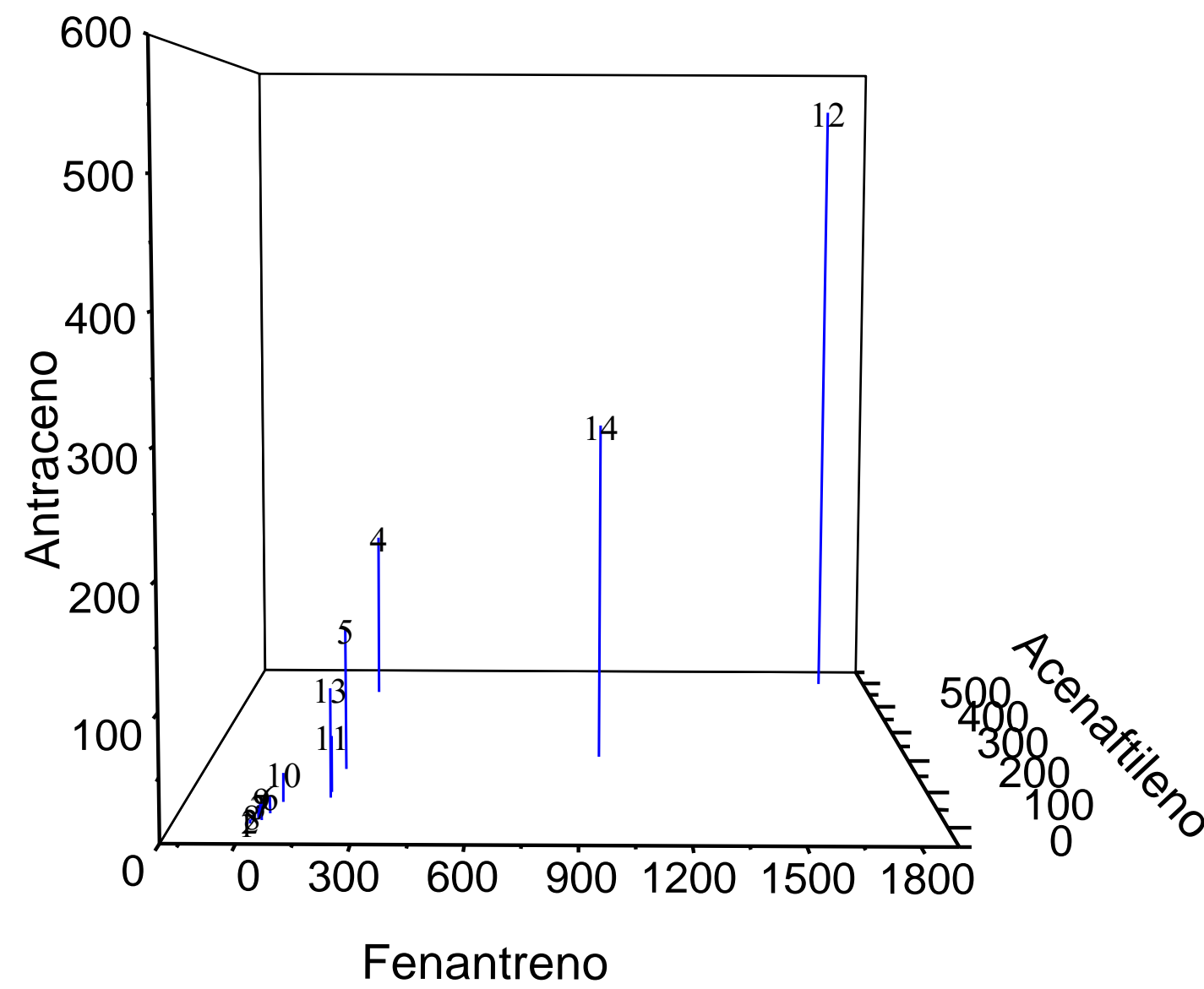

FIGURA 50 Gráfico de dispersão tridimensional abordando os pontos do SESSV referente aos HPA de 3 anéis aromáticos (fenantreno, acenaftileno e antraceno). Os valores estão em ppb. 
Portanto, foi observado um gradiente desde os pontos mais contaminados no fundo do estuário até os pontos nos canais de Santos e São Vicente.

Na FIG 51 estão plotados no gráfico de dispersão tridimensional os HPA de 4 anéis aromáticos, fluoranteno, criseno e pireno. Novamente o que se observa é um padrão no gradiente de contaminação por HPA nos sedimento do SESSV. Os pontos localizados no fundo do estuário se distanciam dos demais por apresentarem altas concentrações desses HPA. O ponto 12 e o 14, foram os que apresentaram as maiores concentrações nos sedimentos em relação a esses compostos. Na parte central do gráfico, estão os pontos 4, 5 e logo em seguida, os pontos 6, 1011 e 13 os quais fecham o grupo dos pontos localizados no fundo do estuário e que apresentaram as maiores concentrações desses compostos. Os pontos localizados no canal de Santos (7, 8 e 9) e São Vicente (1, 2 e 3) se agruparam na parte inferior esquerda do gráfico junto com o ponto da área de descarte (ponto em vermelho). 


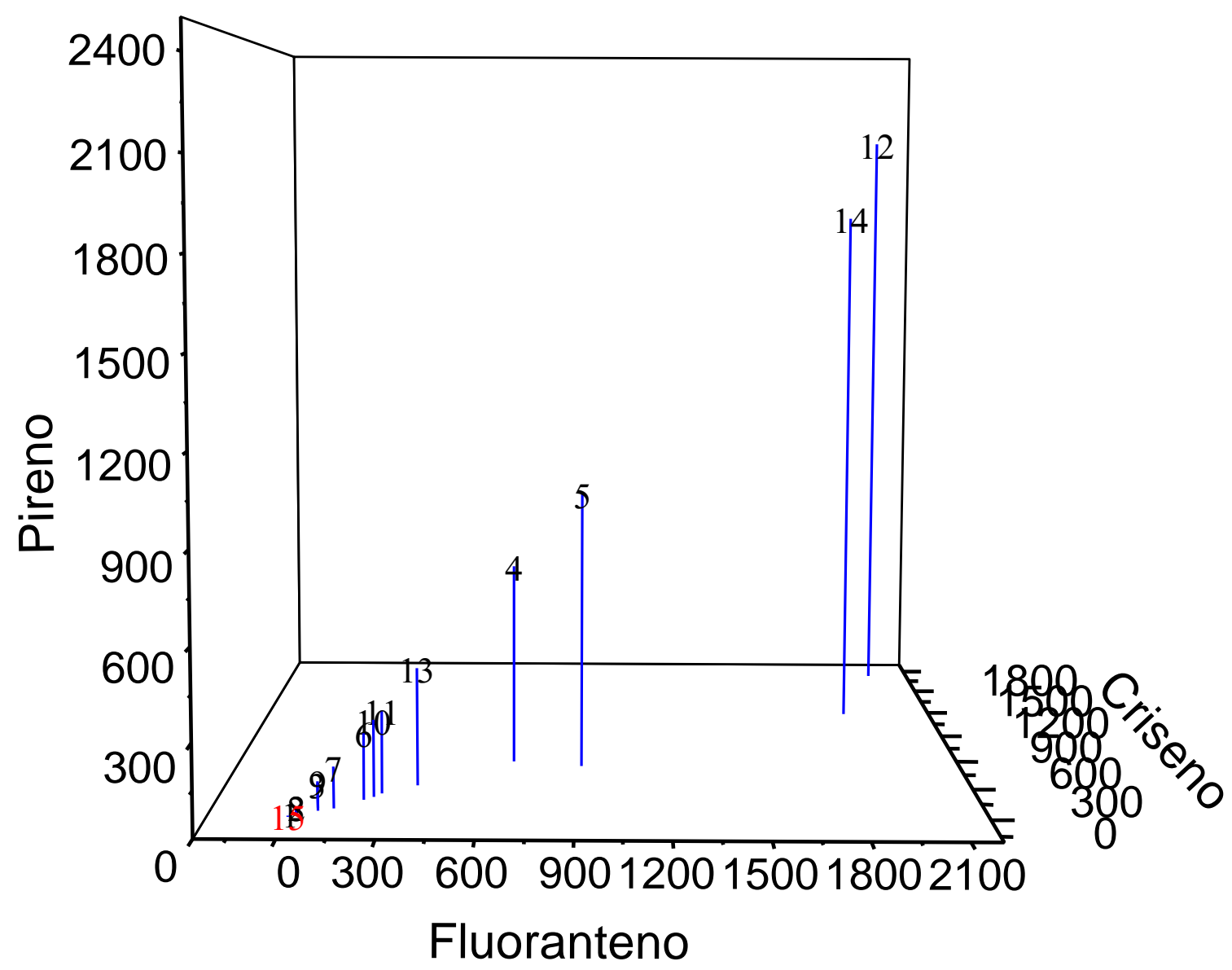

FIGURA 51 Gráfico de dispersão tridimensional abordando os pontos do SESSV e da área de descarte do material dragado (em vermelho) referente aos HPA de 4 anéis aromáticos (fluoranteno, criseno e pireno). Os valores estão em ppb.

Não foram encontradas concentrações desses HPA nos sedimentos da baia de Santos, zona marinha adjacente e PEMLS.

Sendo assim, foi observado a presença de um gradiente desde o fundo do estuário até os canais de Santos e São Vicente e mais à frente, na área de descarte do material dragado.

A FIG 52 expressa o gráfico de dispersão tridimensional dos HPA de 4 e 5 anéis aromáticos (benzo(a)pireno, benzo(e)pireno e benzo(a)antraceno). $O$ mesmo padrão descrito anteriormente para os outros HPA plotados na FIG 49, 50 e 51 foi observado. Os pontos mais contaminados (pontos 12 e 14) ficaram 
localizados distante dos demais pontos seguidos dos pontos $4,5,6,10,11 \mathrm{e}$ 13 todos esses localizados próximos ao complexo industrial de Cubatão.

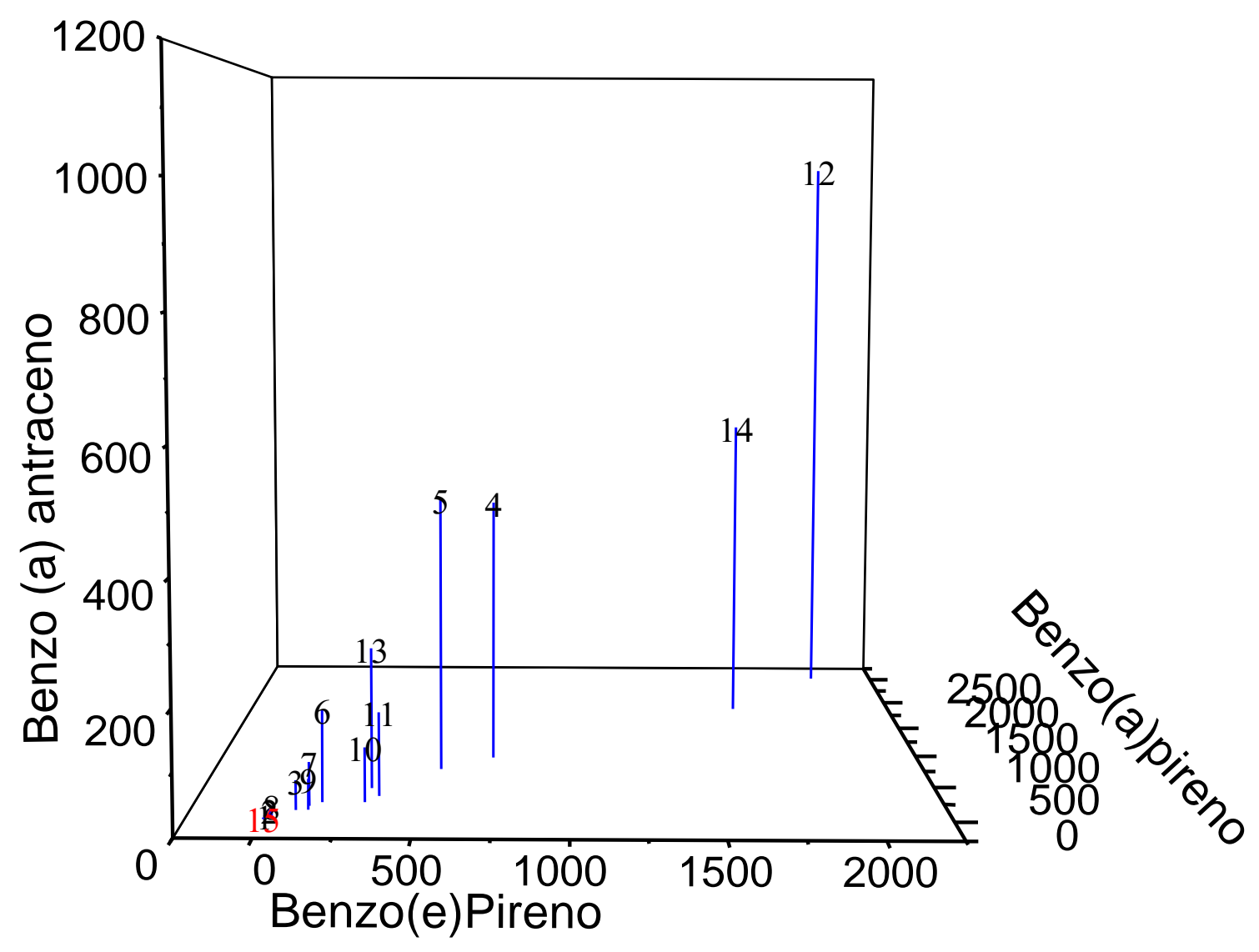

FIGURA 52 Gráfico de dispersão tridimensional abordando os pontos do SESSV e da área de descarte do material dragado (em vermelho) referente aos HPA de 4 e 5 anéis aromáticos (benzo(e)pireno, benzo(a)pireno e benzo(a)antraceno). Os valores estão em ppb.

Ao se distanciar das principais fontes localizadas no fundo do estuário, os pontos 1, 2, 3 (localizado no canal de São Vicente) 7, 8 e 9 (localizado no canal de Santos) apresentaram concentrações inferiores as dos outros pontos e se aproximaram da parte inferior esquerda do gráfico de dispersão tridimensional, junto com a área de descarte do material dragado. Os sedimentos da baia de Santos não apresentaram concentrações desses HPA o que sugere a influência dos sedimentos dragados, contaminados dispostos na área de descarte. 
A FIG 53 apresenta o gráfico de dispersão tridimensional referente aos HPA de 5 anéis aromáticos, benzo(b)fluoranteno, benzo(k)fluoranteno e benzo(j)fluoranteno.

Novamente, foi observado o mesmo padrão de gradiente expresso nos gráficos anteriores (FIG 49, 50, 51 e 52).

Os pontos 12 e 14, considerados mais contaminados, se distanciam dos demais pontos. Na sequência, os pontos 4 e 5 situados na parte central do gráfico e logo depois os pontos 6, 10, 11 e 13. Os pontos localizados no canal de São Vicente $(1,2$ e 3$)$ e de Santos $(7,8,9)$ se agruparam junto com a área de descarte do material dragado, na parte inferior esquerda do gráfico, por apresentarem menores concentrações desses HPA.

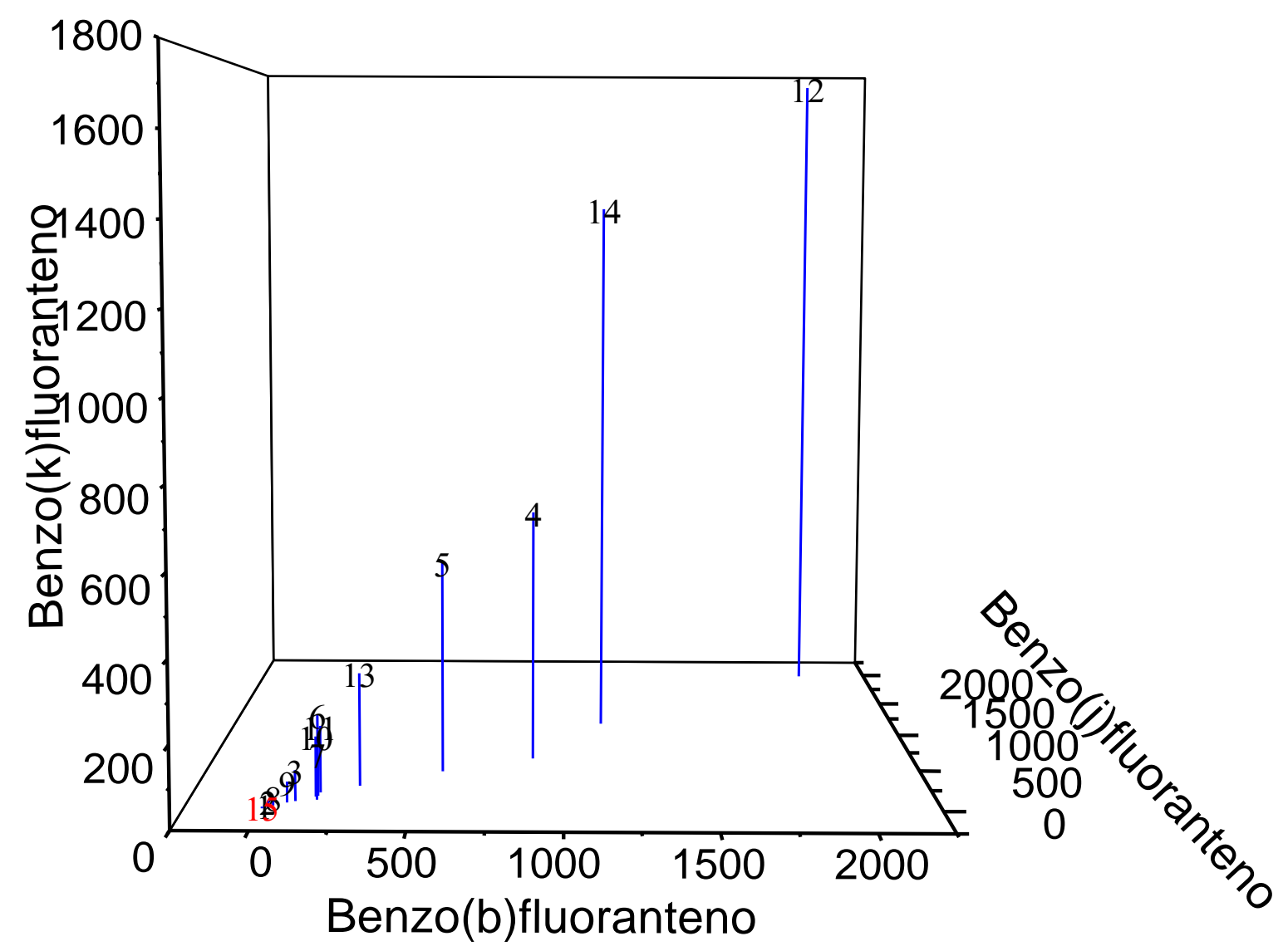

FIGURA 53 Gráfico de dispersão tridimensional abordando os pontos do SESSV e da área de descarte do material dragado (em vermelho) referente aos HPA de 5 anéis aromáticos (benzo(b)fluoranteno, benzo(j)fluoranteno e benzo(k)fluoranteno). Os valores estão em ppb. 
Os sedimentos da baia de Santos, zona marinha adjacente e PEMLS não apresentaram concentrações desses HPA.

Desse modo, um gradiente de contaminação foi observado desde a parte mais interna do estuário até os canais de Santos e São Vicente, seguido da área de descarte do material dragado.

Na FIG 54 estão plotados os pontos do SESSV e da área de descarte do material dragado, referente aos HPA de 5 e 6 anéis aromáticos indeno[1,2,3 cd]pireno, dibenzo(ah)antraceno e benzo(ghi)perileno.

Foi observado, novamente, um gradiente de contaminação em relação a esses HPA, quando comparados com os outros compostos apresentados nas FIG 49 a 53.

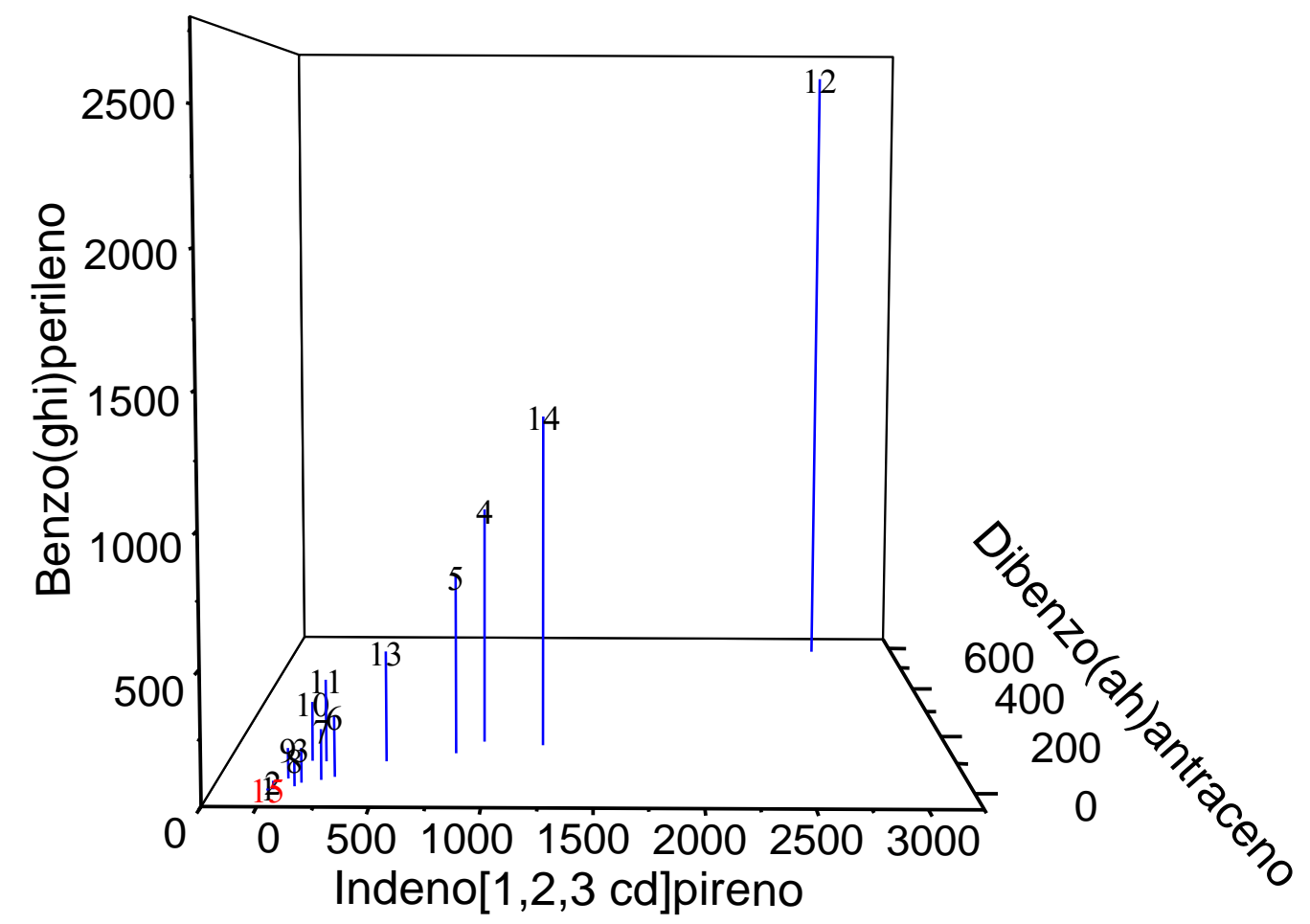

FIGURA 54 Gráfico de dispersão tridimensional abordando os pontos do SESSV e da área de descarte do material dragado (em vermelho) referente aos HPA de 5 e 6 anéis aromáticos (indeno[1, 2, 3 cd]pireno, dibenzo(ah)antraceno e benzo(ghi)perileno). Os valores estão em ppb. 
O ponto 12 se distancia dos demais devido as altas concentrações desses HPA nos sedimentos. O ponto 14 , seguido pelos pontos 4 e 5 , se localizaram na parte central do gráfico apresentando uma contaminação menor do que nos sedimentos do ponto 12 . Os pontos 6, 10, 11 e 13 se agruparam outra vez pela semelhança nas concentrações e logo mais abaixo na parte inferior esquerda estão os pontos dos canais de São Vicente (1, 2 e 3) e de Santos (7, 8 e 9), juntamente com a área de descarte do material dragado.

Nos sedimentos da baia de Santos, zona marinha adjacente e PEMLS não foram encontradas concentrações de HPA.

Deste modo, observou-se um gradiente desde o fundo do estuário, onde estão localizadas as fontes de contaminação, até os canais de Santos e São Vicente foi observado evidenciando a influencia das atividades industriais sobre os sedimentos da região. $\mathrm{Na}$ área de descarte foi observada a concentração desses compostos o que evidencia a influencia dos sedimentos contaminados dispostos nesse local. 


\section{CONCLUSÃO}

De acordo com o presente estudo, as concentrações de metais e hidrocarbonetos nas amostras de sedimentos do SESSV evidenciaram a influência das atividades antropogênicas com a predominância de metais $(\mathrm{Cu}$, $\mathrm{Hg}, \mathrm{Mn}, \mathrm{Ni}, \mathrm{Pb}$ e $\mathrm{Zn}$ ) e HPA, provenientes dos efluentes industriais e domésticos, cujas concentrações apresentaram valores elevados acima dos limites estabelecidos no VGQS.

As principais fontes de metais para o SESSV são provenientes dos efluentes das indústrias siderúrgicas, de fertilizantes e petroquímicas que estão instalados nessa região. Em relação aos hidrocarbonetos, as principais fontes de contaminação incluem a combustão de carvão em processos metalúrgicos, petróleo e óleo diesel nas refinarias e transporte marítimo.

Os sedimentos da baia de Santos não apresentaram uma contaminação muito elevada para os metais e hidrocarbonetos. Entretanto, a área de descarte do material dragado do porto de Santos evidenciou o impacto causado pelos sedimentos contaminados dispostos nesse local, reportando concentrações elevadas de metais, principalmente para o $\mathrm{Hg}$ e $\mathrm{Ni}$.

As concentrações de metais encontradas nos sedimentos do PEMLS apresentaram-se moderadas, o que evidencia os primeiros indícios de contaminação registrados nos sedimentos dessa região, principalmente para os metais $\mathrm{Cr}, \mathrm{Hg}, \mathrm{Ni}, \mathrm{Mn}, \mathrm{Pb}$ e $\mathrm{Zn}$, sugerindo uma contribuição de contaminantes provenientes de fontes localizadas na costa (atividades industriais e/ou área de descarte do material dragado) que atinge o PEMLS através da exportação de material contaminado pelas correntes marinhas. As fontes locais, como as embarcações de mergulho e navios que fundeiam ao largo a espera para entrar no canal do porto também contribuem na diminuição da qualidade ambiental dos sedimentos no PEMLS.

Por outro lado, as concentrações de hidrocarbonetos encontradas nos sedimentos do PEMLS foram baixas, revelando não haver indícios de contaminação por esses compostos nessa região. Entretanto, concentrações relativamente elevadas foram encontradas nos sedimentos da área de descarte 
do material dragado do porto de Santos e podem causa impactos negativos na qualidade ambiental do PEMLS.

Em geral, foi observado a influência nas concentrações de metais nos sedimentos do PEMLS proveniente do gradiente de contaminação nos sedimentos desde o SESSV até o PEMLS, com maiores concentrações no estuário e na área de descarte do material dragado.

Entretanto, um gradiente de contaminação por HPA foi observado desde os sedimentos do SESSV até a área de descarte do material dragado, sendo registrada somente concentrações de 3 HPA nos sedimentos do PEMLS o que evidencia que esses compostos não estão em concentrações elevadas, porem indícios da presença de HPA foram registrados.

Os resultados do presente estudo estão de acordo com os registrados pela literatura, entretanto, um estudo mais detalhado com uma abordagem amostral mais ampla, abordando as correntes e as incertezas associadas a amostragem e as medições analíticas são recomendadas para futuros estudos.

O presente estudo contribui com o primeiro registro das concentrações de metais e hidrocarbonetos nos sedimentos do PEMLS. Além disso, uma abordagem inédita do gradiente de contaminação desde a zona costeira até o PEMLS auxiliará em futuros estudos e nas tomadas de decisões para que esses contaminantes não impactem significativamente essa UC.

Sendo assim, é importante que seja realizado um monitoramento continuo do gradiente de contaminação desde a zona costeira até o PEMLS para garantir a preservação desse ecossistema devido à fragilidade, raridade, relevância, biodiversidade e singularidade entre outras caracteristicas. Dentre as ações, destacam-se o fortalecimento das pesquisas, principalmente os diagnósticos da qualidade ambiental. O estabelecimento de politicas publicas e um plano de manejo específico e adequado para o PEMLS é necessário, uma vez que indícios de contaminação foram encontrados e futuros impactos negativos nessa área de grande importância ecológica podem ser registrados em um futuro próximo. 
ABESSA, D.M.S. Avaliação da Qualidade de Sedimentos do Sistema Estuarino de Santos, SP, Brasil. 2002. Tese de Doutorado. Universidade de São Paulo, Instituto Oceanográfico. São Paulo. 290p.

ABESSA, D.M.S.; PEREIRA, C.D.S. \& MACHADO, M.B. 2004. Toxicidade de Água Coletada na Região do Parque Estadual Marinho da Laje de Santos: Dados Preliminares. Anais do IV Congresso Brasileiro de Pesquisas Ambientais e Saúde. CD-ROM, pp. 202-204.

ABESSA, D.M.S.; CARR, R.S.; RACHID, B.R.F.; SOUSA, E.C.P.M.; HORTELANI, M.A. \& SARKIS, J.E. 2005. Influence of a Brazilian Sewage Outfall on the Toxicity and Contamination of Adjacent Sediments. Marine Pollution Bulletin, 50: 875-885.

ABESSA, DMS; CARR, RS; SOUSA, ECPM; RACHID, BRF; ZARONI, LP; PINTO, YA; GASPARRO, M.R.; BÍCEGO, MC; HORTELLANI, MA; SARKIS, JES; MUNIZ, P. 2008. Integrative Ecotoxicological Assessment of a Complex Tropical Estuarine System. In: Hoffer, T.N. (ed) Marine Pollution: New Research Science Publishers Inc., New York, Chapter 4, p.1-36.

ABOUL-KASSIM, T.A.T., SIMONEIT, B.R.T., 1996. Lipid geochemistry of surficial sediments from the coastal environment of Egypt. 1. Aliphatic hydrocarbons - characterization and sources. Marine Chemistry. 54:135- 158.

ADAMS, W.J.; KIMERLE, R.A.; BARNETT, J.W. 1992. Sediment quality and aquatic life assessment. Environmental Science and Technology, v. 26, n. 10, 1864-1875p.

ALMEIDA

BÍCEGO, M.A.; TANIGUCHI S.; YOGUI, G.T.; MONTONE, R.C.; DA SILVA, D.A.M.B.; LOURENÇO.R.A.; MARTINS, C.C.; SASAKI, S.T.; Pellizari,V.H.; WEBER, R.R. 2006 Assessment of contamination by polychlorinated biphenyls and aliphatic and aromatic hydrocarbons in sediments of the Santos and São Vicente Estuary System, São Paulo, Brazil. Marine Pollution Bulletin 52. 17841832.

BOULOUBASSI, I., SALIOT, A., 1993. Investigation of anthropogenic and natural organic inputs in estuarine sediments using hydrocarbon markers $(\mathrm{NAH}$, LAB, PAH). Oceanological Acta 16:145-161. 
BORDON, I. C. A. C.; SARKIS, J. E. S.; GOBBATO, G. M.; HORTELLANI, M. A.; PEIXOTO, C. M. 2011. Metal concentration in sediments from the Santos estuarine system: a recent assessment. Journal of the Brazilian Chemical Society (Impresso), v. 22, p. 1858-1865, 2011.

BRASIL. 2000. Lei o 9.985, de 18 de julho de 2000. Institui o Sistema Nacional de Unidades de Conservação da Natureza. (SNUC). D.O.U. Brasília

BRASIL, 2004. Resolução CONAMA 344/04. Estabelece as diretrizes gerais e os procedimentos mínimos para a avaliação do material a ser dragado em águas jurisdicionais brasileiras, e dá outras providências.

BRYAN, G. W. 1971. The effects of heavy metals (other than mercury) on marine and estuarine organisms. Proceedings of the Ecological Society of London (B) 177, 389-410.

CCME - Canadian Council of Ministers of the Environment (CCME), Canadian Sediment Quality guidelines for the Protection of Aquatic Life, Canadian Environmental Quality Guidelines, Summary Tables, 2002. Disponível em: http://www.ccme.ca/publications/ceqg rcqe.html?category id=124.

CESAR, A; PEREIRA, C.D.S.; SANTOS, A.R.; ABESSA, D.M.S.; FERNÁNDEZ, N.; CHOUERI R.B.; DELVALLS, T.A.; 2006. Etocoxicology assessment of sediments from Santos and São Vicente Estuarine System. Brazilian Journal of Oceanograph. 54. 55-63.

CESAR, A.; PEREIRA, C.D.S.; SANTOS, A.R.; ABESSA, D.M.S.; CHOUERI, R.B.; RIBA, I.; CASELLES, M.C.M. AND DELVALLS, T.A. 2007. Comparative sediment quality assessment in different littoral ecosystems from Spain (Gulf of Cadiz) and Brazil (Santos and São Vicente estuarine system). Environment International, 33(3): 429-435.

CETESB. 2006. Relatório de qualidade das águas litorâneas do estado de São Paulo: balneabilidade das praias 2006. Relatório Técnico, CETESB. 254p.

CETESB. 2007. Relatório de qualidade das águas litorâneas do estado de São Paulo: balneabilidade das praias 2006, ão Paulo, Relatório Técnico, CETESB, 2007, 365p.

CHOUERI, R.B.; CESAR, A.; ABESSA, D.M.S.; TORRES, R.J.; MORAIS, R.D.; RIBA, I.; PEREIRA, C.D.S.; NASCIMENTO, M.R.L.; MOZETO, A.A.; DELVALLS, T.A.; 2009. Development of site-specific sediment quality 
guidelines for North and South Atlantic littoral zones: Comparison against national and international sediment quality benchmarks. Journal of Hazardous Materials. 170. 320-331.

COLOMBO, J.P., PELLETIER, E., BROCHU, C., KHALIL, M., CATOGGIO, J.A., 1989. Determination of hydrocarbon sources using n-alkane and polyaromatic hydrocarbon distribution indexes. Case study: Rio de la Plata estuary, Argentina. Environ. Sci. and Technol. 23 (7):888-894.

COOK, J. M.; GARDNER, M. J.; GRIFFITHS, A. H.; JESSEP, M. A.; RAVENSCROFT, J. E.; YATES, R. 1997. Marine Pollution Bulletin. 34(8), 637644.

COSTA, F.O.; NEUPARTH, T.; CORREIA, D. \& COSTA, M.H. 2005. Multi-level assessment of chronic toxicity of estuarine sediments with the amphipod Gammarus locusta: II. Organism and population-level endpoints. Marine Environmental Research, 60. 93-110p.

COX, M. E.; PREDA, M. 2003. Trace metal distribution and relation to marine sediment mineralogy, Gulf of Carpentaria, Northern Australia. Marine Pollution Bulletin., 46(12), 1622-1629

DA SILVA, M. C. M.; HONÓRIO, K. M.; BRIGANTE, J.; ESPÍNDOLA, E. L. G.; VIEIRA, E. M.; GAMBARDELLA, M. T. P.; DA SILVA, A. B. F.; 2005. A Chemometric Study on the Accumulation of Heavy Metals Along the Mogi Guaçu River Basin Journal Brazilian Chemical Society.16, 1104.

DELVALLS, T.A.; FORJA, J.M. \& GOMÉZ-PARRA, A. 2002. Seasonality of contamination, toxicity, and quality values in sediments from litoral ecosystems in the Gulf of Cádiz (SW Spain). Chemosphere, 46: 1033-1043p.

DIEGUES, A. C., 1985. Conservação e Recursos Vivos do Mar. Programa de Pesquisa e Conservação de Áreas Úmidas do Brasil. Série: Trabalhos e Estudos. IOUSP.

FARRINGTON, J.W., FREW, N.M., GESHWEND, P.M., TRIPP, R.W., 1977. Hydrocarbons in cores of northwestern Atlantic coastal and continental margin sediments. Estuarine Coastal Marine Science. 5: 793-808.

FERREIRA, MÁRCIA M. C.; ANTUNES, ALEXANDRE M.; MELGO, MARISA S.; VOLPE, PEDRO L. O. 1999. Quimiometria I: calibração multivariada, um tutorial. Química. Nova . vol.22, n.5, pp. 724-731. 
FOLK, R.L, WARD, W.C. 1957. Brazos River bar: a study in the significance of grain size parameters. Journal of Sedimentary Petrology 27: 3-26.

González-Vila, F.J, Polvillo, O., Boski, T., Moura, D., de Andres, J.R., 2003. Biomarker in a time-resolved holocene/terminal Pleistocene sedimentary sequence from the Guadiana river estuarine area (SW Portugal/Spain border) Organic Geochemistry. 34. 1601-1613.

GOUGH, M. A. AND ROWLAND, R. J.: 1990, Characterization of unresolved complex mixtures of hydrocarbon in petroleum, Nature 344: 648-650.

HARARI, J., CAMARGO, R., 1998. Modelagem numérica da região costeira de Santos (SP): circulação de maré. Revista Brasileira de Oceanografia. 46:135156.

HARARI, J. ; GORDON, Michel . Simulações numéricas da dispersão de substâncias no Porto e Baía de Santos, sob a ação de marés e ventos. Revista Brasileira de Recursos Hídricos, Brasil, (RS), v. 6, n. 2, p. 115-131, 2001.

HARARI, J. ; CAMARGO, R. FRANÇA, C. A. S. 2007. Numerical Simulations of the coastal circulation in the State Maritime Preservation Park of "Laje de Santos" - SP, Brazil. In: International Conference on Engineering and Computer Education. 225 - 229.

HORTELLANI, M.A.; SARKIS, J.E.S.; BONETTI, J; BONETTI, C. 2005. Evaluation of Mercury Contamination in Sediments from Santos - São Vicente Estuarine System, São Paulo State, Brazilian Journal of Brazilian Chemistry Society. Vol. 16, No. 6A, 1140-1149p.

HORTELLANI, M.A.; SARKIS, J.E.S.; ABESSA, D.M.S \& SOUSA, E.C.P.M. 2008. Avaliação da contaminação por elementos metálicos dos sedimentos do Estuário Santos - São Vicente. Química Nova 31(1):10-19.

HOSTETTLER, F.D., PEREIRA, W.E., KVENVOLDEN, K.A., Van GREEN, A., LUOMA,

S.N., FULLER, C.C. \& ANIMA, R. A record of hydrocarbon input to San Francisco Bay as traced by biomarkers profiles in surface sediment and sediment cores. Marine Chemistry, v. 64, p. 115-127. 1999

IF - INSTITUTO FLORESTAL. 2009. Disponível em:

http://www.iflorestal.sp.gov.br/unidades conservacao/index.asp. Acessado em: 21/10/2009. 
Instituto Nacional de Metrologia, Normalização e Qualidade Industrial (INMETRO); Orientações sobre Validação de Métodos de Ensaios Químicos, 2003.

KENNISH, M.J. 1992. Ecology of estuaries: anthropogenic effects, Boca Raton, CRC Press, $494 \mathrm{p}$.

KRAUSE, P.; ERBSLOH, B.; NIEDERGESAB, R.; PEPELNIK, R.; PRANGE, A.; Fresenius. 1995. Journal of Analitical Chemistry., 353, 3.

LAMPARELLI, M. L.; COSTA, M. P.; PRÓSPERI, V. A.; BEVILÁCQUA, J. E.; ARAÚJO, R. P. A.; EYSINK, G. G. L. \& POMPÉIA, S. 2001. Sistema Estuarino de Santos e São Vicente. Relatório Técnico CETESB. São Paulo. 178p.

LIA, L, R, 2008..Diagnostico ambiental integrado da área de influencia do descarte do material dragado do estuário de Santos. Tese de Doutorado. Universidade Estadual de Campinas, Faculdade de Engenharia Química. 283p

LIU, Y; CHEN, L.; JIANFU, Z.; QINGHUI, H.; ZHILIANG, Z.; HONGWEN, G. 2008. Distribution and Sources of Polycyclic Aromatic Hydrocarbons in surface sediments of rivers and an estuary in Shanghai, China. Environmental Pollution, v. 154, p. $298-305$.

LONG, E.R., MACDONALD, D.D., 1998. Recommended uses of empirically derived, sediment quality guidelines for marine and estuarine ecosystems. Human Ecological Risk Assessment. 4:1019-1039.

LONG, E.R; INGERSOLL, C.G; MAC DONALD, D.D . 2006. Calculation and uses of mean sediment quality guideline quotient, a critical review, Environmental Science Technology. 40:1726-1736

MACHADO, W.; SILVA-FILHO, E.V.; OLIVEIRA, R.R.; LACERDA, L.D. 2002. Trace metal retention in mangrove ecosystems in Guanabara Bay, SE, Brazil. Marine Pollution Bulletin.44, 1277-1280p.

MACDONALD, D.D., CARR, R.S., CALDER, F.D., LONG, E.R., INGERSOLL, C.G. 1996. Development and evaluation of sediment quality guidelines for Florida coastal waters. Etocoxicology 5, 253-278.

Magalhães, C.A. ; Taniguchi, S. ; Cascaes, M.J. ; Montone, R.C. . PCBs, PBDEs and organochlorine pesticides in crabs Hepatus pudibundus and 
Callinectes danae from Santos Bay, State of São Paulo, Brazil. Marine Pollution Bulletin., v. 64, p. 662-667, 2012.

MARTINS, C.C.; MAHISQUES, M.M.; BICEGO, M.C.; FUKUMOTO. M.M.; MONTONE, R. C. 2007. Comparison between anthropogenic hydrocarbons and magnetic susceptibility in sediment cores from the Santos Estuary, Brazil. Marine Pollution Bulletin. 54 (2):240-246.

MARTINS, C. C.; FERREIRA, J. A.; TANIGUCHI, S.; MAHIQUES, M. M.; BÍCEGO, M. C.; MONTONE, R.M. 2008. Spatial distribution of sedimentary linear alkylbenzenes and faecal steroids of Santos Bay and adjoining continental shelf, SW Atlantic, Brazil: Origin and fate of sewage contamination in the shallow coastal environment. Marine Pollution Bulletin. 56. 1353- 1376

MARTINS, C. C. ; BÍCEGO, M. C. ; MAHIQUES, M. M. ; FIGUEIRA, R. C. L. ; TESSLER, M. G. ; MONTONE, R. C. 2010. Depositional history of sedimentary linear alkylbenzenes (LABs) in a large South American industrial coastal area (Santos Estuary, Southeastern Brazil). Environmental Pollution (1987), v. 158, p. 3355-3364,

MARTINS, C. C; BÍCEGO, M. C; MAHIQUES, M. M; FIGUEIRA, R. C. L; TESSLER, M. G; MONTONE, R. C. 2011. Polycyclic aromatic hydrocarbons (PAHs) in a large South American industrial coastal area (Santos Estuary, Southeastern Brazil): Sources and depositional history. Marine Pollution Bulletin. 63. 452-458.

MAZUREK, M. A. AND SIMONEIT, B. R. T.: 1984, 'Characterization of Biogenic and Petroleum-Derived Organic Matter in Aerosols over Remote, Rural and Urbans, in L. H. Keith (ed.), Identification and Analysis of Organic Pollutants in Air. Ann Harbor Science/Butterworth, Boston, pp. 353- 378.

McLUSKY, D.S. \& ELLIOTT, M. 2004. The estuarine ecosystem: ecology, threats, and management, 3 ed., Oxford University Press, 214p.

MEDEIROS, P.M. \& BÍCEGO, M.C. 2004. Investigation of natural and anthropogenic hydrocarbon inputs in sediments using geochemical markers II. São Sebastião, SP-Brazil. Marine Pollution Bulletin, v.49, p.892-899.

MENDONCCA, A. L. F.; LEONEL, C.; MARINO, L.; BARROS, M. R., NETO, P. N.; JORDẤ, S. 2000. Áreas especialmente protegidas no Estado de São Paulo: Levantamento e definição de parâmetros para administração e manejo. In: Congresso Brasileiro de Unidades de Conservação, 2, , Campo Grande. 
Anais. Campo Grande: Rede Nacional Pró Unidades de Conservação: Fundação O Boticário de Proteção à Natureza, 2000, 3v., p. 654-662.

NIPPER, M.G.; GREENSTEIN, D.J.; BAY, S.M. 1989. Short- and long-term sediment toxicity test methods with the amphipod Grandidierella japonica. Environmental Toxicology and Chemistry. 8. 1191-1200.

NISHIGIMA, F.N.; WEBER, R.R. \& BÍCEGO, M.C. 2001. Aliphatic and aromatic hydrocarbons in sediments of Santos and Cananéia, SP, Brazil. Marine Pollution Bulletin, 42(11):1064-1072.

NOTAR, M.; LESKOVSEK. H; FAGANELI, J. 2001. Composition, distribution and soucers of polycyclic aromatic hydrocarbons in sediments of the Golf of Triestre, Northern Adriatic Sea. Mar. Poll. Bull. 42:36-44.

NRC - NATIONAL RESEARCH COUNCIL , 2002. Oil in the Sea III, Inputs, Fates and Effects. Academic press. Washington D.C. Disponível em: URL:http://dels.nas.edu/resources/static-assets/materials-basedonreports/reports-in-brief/oil in the sea final.pdf

PEREIRA, C.D.S. 2008. Biomarcadores de exposição, efeito e bioacumulação de xenobióticos em mexilhões Perna perna (Linnaeus,1758) transplantados ao longo do litoral de São Paulo. Tese de Doutorado. Universidade de São Paulo. Instituto Oceanográfico. 319p.

PRATES, A.P.L. \& PEREIRA, P.M., 2000. "Representatividade das Unidades de Conservação Costeiras e Marinha: Análise e Sugestões". II Congresso Brasileiro de Unidades de Conservação. Anais. Campo Grande: Rede Nacional Pró Unidades de Conservação: Fundação O Boticário de Proteção à Natureza, $3 \mathrm{v}$

PRÓSPERI V.A. Comparação de métodos etocoxicológicos na avaliação de sedimentos marinhos e estuarinos. Doctorate Thesis. Universidade de São Paulo, Escola de Engenharia de São Carlos; 2002. São Carlos. 118 p.

QUINÁGLIA, G.A. 2006. Caracterização dos níveis basais da contaminação por metais nos sedimentos do Sistema Estuarino da Baixada Santista. Tese de doutorado. Universidade de São Carlos. Instituto de Química. 269p.

READMAN, J.W., FILLMANN, G., TOLOSA, I., BARTOCCI, J., VILLENEUVE, J.-P., CATINNI, C., MEE, L.D., 2002. Petroleum and PAH contamination of the Black Sea. Marine Pollution Bulletin. 44:48-62 
ROJAS, C. \& ABESSA, D.M.S. 2008. Usos e Conflitos de Interesse em algumas Unidades de Conservação Insulares do Estado de São Paulo, Brasil. Olam Ciência e Tecnologia. 8(1): 131-151.

RONTANI, J.F; BONIN, P. 2011. Production of pristane and phytane in the marine environment: role of prokaryotes. Research in Microbiology. In press.

São Paulo, 1993. DECRETO 37.537/1993. Parque Estadual Marinho da Laje de Santos. Diário Oficial v.103, n.182.

São Paulo. 2011. DECRETO 53526/2008 APA MARINHA DO LITORAL CENTRO. Disponível em http://lajevivaapamarinhalitoralcentro.shutterfly.com/ Acessado em 15 de maio de 2011.

SILVA, L.W.; MATOS, R.H.R; KIRSTOCH, G.C.; MACHADO, W.; 2006. Variabilidade espacial e sazonal da concentração de elementos traços em sedimentos do sistema estuarino de Santos-Cubatão. Química Nova 29(2):256263.

SEMMLER, M. G. M. C. 2007. Biomonitoração de Hg, Cd, Pb e outros elementos em áreas costeiras do Estato de São Paulo por meio do mexilhão transplantado Perna perna (Linnaeus, 1758). Instituto de Pesquisas Energéticas e Nucleares. 295p.

SHEPARD. F. P. 1954. Nomemclature based on sand silt-clay ratios. Journal Sediment Petroleum, (24):151-158.

SOUSA, E.C.P.M.; ABESSA, D.M.S.; GASPARRO, M.R.; ZARONI, L.P.; RACHID, B.R.F. 2007. Etocoxicological Assessment of Sediments from the Port of Santos and the Disposal Sites of Dredged Material. Brazilian Journal of Oceanography. 55(2): 75-81.

STEINHAUER, M.S., BOEHM, P.D., 1992. The composition and distribution of saturated and aromatic hydrocarbons in nearshore sediments, river sediments, and coastal peat of Alaskan Beaufort Sea: implications for detecting anthropogenic hydrocarbon inputs. Mar. Environ. Res. 33:223-253.

SWARTZ, R.C.; DEBEN, W.A.; JONES, J.K.P.; LAMBERSON, J.O.; COLE, F.A. 1985. Phoxocephalid amphipod bioassay for marine sediment toxicity. In: Symposium on Aquatic Toxicology and Hazard Assessment, Philadelphia, ASTM, v. 7, 284-307p. 
TOMMASI, L. R. 1987. Poluição marinha no Brasil: uma síntese do conhecimento. Publicação Especial do Instituto Oceanográfico, São Paulo, 5:130 .

TORRES, R. J. 2007. Efeitos da dragagem sobre a qualidade de sedimentos contaminados no canal do Porto de Santos: biodisponibilidade e toxicidade de metais e compostos orgânicos persistentes, SP. Tese de Doutorado. São Carlos: Departamento de Química. 159 p.

UNEP. 1992. Determinations of Petroleum Hydrocarbons in Sediments. United Nations Environment Programme. Reference Methods for Marine Pollution Studies, 97p.

U.S EPA 2000. Bioaccumulation Testing and Interpretation for the Purpose of Sediment Quality Assessment - Status and needs. 136p.

U.S EPA. Método U.S EPA 3051a. 2007. Microwave assisted acid digestion of sediments, sluds, soils and oils. 30p.

VOLKMAN, J.K., HOLDSWORTH, D.G., NEILL, G.P., BAVOR JR., H.J., 1992. Identification of natural, anthropogenic and petroleum hydrocarbons in aquatic sediments. Science of Total Environment. 112. 203-219.

WALDICHUK, M. 1985. Biological availability of metals to marine organisms. Marine Pollution Bulletin 16, 7-11

WALKER, C.H. 2009 Organic Pollutants: an etocoxicological perspective. CRC press. Boca Raton, Florida. $2^{\text {nd }}$ edition. $414 p$.

WANG, Z.; FINGAS, M.; PAGE, D. S. 1999. Oil spill identification. Journal of Chromatograph Analyses. 843; 369-411.

YU, K. C.; TSAI, L. J.; CHEN, S. H. ; HO, S. T.; 2001. Correlation analyses on binding behavior of heavy metals with sediment matrices. Water Research. 35(10), 2417-2428

YUNKER, M.B., MACDONALD, R.W., VINGARZAN, R., MITCHELL, H., GOYETTE, D., SYLVESTRE, S., 2002. PAHs in the Fraser river basin: a critical appraisal of $\mathrm{PAH}$ ratios as indicators of PAH source and composition. Organic Geochemistry. 33, 489-515. 
YUNKER, M.B., MACDONALD, R.W., 2004. Alkane and PAH depositional history, sources and fluxes in sediments from Fraser River basin and Strait of Georgia, Canada. Organic Geochemistry. 34:1429-1454.

ZAR, J.H. 1996. Biostatistical analysis, 3rd ed. Nova Jersey, Prentice-Hall, 662p.' 